\title{
EXPLORATION OF SYSTEM VULNERABILITY IN NAVAL SHIP CONCEPT DESIGN
}

\author{
David Benjamin Goodfriend
}

Thesis submitted to the Faculty of Virginia Polytechnic Institute and State University in partial fulfillment of the requirements for the degree of

\section{MASTER OF SCIENCE}

in

\author{
Ocean Engineering
}

\author{
Alan Brown, Chair \\ John A. Waltham-Sajdak, Co-Chair \\ Wayne Neu
}

September 24, 2015

Blacksburg, Virginia

Keywords: ship survivability, vulnerability, ship concept design, general arrangements, distributed systems 


\title{
EXPLORATION OF SYSTEM VULNERABILITY IN NAVAL SHIP CONCEPT DESIGN
}

David Benjamin Goodfriend

\begin{abstract}
This thesis presents a methodology and analysis tool to explore ship system vulnerability using a simplified preliminary arrangement and vulnerability modeling approach in the Concept and Requirements Exploration (C\&RE) process used at Virginia Tech. C\&RE uses a Multi-Objective Genetic Optimization (MOGO) to explore the design space for non-dominated ship design solutions based on design effectiveness, risk, and cost. The current C\&RE process evaluates ship characteristics and intact system options to determine a design Overall Measure of Effectiveness (OMOE) through the calculation of Measures of Performance (MOPs). Using a new Preliminary Arrangement and Vulnerability (PA\&V) model, an Overall Measure of Vulnerability (OMOV) is calculated for each ship design using the developed process and tools described in this thesis. The OMOV is calculated by combining the Vulnerability Measure of Performance (VMOP) scores across multiple ship mission capabilities. It is then combined with the intact MOPs to calculate a more complete warfighting OMOE which can be used in the C\&R
\end{abstract}




\section{ACKNOWLEDGEMENTS}

I would like to express my deepest gratitude to my advisor, Dr. Alan Brown, for his guidance, caring, passion for Naval Ship Design research and providing such a positive atmosphere for graduate research. I thank you for always taking my phone calls, no matter the subject or time, sharing your experiences with me, editing my writing, and financially supporting my research.

I would also like to thank Dr. Waltham-Sajdak for guiding my research over the past several years and helping me to develop my background in Ship Systems and Survivability.

I would like to thank Dr. Neu for being a member of my thesis committee and originally accepting me as an undergraduate researcher, which sparked my initial interest in graduate school.

Thank you to Grant Raisig for teaching me how to more simply and efficiently code big-data solutions.

Thank you to my parents for being the best support system and motivators I could ever imagine having. Thank you to my brother, and sister for always supporting me and encouraging me with their best wishes.

Thank you to Andrew Stevens and Sean Stark for joining me in this collaborative research effort. I wish you the best of luck completing your degrees.

Finally, I would like to thank my fiancée, Emily Connors for being my rock throughout this long two (+) years. You were always interested when you had no idea what I was saying, caring when you didn't care, and patient when I tested your patience. Now, let's plan a wedding. 


\section{TABLE OF CONTENTS}

SECTION

PAGE

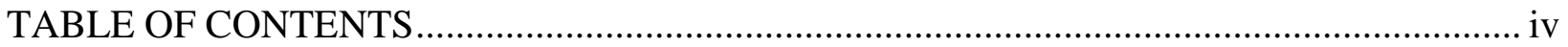

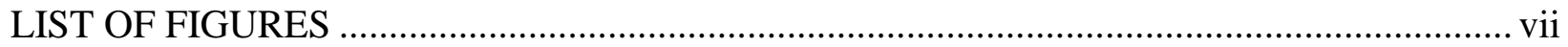

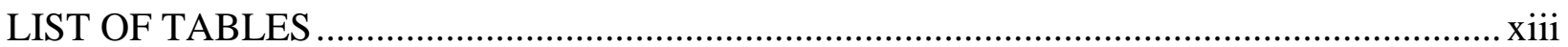

LIST OF ACRONYMS AND ABBREVIATIONS …...................................................

CHAPTER 1 - INTRODUCTION AND MOTIVATION …............................................ 1

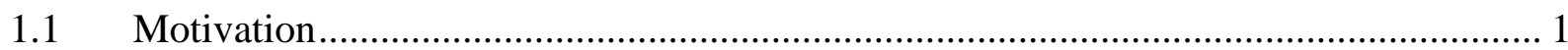

1.1.1 The Concept Design Process ............................................................................... 2

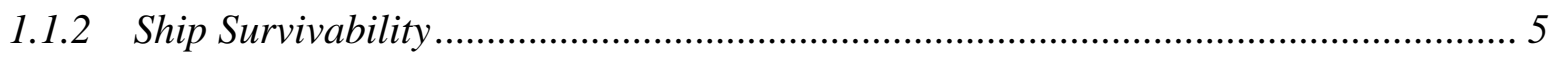

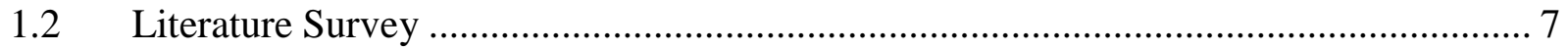

1.2.1 Historical Significance .............................................................................. 8

1.2.2 Existing Survivability Evaluation Tools...................................................... 16

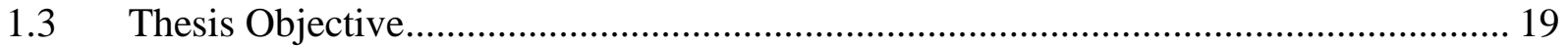

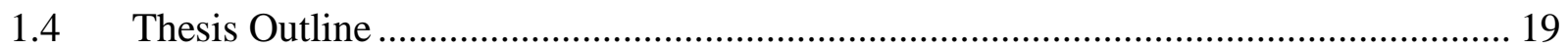

CHAPTER 2 - TOOLS AND METHODOLOGY ...................................................... 21

2.1 Concept and Requirements Exploration (C\&RE) ................................................ 21

2.2 Vulnerability Exploration Motivation and Methodologies ........................................ 28

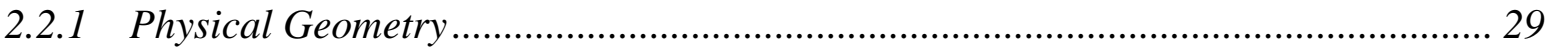

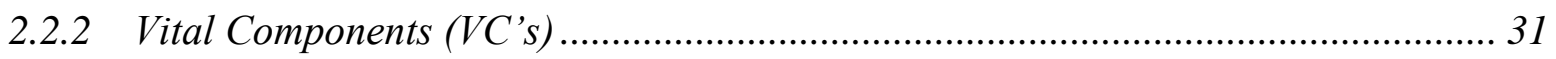

2.2.3 Vital Component Hit Damage Methods ............................................................... 34 


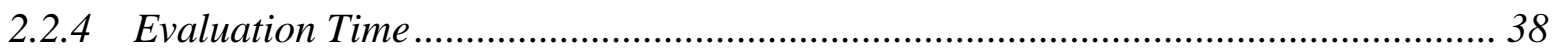

2.3 Operational Effectiveness Modeling ...................................................................... 39

\section{CHAPTER 3 - DEVELOPMENT OF A PRELIMINARY ARRANGEMENT AND}

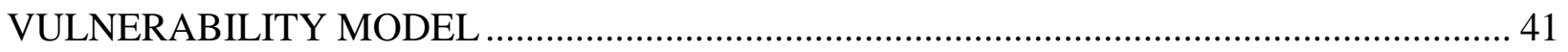

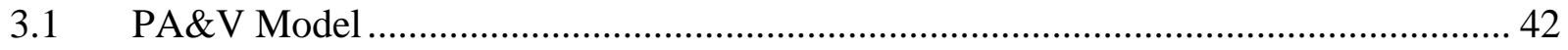

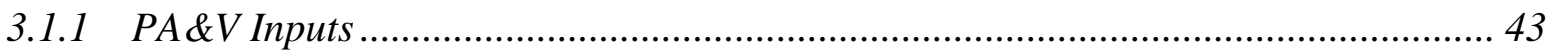

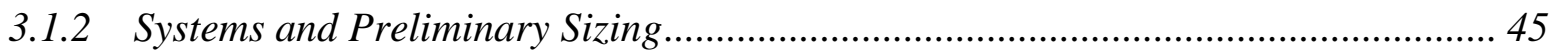

3.1.3 PA\&V Hullform, Subdivision, and Deckhouse Modules …………….................... 46

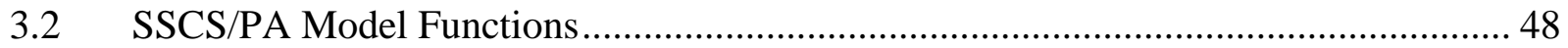

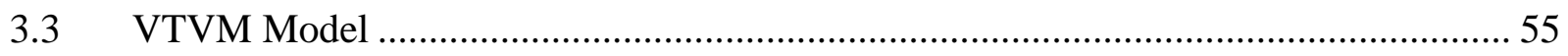

3.3.1 VTVM Ship Geometry and Preliminary Arrangements (Step 1)............................ 56

3.3.2 VTVM Ship Systems and Vital Components (Step 2) .............................................. 58

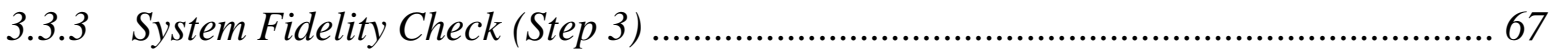

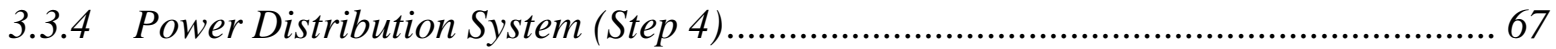

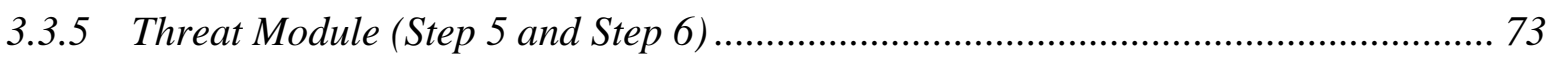

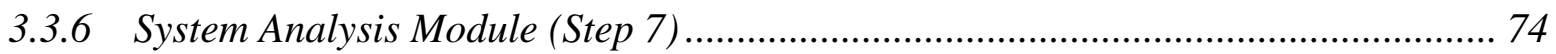

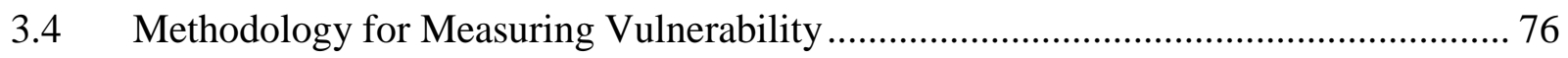

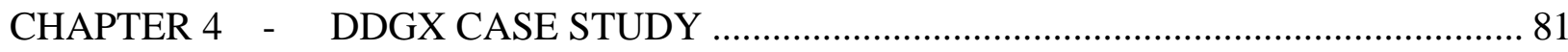

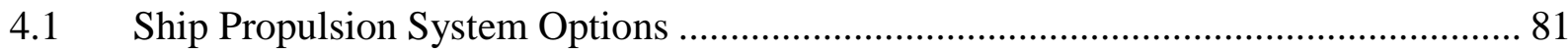

4.1.1 Combined Diesel and Gas Turbine (CODAG), Option 5 ...................................... 82

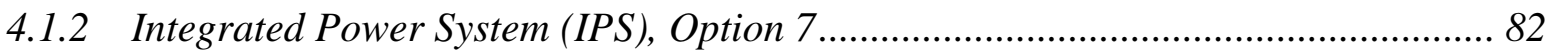

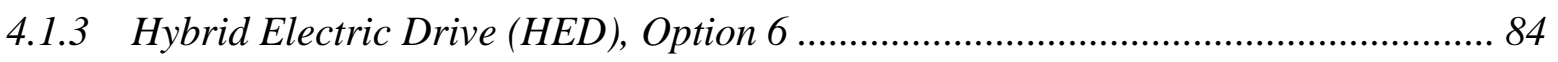

4.2 Ship Power Generation and Distribution System ………………........................... 85 


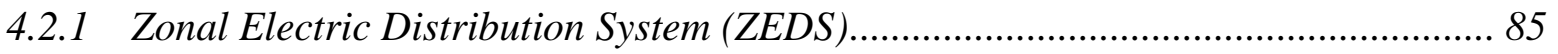

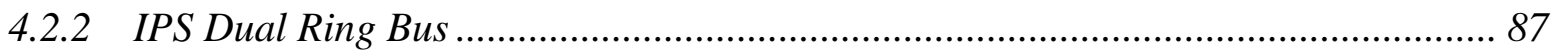

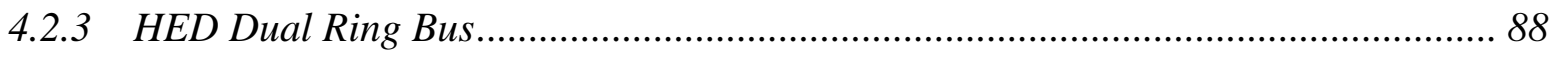

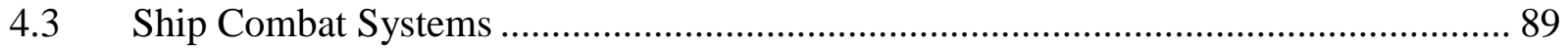

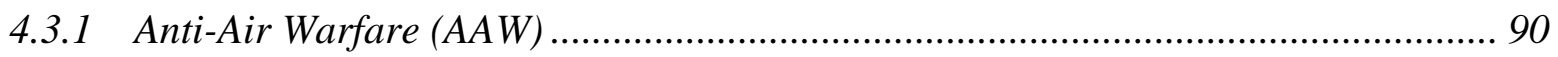

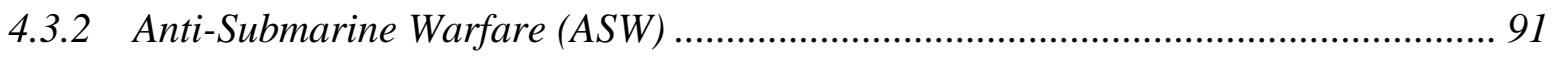

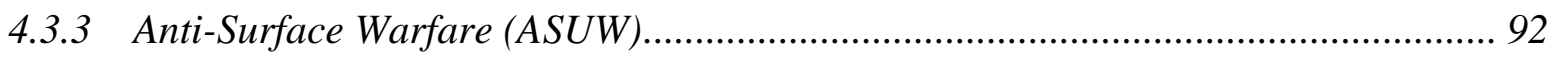

4.4 DDGX PA\&V Process and Overall Measure of Vulnerability ………………............. 95

4.5 Comparison of MOGO with and without OMOV .................................................. 102

CHAPTER 5 - CONCLUSIONS AND FUTURE WORK ………………………….......... 108

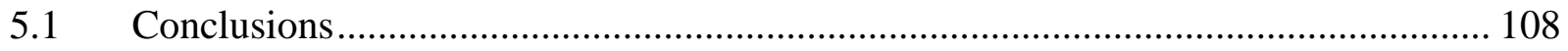

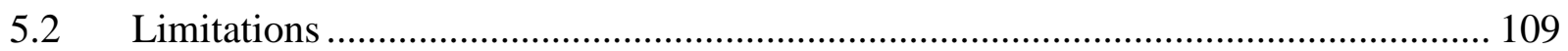

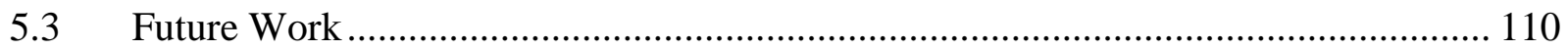

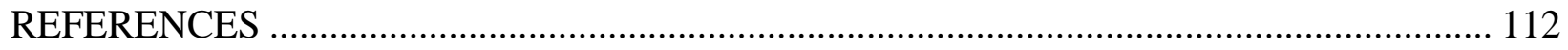

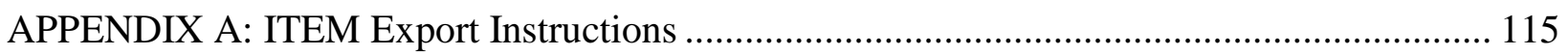

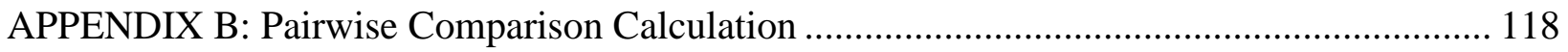




\section{LIST OF FIGURES}

FIGURE

PAGE

Figure 1-1 - NAVSEA Design Stage Process NSWC Code 223 "The Navy Ship Design

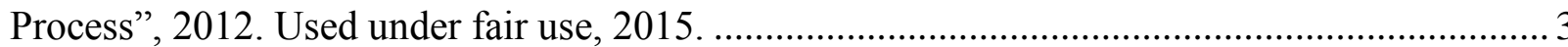

Figure 1-2- Virginia Tech Concept and Requirements Exploration Module (C\&RE) Brown, A.J., Barentine, J., "The Impact of Producibility on Cost and Performance in Naval Combatant Design", paper presented to SNAME NE Section, November, 1996 .Used under fair use, 2015.

Figure 1-3 - Survivability through Time Survivability through Time. Brown, A.J. (2004), "AOE 5315 Naval Ship Vulnerability and Underwater Explosion - Introduction to Survivability OnLine Lecture 1", Virginia Tech Department of Aerospace and Ocean Engineering, January 2004. Used under fair use, 2015.

Figure 1-4 - US Navy Casualties since 1950 US Navy Casualties since 1950. "AOE 5315 Naval Ship Vulnerability and Underwater Explosion - Introduction to Survivability OnLine Lecture 1", Virginia Tech Department of Aerospace and Ocean Engineering, January 2004, Used under fair use, 2015.

Figure 1-5 - USS Stark ASM Impact Damage. Hicks, PH2 U.S. Navy photo DVID \#DN-ST88-10218. Used under fair use, 2015

Figure 1-6 - USS Stark Listed and On Fire Post Weapon Impact, Navsource Online, U.S.

Navy photo DVID \#DN-SC-87-06412. Used under fair use, 2015. 
Figure 1-7 - ROKS Cheonan Starboard Propeller Damage ROKS Cheonan Starboard Propeller Damage, Chung, Jung-Hoon "Close-in UNDEC Shock Simulation ROKNS Cheonan Recent Related R\&D Activities”, 2014. Used under fair use, 2015.

Figure 1-8 - ROKNS Cheonan Damage from UNDEX , Chung, Jung-Hoon “Close-in UNDEC Shock Simulation ROKNS Cheonan Recent Related R\&D Activities”, 2014. Used under fair use, 2015.

Figure 1-9 - ROKS Cheonan (Bow) being lifted following its 2010 sinking (International Journal of Socialist Renewal, 2012) Used under fair use, 2015.

Figure 1-10 - Damage to the USS Cole in 2010 Explosion https://www.fbi.gov/aboutus/history/famous-cases/uss-cole Used under fair use, 2015.

Figure 1-11 - USS Cole being carried by the MV Blue Marlin https://www.fbi.gov/aboutus/history/famous-cases/uss-cole U.S. Navy photo by PH2 Leland Comer. Used under fair use, 2015.

Figure 1-12 - USS Cole SPY 1-D Damage following terrorist attack https://www.fbi.gov/about-us/history/famous-cases/uss-cole U.S. Navy photo by Robert Hurst. Used under fair use, 2015.

Figure 1-13 - USS Cole Propeller Shaft Seal after Damage Control https://www.fbi.gov/about-us/history/famous-cases/uss-cole Used under fair use, 2015.

Figure 1-14 - USS Cold Machinery Space Flooding https://www.fbi.gov/aboutus/history/famous-cases/uss-cole Used under fair use, 2015.

Figure 1-15 - MOTISS Analysis Assessment Process from Alionscience.com. Used Under fair use, 2015 
Figure 1-16 - MOTISS AABB Model from Alionscience.com. Used Under fair use, 2015..... 17

Figure 2-1 - Example 2-D Non-Dominated Frontier ....................................................... 25

Figure 2-2 - Ship Synthesis and MOGO Model in Model Center .......................................26

Figure 2-3 - Example 3D Non-Dominated Frontier.................................................... 27

Figure 2-4 - Curvilinear Hullform vs AABB Hullform.................................................. 30

Figure 2-5 - CIWS System Fault Tree ................................................................... 32

Figure 2-6 - SPY-1D Fault Tree Example ............................................................... 32

Figure 2-7 - Example C-701 Hit Distribution ........................................................... 35

Figure 2-8 - Example 2-D Damage Ellipsoid Intersection Diagram................................... 36

Figure 2-9 - Example 2-D Damage Volume Diagram ........................................................... 37

Figure 2-10 - MANA Red vs Blue Scenario in the Yellow Sea ........................................ 40

Figure 3-1 - Preliminary Arrangements and Vulnerability Process .................................... 41

Figure 3-2 - Preliminary Arrangements and Vulnerability Model Center Model.................... 43

Figure 3-3 - Notional Preliminary Subdivision in Rhino ............................................... 47

Figure 3-4 -Subdivision Block Generation Using AABBs ............................................ 47

Figure 3-5 - SSCS/PA “Input” Sheet (Left Side) ….................................................... 49

Figure 3-6 - SSCS "Mission Support” Classification Sheet .............................................. 50

Figure 3-7 - SSCS "Human Support” Classification Sheet................................................. 51

Figure 3-8 - SSCS “Ship Support” Classification Sheet ................................................ 51 
Figure 3-9 - SSCS/PA “Input” Sheet (Right Side). 52

Figure 3-10 - SSCS/PA “Compartments" Sheet ……………................................................53

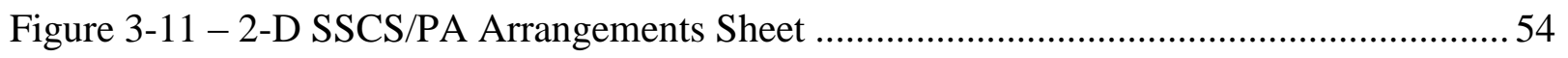

Figure 3-12 - Example Arrangeable Area 2-D Model .......................................................... 54

Figure 3-13 - VTVM Primary Subdivision Input Sheet............................................................. 57

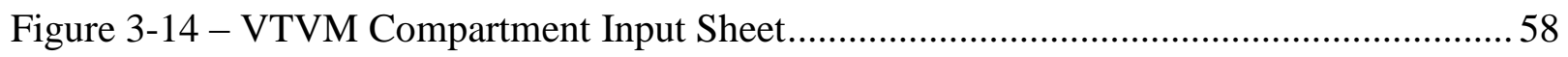

Figure 3-15 - Total Ship Capability RBD ........................................................................... 59

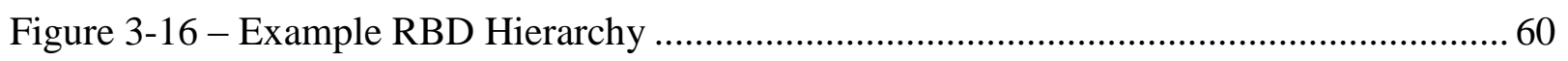

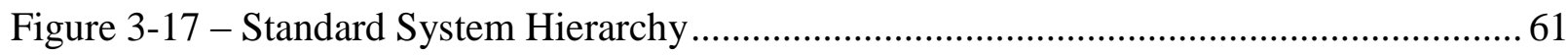

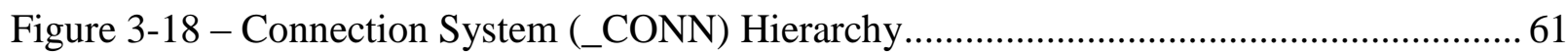

Figure 3-19 - Full Example System Logic Build Methodology Required for the VTVM......... 62

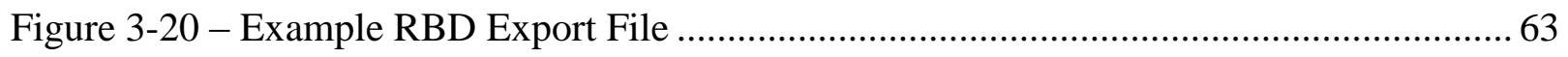

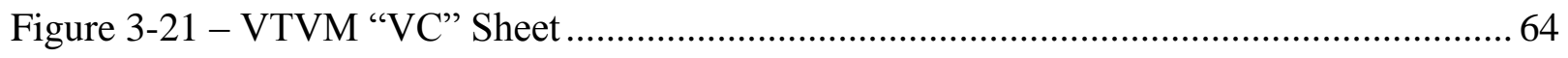

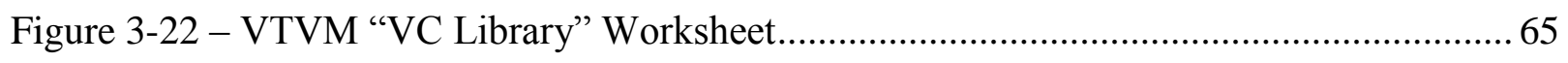

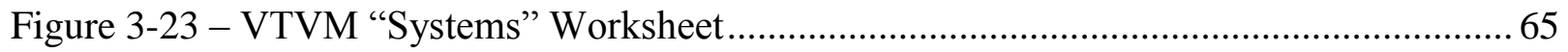

Figure 3-24 - IPS Dual Ring Bus Distribution System adapted from "Electric Architecture Leap Ahead Swampworks Project" by Bradshaw and Robinson, 2013. Used under fair use,

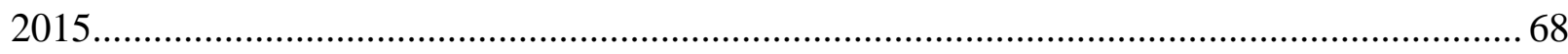

Figure 3-25 - Example Load Center Power Distribution System RBD ......................................69

Figure 3-26 - Example Connection Power Distribution System RBD ………………................ 70 
Figure 3-27 - Zonal Power Options.

Figure 3-28 - Power Distribution System Application (AND Gate).................................... 72

Figure 3-29 - Power Distribution System Application (OR Gate) ...................................... 73

Figure 3-30 - VTVM “Threat Library” Sheet ............................................................. 74

Figure 3-31 - VTVM "VC Availability” sheet............................................................ 75

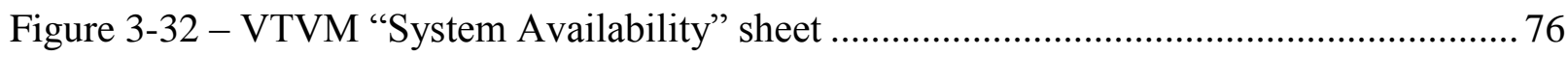

Figure 3-33 - Overall Measure of Vulnerability Hierarchy ............................................. 79

Figure 4-1 - CODAG System Architecture .............................................................. 83

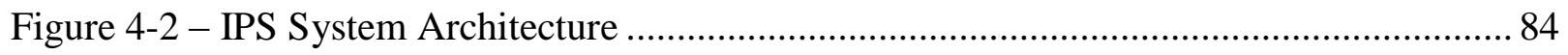

Figure 4-3 - Example Hybrid Electric Drive System Architecture ....................................... 86

Figure 4-4 - Zonal Electric Distribution adapted from "Electric Architecture Leap Ahead Swampworks Project” by Bradshaw and Robinson, 2013. Used under fair use, 2015. 87

Figure 4-5 - IPS Dual Ring Bus Distribution System adapted from “Electric Architecture Leap Ahead Swampworks Project” by Bradshaw and Robinson, 2013. Used under fair use, 2015...88

Figure 4-6 - Hybrid Dual Ring Bus Distribution System adapted from "Electric Architecture Leap Ahead Swampworks Project” by Bradshaw and Robinson, 2013. Used under fair use, 2015. 89

Figure 4-7 - AAW RBD System Architecture 92

Figure 4-8 - ASW RBD System Architecture. 93

Figure 4-9 - ASWCS SQQ89 System RBD 94 
Figure 4-10 - ASUW RBD System Architecture 95

Figure 4-11 - Case Study Preliminary Arrangement Example (Bow, Zones 1, 2, 3) ................98

Figure 4-12 - Case Study Preliminary Arrangement Example (Stern, Zones 3, 4).................... 98

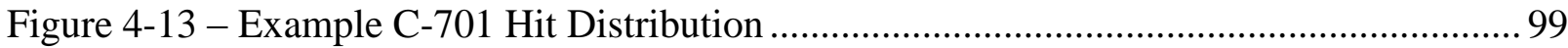

Figure 4-14 - Subdivision Block Probability of Ellipsoid Intersection........................................ 99

Figure 4-15 - Case Study MOGO PSYS Results Histogram (w/o OMOV; with OMOV) ...... 103

Figure 4-16 - Case Study MOGO OMOE Results Histogram (w/o OMOV; with OMOV).... 103

Figure 4-17 - Case Study MOGO OMOR Results Histogram (w/o OMOV; with OMOV) ... 103

Figure 4-18 - Case Study MOGO Cfola Results Histogram (w/o OMOV; with OMOV)....... 103

Figure 4-19 - Influence of Design Variables on OMOE (w/o OMOV; with OMOV) .............. 104

Figure 4-20 - DDGX Non-Dominated Frontier (without Vulnerability)................................... 106

Figure 4-21 - DDGX Non-Dominated Frontier (with Vulnerability) ........................................ 106

Figure 4-22 - DDGX Effectiveness vs Cost and OMOV (with Vulnerability)......................... 107

Figure 4-23 - DDGX Effectiveness vs Cost and PSYS (with Vulnerability) ........................... 107

Figure A - 1 - ITEM Export Step 1 ………………………................................................115

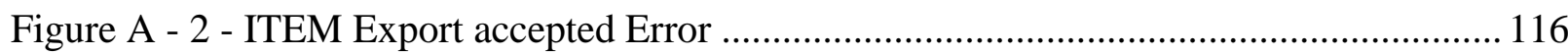

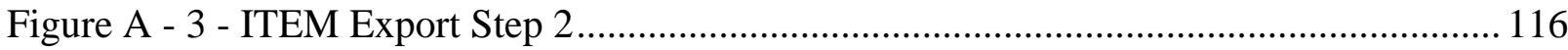

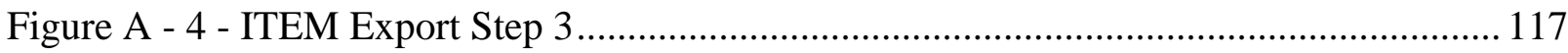

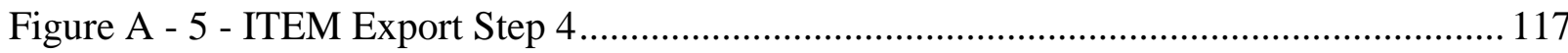




\section{LIST OF TABLES}

TABLE

PAGE

Table 2-1 - DDGX Design Variable Table 23

Table 2-2 - DDGX Combat System Design Variable Table. 24

Table 3-1 - PA\&V Input Design Variables 43

Table 3-2 - PA\&V Design Parameters 44

Table 3-3 - VTVM Primary Subdivision Block Inputs 56

Table 3-4 - VTVM Compartment Input Categories 57

Table 3-5 - VTVM Systems Input Data Categories. 66

Table 4-1 - Propulsion and Power System Options .... 81

Table 4-2 - AAW System Options 90

Table 4-3 - ASW System Options 93

Table 4-4 - ASUW System Options. 94

Table 4-5 - Case Study System Baseline Design Characteristics 97

Table 4-6 - Subdivision Block Probability of Ellipsoid Intersection 99

Table 4-7 - Vulnerability Analysis Results 100

Table 4-8 - OMOE MOP Weights 101

Table 4-9 - MOGO Design Variables and Bounds 102

Table 4-10 - MOGO System Design Options .... 102

Table 4-11 - PSYS Selection Probability in ND Set 104 
Table 4-12 - Characteristic Mean Values for ND Set. 


\section{LIST OF ACRONYMS AND ABBREVIATIONS}

AABB Axis Aligned Bounding Box

AAW Anti-Aircraft Warfare

AP Armor-Piercing

AMM Anti-Missile Missile

ARM Anti-Radiation Missile

ASM Anti-Ship Missile

ASW Anti-Submarine Warfare

ASUW Anti-Surface Warfare

c Speed of Light

C4I Command, Control, Communication, Computer and Intelligence

CIWS Close-In Weapon System

ECM Electronic Countermeasures

EMP Electromagnetic Pulse

EO Electro-Optics

GPS Global Positioning System

INS Inertial Guidance System

IR Infra-Red

ISR Intelligence, Surveillance and Reconnaissance

PA Probability of an Active Threat

PD Radar Probability of Detection

PD|A Probability of Detection given an Active Threat

Pfa Radar Probability of False Alarm

PH Probability of Hit (Susceptibility)

PH|L Probability of Hit given a launch

PK $\mid \mathrm{H}$ Probability of Kill given a Hit (Vulnerability)

PL|T Probability of Launch given being Tracked/Identified/Classified

PK Probability of Kill (Killability)

PS Probability of Survival (Survivability)

PT|D Probability of being Tracked/Identified/Classified given detection

RAM Radar Absorbing Material

RAS Radar Absorbing Structure

RCS Radar Cross-Section

RPG Rocket-Propelled Grenades

SAP Semi-Armor-Piercing

TS Target Strength

UAV Unmanned Aerial Vehicle

USS United States' Ship

USV Unmanned Surface Vessel

UUV Unmanned Underwater Vehicle

VC Vital Component 


\section{CHAPTER 1 - INTRODUCTION AND MOTIVATION}

\subsection{Motivation}

In the United States Department of Defense (DoD) acquisition process concept design is initiated in response to an Initial Capability Document (ICD), and an important product of this process is the Concept Development Document (CDD) (Tibbitts and Keane, 1995). The CDD is the DoD's primary means of defining requirements using Key Performance Parameters (KPPs). Survivability is one of the six "required" or "mandatory" Joint Requirements Oversight Council (JROC) KPPs for naval ships, however, the Analysis of Alternatives (AoA) and ship feasibility studies often neglect the consideration of survivability. This may be due to a number of factors including: the lack of available concept design stage survivability evaluation tools; a perceived lack of sufficient design detail for analysis; and the lack of measurable and objective survivability performance criteria. OPNAV INSTRUCTION 9070.1A states that "Survivability shall be considered a fundamental design requirement of no less significance than other inherent ship characteristics." (DoN, 2012)

Designers are frequently tempted to prescribe ship requirements and design characteristics from the beginning of design before they understand the relationship between design cost, risk and effectiveness. In order to avoid this trap, it is best to start only with mission needs and capability gaps and identify non-dominated designs with the objective of maximizing effectiveness for a given cost and risk. This approach, in addition to any necessary constraints and a clear concept of operations and capabilities requirements list, is essential for a successful design exploration. As stated in "Still Re-Engineering the Naval Ship Concept Design Process" (Brown and Sajdak, 2015), "requirements must wait until design effectiveness has been defined, the appropriate design 
space has been explored, and significant effort has been applied to collecting data and studying thousands if not millions of alternatives using appropriate visualization tools and metrics."

In order to properly determine naval ship effectiveness, careful consideration must be given to ship performance in battle after weapon hits and damage considering mission-degraded states in addition to intact performance. Several questions are introduced when attempting to evaluate a degraded system. First, is it possible to generate sufficient model detail and fidelity during concept design to make a reasonable survivability assessment which maintains its significance through ship construction and operation? If sufficient detail is available for evaluation during concept design, would early survivability assessment change the resulting system architecture or preliminary arrangement selection? Finally, if a survivability assessment at concept design does impact design selection, how does this impact cost, effectiveness, and risk?

The objective of this thesis is to present an analysis tool and methodology to explore naval ship vulnerability using a simplified modeling approach to enable the inclusion of vulnerability in the concept design process and to ultimately assess the impact of this inclusion.

\subsubsection{The Concept Design Process}

In the United States Navy, ship design typically follows a design process similar to that shown in Figure 1-1 (NSWC, 2012). This process has three general design stages: Exploratory/Concept Design, Engineering Design, and Production Design. These three stages support an engineering progression from ship mission statement to ship construction.

The US Naval Sea Systems Command (NAVSEA) partitions the Concept Design Stage into two sub stages: 1) Rough Order of Magnitude Design and 2) Technology Assessment and Analysis of Alternatives \& Feasibility Studies. During this stage, naval technologies are implemented in a balanced design, evaluated and modified to best satisfy the ship's mission needs. 


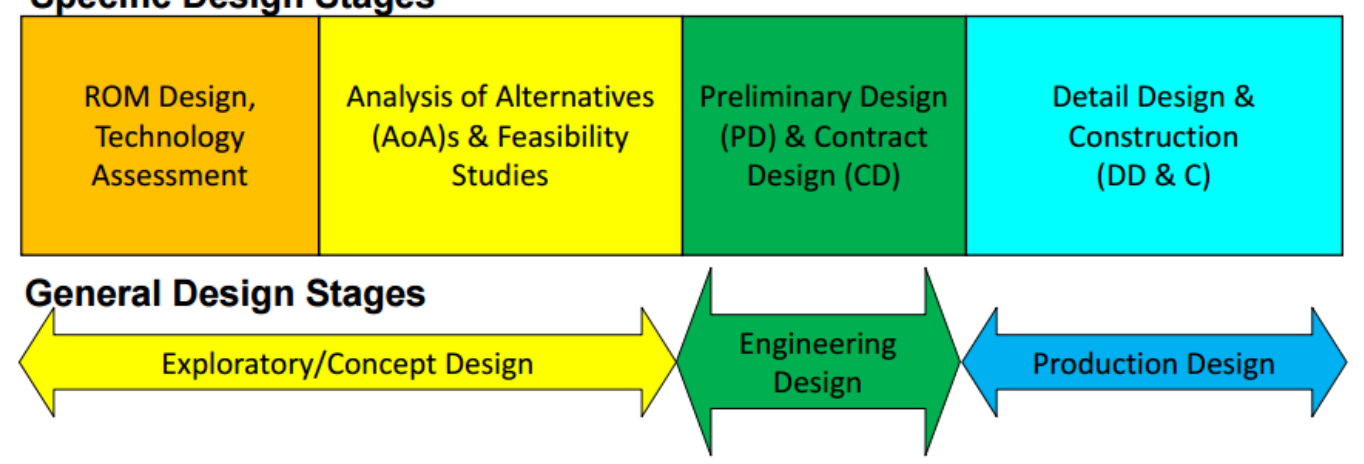

Figure 1-1 - NAVSEA Design Stage Process NSWC Code 223 "The Navy Ship Design

Process", 2012. Used under fair use, 2015.

NAVSEA considers six general technology or system areas that are interdependent and determine the overall cost, effectiveness, and risk of the total ship system of systems (NSWC, 2012). These are:

- Hull Systems

- Mission Systems

- Propulsion/ Power /Machinery Systems

- Human Systems

- Survivability

- Design Integration and Management

At Virginia Tech, the Concept and Requirements Exploration (C\&RE) process shown in Figure 1-2 is used for exploratory design. A primary goal of this process is to understand the relationship between cost, effectiveness, and risk for the proposed technologies in balanced ship designs. Steps in this process developed in the current research and described in this thesis are outlined in red. The overall C\&RE process is described in Section 2.1. Until now, only intact system performance was considered in this process. No consideration was given to system vulnerability and degradation due to warfighting weapon effects and losses or to overall ship survivability. The 
following section details what survivability means and how data acquired through survivability analyses may be incorporated into concept design.

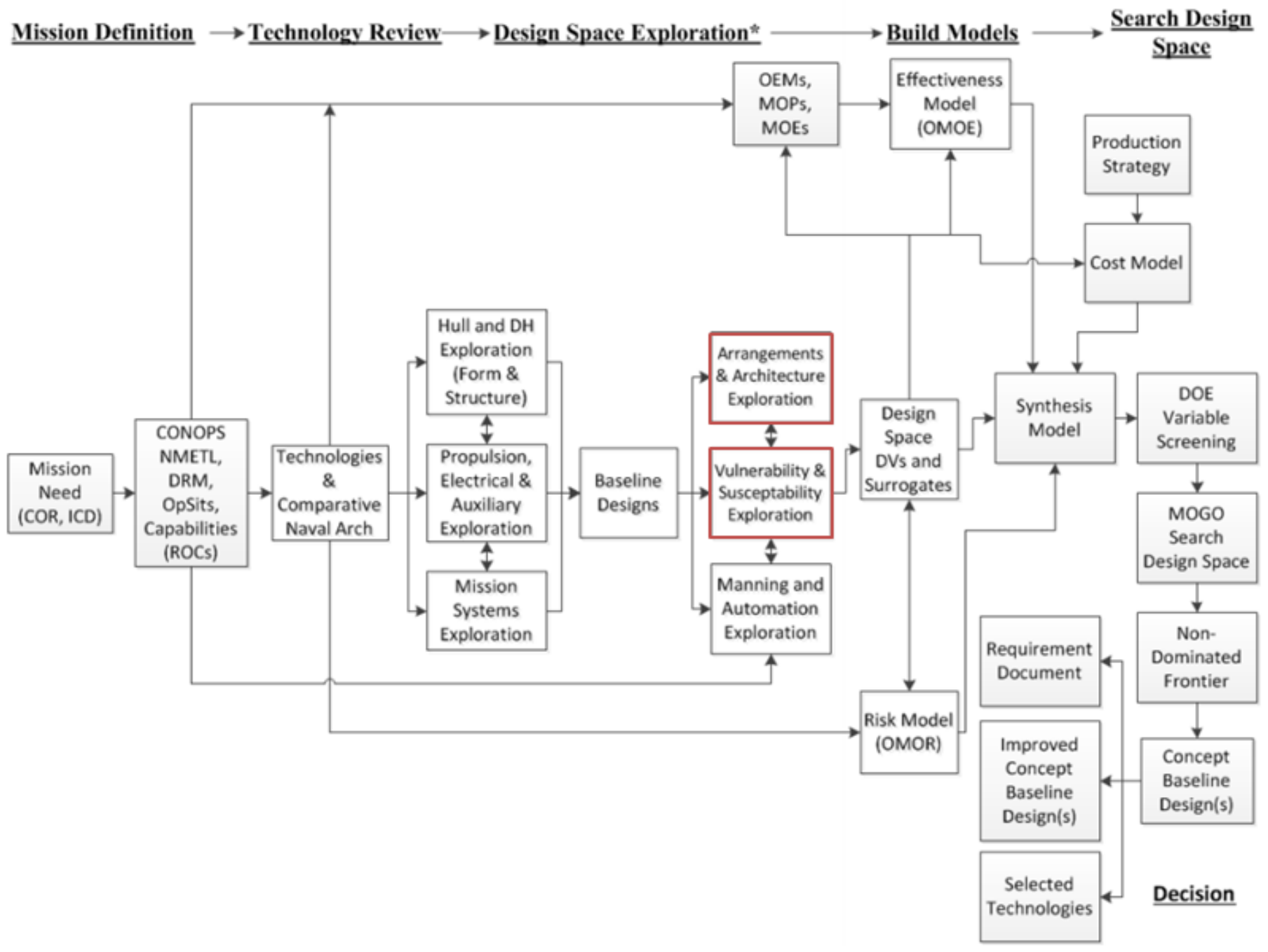

Figure 1-2- Virginia Tech Concept and Requirements Exploration Module (C\&RE) Brown,

\section{A.J., Barentine, J., "The Impact of Producibility on Cost and Performance in Naval}

Combatant Design", paper presented to SNAME NE Section, November, 1996 .Used under

fair use, 2015. 


\subsubsection{Ship Survivability}

Survivability is defined as "the capacity of the total ship system to avoid and withstand damage and maintain and/or recover mission integrity (DON, 2012)". The accepted mathematical expression for survivability is described by Equation (1-1):

$$
S=1-P_{h} P_{\frac{k}{h}}\left(1-P_{\frac{r}{k}}\right)
$$

In Equation (1-1), $\mathrm{S}$ is the probability of survival, $\mathrm{P}_{\mathrm{h}}$ is probability of being hit, or Susceptibility, $\mathrm{P}_{\mathrm{k} / \mathrm{h}}$ is the probability of kill given hit, or Vulnerability, and $\mathrm{P}_{\mathrm{r} / \mathrm{k}}$ is the probability of recovery given kill, or Recoverability. Susceptibility reduction focuses on decoy and defensive systems and on reducing detectable ship characteristics such as: Radar Cross Section (RCS), infrared (IR), acoustic, magnetic, visual and electro-optical (VE/O) and thermal signatures. Vulnerability reduction and the assessment of mission capability after hit are addressed in this thesis. Susceptibility and recoverability are not considered directly.

Understanding the level of degradation to a ships mission capability following a threat hit is critical in evaluating the ships inherent capability to complete its mission during wartime. Ship capabilities are generally grouped into two categories, Primary Capabilities and Secondary Capabilities. Primary capabilities for a naval ship include: ship control and propulsion; command and control; navigation; surface, air, and underwater surveillance; countermeasures; launch, recover, fuel, rearm aircraft and small craft; essential maintenance of aircraft and ordnance; weapons stowage, control, launch, and guidance; replenish at sea; mine-hunting and sweeping; combat payload transport; casualty and damage control. All other capabilities are considered Secondary Capabilities.

Primary and Secondary intact capabilities are called Required Operational Capabilities (ROC's) in the United States Navy. Each ship is assigned a set of ROCs which are necessary for a 
ship to complete its intended mission. In order to assess a ship's vulnerability, evaluation of a simplified set of capability criteria with metrics is necessary. Capabilities can then be evaluated at a single time step or through time, as shown in Figure 1-3. In this thesis, Vulnerability is assessed immediately after hit and considers the immediate and potentially cascading damage generated by the hit. Immediately following the damage event, referred to as time $t=0+$, damage control responses are initiated by automated systems or crew processes which begin the recoverability stage.

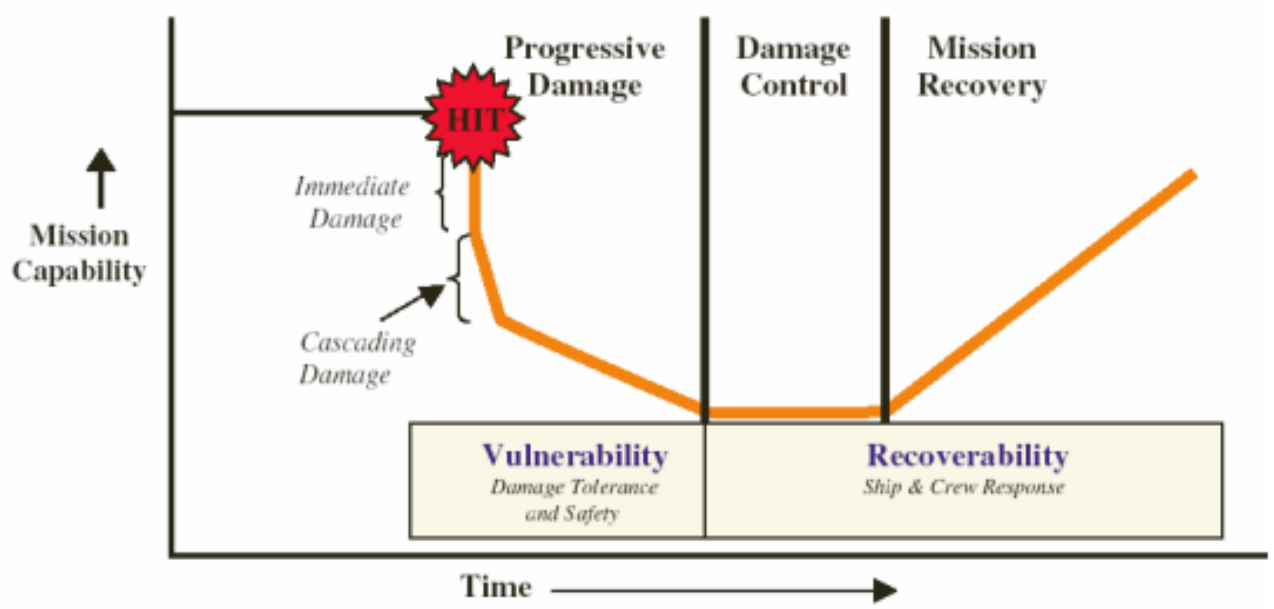

Figure 1-3 - Survivability through Time Survivability through Time. Brown, A.J. (2004),

"AOE 5315 Naval Ship Vulnerability and Underwater Explosion - Introduction to

\section{Survivability OnLine Lecture 1", Virginia Tech Department of Aerospace and Ocean}

Engineering, January 2004. Used under fair use, 2015.

While consideration for vulnerability and recoverability through-time would seem to require a through-time survivability analysis, predications of the capability of ship response to immediate and cascading damage can be approximated. Taking into consideration the availability of damage control VC's in various subdivision blocks and zones through the ship provides some indication of the ships through-time recoverability capability. 


\subsection{Literature Survey}

There are various threat types that naval ships may encounter. Ships can incur damage from direct threats such as an attack from an Anti-Ship missile (ASM), as experienced by the USS Stark in 1987, an attack from a torpedo, as experienced by the ROKN Cheonan in 2010, or an asymmetric threat, as experienced by the USS Cole in 2000. Naval ships have also encountered collisions, as experienced by the USS Porter (DDG-78) in 2012, or grounding scenarios, as experienced by the USS Port Royal in 2009. Ships can also have fires, accidental or otherwise that put the vessel and crew at risk or accidental explosions, as experienced by the USS Iowa in 1989. Figure 1-4 shows a summary of some of the major casualties specifically from weapon damage that US Navy ships have experienced in the last 50 years.

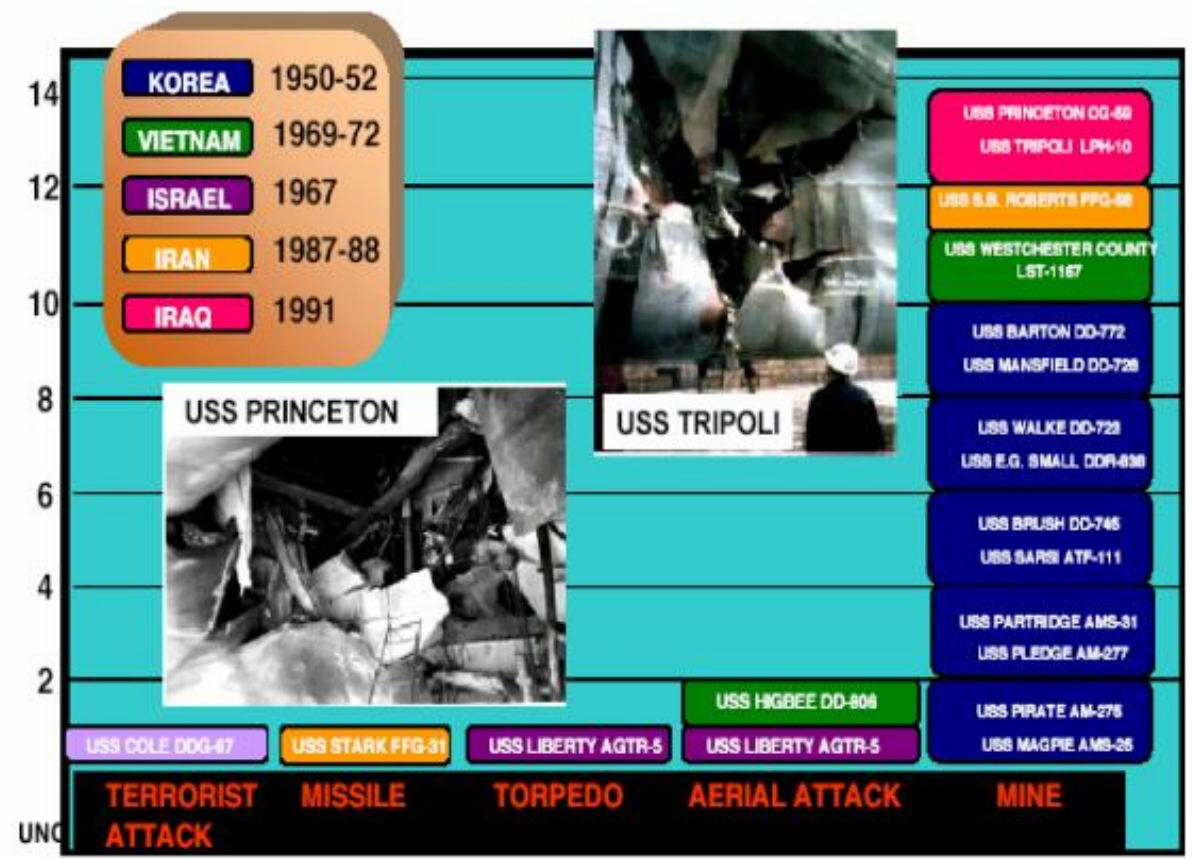

Figure 1-4 - US Navy Casualties since 1950 US Navy Casualties since 1950. "AOE 5315 Naval Ship Vulnerability and Underwater Explosion - Introduction to Survivability OnLine Lecture 1", Virginia Tech Department of Aerospace and Ocean Engineering, January 2004, Used under fair use, 2015. 
Explosive threats are generally categorized as either underwater explosions (UNDEX) or air explosions (AIREX). Threats are also often categorized based on whether they detonate internally or externally to the ship and if external, by their proximity to the ship. Events, predictable or otherwise, which have the capability to degrade a ship's ability to perform it's mission should be considered as a part of the concept design process in order to plan and account for these damage scenarios. This thesis explores whether or not a method accounting for these damage scenarios during early stage design would significantly impact design decisions. The case study presented in this thesis deals primarily with AIREX threats, but research to assess UNDEX effects is ongoing and will be incorporated into the vulnerability model in the future.

\subsubsection{Historical Significance}

While many events have taken place on the last 30 years which have impacted both the United States Navy, and international navies, the following events show cases where ships were all unable to complete their mission following threat events: USS Stark, 1987, ROKS Choenan 2010, and the USS Cole in 2000. These events resulted in various ship states ranging from capsize to heavy flooding and fire spread, each of which presents a unique area for investigation as to whether the inclusion of these scenarios for analysis during concept design will lead to a more robust design selection.

The USS Stark was struck by two Exocet ASMs fired from an Iraqi fighter jet in May of 1987 following the failure of ship systems to defend the ship. Neither the Phalanx CIWS or Mark 36 SRBOC countermeasures armed until seconds prior to missile strike. Both the aircraft and missiles were in a blind spot of the Mk 75/54mm caliber naval gun and the Mk 92 guided missile fire control system. The Anti-Ship Missiles (ASMs) were in the clear for the Mk 92 combined antenna system and the Mk 13 Mod 4 single-arm launcher, but ship systems failed to maneuver 
and respond to the threat in time to prevent missile contact with the port side of the deckhouse on the main deck, Figure 1-5.

While the ship took significant structural damage, ship fires and stability problems were eventually controlled by the crew. This was attributed to the availability of firefighting damage control, and power distribution systems, despite the fact that the first ASM strike severed the firemain that supplied the forward part of the ship. The crew fought fires for 48 consecutive hours to save the ship, despite the availability of only 1 of 3 damage control lockers within the ship, a testament to the significant role damage control teams play in a ship's survivability post threat impact. The Stark also had sufficient power and propulsion capabilities to make its way to Bahrain for temporary repairs under her own power prior to its return to Mississippi for permanent repairs.

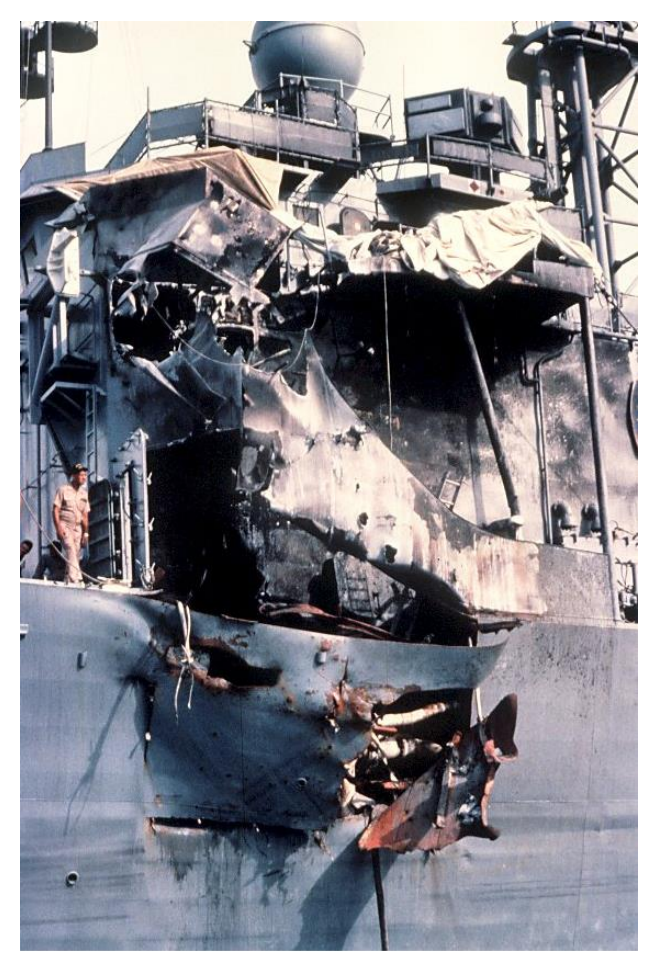

Figure 1-5 - USS Stark ASM Impact Damage. Hicks, PH2 U.S. Navy photo DVID \#DN-ST88-10218. Used under fair use, 2015. 


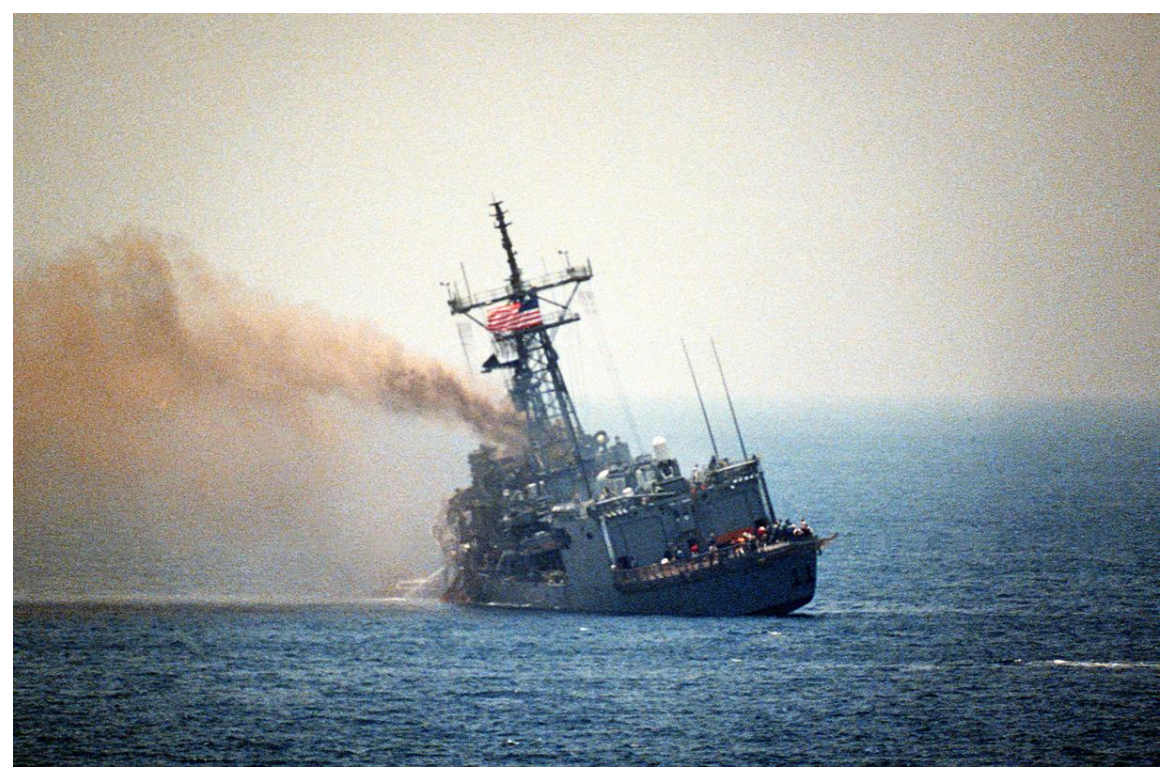

Figure 1-6 - USS Stark Listed and On Fire Post Weapon Impact, Navsource Online, U.S. Navy photo DVID \#DN-SC-87-06412. Used under fair use, 2015.

On March 26, 2010, the ROKS Cheonan sank off the west coast of South Korea following an underwater explosion. The underwater explosion is said to have been that of a North Korean torpedo detonation fired from a midget submarine, an accusation that is denied by North Korea. The Cheonan was patrolling waters less than 10 miles off the North Korean coast in the Yellow Sea. While North and South Korea have an armistice and the region in question is south of the agreed upon Northern Limit Line which divides North and South Korea, the region in which the Cheonan was patrolling does not explicitly belong to either country. Many theories exist for the true cause of the Cheonan sinking, but following an investigation by the South Korean National Assembly's defense committee, Chairman Kim Hak-song stated that the damage to the ship was "inevitably the result of a torpedo or mine attack". According to Dr. Jung-Hoon Chung of KIMM (Chung, 2014), 46 of the 103 ROKN sailors were killed in the incident and one of the propellers was damaged beyond use, Figure 1-7. 


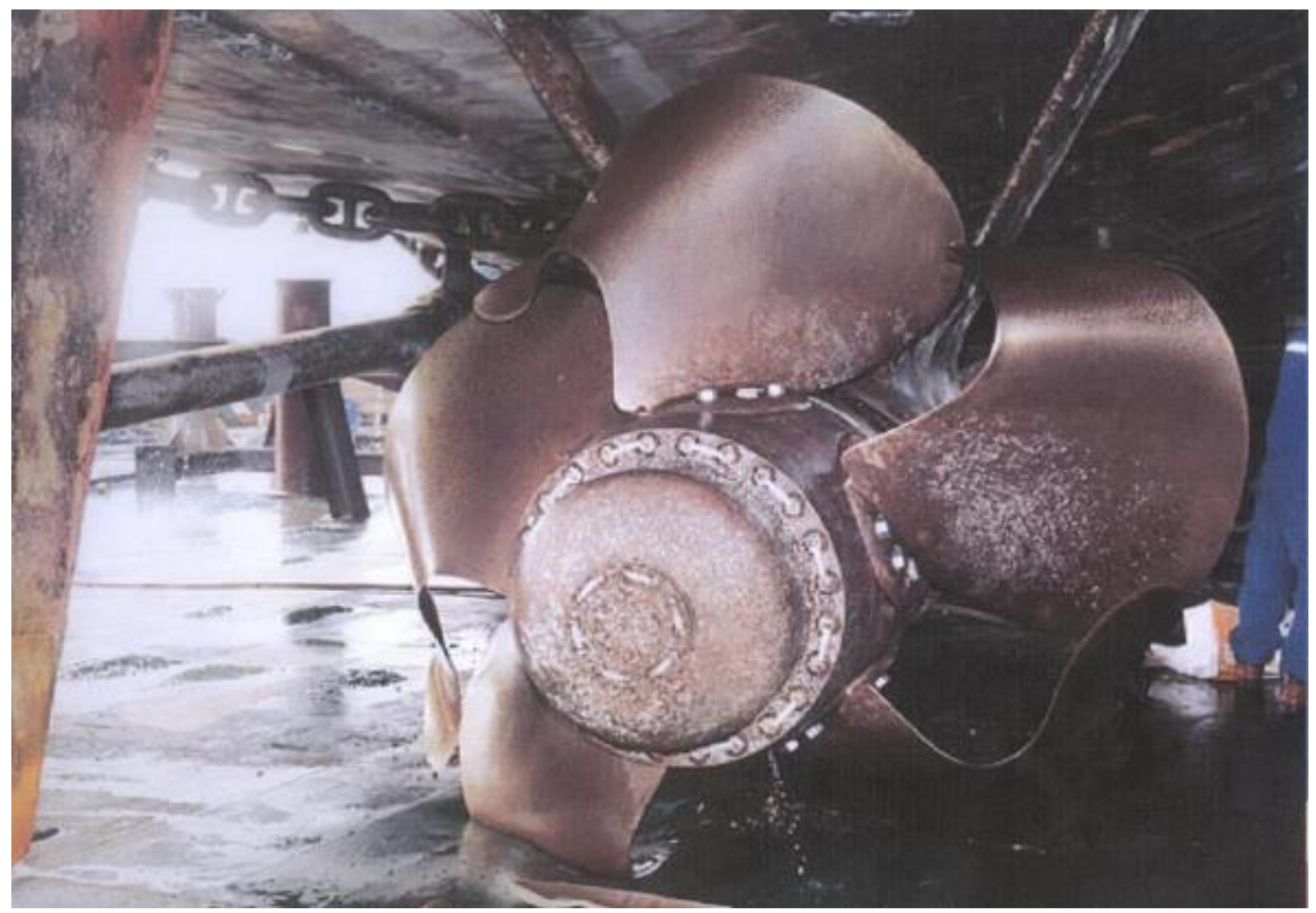

Figure 1-7 - ROKS Cheonan Starboard Propeller Damage ROKS Cheonan Starboard

\section{Propeller Damage, Chung, Jung-Hoon "Close-in UNDEC Shock Simulation ROKNS}

Cheonan Recent Related R\&D Activities", 2014. Used under fair use, 2015.

Any equipment within the Gas Turbine room would have been rendered useless following the incident, even if the Cheonan had been able to stay afloat as this area was directly impacted by the standoff explosion, Figure 1-8. 


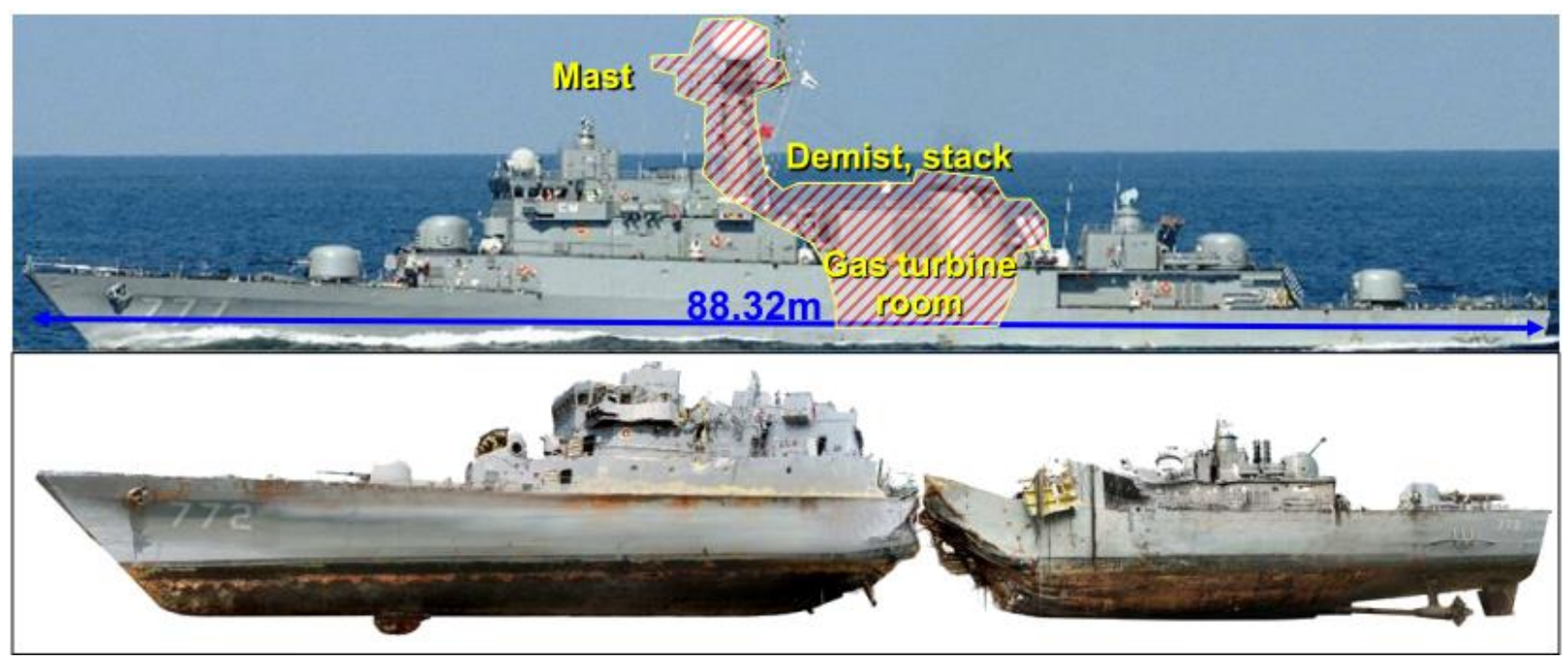

Figure 1-8 - ROKNS Cheonan Damage from UNDEX, Chung, Jung-Hoon "Close-in

UNDEC Shock Simulation ROKNS Cheonan Recent Related R\&D Activities", 2014. Used

under fair use, 2015.

The UNDEX impacted the ship immediately below the gas turbine room splitting the ship into two pieces, and causing it to sink. Figure 1-9 shows the Cheonan's largely intact bow being lifted following it's capsize and sinking.

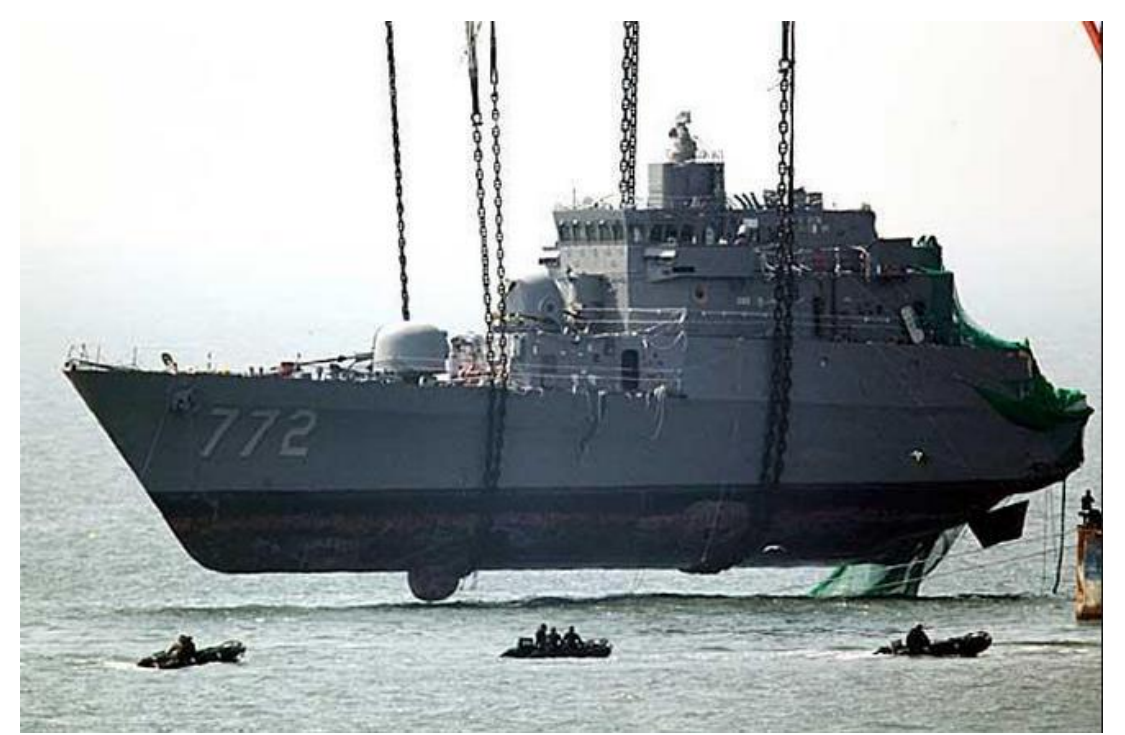

Figure 1-9 - ROKS Cheonan (Bow) being lifted following its 2010 sinking (International Journal of Socialist Renewal, 2012) Used under fair use, 2015.

The USS Cole (DDG-67) was attacked by the terrorist group Al-Qaeda in October 2000 while refueling in port in Aden, Yemen. The detonation of 200-300kg of explosive shape charges 
created a 40 by 60 foot hole along the waterline on the port side. The explosion was forward of amidships impacting the galley where crew members were staged for lunch. 17 people were killed and 39 were injured in this attack. The USS Cole is an Arleigh Burke-class destroyer, with outward slanting sideshell. The explosion generated a blast with forces directed sideways and upwards, a damage pattern not expected in modern warfare [33]. While the ship's propulsion and power systems remained largely intact, there was too much hull damage to safely navigate the vessel for repairs so she was lifted by a heavy-lift ship, Figure 1-10 and Figure 1-11. Despite the large distance between the explosion and the Cole's port side, the aft SPY 1-D radar array rubber protective cover was perforated, Figure 1-12.

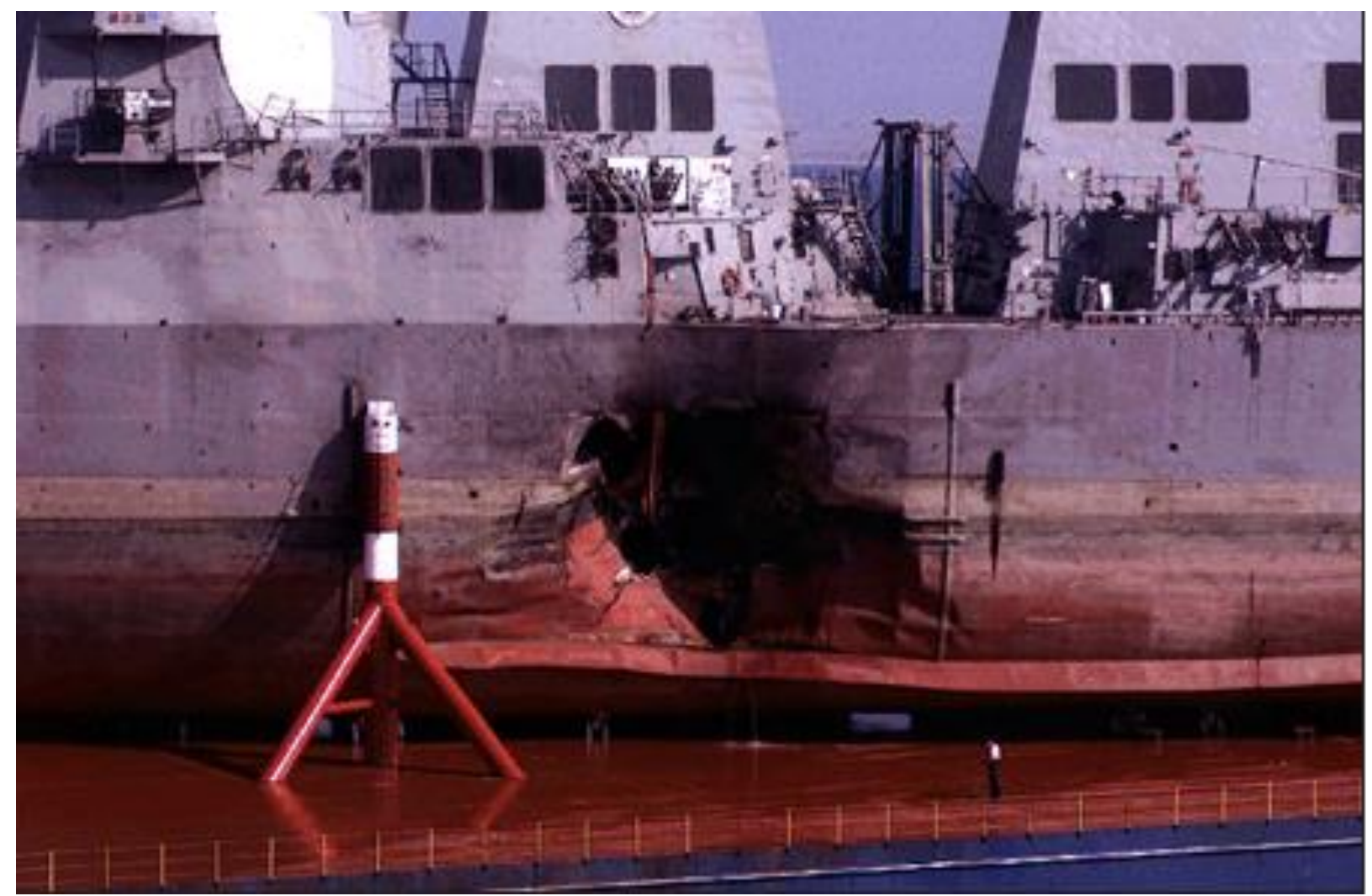

Figure 1-10 - Damage to the USS Cole in 2010 Explosion https://www.fbi.gov/aboutus/history/famous-cases/uss-cole Used under fair use, 2015. 


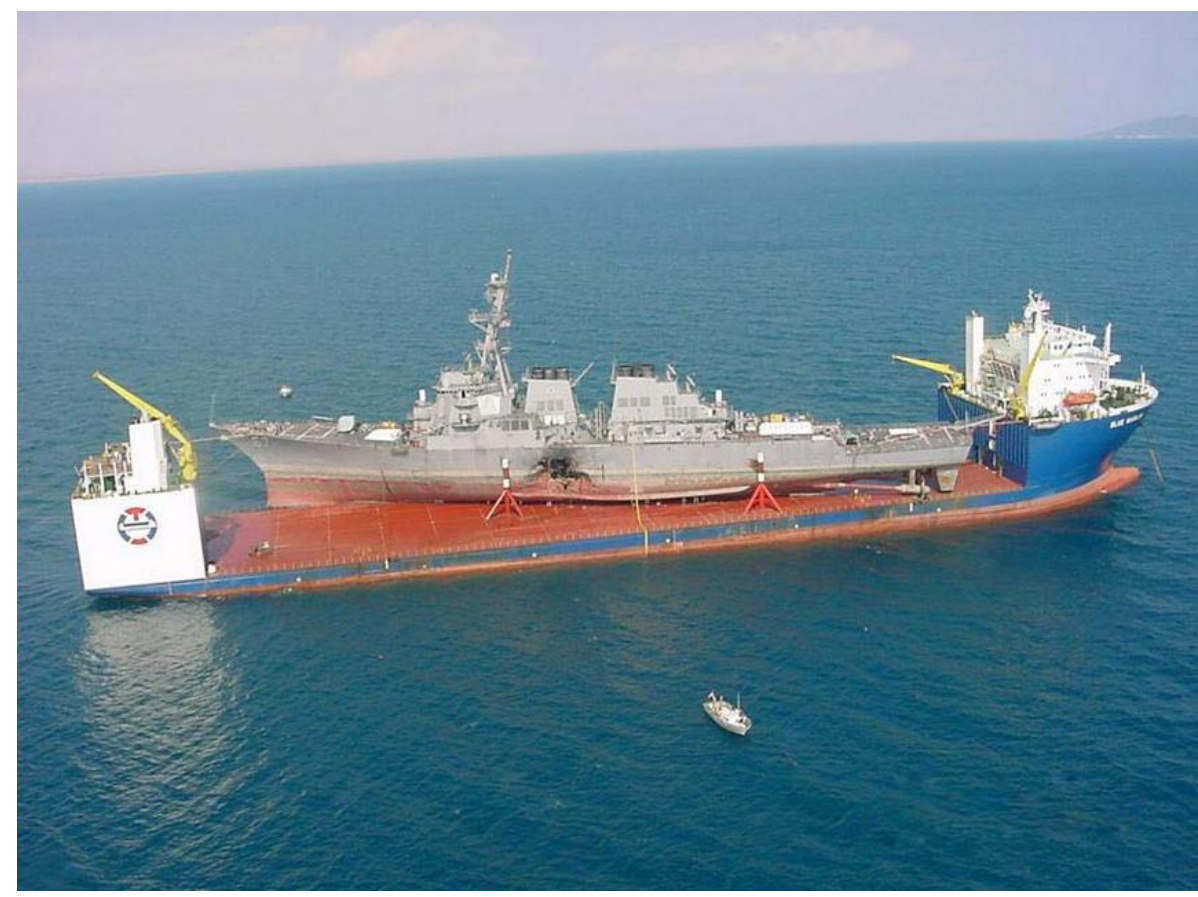

Figure 1-11 - USS Cole being carried by the MV Blue Marlin https://www.fbi.gov/aboutus/history/famous-cases/uss-cole U.S. Navy photo by PH2 Leland Comer. Used under fair use, 2015.

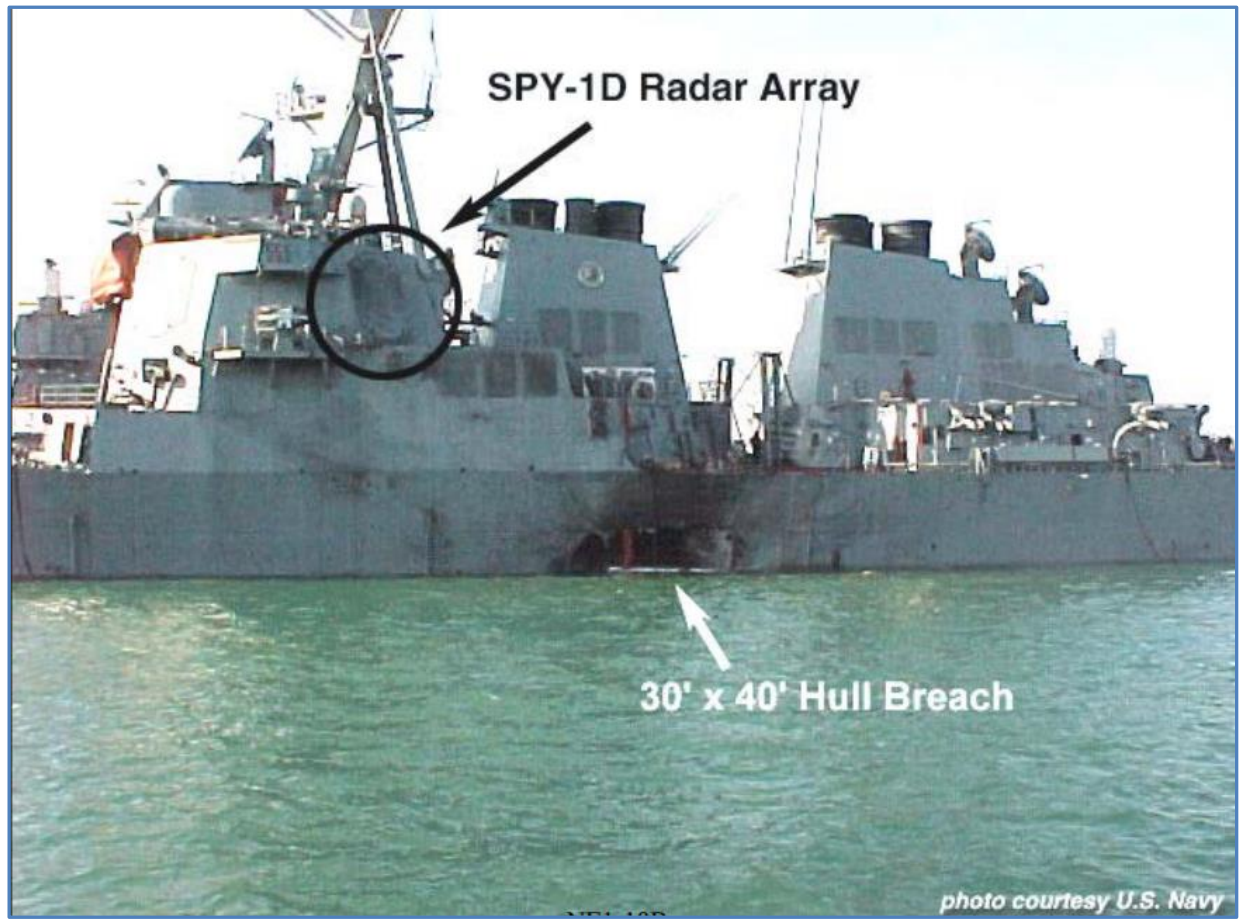


Figure 1-12 - USS Cole SPY 1-D Damage following terrorist attack

https://www.fbi.gov/about-us/history/famous-cases/uss-cole U.S. Navy photo by Robert

Hurst. Used under fair use, 2015.

One of the propeller shaft bulkhead seals was also damaged during the explosion, a damage control team was needed to prevent additional progressive flooding, Figure 1-13 and Figure 1-14.

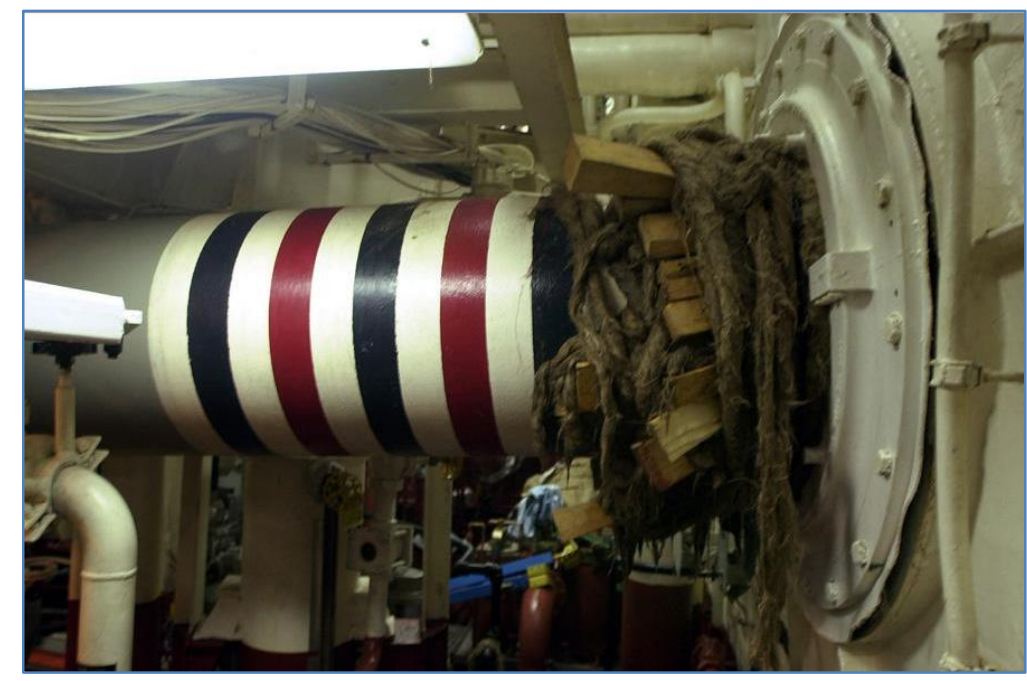

Figure 1-13 - USS Cole Propeller Shaft Seal after Damage Control

https://www.fbi.gov/about-us/history/famous-cases/uss-cole Used under fair use, 2015.

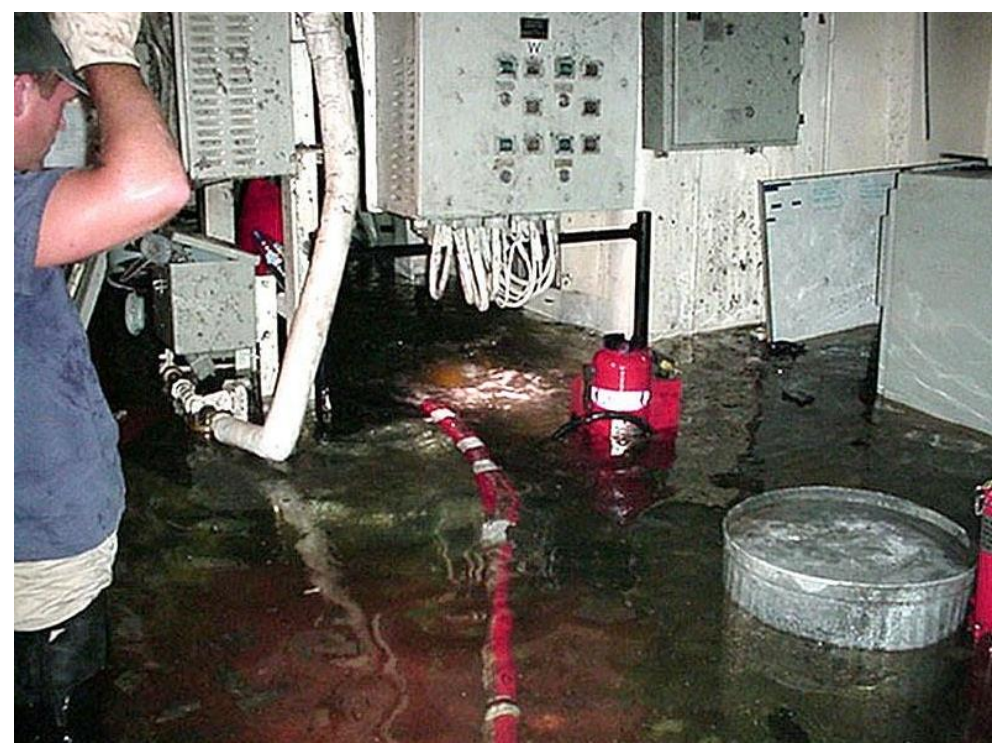

Figure 1-14 - USS Cold Machinery Space Flooding https://www.fbi.gov/aboutus/history/famous-cases/uss-cole Used under fair use, 2015. 


\subsubsection{Existing Survivability Evaluation Tools}

Around the world, several ship survivability analysis tools are available for commercial and government use, including ASAP, MOTISS, PREVENT, PRIMA, SURMA, SURVIVE, SVM and VIVA. Each of these tools was designed to help ship designers, at various design stages, improve assess and improve ship survivability. While each tool has strengths and weaknesses, none allow for the inclusion of a simplified model with the level of fidelity available at concept design. The following sections discuss the three tools that most influenced the assumptions and processes generated within this thesis.

\subsubsection{Measure of Total Integrated Ship Survivability (MOTISS)}

MOTISS (Measure of Total Integrated Ship Survivability) (MOTISS, 2011) is a computer program and process, shown in Figure 1-15, used by Alion Science and Technology to assess the survivability of a ship through the evaluation of physics-based events applied to a 3-D model. MOTISS differs from other survivability analyses in its shorter time required for analysis. MOTISS uses Axis Aligned Bounding Blocks (AABB's) as shown in Figure 1-16 to substantially reduce the calculation time required by a curvilinear geometry. 


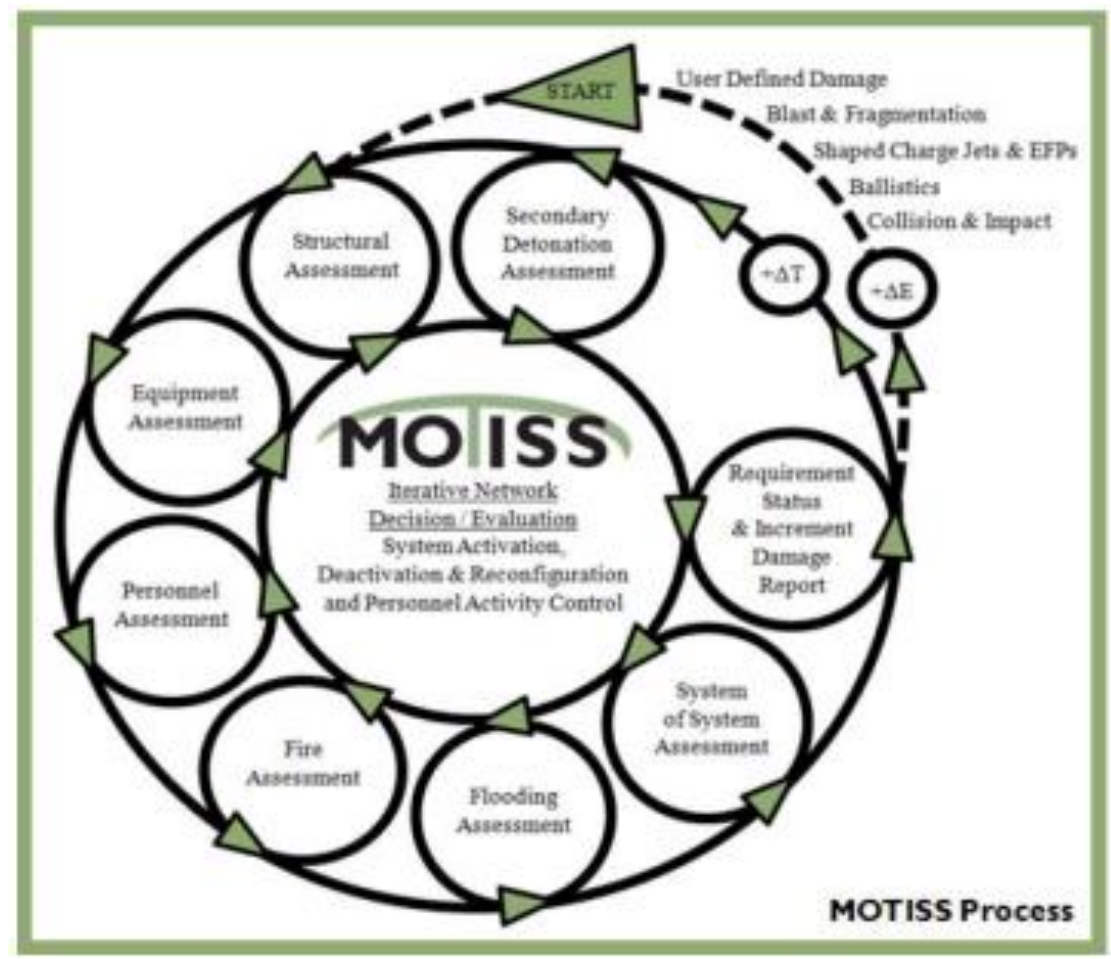

Figure 1-15 - MOTISS Analysis Assessment Process from Alionscience.com. Used Under fair use, 2015.

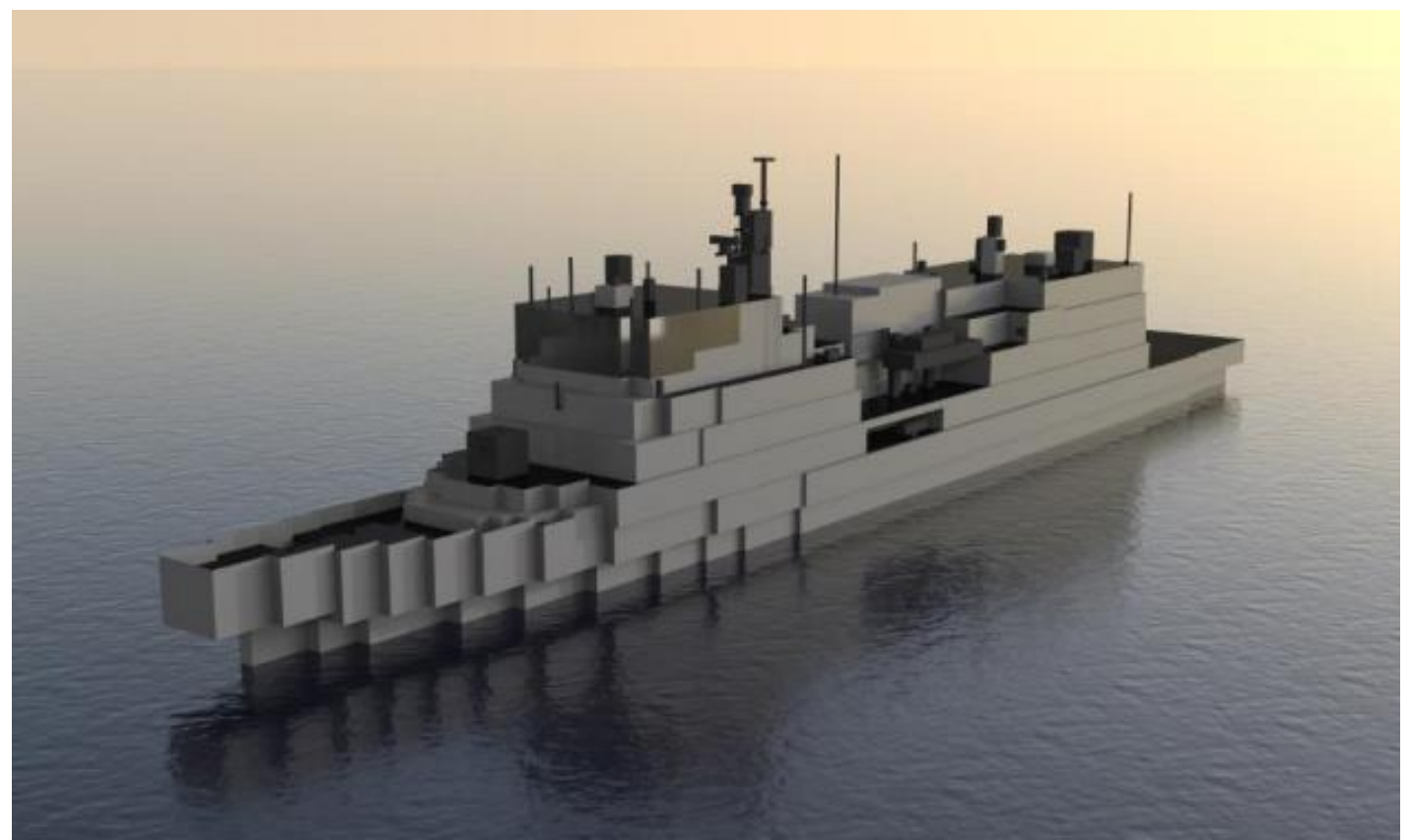

Figure 1-16 - MOTISS AABB Model from Alionscience.com. Used Under fair use, 2015.

Analysis time can be substantially decreased while still providing sufficient accuracy. MOTISS uses Microsoft Excel and Rhino 3D modeling software GUI's in conjunction with a series of 
Matlab modules to evaluate various damage events. The following list represents the types of damage scenarios currently evaluated in MOTISS:

- Detonations (MOTISS Blast or Damage Ellipsoid)

- Simulated Collisions (SIMCOL)

- Flooding

- Ballistic Threats

- Fire

MOTISS generates thousands of probabilistic damage scenarios within each damage category to perform a statistical analysis of VCs, structural, and system availability following a damage event. Each scenario uses statistically generated threat parameters and hit locations to capture a distribution of threat impacts on the vessel, thus providing a probabilistically determined assessment of occurrences similar to a real world threat event. MOTISS structural models are created using combinations of AABB's to allow for more rapid processing over traditional modeling and simulation methods while still maintaining simulation accuracy for large structures. Component and system models are also generated using AABB's for rapid component modeling.

Incorporated within MOTISS is the ability to calculate internal overpressure, ballistic and fragment penetration, linear jet theory for shaped charges, hull rupture and holing, rule based component lethality including shock impulse, acceleration, kinetic impact, temperature and saturation failures, fault tree analysis and network decision theory for system deactivation and reactivation re-evaluation, zonal fire spread, solid and liquid fuel loads allowing for thermal pulse ignition, options for sprinkling, water-mist, foam agent and gas agent fire suppression systems, progressive flooding, tank loading, and the inclusion of firewater release and education. 


\subsubsection{Advanced Survivability Assessment Program (ASAP)}

The Advanced Survivability Assessment Program (ASAP) is a Naval Surface Warfare Center Carderock Division program which simulates AIREX and UNDEX threat effects on Navy Surface Combatants. ASAP uses a probabilistic analysis to capture physics in Data Driven Modules (DDMs). DDMs typically were developed independently as independent programs and were then modified and implemented into ASAP. ASAP uses Finite Elements for the base structure to build models for evaluation.

\subsubsection{Volumetric Integrated Vulnerability Assessment (VIVA)}

The Volumetric Integrated Vulnerability Assessment (VIVA) program and methodology were developed for a congressionally mandated study with a focus on alternate propulsion methods for amphibious warfare ships and surface combatants (Doerry, 2005). VIVA uses arrangement and profile data in combination with deactivation one line diagrams as determined by ship synthesis programs in order to evaluate the probability of ship, ship mission, and ship mobility loss.

\subsection{Thesis Objective}

The primary objective of this thesis is to begin the development of an analysis tool and methodology to explore naval ship vulnerability during concept design, without adding significant design cost and time, for future demonstration of the impact of vulnerability on early design decisions.

\subsection{Thesis Outline}

Chapter 1 provides the motivation for this study and introduces to the need for including vulnerability exploration in concept design. Chapter 2 describes the analysis tools and methodology used in this thesis. Chapter 3 describes the Preliminary Arrangements and Vulnerability (PA\&V) Model developed in response to the issues raised in Chapter 1. Chapter 4 
presents a case study where the Virginia Tech Vulnerability Model is used within the PA\&V Model and C\&RE to perform a simple preliminary arrangement and assesses the vulnerability of various system options. Conclusions and Future Work of this study are included in Chapter 5. 


\section{CHAPTER 2 - TOOLS AND METHODOLOGY}

\subsection{Concept and Requirements Exploration (C\&RE)}

The Virginia Tech Concept and Requirements Exploration (C\&RE) process shown in Figure 1-2 has continuously evolved over the last 20 years under the supervision of Dr. Alan Brown at Virginia Tech and MIT. The C\&RE process considers a large design space with a range of inputs for hullform characteristics, propulsion system options, and combat system options, performs a series of system and subsystem explorations, develops metrics, assembles a synthesis model from surrogates and data generated in these explorations, and searches the design space for nondominated designs using a multi-objective genetic optimization (Brown 2010). The C\&RE covers the analysis of alternatives and pre-preliminary design stages of ship design with the following objectives (Brown, 1998):

- Provide a consistent format and methodology for making affordable multi-objective acquisition decisions and trade-offs in a non-dominated design space

- Provide practical and quantitative methods for measuring mission effectiveness and for measuring risk

- Provide an efficient and robust method to search a design space for optimal concepts

- Provide an effective framework for transitioning and refining concept development in a multidisciplinary design optimization

- Use the results of first-principle analysis codes at earlier stages of design.

- Consider designs and requirements together. Consider, initially, a very broad range of designs, requirements, cost and risk 
The first step in the C\&RE process is to expand the mission description from the Initial Capabilities Document to include the following:

- Concept of Operations

- Naval Mission Essential Task List (NMETL)

- Operational Situations (OpSits)

- Design Reference Mission (DRM)

- Required Operational Capabilities (ROCs)

Each of these documents is used to develop Measures of Effectiveness (MOEs), Measures of Performance (MOPs) and Operational Effectiveness Models (OEMs).

The process continues with a collection and review of applicable technologies and a comparative naval architecture study of existing ships with similar missions. These studies begin to define the design space and a preliminary Baseline Design. Next the process expands into concept explorations of six critical categories: hullform and deckhouse geometry, structures, machinery and propulsion, mission systems, arrangements, manning and automation, and survivability. These explorations result in the collection and analysis of data for each discipline using a design of experiment (DOE) approach, identification of key design variables and parameters, definition and refinement of the design space for each area, and response surface models (RSMs) that approximate the relationships between input design variables and the response characteristics for use in a design-specific synthesis model. Because generic parametric equations and a generic synthesis model based on limited data from past ship designs are not sufficiently applicable or flexible for thinking outside the box in new designs, a more physics-based, designspecific approach is required. Once these individual explorations are a complete, a set-based integration approach may be used to define an integrated design space for ship synthesis. With 
the initial ship mission and required capabilities defined, an initial set of Design Variables (DV's) and Design Parameters (DP's) are selected and examined including the generation of a baseline design complete with hullform, propulsion and power, and mission systems.

A DV is a ship characteristic such as length overall, beam to draft ratio, or propulsion system architecture option that is varied over specific ranges to examine their impact on the design's cost, risk, and effectiveness. A typical set of DV's and their associated ranges is shown in Table 2-1 and Table 2-2.

Table 2-1 - DDGX Design Variable Table

\begin{tabular}{|c|c|c|c|}
\hline DV & Design Variables & Values & Description \\
\hline 1 & Length on Deck (LOA) & 130 to $160 m$ & \\
\hline 2 & LtoB Ratio & 7 to 8.5 & \\
\hline 3 & Long'I Prismatic Control & 0.1 to .4 & \\
\hline 4 & Section Tightness Fwd & .15 to .99 & \\
\hline 5 & Deadrise Mid & $.1-.8$ & \\
\hline 6 & Fullenss Fwd & .3 to .6 & \\
\hline 7 & Stem Curvature & -0.3 to 0.3 & \\
\hline 8 & Crd & .6 to .8 & \\
\hline 9 & Volume of Deckhouse (VD) & $4000-8000 \mathrm{m3}$ & \\
\hline 10 & Manning and Automation Factor (CMAN) & $0.5-1.0$ & \\
\hline 11 & Degaussing (DEGAUS) & 0,1 & $0=$ none, $1=y e s$ \\
\hline 12 & CPS & $0,1,2$ & $0=$ none, $1=$ partial, $2=$ full \\
\hline 13 & Provisions Duration (Ts) & & 30-60 days \\
\hline 14 & Deckhouse Material (CDHMAT) & $1,2,3$ & 1=steel, $2=$ aluminum, $3=$ composite \\
\hline \multirow[b]{4}{*}{15} & \multirow[b]{4}{*}{ Propulsion System (PSYS) - Architecture } & \multirow[b]{4}{*}{1 thru 7} & 1=MD CODAG, 2 shafts,1xGTMPE 2xDMPE \\
\hline & & & 2=MD COGAG,2 shaft,2xGTMPE,2xDMPE \\
\hline & & & 3=MD COGAG, 2 Shaft, 2xGTMPE \\
\hline & & & $\begin{array}{l}\text { 4=IPS, } 2 x \text { shaft, } 1 \text { GTMPE } \\
\text { 5=IPS, } 2 x \text { shaft, } 2 \text { GTMPE } \\
\text { 6=IPS, } 2 x \text { shaft, } 2 \text { GTMPE } \\
\text { 7=IPS, } 2 x \text { shaft, } 2 \text { DMPE }\end{array}$ \\
\hline 16 & Main Gas Turbine Engine (GTMPE) & 1,2 & $\begin{array}{l}1=\mathrm{MT} 30 \\
2=\mathrm{LM} 2500+\end{array}$ \\
\hline 17 & Main Diesel Engine (DMPE) & 1,2 & $\begin{array}{l}1=\text { CAT } 280 \mathrm{~V} 8 \\
2=\text { CAT } 280 \mathrm{~V} 12\end{array}$ \\
\hline 18 & Ship Service Generator Engine (SSGENG) & $1,2,3$ & $\begin{array}{l}1=\text { Allison } 501 \mathrm{~K} \mathrm{SSGTG} \\
2=\text { CAT } 280 \mathrm{~V} 12 \mathrm{SSDG} \\
3=\text { CAT } 280 \mathrm{~V} 8 \mathrm{SSDG}\end{array}$ \\
\hline
\end{tabular}


Table 2-2 - DDGX Combat System Design Variable Table

\begin{tabular}{|c|c|c|c|}
\hline DV & Design Variables & Values & Description \\
\hline \multirow{3}{*}{19} & \multirow{3}{*}{ AAW/SEW/GMLS/STK } & Option 1 & $\begin{array}{l}\text { SPY-1D RADAR, ICMS, AIMS IFF, } 64 \text { cell } \\
\text { MK41, AIEWS, AEGIS, COMBAT DF, } 3 x \\
\text { SRBOC, } 2 \text { x NULKA, AIEWS advances sew } \\
\text { system, WBR } 2000 \text { ESM, } 3 \text { X SPG62, } 1 x \\
\text { CIWS, 2x MK141 }\end{array}$ \\
\hline & & Option 2 & $\begin{array}{l}\text { SPY-1F RADAR, } 32 \text { cell MK41,32 cell } \\
\text { MK48, AIMS IFF, COMBAT DF, } 2 \text { x SRBOC, } \\
\text { AEGIS, AIEWS advanced SEW system, } \\
\text { WBR } 2000 \text { ESM,2xSPG62, 1X CIWS,2x }\end{array}$ \\
\hline & & Option 3 & $\begin{array}{l}\text { Radar, } 32 \text { cel MK48,AIMS IFF, EDOES } 3601 \\
\text { ESM, ICMS, COMBAT DF, AIEWS } \\
\text { advanced SEW system, WBR } 2000 \text { ESM,1x } \\
\text { CIWS, 1x Mk141, MK143,Mk112 }\end{array}$ \\
\hline \multirow{3}{*}{19} & \multirow{3}{*}{ ASUW/NSFS } & Option 1 & $\begin{array}{l}\text { 11m RHIB, 30mm CIGS, MK } 45 \text { 5"/62 gun, } \\
\text { MK } 86 \text { GFCS, VLS } 64 \text { cell, VLS } 32 \text { cell, } 2 x \\
\text { Tomahawk missiles }-8 \text { rds, } 2 \times \text { SM-2ER, } \\
32 \text { VLS missiles }\end{array}$ \\
\hline & & Option 2 & $\begin{array}{l}\text { AN/SPS-73 Surface Search radar, IRST, } \\
\text { 11m RHIB, 30mm CIGS, Oto Melara 76mm } \\
\text { Super Rapid, DORNA EOD EO/IR, VLS } 64 \\
\text { cell, VLS } 32 \text { cell, } 2 \text { x Tomahawk missiles- }\end{array}$ \\
\hline & & Option 3 & $\begin{array}{l}\text { AN/SPS-73 Surface Search radar, FLIR, 7m } \\
\text { RHIB, 57mm MK } 3 \text { Naval gun, SEASTAR } \\
\text { SAFIRE III E/O IR, EMRG,, VLS } 32 \text { cell, VLS } \\
\text { JUJ-JJD-D,LIA/VDJ,JNU-IJ, IVIAIL, }\end{array}$ \\
\hline \multirow{3}{*}{20} & \multirow{3}{*}{ ASW/MCM } & Option 1 & $\begin{array}{l}\text { TRIPWIRE, SQQ-89, MK 309, MK116, SSTD, } \\
\text { SVTT, Mine Avoidance Sonar }\end{array}$ \\
\hline & & Option 2 & $\begin{array}{l}\text { SQS-56, TACTAS, NIXIE, TRIPWIRE, SQQ- } \\
\text { 89, MK309, MK116, SSTD, SVTT }\end{array}$ \\
\hline & & Option 3 & $\begin{array}{l}\text { SQS-56, SQQ-89, MK309, MK116, SSTD, } \\
\text { SVTT }\end{array}$ \\
\hline \multirow{2}{*}{21} & \multirow{2}{*}{ CCC } & Option 1 & ADVANCED C4I SYSTEM \\
\hline & & Option 2 & \begin{tabular}{|l|} 
ExComm Level B, Cooperative \\
Engagement Capability (CEC) and Link
\end{tabular} \\
\hline \multirow{3}{*}{21} & \multirow{3}{*}{ AIR } & Option 1 & Embarked 2xLAMPS w/ Hangar, $2 x$ UAV \\
\hline & & Option 2 & COMMS SUITE LEVEL A \\
\hline & & Option 3 & COMMS SUITE LEVEL B \\
\hline
\end{tabular}


A Design Parameter (DP) is a ship characteristic that is assigned a fixed (constant) value that is shared across all potential ships in the design space. The list of DP's and DV's are used as the input to a ship synthesis model (SSM) to generate complete designs and assess their feasibility. The SSM is then used in a Multi Objective Genetic Optimization to search the design space based on their associated risk, cost, and effectiveness and to identify a set of non-dominated designs as shown in Figure 2-1.

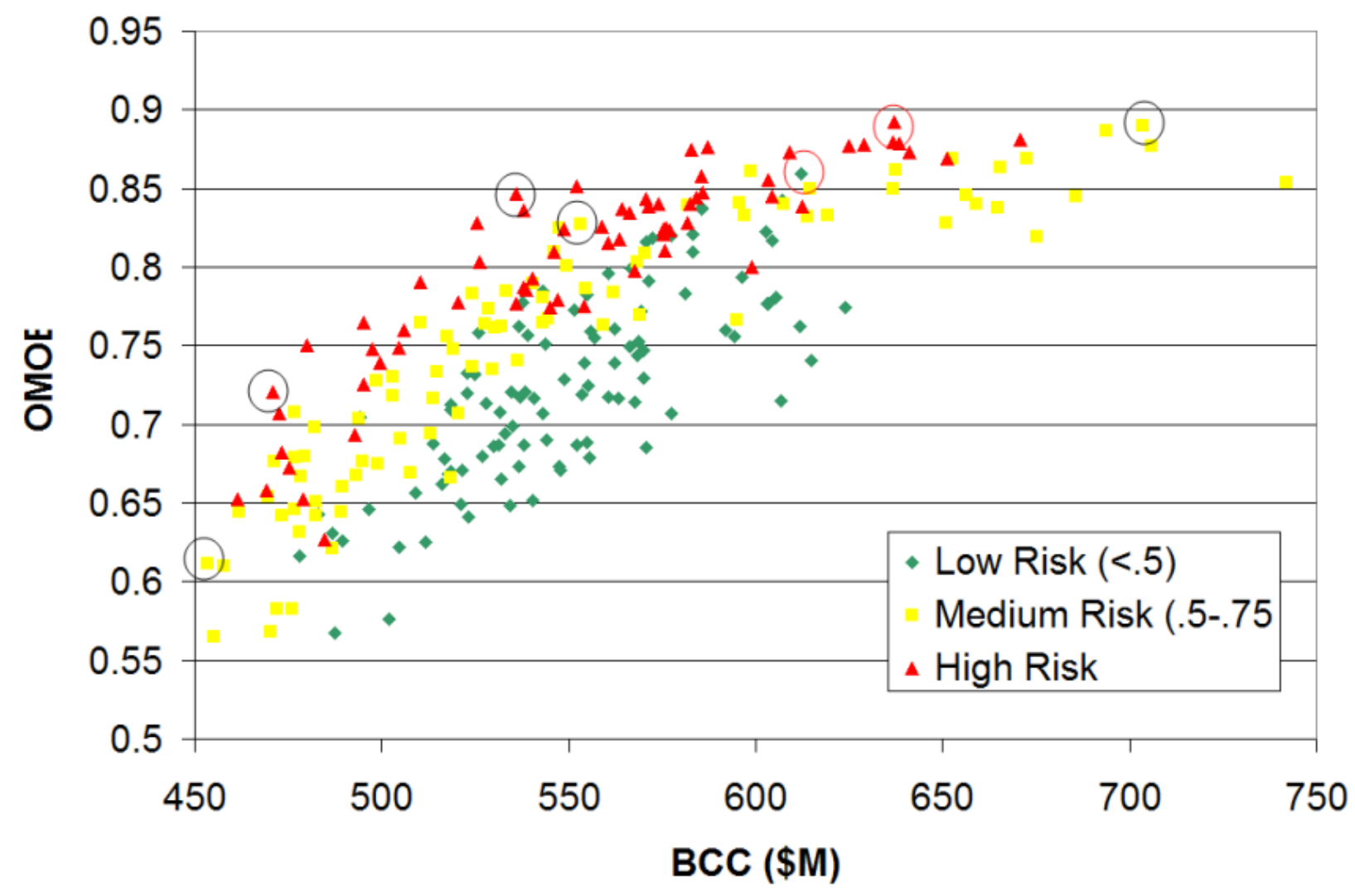

Figure 2-1 - Example 2-D Non-Dominated Frontier

Examination of the Non-Dominated Frontier in Figure 2-1 enables the selection of preferred designs and tradeoffs between cost, risk, and effectiveness can be considered. Often preferred selections are at "knees in the curve", designs at the top of steep effectiveness slopes. The SSM with MOGO in Model Center is shown in, Figure 2-2 (Brown, 2003, 2010) 


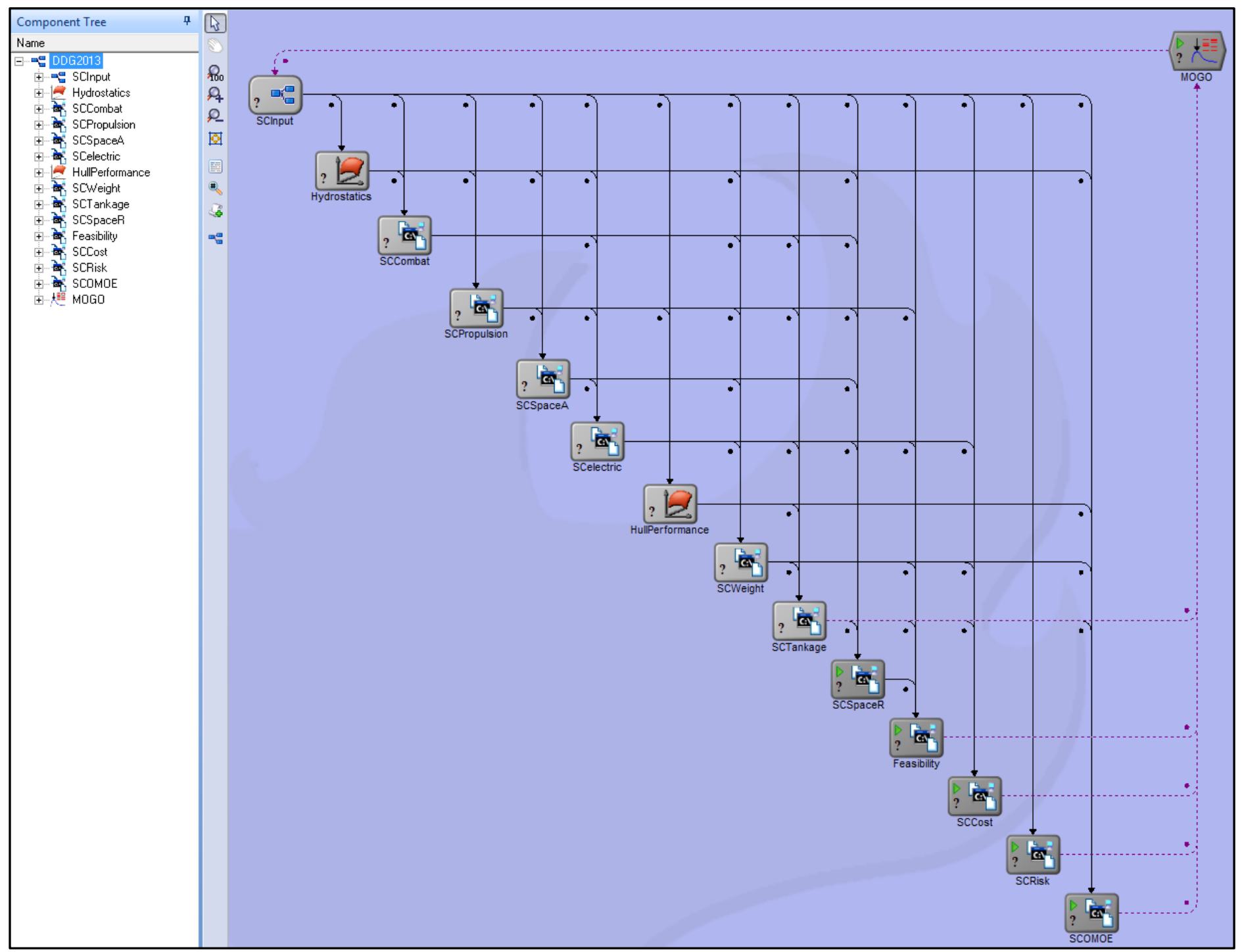

Figure 2-2 - Ship Synthesis and MOGO Model in Model Center

There are 13 modules in this figure, nine of which make up the ship synthesis model (SSM) and four other modules assessing Feasibility, Cost, OMOR (Risk), and OMOE (Effectiveness) for each design. The Feasibility Module determines design feasibility by comparing the current design's characteristics and performance to required design characteristics, checking for sufficient power, space, stability, etc. The Cost, OMOR, and OMOE Modules assess the three primary objectives of the design process with the goal of minimizing cost and risk while maximizing effectiveness. The MOGO module searches the design space for non-dominated designs, 
visualized using 2D or 3D Non-Dominated frontiers, as shown in Figure 2-1 and Figure 2-3. The NDF is used to select baseline designs for further design development. The other modules determine the amount of space required for each of the combat, propulsion, electrical, weight, and tankage in order to determine ship feasibility, cost, risk, and effectiveness.

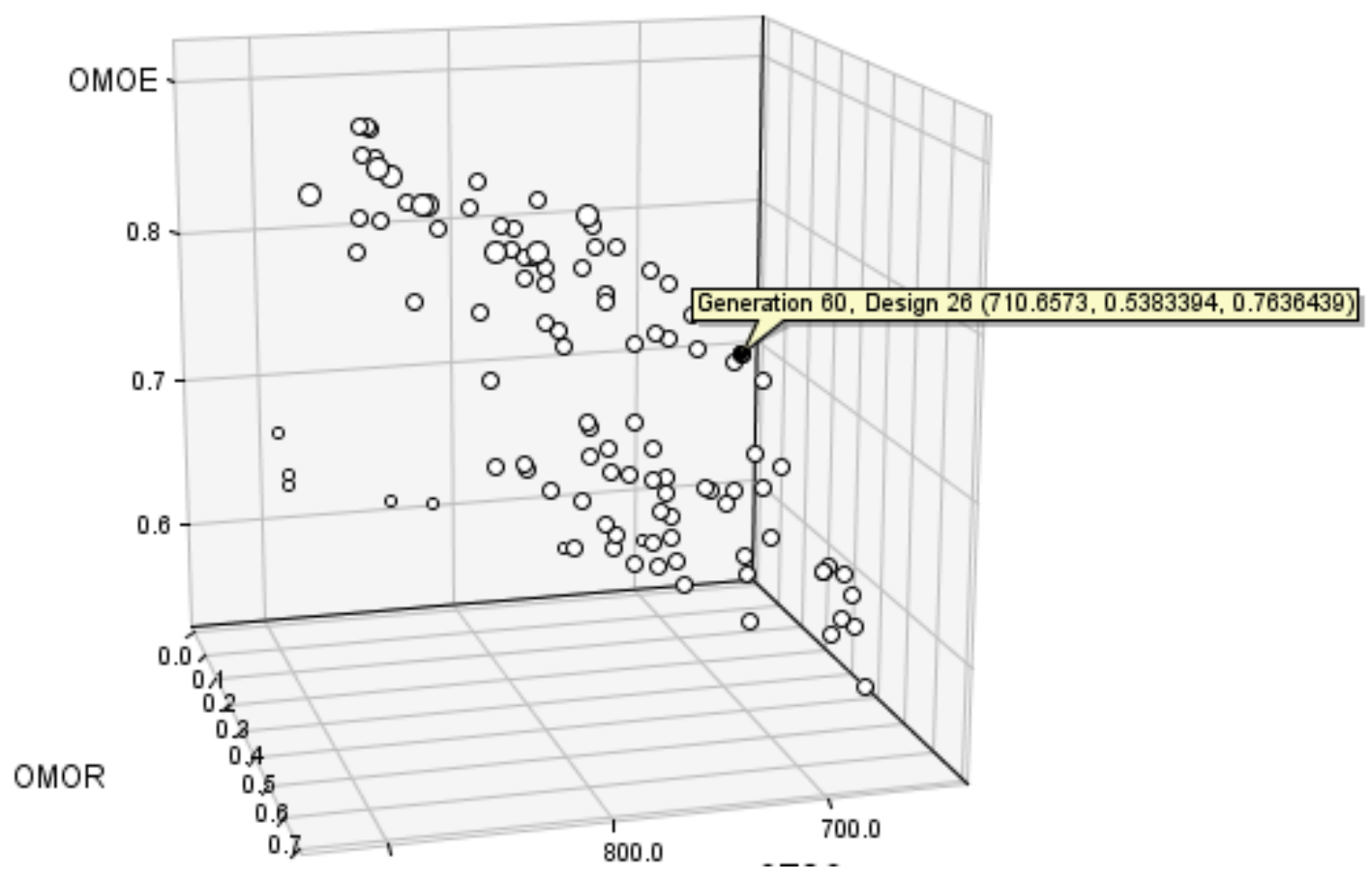

Figure 2-3 - Example 3D Non-Dominated Frontier

Included in the SSM modules are Response Surface Models (RSM's) for Hydrodynamic and Hull Performance developed during Hullform Exploration. RSM modules are developed from data obtained by performing various exploration Design of Experiments (Brown, 2012).

The current $C \& R E$ evaluates each of the designs through this process to determine intact design effectiveness, meaning that the effectiveness is based on all ship systems being functional, but it is important to include inherent measures to ensure the completion of ship mission with warfighting damage (Vulnerability). Vulnerability is the ships ability to withstand damage and is heavily dependent on ship arrangements, VC locations, and system architecture. It is expected 
that assessing arrangements, system architectures, and VC options can improve mission effectiveness and reduce design cost by making decisions early instead of costly decisions later in the design or construction process. This additional consideration in the C\&RE is the subject of this thesis.

\subsection{Vulnerability Exploration Motivation and Methodologies}

Our Vulnerability Exploration process begins with inputs from the C\&RE process, such as 3-D ship geometry and system architecture. When building a vulnerability evaluation tool, it was important to determine the minimum but sufficient level of fidelity of the model because model fidelity determines the level of detail required across all aspects of the model, from threat calculation methodologies, to system description, to model analysis parameters.

In order to determine the sufficient level of fidelity the following were considered:

1) In our current $C \& R E$ process, thousands of designs must be synthesized and assessed even in a very efficient search of the design space;

2) The current level of detail in our C\&RE models;

3) Approaches to add additional detail early in 3D geometry and arrangements;

4) It is computationally expensive for all VC's to be arranged in specific locations within compartments particularly with pipe and cable ways determined. These decisions are typically made at much later design stages;

5) Probabilistic vulnerability analysis must incorporate statistics by using many runs to determine a result. Any analysis that takes longer than a few minutes per concept design option, across a potential set of thousands of design options is prohibitive to the designer.

Based on the information available for most concept designs and the limited time required to calculate and process the results of a huge number of ship designs, a simplified statistical model 
and process was developed to determine Vulnerability Measures of Performance values as metrics describing the design's ability to resist mission loss. Important considerations and methods in developing this model are described in Sections 2.2.1 through 2.2.4. The model is described in detail in Chapter 3.

\subsubsection{Physical Geometry}

In consideration of the level of detail available in our C\&RE process, with respect to both VC arrangements and ship structural properties, it was determined to minimize the geometrical details for locating compartments and VCs. Instead of using a full x,y,z geometry, each unique compartment containing a vital component (VC) is assigned to a Primary Subdivision Block (SDB). A Primary Subdivision Block is the same as a single AABB with boundaries from Bulkhead to Bulkhead and Deck to Deck, as shown in Figure 2-4. Compartments have no specific boundaries or location within their assigned subdivision block.

Vital Components are assigned to compartments and in turn, the compartments to SDBs. VC's are elements of systems and subsystems with their architecture defined initially using one line diagrams and later RBDs. System options are defined and selected during the C\&RE process. System characteristics include one line system schematics, RBD's, basic performance and geometry characteristics, but do not include 3D locations within the ship. This means that the

physical ship model in the VTVM is comprised solely of Primary Subdivision Blocks which are assigned a set of compartments and VC's. The compartments act as the "parents" to the VC's assigned to them. 
Curvilinear Model

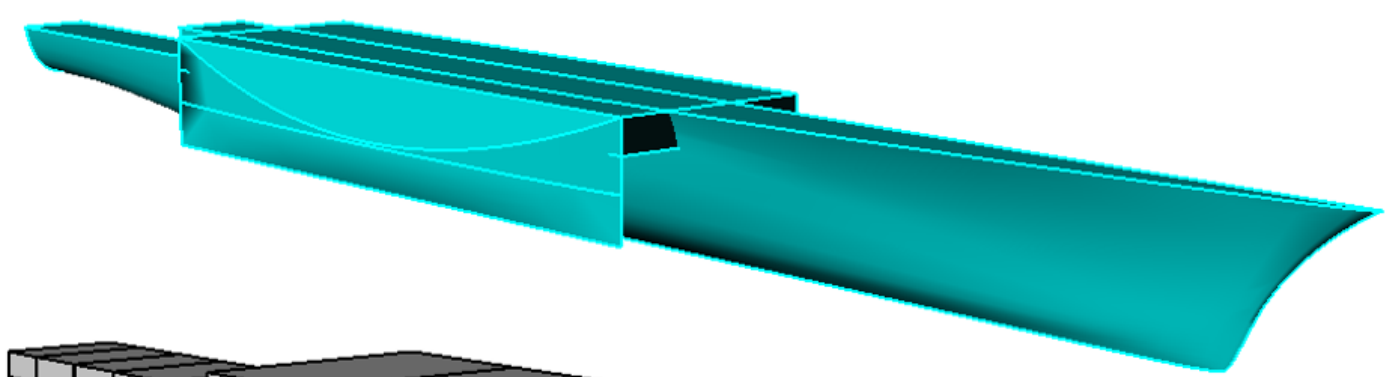

AABB Model

Curvilinear and

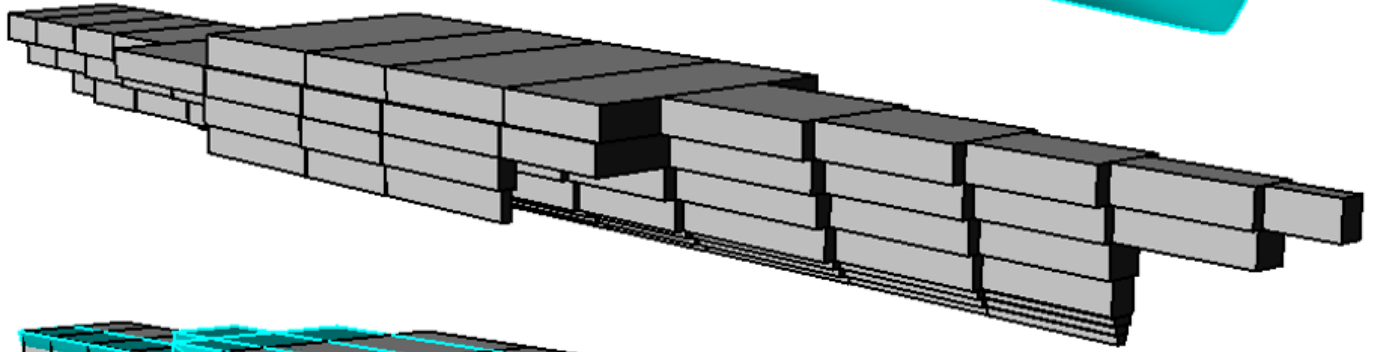

AABB Model

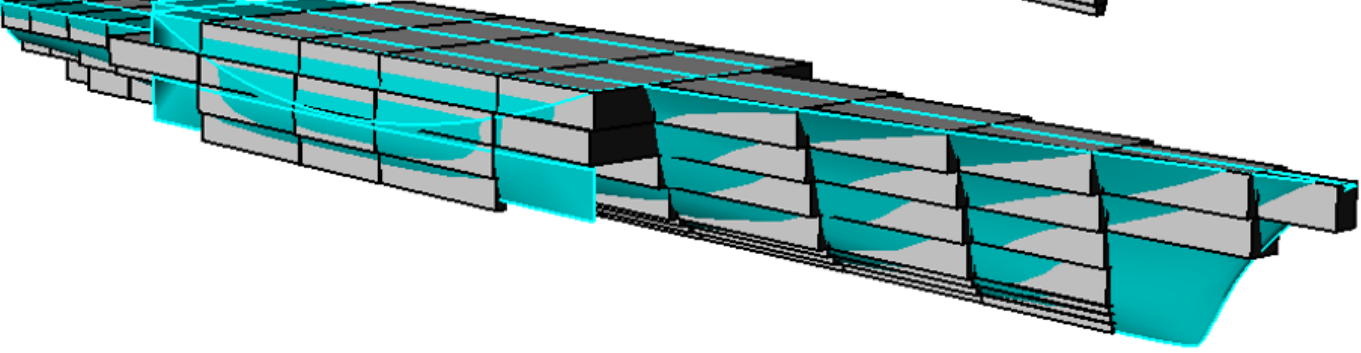

Figure 2-4 - Curvilinear Hullform vs AABB Hullform

The compartment arrangement process and associated tools described in this thesis are being developed by Andrew Stevens in his thesis using a SSCS/PA preliminary Arrangement generation module within the $C \& R E$. The $C \& R E$ passes data to the PA\&V module where the Ship Space Classification System (SSCS/PA) model is used to generate feasible arrangements, as discussed in Section 3.2. Other General Arrangement tools and approaches may be considered and implemented for this process in the future, such as tools developed and discussed by Justin Gillespie (Gillespie, 2012) in "A network Science Approach to Understanding and Generating Ship Arrangements in Early-Stage Design" and the Intelligent Ship Arrangement (ISA) tool created at the University of Michigan. Other General Arrangement theories have also been developed, using network theory from a non-spatial point of view (Gillespie, 2012), which introduces methods different from traditional naval architectural approaches. 
The results of our Preliminary GA generation are primary subdivision blocks that contain assigned compartments, and compartments contain VC's. This is a significant simplification from full 3D geometry which can only be sufficient if we can develop a damage-analysis method to compliment it, as discussed in Section 2.2.3.

\subsubsection{Vital Components (VC's)}

Vital Components or "VC's" are ship equipment vital to ship system capability. A Vital component can be a ship service generator, switchboard, sprinkler, VLS launcher, or any other equipment that exists within a deactivation diagram for ship systems considered in the Vulnerability Model. For example, having a weapon capability requires: the availability of the weapon in question, the ability to control that weapon and the ability to detect an incoming threat or target (detect, control, and engage). The "availability of the weapon" refers to the physical weapon with its required power for functionality. The "ability to detect and control the weapon" refers to those systems and VC's necessary to support the weapon, and locate the target. Each of these systems requires combinations of VCs and power to support functionality of its VCs. Some other ship systems and their VCs like chilled water, data and compressed air, may be neglected as these systems are either inherent to system architectures or require too much detail for concept design. Figure 2-5 illustrates how the CIWS functionality requires various detect, control and engage systems. Detection, control, and engage capabilities are supplied by one or more system options. As the system description extends down to subsystems and VCs, systems become increasingly complex as shown in the SPY 1-D fault tree, Figure 2-6, required by the CIWS system. 


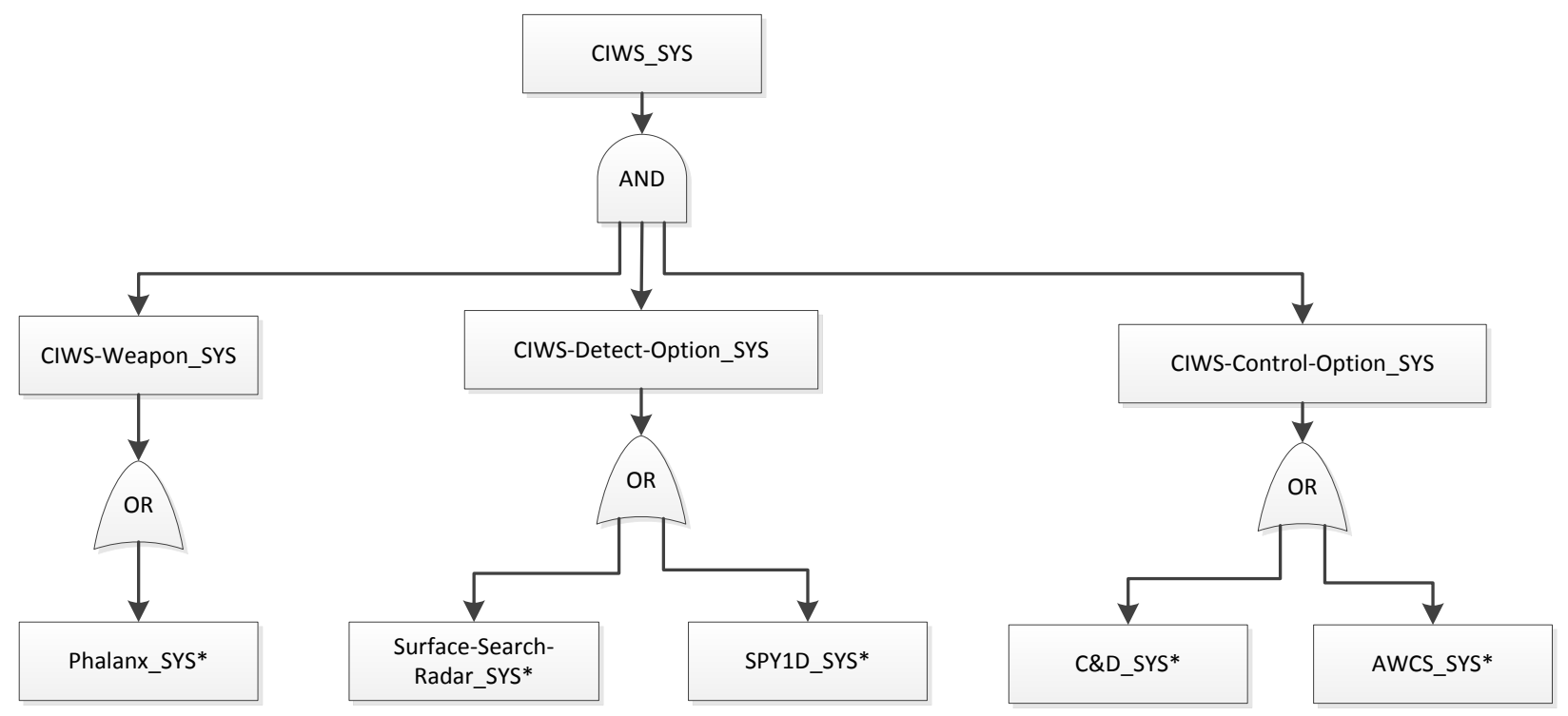

Figure 2-5 - CIWS System Fault Tree

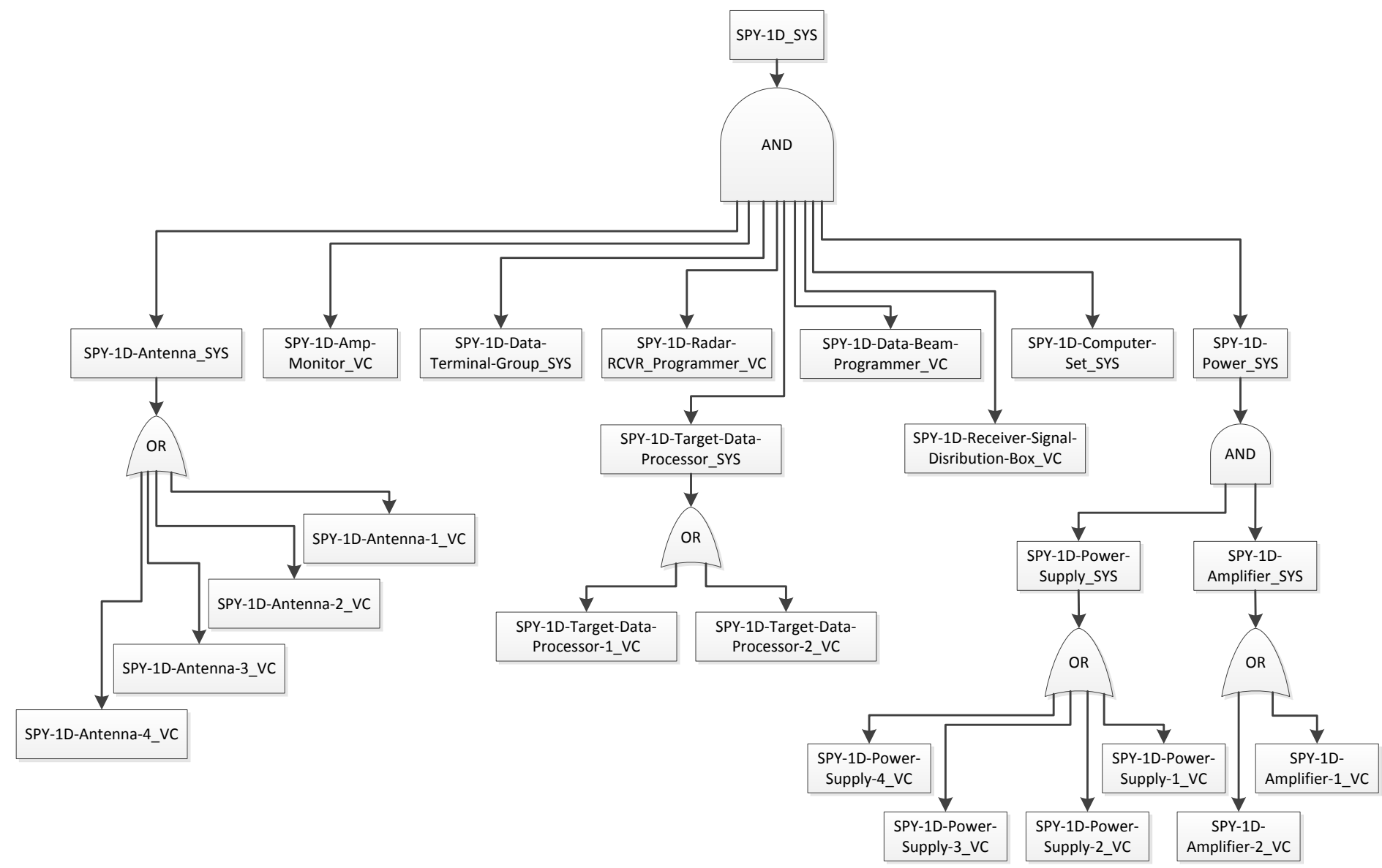

Figure 2-6 - SPY-1D Fault Tree Example 
In Figure 2-5 and Figure 2-6, some systems are noted with "_SYS*”. This notation is used to simplify the fault tree visual diagram for elements whose detailed architecture is shown in another sheet. As described in Section 3.3.2, any element including other elements shown immediate below it is designated with a "_SYS".

Data required for each VC to determine its availability after a hit may include the following:

- Physical Location

- Dimensions

- Mass

- Acceleration Limits

- power input required

- connections to other systems/VCs

- whether or not human interaction is required for operation

- any automatic activation events

There may be other VC specific information that could be required to calculate availability, however, in concept design a significant amount of this information is not available. Simplifying assumptions include:

- While most VCs in a model require power, the amount of power required for availability is not tracked. Power is applied through binary availability, discussed in 3.3.4

- Data communications between VCs may be required but connections (Cable, fiber optics) are not considered explicitly

- Human interaction is not considered explicitly

- No VC dimensions or physical locations are considered. VCs are only "assigned" to SDBs 
Vital Components serve as the basic building block of the system architecture, and deactivation system availability. Therefore, having a conservative estimation of the impact of their loss and their approximate locations in the ship is critical.

\subsubsection{Vital Component Hit Damage Methods}

The VTVM will eventually be able to apply damage to the ship using two different methods, but only a simplified method is considered in this thesis. These damage methods are described in the following sections. Each damage method uses a hit distribution generated for the specific ship and threat, and applies damage to determine the failure of Vital Components. Using the extents of the ship geometry, the hit distribution is applied to the ship using Gaussian distributions, Figure $2-7$. The ship is assigned a longitudinal mean hit location at $1 / 2$ of the overall length, and a height mean as a fraction of the draft height, which varies by threat. A standard distribution is applied to the longitudinal locations and heights as fractions of the overall length and height, depending on the selected threat parameters. The transverse distance (threat penetration) is calculated using a fuse delay timer, and is applied based on the threat speed. Each of these values is threat specific. The resulting distribution is a set of coordinates in 3 dimensional space and is used to provide a set of detonation points for the chosen damage application method selected at random based on the distributions. The number of detonation points required for an analysis depends on the principal characteristics of the ship, as investigated in Sean Stark's Thesis. In MOTISS basic design, and our VTVM, a Gaussian distribution is generated for each ship threat based on threat trajectory, fusing and threat targeting technologies with no adjustment for signatures, however signatures are considered in our Operational Effectiveness Models (OEMs) to determine whether a not a weapon reaches a point of terminal approach (terminal origination point). This is treated as part of the susceptibility problem. 


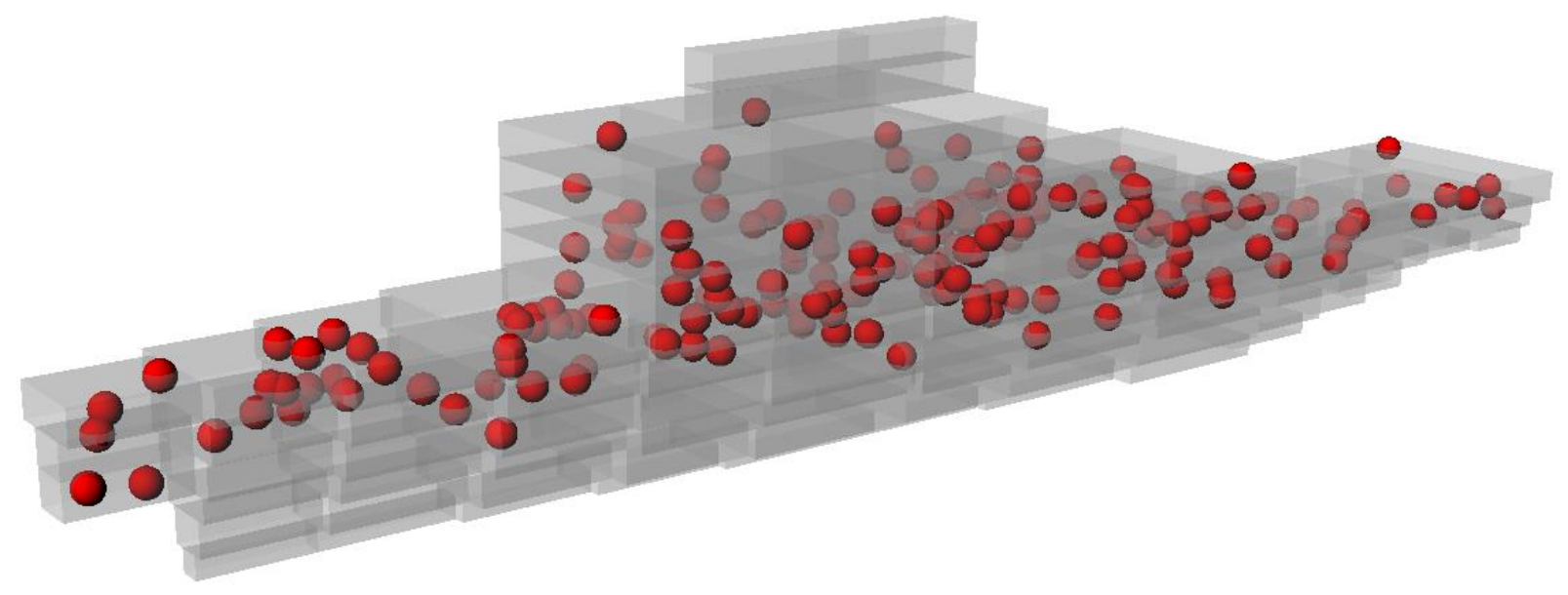

Figure 2-7 - Example C-701 Hit Distribution

\subsubsection{Hit Damage Method \#1}

The first damage generation method applied in the VTVM is the simplest and most conservative method and uses each point from the hit distribution as the center of a damage ellipsoid. The radii of the ellipsoids are determined based on the methods developed for use with MOTISS, as originally developed by Dr. John Sajdak and Grant Raisig (MOTISS, 2011). New methods are currently being developed by Sean Stark because the MOTISS method is used at a later design stage when $\mathrm{x}, \mathrm{y}, \mathrm{z}$ preliminary $\mathrm{VC}$ locations have been determined for the design being evaluated. These ellipsoids are then used to evaluate the availability of VCs by analyzing the intersection of the ellipsoid with the SDBs and the VCs. Since VCs are only assigned to SDBs in the model without $\mathrm{x}, \mathrm{y}, \mathrm{z}$ locations, the damage model applies the extents of the damage ellipsoid and considers any VC within a subdivision block that is intersected in any amount by the ellipsoid as having an availability of "0" (not functional). An illustration of this method is shown in Figure $2-8$. 


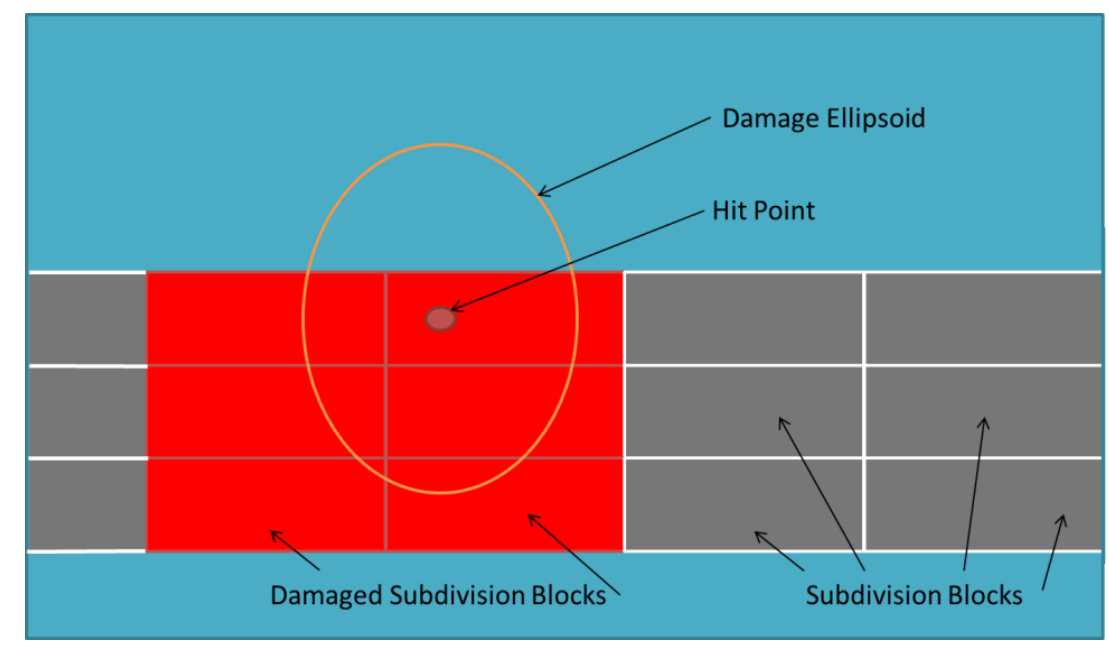

Figure 2-8 - Example 2-D Damage Ellipsoid Intersection Diagram

This method can be considered to simulate not only the potential damage generated by the initial detonation, but potential progressive damage in the region (within SDB) immediately adjacent to the hit region and additional VCs and power purposely secured in the damage control process. As stated in Doerry, 2008 "The restoration of power in general should not occur until the operator is assured that it is safe to do so" because following a threat event, damage control teams are often instructed to secure power to the entire damaged zone, therefore any VC in the zone with power secured will be unavailable. This damage methodology informs the designer as to what VC will be permanently unavailable and the temporary unavailability of VCs following a hit provides further insight as to whether or not the ship is able to survive and fight through.

\subsubsection{Hit Damage Method \#2}

The second damage application method uses a more rigorous calculation then the first, by considering the individual Vital Component resistance to the potential accelerations generated by a detonation. A Pressure Lethality for each VC must be determined in this method. This will be based on the MOTISS blast algorithm developed for preliminary design used by Dr. John Sajdak and Grant Raisig (MOTISS, 2011). The MOTISS blast algorithm tracks internal and external pressures and any fragments generated by a detonation. Each VC is assigned a "shock lethality" 
which represents a VC's resistance to damage induced by the threat. Since the level of fidelity required to consider each specific VC's "shock lethality" is unavailable in concept design, our model uses simplified damage and lethality algorithms, calculating Pressure and Pressure Lethalities. In this method less damage calculation and VC data is necessary. A component's Pressure Lethality is compared to the incurred Damage Pressure in the SDB in which it resides as shown in Figure 2-9.

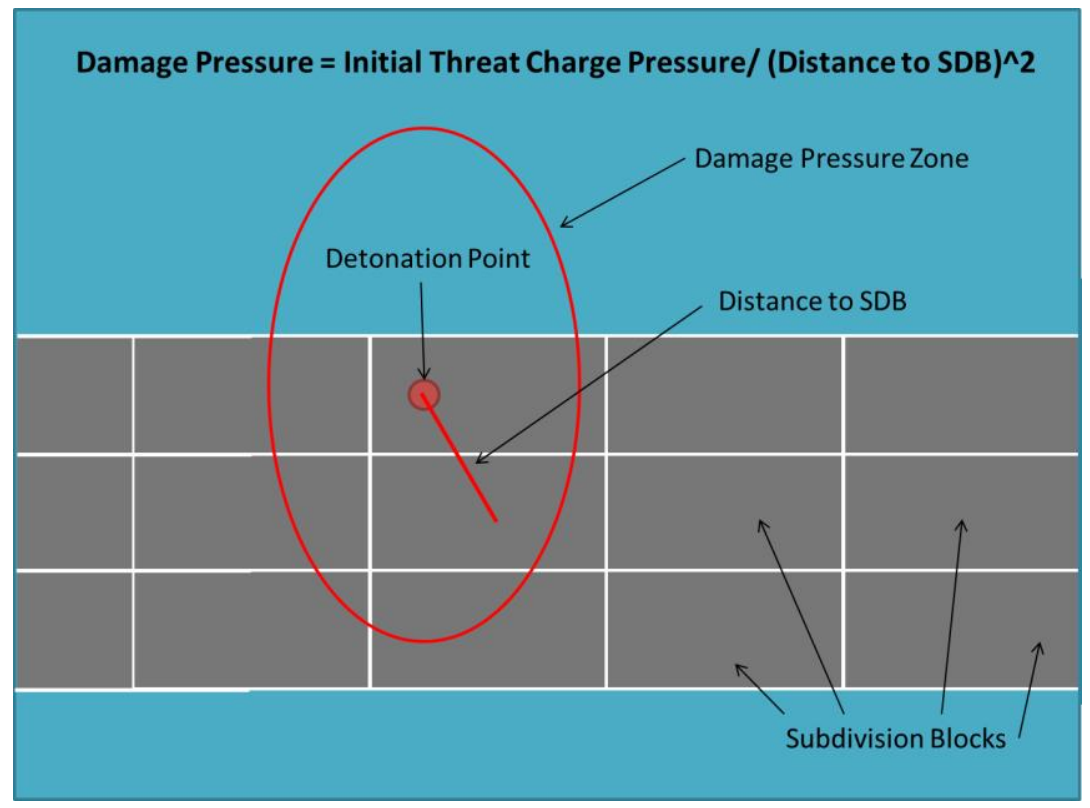

Figure 2-9 - Example 2-D Damage Volume Diagram

Pressure Lethality represents the VC's functional limitation in response to the potential acceleration and fragmentation it experiences following a detonation. For each detonation, each subdivision is intersected by Damage Pressure defined by a function which decreases the pressure radially from the center of the initial hit location. If the Damage Pressure calculated for a Subdivision Block exceeds the Pressure Lethality limit for a VC assigned to that Subdivision Block then the VC is assigned a functionality of " 0 ". If the SDB Damage Pressure does not exceed the VCs Lethality limit, the VC is assigned a functionality of " 1 ". 


\subsubsection{Evaluation Time}

It is important to consider system capability immediately post impact or at time " $0+$ ", but it is also valuable to predict the ship's potential recoverability by considering damage control losses, such as automated recovery systems and damage control personnel/VCs and the potential for subsequent progressive flooding and fire. Time " $0+$ " refers to the quasi-static state immediately following the initial damage. Some survivability analyses, as described in section 1.2.2, meticulously calculate the ships response to blast effects, flooding, fires, etc. over a simulated time (i.e. continuously over 30 to 60 minutes post impact). This requires advanced numerical calculations with significant run times associated with each calculation. Using a model that evaluates ship status at a single time $\mathrm{t}=0+$ requires that Man-In-the-Loop-Operations (MILTO) or reset times on VCs be taken into consideration indirectly for damage control systems or processes which are not automated and immediate. Any automated recoverability systems that exist within the model can be evaluated based on the system's inherent ability to become available following the damage event. For example, measuring the ability to provide power to a switchboard in the model would depend only on the availability of the generator, power conversion module, load center, and switchboard. A through-time calculation requires the understanding of dynamic effects such as quality of power and power availability. This is not considered explicitly in our model, but simplified methods for doing this are being studied.

Progressive effects such as fire spread and flooding are also not explicitly considered for damage application to ship VCs. However, the consideration of static evaluation rules, such as failing every $\mathrm{VC}$ in the model if three consecutive subdivision blocks below the waterline are breached by a single detonation, can be applied to the model to simulate greater extents of damage based on specific scenarios. 


\subsection{Operational Effectiveness Modeling}

In our VTVM, probabilities of VC and system availability are calculated using the methodologies discussed in Section 3.4 and a single Overall Measure of Vulnerability is determined for each design.

While this thesis focuses on the calculation of a single metric representing the relative vulnerability performance of a ship design, as discussed in Section 3.4, the data generated through the process can also be used during operational effectiveness modeling (OEM). Our future plan is to use MANA, an agent-based warfighting model developed by New Zealand's Defense Technology Agency, to model operational scenarios and calculate the operational effectiveness of design variants $[36,37,38]$. Inputs to the MANA Operational Effectiveness Models (OEMs) will include various weapon system and ship performance characteristics, some provided and some calculated. Included in the system performance characteristics are system probabilities of Kill given a hit $(\mathrm{Pk} / \mathrm{h})$ as calculated in the vulnerability model using baseline design variant system combinations with preliminary arrangements (Kerns, 2011). Within MANA, agents have preset behaviors and can be aware of other detectable agents. Agents are able to respond to their environment using pre-defined triggers. MANA does not calculate the physical performance of ships and ship systems, but instead models battlefield effectiveness. This requires that ship system performance be determined independently using separate models. MANA uses weapon and sensor performance characteristics specific to an individual threat or ship design characteristic. These inputs may be modeled probabilistically as probability of detection and probability of kill. Figure 2-10 shows a simplified Red vs Blue scenario in MANA currently used to test weapon performance, decoy, sensor, and ship design models. 


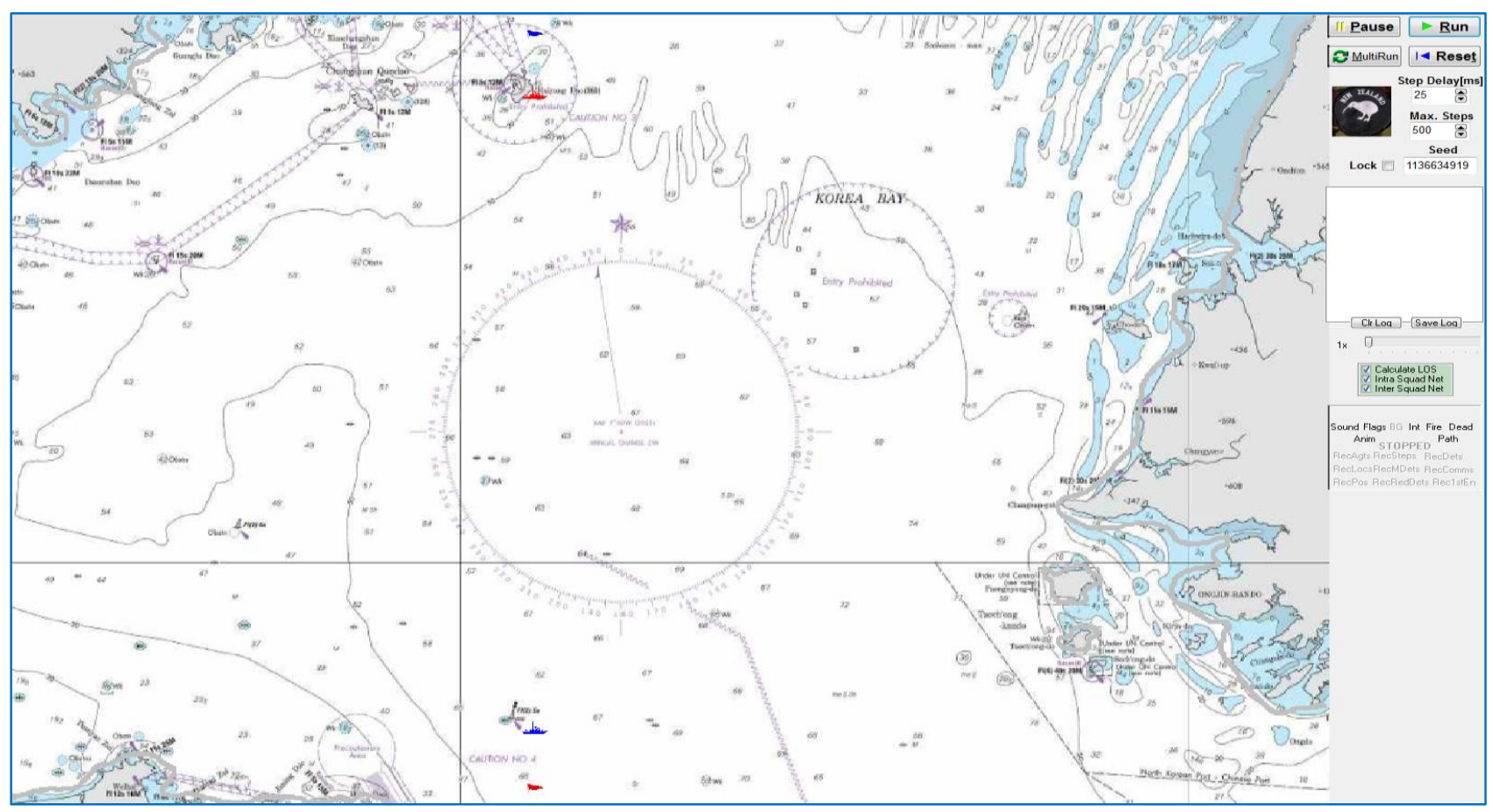

Figure 2-10 - MANA Red vs Blue Scenario in the Yellow Sea

MANA will have a Model Center interface and database able to accept varying ship, weapon and sensor Measures of Performance (MOP) in a Design of Experiments (DOE) resulting in a database of design Measures of Effectiveness (MOE) in response to input MOPs after which an RSM will be built to calculate the MOE as a function of the MOPs to be interfaced with other Model Center modules in order to provide OMOE values for many designs. This becomes one of three objective attributes (cost, effectiveness, risk) in the design space search (MOGO). To use MANA, probabilities of kill will be determined for a given design (agent) using our vulnerability exploration module through the implementation of threat scenarios using deactivation diagrams, to define system architecture and arrangements and to determine system availability, or probability of kill. 


\section{CHAPTER 3 - DEVELOPMENT OF A PRELIMINARY}

\section{ARRANGEMENT AND VULNERABILITY MODEL}

As discussed in Chapter 2, the need for a simplified model for vulnerability exploration and assessment in naval ship concept design motivated the development of the Vulnerability Model, the VTVM, within a Preliminary Arrangements and Vulnerability (PA\&V) process, Figure 3-1. The VTVM uses inputs from the C\&RE and PA\&V model, Figure 3-2, to generate a preliminary arrangement and system option architecture set for each system combination to be considered in the C\&RE design space.

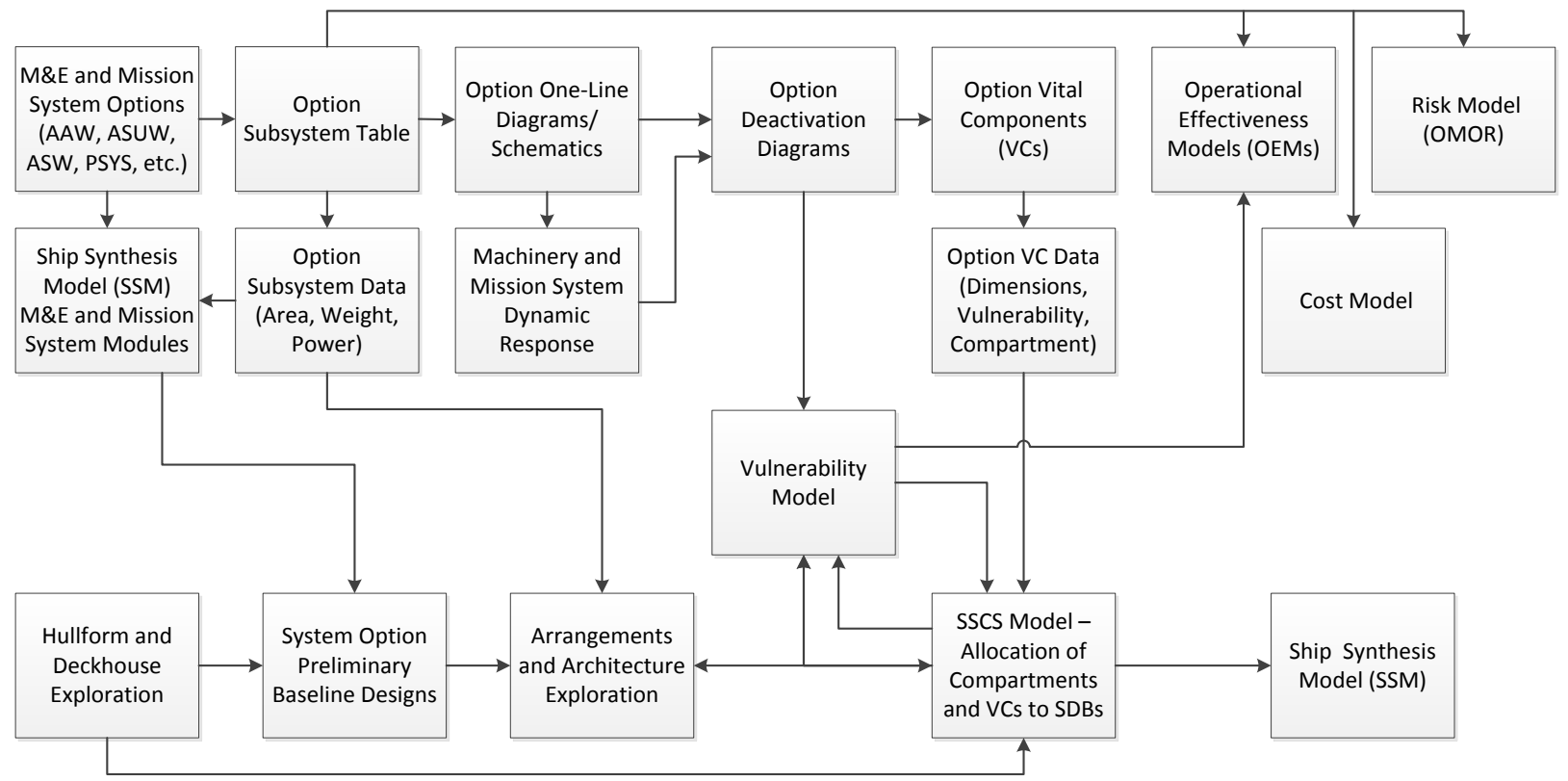

Figure 3-1 - Preliminary Arrangements and Vulnerability Process

In the PA\&V process, all combinations of mechanical and electrical and mission system options with their associated weight, volume, and power requirements, system option architectures, VC lists, deactivation diagrams and preliminary hullform model are integrated in the SSCS/PA model to define a preliminary arrangement of compartments and VCs used in the vulnerability model. The input to the VTVM from the SSCS/PA model includes vital 
compartments containing VCs, assigned to primary subdivision blocks, as described in Section 2.2.1, and system deactivation diagrams and associated VC data with applicable threats determined in the Design Reference Mission (DRM) and Operational Situation (Opsit) documents.

The VTVM determines Vulnerability Measures of Performance (VMOPs) describing a ships inherent capability to maintain mission capabilities following weapon hits on the ship's structure

and systems within the design space. This assessment is performed for all system combinations, for each threat, and for each of multiple compartment arrangements (only one per system combination in this thesis). The VTVM performs a number of analyses to calculate Vulnerability Measures of Performance (VMOPs) for a given concept design and combines these into an Overall Measure of Vulnerability (OMOV). Later in the C\&RE, VTVM output is provided to the OMOE calculation or OEM analysis for each ship variant during ship synthesis and design space search (MOGO).

\subsection{PA\&V Model}

The Preliminary Arrangements and Vulnerability (PA\&V) model, shown in Figure 3-2, provides the VTVM the data it requires to perform a vulnerability analysis. The PA\&V model uses ship and system data from the C\&RE to generate a preliminary hullform sized approximately to accommodate the specified system options, for each system option combination and to generate a preliminary arrangement of compartments and VC's in this hullform for vulnerability analysis.

The Concept and Requirements Exploration process functions as the initial generator of all data for the PA\&V and VTVM inputs. The C\&RE determines the number, types, and combinations of combat, power generation and distribution, and propulsion systems to be considered. It also determines the ship dimensions, compartments list, and threats used to evaluate vulnerability. Sections 3.1.1 through 3.1.3 describe these inputs and the modules used in the PA\&V model 
necessary for input to the SSCS/PA and VTVM modules (Sections 3.2 and 3.3) and describe the organization of the data within the model.
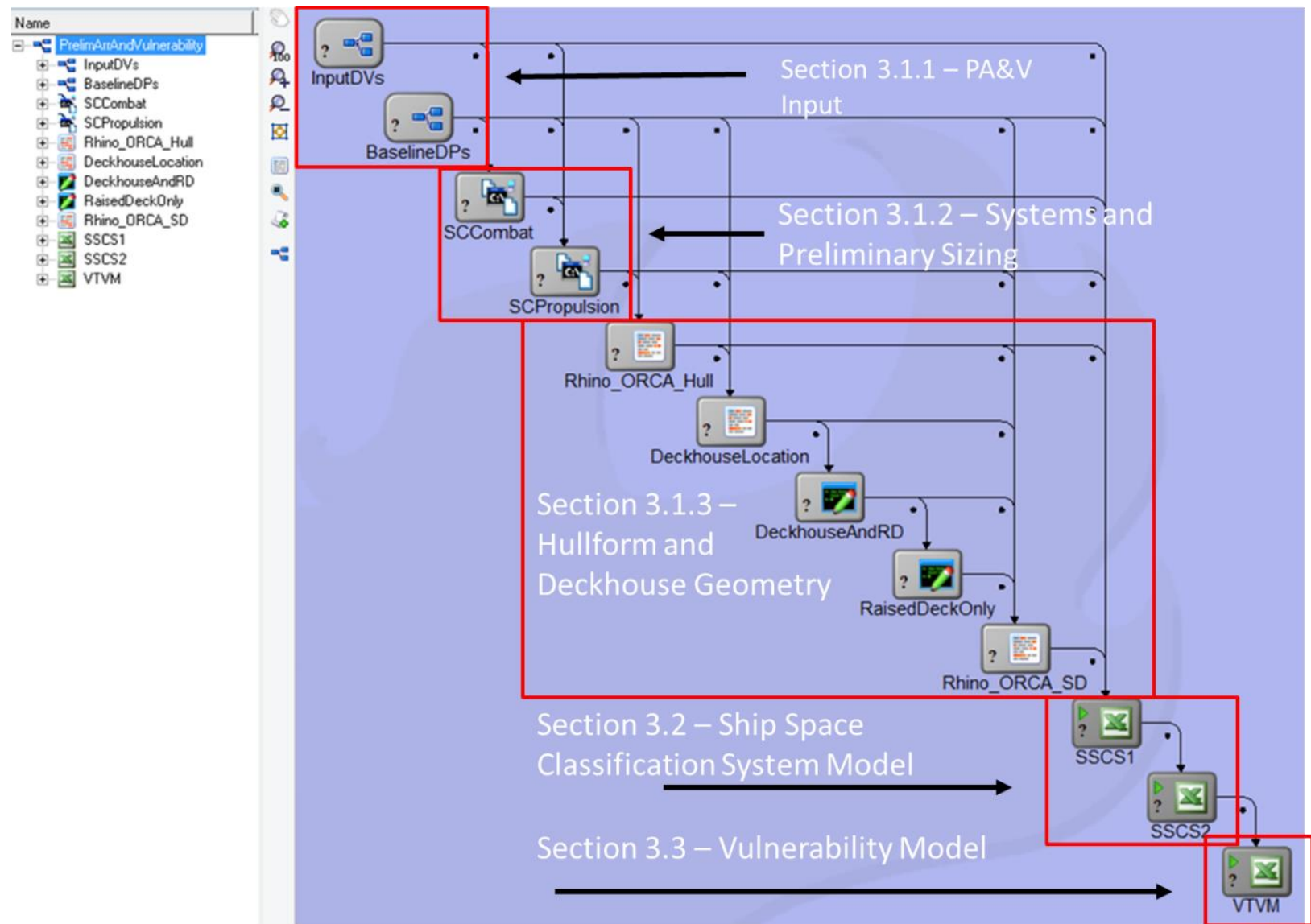

Figure 3-2 - Preliminary Arrangements and Vulnerability Model Center Model

Table 3-1 - PA\&V Input Design Variables

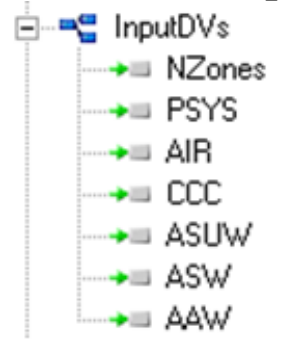

4
7
1
1
1
1
1

\subsubsection{PA\&V Inputs}

The PA\&V inputs (Figure 3-2) include a subset of the total ship design space of Design Variables (DV's), Table 3-1, and Design Parameters (DP's), Table 3-2, used in the C\&RE. The 
$\mathrm{PA} \& \mathrm{~V}$ reduces the quantity of these variables to the minimum required to specify a preliminary sizing and arrangements for vulnerability assessment.

\section{Table 3-2 - PA\&V Design Parameters}

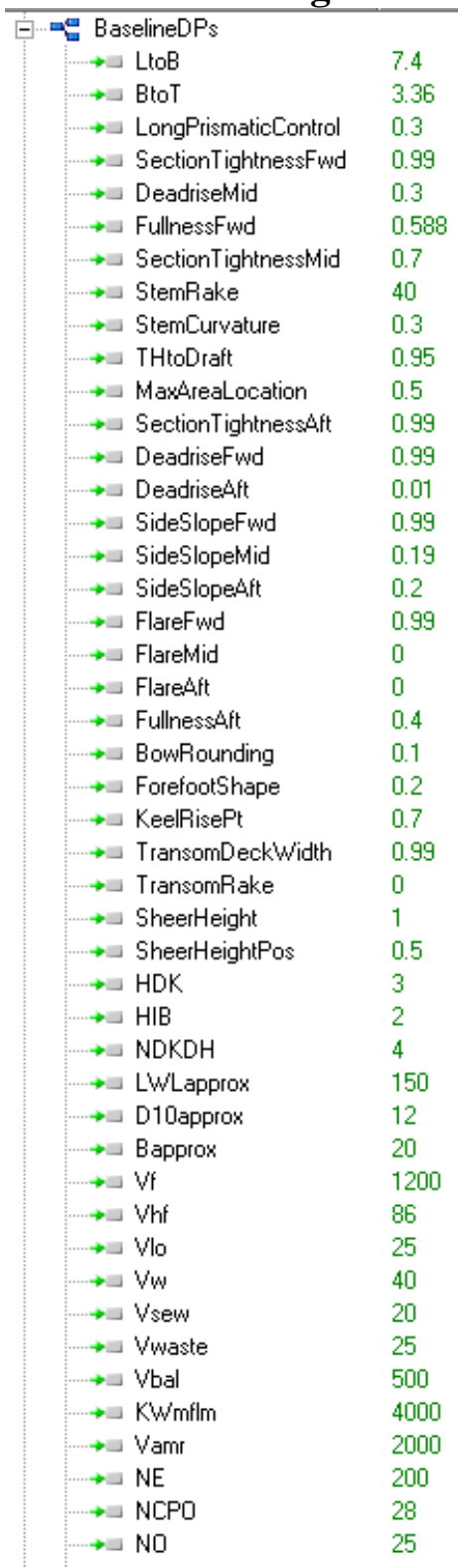

The combat systems (AAW, ASW, ASUW, CCC, AIR), propulsion and power systems (PSYS), and number of ship subdivision zones (NZones) are the only variables used here to calculate the preliminary ship dimensions for sizing as discussed in Section 3.1.2. All combinations of system DV options are considered in the PA\&V so that these results are available 
for effectiveness assessment in ship synthesis and optimization. The number of zones has a major impact on compartment and VC arrangements, architecture and vulnerability. Other DVs in the C\&RE are ultimately important to cost, effectives, and risk, but have only a secondary effect on vulnerability. PA\&V DP values are the same as those used in the C\&RE plus a set of mid-range hullform DV values that are fixed as DP's for the PA\&V only.

\subsubsection{Systems and Preliminary Sizing}

After identifying alternative technologies and system options in the C\&RE, system data is passed to the PA\&V to provide the VTVM with the data necessary to assess system option combinations in baseline ship designs. This is done in the Combat Systems and Propulsion modules shown in Figure 3-2. Each combination of systems has an associated machinery and payload weight which are used to estimate preliminary ship displacement and ship overall length (LOA) required to support the systems. A simplified calculation at the end of the propulsion module determines the lightship weight (Wls) Equation (3-1), using the system options payloads weight (Wp), variable payload weight (Wvp) and payload fraction (PF).

$$
W l s=(W p-W v p) / P F
$$

This lightship weight assumes traditional mechanical and electrical systems. To account for heavier power systems, lightship weight is adjusted for a specific propulsion and electrical system weight using Equation (3-2) and Equation (3-3) where Wbm and Wbme are the basic machinery weights for the selected propulsion and electrical systems:

$$
\begin{gathered}
W_{2 \_3}=.09 * W l s * \frac{W b m+W b m e}{824}+.06 * W l s \\
W l s=0.85 * W l s+W_{2 \_3}
\end{gathered}
$$


Lightship weight is used to calculate preliminary miscellaneous loads weight (Wmiscloads), Equation (3-4). Preliminary fuel weight (Wfuel), Equation (3-5), is based on the sfc for the selected machinery system, endurance power, and baseline endurance range $(5000 \mathrm{~nm}$ in this case). This simplified method is based on transport factors (Kennell, 2011). These weights are added to determine a preliminary total weight (Wtprelim), Equation (3-6).

$$
\begin{gathered}
\text { Wmiscloads }=0.01 * \text { Wls } \\
\text { Wfuel }=1400 * \frac{\text { Pbengend }}{22000} * \frac{\text { SFCepe }}{226} \\
\text { Wtprelim }=\text { Wlsm }+ \text { Wvp }+ \text { Wmiscloads }+ \text { Wfuel }
\end{gathered}
$$

The preliminary weight is then used to calculate the preliminary overall length (LOA) using a baseline DLR from Hullform Exploration, Equation (3-7), which with the specified hullform DP values allows a 3D hullform to be created in Rhino/Orca3D as discussed in Section 3.1.3.

$$
\text { LOAprelim }=\frac{\text { Wtprelim }}{D L R} * 10.15
$$

This process provides a hullform design with sufficient displacement and space for compartments and VC's required by the specified systems.

\subsubsection{PA\&V Hullform, Subdivision, and Deckhouse Modules}

Referring to Figure 3-2, Hullform (Winyall, 2012), Subdivision and Deckhouse modules provide the 3D geometry to the SSCS/PA to produce an AABB architecture and complete the preliminary arrangement. The hullform design variables are used to build hullform models and then response surface models to estimate hullform hydrostatics, seakeeping, and radar crosssection parameters used to assess the influence of these variables on the design performance. One of the challenges in generating a hullform is developing the hullform shape parametrically. Using Orca3D's Hull Assistants, a 3D NURBS surface is created in Rhino to produce the hull shape. In 
the PA\&V, hull characteristics are specified with Orca3D design parameters and variables, most of which are ratios, except for the overall length (LOA). The LOA is estimated as described in 3.1.2 and together with the hullform DPs are used to generate the hullform in Rhino/Orca3D.

The Deckhouse module is used only to locate deckhouse forward and aft faces and to determine the number of decks for blocking out using AABBs. The hullform and subdivision are used to generate hullform AABBs. Subdivision is determined considering required tankage, machinery spaces, hangar location, floodable length and large objects spaces, calculated and determined using simplified parametrics (Winyall, 2012). In the PA\&V Hull and Deckhouse modules the DV's and DP's include:

- Preliminary Length Overall (LOA)

- average deck height (HDK)

- inner bottom height (HIB)

- deckhouse volume (VDHmin)

- number of decks in the deckhouse (NDHDK)

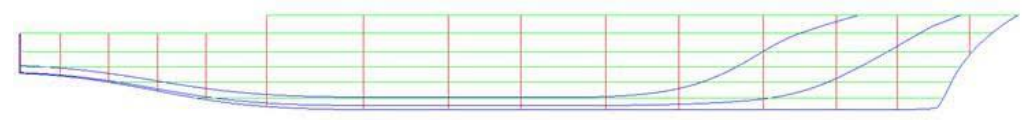

Figure 3-3 - Notional Preliminary Subdivision in Rhino

The $\mathrm{x}, \mathrm{y}, \mathrm{z}$ point intersections of the hull, transverse bulkheads (red lines in Figure 3-3) and decks (green lines in Figure 3-3) are calculated and used as subdivision block nodes for the AABB generation shown in Figure 3-4.

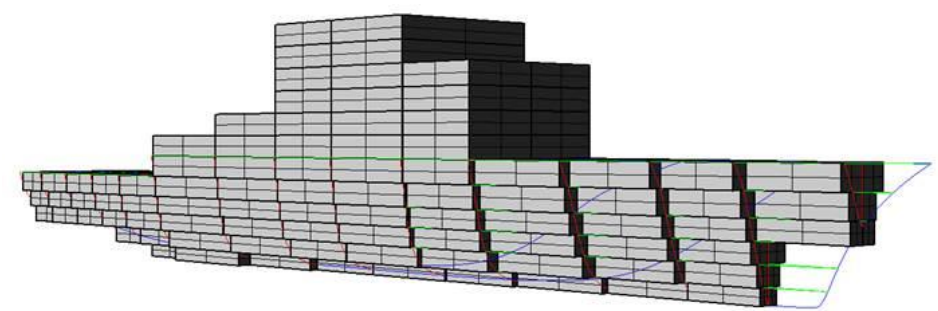

Figure 3-4 -Subdivision Block Generation Using AABBs 


\subsection{SSCS/PA Model Functions}

The Ship Space Classification System and Preliminary Arrangements (SSCS/PA) model shown in Figure 3-2, is used to generate the Subdivision Blocks (SDBs), Figure 3-4, and assign ship compartments to SDBs using the following process:

1. Receive input data from other modules (PA\&V or SSM) and interact with the hullform geometry in Rhino/Orca3D.

2. Specify required compartments for the design.

3. Calculate the required SSCS compartment area consistent with ship principal characteristics and systems.

4. Generate AABB's consistent with the ship hullform as determined by the PA\&V or SSM.

5. Assign compartments to Subdivision Blocks (AABBs) based on specified operability preference and minimum calculated vulnerability.

Figure 3-5 shows the data for Step 1 in the SSCS/PA Module, where the Ship Geometry (Rhino/Orca3D), SSCS areas, and System inputs to the SSCS/PA Module are input and stored. This data is used to assign the vital compartments to SDBs considering their required areas, priority, location and (in the future) vulnerability. 


\begin{tabular}{|c|c|c|c|c|c|}
\hline 4 & 1 & 2 & 3 & 5 & 6 \\
\hline 1 & & \multicolumn{2}{|c|}{ Principal Characteristics: } & & \\
\hline 2 & & Displ & 10176.5 & NZones & 4 \\
\hline 3 & & LBP & 155.2681 & XZone1 & -2 \\
\hline 4 & & $\mathrm{~B}$ & 19.65244 & xZone2 & 42 \\
\hline 5 & & Ts & 50 & xZone3 & 82 \\
\hline 6 & & 00 & 15.70793 & XZone4 & 114 \\
\hline 7 & & D6.5 & 15.70793 & & \\
\hline 8 & & D10 & 15.70793 & TBHDs & 15 \\
\hline 9 & & $\mathrm{D} 20$ & 12.70793 & XTBHDO & -2 \\
\hline 10 & & HDK & 3 & XTBHD1 & 8 \\
\hline 11 & & & & XTBHD2 & 18 \\
\hline 12 & & & & XTBHD3 & 30 \\
\hline 13 & & 1_Mission: & 105.72 & XTBHD4 & 42 \\
\hline 14 & Sonar Dome Volume & $\bar{v} s d$ & 163.5 & XTBHD5 & 54 \\
\hline 15 & Communications and Radio & 1.111 & 105.72 & XTBHD6 & 70 \\
\hline 16 & Radar Equipment/A.rray Rooms & 1.12111 & 302.18 & XTBHD7 & 82 \\
\hline 17 & Director Equipment Rooms & 1.12112 & 60.06 & XTBHD8 & 98 \\
\hline 18 & Sonar Equipment and Control & 1.1221 & 107.52 & ХTBHD9 & 114 \\
\hline 19 & TACTASS Winch Room & 1.1223 & 47.3 & XTBHD10 & 124 \\
\hline 20 & Sonobuoy Stowage & 1.1224 & 10.3 & XTBHD11 & 132 \\
\hline 21 & SURFACE SURV INFRARED & 1.123 & 1.99 & XTBHD12 & 140 \\
\hline 22 & $\mathrm{CIC}$ & 1.1311 & 226.6 & XTBHD13 & 148 \\
\hline 23 & CSER & 1.1312 & 267.93 & XTBHD14 & 155.16815 \\
\hline 24 & EW Room & 1.141 & 16 & XTBHD15 & 0 \\
\hline 25 & Nixie Winch Room & 1.142 & 0 & & \\
\hline 26 & Chaff Equipment Rooms & 1.143 & 17.1 & $\mathrm{x}$ DHFwdFP & 42 \\
\hline 27 & Gun Loader Drum \& Service & 1.211 & 44 & $\mathrm{xDHaftFP}$ & 114 \\
\hline 28 & Ammo Stowage Space & 1.2141 & 82 & $\mathrm{ZDH}$ bot & 15.71 \\
\hline 29 & ClWS & 1.215 & 37.14 & ZDHtop & 27.71 \\
\hline 30 & VLS Fwd & 1.221 & 82 & $\mathrm{HDK}$ & 3 \\
\hline 31 & VLS aft & 1.222 & 164 & $\mathrm{NDKDH}$ & 4 \\
\hline 32 & Torpedoe Stowage & 1.24 & 36.1 & & \\
\hline 33 & Special Weapon Stowage & 1.26 & 4.1 & $\mathrm{NHDK}$ & 2 \\
\hline 34 & Helo Control \& RAST System & 1.321 & 21.9 & & \\
\hline 35 & Hangar (2 decks) & 1.342 & 425.00 & NNJHDK & 6 \\
\hline 36 & Aviation Shops and Office & 1.36 & 35 & Keel & 0 \\
\hline 37 & Aircraft Ordinance Magazine & 1.374 & 51.75 & Hib & 2 \\
\hline 38 & JP-5 Hose Room and Refueling Station & 1.3811 & 13.4 & $\mathrm{H} 2$ & 4.569309 \\
\hline 39 & Aviation Storeroom & 1.39 & 35.7 & $\mathrm{H} 3$ & 7.138618 \\
\hline 40 & Whi & 1.38134 & 2.1 & $\mathrm{H}_{4}$ & 9.707927 \\
\hline 41 & Special Missions, Modular Stowage & 1.8 & 0 & $\mathrm{H} 5$ & 12.707927 \\
\hline 42 & Small Arms & 1.91 & 2.1 & $\mathrm{H} 6$ & 15.707927 \\
\hline 43 & & 2_Human & 229 & & \\
\hline 44 & & $\overline{N E}$ & 200 & NSSCS & 0 \\
\hline 45 & & NCPO & 28 & NVTVM & 0 \\
\hline 46 & & NO & 25 & NSSCS2 & 0 \\
\hline 47 & & $\mathrm{NO}+$ & 29 & & \\
\hline 48 & & NT & 257 & $A A W$ & 1 \\
\hline 49 & & 3.9_Tanks & & $A S W$ & 1 \\
\hline 50 & & $\mathrm{~V} / \mathrm{F}$ & 1200 & ASU'W' & 1 \\
\hline
\end{tabular}

Figure 3-5 - SSCS/PA “Input" Sheet (Left Side)

The Ship Space Classification System sheets estimate required area and volume for Mission Support (Figure 3-6), Human Support (Figure 3-7), Ship Support (Figure 3-8), Tanks, and Ship Machinery. These areas are required for the compartments, and are summarized on the "Compartments" sheet, Figure 3-10. The SSCS/PA module is also used in the Ship Synthesis Model (SSM). 


\begin{tabular}{|c|c|c|c|c|c|c|c|c|}
\hline $\operatorname{sscs}$ & sscs Category & Compartment Name & $\#$ & Quantity & $A(\mathrm{~m} 2 \mathrm{ea})$ & A $N$ & DDG51 F1 m2 & Location \\
\hline 1 & MISSION SUPPORT & & & & & 2302.56 & 1668 & \\
\hline 1.1 & COMMAND,COMMUNICATION+SURV & & & & & 1237.37 & 1159 & \\
\hline 1.11 & EXTERIOR COMMUNICATIONS & & & & & 111.62 & 133 & \\
\hline \multirow[t]{3}{*}{1.111} & RADIO/MESSAGE PROCESSING & & & & & 105.72 & 127 & \\
\hline & & Comm_Center & 1 & 1 & 95.1 & 95.15 & & $\begin{array}{l}\text { high in deckhouse, often behind } \\
\text { chart room; includes TTY and } \\
\text { Facsimile Systems }\end{array}$ \\
\hline & & Emerg Radio Room & 2 & 1 & 10.6 & 10.57 & & aft, deckhouse \\
\hline 1.113 & VISUAL COM & Signal Bridge & 3 & 1 & 5.9 & 5.90 & 5.9 & $\begin{array}{c}\text { external, top of deckhouse, may be } \\
\text { omitted }\end{array}$ \\
\hline 1.12 & SURVEILLANCE SYS & & & & & 491.47 & 465 & \\
\hline 1.121 & AIR \& SURFACE SURV (RADAR) & & & 1 & & 326.35 & 154.6 & \\
\hline 1.1211 & RADAR ELECTRONICS (ROOMS) & & & & & 302.18 & 302.2 & \\
\hline \multirow[t]{6}{*}{1.12111} & Fwd & Radar_Equip_Rm_1 & 4 & 1 & 90.7 & 90.65 & 90.654 & deckhouse near/behind radars fwd \\
\hline & & Radar_Array_Rm_1 & 5 & 1 & 30.2 & 30.22 & 37.7725 & deckhouse near/behind radars fwd \\
\hline & & Radar_Array_Rm_2 & 6 & 1 & 30.2 & 30.22 & 37.7725 & deckhouse near/behind radars fwd \\
\hline & Aft & Radar_Equip_Rm_2 & 7 & 1 & 90.7 & 90.65 & 60.436 & deckhouse near/behind radars aft \\
\hline & & Radar_Array_Rm_3 & 8 & 1 & 30.2 & 30.22 & 37.7725 & deckhouse near/behind radars aft \\
\hline & & Radar_Array_Rm_4 & 9 & 1 & 30.2 & 30.22 & 37.7725 & deckhouse near/behind radars aft \\
\hline \multirow[t]{2}{*}{1.12112} & Fwd & Radar_Director_Equip_Rm_1 & 10 & 1 & 30.03 & 30.03 & & Ingn in aecknouse, oelow alrector \\
\hline & Aft & Radar_Director_Equip_Rm_2 & 11 & 1 & 30.03 & 30.03 & & nign in oecknousê, , Delow alrector \\
\hline \multirow[t]{2}{*}{1.1212} & RADAR COOLING (ROOMS) & Radar_Cooling_Equip_Rm_1 & 12 & 1 & 24.2 & 24.17 & & adjacent radar efectronics or lower, \\
\hline & & Radar_Cooling_Equip_Rm_2 & 13 & 1 & 24.2 & 24.17 & & adjacentradar efectronics of tower, \\
\hline 1.122 & UNDERWATER SURV (SONAR) & & & & & 165.12 & 310.6 & \\
\hline \multirow[t]{4}{*}{1.1221} & SONAR ELECTRONICS (ROOMS) & Sonar Equipment Room 1 & 14 & 1 & 10.8 & 10.75 & & sonar rooms low towards bow \\
\hline & & Sonar Equipment Room 2 & 15 & 1 & 21.5 & 21.50 & & sonar rooms low towards bow \\
\hline & & Sonar Equipment Room 3 & 16 & 1 & 64.5 & 64.51 & & sonar rooms low towards bow \\
\hline & & $\begin{array}{l}\text { Sonar coomg Equipment } \\
\text { Ronm }\end{array}$ & 17 & 1 & 6.5 & 6.45 & & sonar rooms low towards bow \\
\hline 1.1222 & SONAR CONTROL & Sonar Control Room & 18 & 1 & 4.3 & 4.30 & & near $\mathrm{ClC}$ \\
\hline
\end{tabular}

\section{Figure 3-6 - SSCS “Mission Support” Classification Sheet}

Figure 3-10 shows the data for Step 2 and 3 in the SSCS/PA Module, where each of the compartments specified in the design are arranged on the "Compartments" sheet with SSCS areas based on ship principal characteristics and systems. 


\begin{tabular}{|c|c|c|c|c|c|c|c|}
\hline sscs & SSCS Category & Related Compartments & 吊 & Quantity & $A(\mathrm{~m} 2 \mathrm{ea})$ & $A$ & Location \\
\hline 2 & HUMAN SUPPORT & & & & & 1409.27 & \\
\hline 2.1 & LIVING & & & & & 760.40 & \\
\hline 2.11 & OFFICER LIVING & & & & & 216.00 & \\
\hline 2.111 & BERTHING & & & & & 216.00 & \\
\hline 2.1111 & SHIP OFFICER & & & & & 186.00 & \\
\hline \multirow[t]{2}{*}{2.1111} & COMMANDING OFFICER STATEROOM & CO Stateroom and Office and Sanitary & 70 & 1 & 30.00 & 37.00 & Main deck or $01 / 02$ Level in $\mathrm{DH}$ \\
\hline & & CO At-Sea Cabin & 71 & 1 & 6.00 & 6.00 & \\
\hline 2.1111 & EXECUTIVE OFFICER STATEROOM & XO Stateroom and Office and Sanitary & 72 & 1 & 14.00 & 19.00 & Main deck or second deck midship, near administrative office \\
\hline 2.1111 & OFFICE, EXECUTIVE OFFICER & & & & & & \\
\hline \multirow[t]{2}{*}{2.1111} & DEPARTMENT HEAD STATEROOM & Bed_WC_Department_Head_1 & 73 & 2 & 10.00 & 20.00 & Often main deck or 01 Level in DH, 1 man \\
\hline & & Bed_WC_Department_Head_2 & 74 & 2 & 10.00 & 20.00 & \\
\hline \multirow[t]{2}{*}{2.1111} & OFFICER STATEROOM (DBL) & Officer Staterooms and Sanitary 1 & 75 & 4 & 13.00 & 52.00 & Officer's Country 01 level or main deck near ward room, 2 man \\
\hline & & Officer Staterooms and Sanitary 2 & 76 & 4 & 13.00 & 52.00 & Separate from Officer Staterooms and Sanitary 1,2 man \\
\hline 2.1112 & BATH, WARDROOM & & & 1 & 4.00 & 4.00 & next to Wardroom \\
\hline 2.1114 & AVIATION OFFICER STATEROOM & Aviation Officers Staterooms & 77 & 2 & 13.00 & 30.00 & Deckhouse near hangar upper level, 2 man \\
\hline 2.112 & SANITARY & & & & & & \\
\hline 2.1121 & SHIP OFFICER & & & & & & \\
\hline 2.1121 & COMMANDING OFFICER BATH & & & 1 & 7.00 & 7.00 & adjacent $\mathrm{CO}$ berthing \\
\hline 2.1121 & EXECUTIVE OFFICER BATH & & & 1 & 5.00 & 5.00 & adjacent XO berthing \\
\hline 2.1121 & OFFICER TOILET/SHOWER & & & 8 & 4.00 & 32.00 & near officer/DH berthing \\
\hline 2.1124 & AVIATION OFFICER TOILET/SHOWER & & & 1 & 4.00 & 4.00 & near aviation officer berthing \\
\hline 2.12 & CPOLIVING & & & & & 96.00 & \\
\hline \multirow[t]{2}{*}{2.121} & BERTHING (4) & CPO Berthing and Sanitary 1 & 78 & 5 & 12.00 & 60.00 & sleeping and lounge, main or 2 nd deck, 4 man \\
\hline & & CPO Berthing and Sanitary 2 & 79 & 3 & 12.00 & 36.00 & separate from CPO Berthing and Sanitary 1 \\
\hline 2.122 & SANITARY & & & 5 & 4.00 & 20.00 & adjacent CPO berthing \\
\hline \multirow[t]{5}{*}{2.13} & CREW LIVING & & & & & 420.40 & \\
\hline & & Crew Berthing and Sanitary 1 & 80 & 1 & 105.10 & 105.10 & below main/2nd deck, usually 2 levels, $12 \times 6$ man cells, 72 men total \\
\hline & & Crew Berthing and Sanitary 2 & 81 & 1 & 105.10 & 105.10 & below main/2nd deck, usually 2 levels, $12 \times 6$ man cells, 72 men total \\
\hline & & Crew Berthing and Sanitary 3 & 82 & 1 & 105.10 & 105.10 & below main/2nd deck, usually 2 levels, $12 \times 6$ man cells, 72 men total \\
\hline & & Crew Berthing and Sanitary 4 & 83 & 1 & 105.10 & 105.10 & below main/2nd deck, usually 2 levels, $12 \times 6$ man cells, 72 men total \\
\hline 2.131 & BERTHING (6) & & & 33 & 10.00 & 330.00 & 6 man cells \\
\hline 2.132 & SANITARY & & & 16 & 4.00 & 64.00 & 12 man ea \\
\hline 2.133 & RECREATION & & & & & 26.40 & \\
\hline 2.14 & GENERAL SANITARY FACILITIES & & & & & 2.00 & \\
\hline 2.141 & DECK TOILET & & & 0 & 2.00 & 0.00 & fwd, midship, aft \\
\hline 2.142 & BRIDGE WASHRM \& WC & Bridge WC & 84 & 1 & 2.00 & 2.00 & adjacent bridge \\
\hline 2.15 & SHIP RECREATION FAC & Crew Recreation Room & 85 & 1 & 20.00 & 20.00 & 2nd deck or below \\
\hline 2.16 & TRAINING and FITNESS & Crew Training, Physical Fitness Room & 86 & 1 & 6.00 & 6.00 & 2nd deck or below \\
\hline 2.2 & COMMISSARY & & & & & 364.73 & \\
\hline 2.21 & FOOD SERVICE & & & & & 215.80 & \\
\hline 2.211 & WARDROOM MESSRM \& LOUNGE & Wardroom & 87 & 1 & 59.80 & 59.80 & main deck or 01 level near officer country \\
\hline 2012 & CPO MESSRONM ANDI OIINGF & CPR Mess and I nunne & 80 & & $56 \cap 0$ & 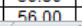 & adiacent C.PO herthinn near crew mess \\
\hline 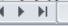 & Input Compartments Arrangement & 1.0 MissionSupport $\quad 2.0$ HumanSt & port & $3.0 \mathrm{~S}$ & upport & 3.9 Tar & 4.0 Ship Machinery Arri 1 \\
\hline
\end{tabular}

Figure 3-7 - SSCS “Human Support” Classification Sheet

\begin{tabular}{|c|c|c|c|c|c|c|c|c|}
\hline sscs & SSCS Category & Related Compartments & $\#$ & \# & Quantity & $A(m 2$ ea) & A & Location \\
\hline 3 & SHIP SUPPORT & & & & & & 1949.3 & \\
\hline 3.1 & SHIP CNTL SYS (STEERING) & & & & & & 50.4 & \\
\hline 3.11 & STEERING GEAR & Steering_Gear_Rm & 116 & & 1 & 50.4 & 50.4 & 2nd deck or below, above rudders \\
\hline 3.12 & ROLL STABILIZATION & & & & & & & \\
\hline 3.15 & STEERING CONTROL & & & & & & & \\
\hline 3.2 & DAMAGE CONTROL & & & & & & 161.2 & \\
\hline 3.21 & DAMAGE CNTRL CENTRAL & Central Contol Station / DC Central (CCS) & 117 & & 1 & 93.2 & 93.2 & 2nd deck, midship \\
\hline \multirow[t]{4}{*}{3.22} & REPAIR STATIONS & & & & & & 41.7 & \multirow{4}{*}{3 ea, DC deck, 2-fwd/5-midship/3-aft } \\
\hline & & Repair Locker 5 (Machinery Rooms) & 118 & & 1 & 10.6 & 10.6 & \\
\hline & & Repair Locker 2 (Fwd) & 119 & & 1 & 15.5 & 15.5 & \\
\hline & & Repair Locker 3 (Aft) & 120 & & 1 & 15.5 & 15.5 & \\
\hline \multirow[t]{5}{*}{3.25} & FIRE FIGHTING & & & & & & 26.4 & \\
\hline & & Fire Fighting Station 1 & 121 & & 1 & 6.2 & 6.2 & 2nd deck above MMRs, AMRs \\
\hline & & Fire Fighting Station 2 & 122 & & 1 & 6.2 & 6.2 & 3rd deck above MMRs, AMRs \\
\hline & & Fire Fighting Station 3 & 123 & & 1 & 6.2 & 6.2 & 4th deck above MMRs, AMRs \\
\hline & & CO2 Room & 124 & & 1 & 7.8 & 7.8 & weather deck, 01 level \\
\hline 3.3 & SHIP ADMINISTRATION & & & & & & 159.2 & \\
\hline 3.301 & GENERAL SHIP & Ship's Office & 125 & & 1 & 36.7 & 36.7 & 2nd deck midship \\
\hline 3.302 & EXECUTIVE DEPT & & & & & & & \\
\hline 3.303 & ENGINEERING DEPT & Engineering Office & 126 & & 1 & 16.2 & 16.2 & aft midship 2nd deck or below \\
\hline 3.304 & SUPPLY DEPT & Supply Office & 127 & & 1 & 38.8 & 38.8 & fwd midship 2nd deck or below \\
\hline 3.305 & DECK DEPT & Deck Department Office & 128 & & 1 & 19.4 & 19.4 & main deck, deckhouse \\
\hline 3.306 & OPERATIONS DEPT & Operations Department Office & 129 & & 1 & 25.9 & 25.9 & 01 level or above deckhouse \\
\hline 3.307 & WEAPONS DEPT & Weapons Department Office & 130 & 114 & 1 & 22.2 & 22.2 & 01 level or above deckhouse \\
\hline 3.5 & DECK AUXILIARIES & & & & & & 98.3 & \\
\hline \multirow[t]{3}{*}{3.51} & ANCHOR HANDLING & & & & & & 76.3 & \\
\hline & & Chain Lockers (2) & 131 & & 1 & 25.4 & 25.4 & \multirow{2}{*}{$\begin{array}{c}\text { just below weather deck in bow with hydraulics below and chain hausers } \\
\text { connecting to chain lockers below near keel }\end{array}$} \\
\hline & & Windlass/Capstan Hydraulics Room & 132 & & 1 & 50.9 & 50.9 & \\
\hline 3.52 & LINE HANDLING & & & & 0 & & 0.0 & \\
\hline \multirow[t]{2}{*}{3.53} & TRANSFER-AT-SEA & & & & & & 16.0 & \\
\hline & & RAS/FAS Gear Locker 1 - fwd & 133 & & 1 & 8.0 & 8.0 & p/s deckhouse opening on weather deck, 01 level \\
\hline
\end{tabular}

Figure 3-8 - SSCS “Ship Support” Classification Sheet

In Step 4 the SSCS/PA Module generates AABB's using an offsets table extracted from the hullform generated in the PA\&V. The offsets table is a set of points at each transverse bulkhead and deck location in the ship. The AABB generation module in rhino "shoots" lines at each X and Y point location in order to determine AABB boundaries, 4 adjacent boundaries generate a box, 
the result of which is a full set of AABBs imported to excel to generate a list of Subdivision Blocks,

Figure 3-9, with minimum and maximum X, Y, and Z boundary locations to make up the rectilinear

boxes and SDB available areas.

\begin{tabular}{|c|c|c|c|c|c|c|c|c|c|c|c|}
\hline J & K & L & M & N & 0 & $\mathrm{P}$ & Q & R & s & T & $u$ \\
\hline \multicolumn{12}{|c|}{ Subdivision Blocks Summary (formerly Compartment plus geometry) } \\
\hline \multicolumn{4}{|c|}{ SDB Description } & \multicolumn{8}{|c|}{ SBD Geometry } \\
\hline $\begin{array}{l}\text { Subdision Block } \\
\text { Name }\end{array}$ & SDBID & Sub Category & $\begin{array}{c}\text { SDB } \\
\text { Number }\end{array}$ & $\underset{(m)}{X \min }$ & $\underset{(m)}{Y \min }$ & $\underset{(m)}{Z \min }$ & $\begin{array}{c}\text { Xmax } \\
(\mathbf{m}]\end{array}$ & \begin{tabular}{c|c}
$\max$ \\
$(\mathbf{m})$
\end{tabular} & $\underset{(m)}{Z \max }$ & $\begin{array}{l}\text { Deck } \\
\text { Area } \\
\left(\mathrm{m}^{2}\right)\end{array}$ & $\begin{array}{c}\text { Yolume } \\
\text { (m') }\end{array}$ \\
\hline 1.4_SDB & 230100001 & 1 & 1 & -2 & -1.981 & 7.138618 & 8 & 1.981 & \begin{tabular}{|l|}
9.707927 \\
\end{tabular} & 39.62 & 101.80 \\
\hline 14 SSDB & 230200002 & 2 & 2 & -2. & & 7.138618 & 8 & 1.981 & 9.707927 & 19.81 & 50.90 \\
\hline 14 P SDB & 230300003 & 3 & 3 & -2.2 & -1.981 & 7.138618 & 8 & 0 & $\begin{array}{l}9.707927 \\
\end{array}$ & 19.81 & 50.90 \\
\hline $15 \mathrm{SDB}$ & 230400004 & 4 & 4 & -2 & -2.3978 & \begin{tabular}{|c|}
9.707927 \\
\end{tabular} & 8 & 2.39775 & $\begin{array}{l}12.70793 \\
\end{array}$ & 47.96 & 143.87 \\
\hline $15 \mathrm{~s}$ sDB & 230500005 & 5 & 5 & -2 & & 9.707927 & 8 & 2.39775 & 12.70793 & 23.98 & 71.93 \\
\hline $15 \mathrm{P} S \mathrm{SDB}$ & 230600006 & 6 & 6 & -2 & -2.3978 & 9.707927 & 8 & 0 & $\begin{array}{l}12.70793 \\
\end{array}$ & 23.98 & 71.93 \\
\hline $16 \mathrm{SDOB}$ & 230700007 & 7 & 7 & -2 & -3.7638 & 12.70793 & 8 & 3.76375 & 15.70793 & 75.28 & 225.83 \\
\hline 16 S SDB & 230800008 & 8 & 8 & -2 & & 12.70793 & 8 & 3.76375 & 15.70793 & 37.64 & 112.91 \\
\hline $16 \mathrm{PSDB}$ & 230900009 & 9 & 9 & -2 & -3.7638 & 12.70793 & 8 & 0 & 15.70793 & 37.64 & 112.91 \\
\hline $21 \mathrm{sDB}$ & 231000010 & 10 & 10 & 8 & -1.259 & 0 & 18 & 1.259 & 2 & 25.18 & 50.36 \\
\hline 2_1_s_SDB & 231100011 & 11 & 11 & 8 & 0 & 0 & 18 & 1.259 & 2 & 12.59 & 25.18 \\
\hline 2 _1_P_SDB & 231200012 & 12 & 12 & 8 & -1.259 & 0 & 18 & 0 & & 12.59 & 25.18 \\
\hline $22 \mathrm{SDB}$ & 231300013 & 13 & 13 & $\frac{8}{8}+x-1$ & $\mid-1.781$ & & $\frac{10}{18}$ & 1.781 & 4.569309 & 35.62 & 91.52 \\
\hline $22 \mathrm{~s} s \mathrm{sDB}$ & 231400014 & 14 & 14 & 8 & & 2 & 18 & 1.781 & 4.569309 & 17.81 & 45.76 \\
\hline P SDB & 231500015 & 15 & 15 & 8 & -1.781 & & 18 & 0 & 4.569309 & 17.81 & 45.76 \\
\hline $23 \mathrm{SDB}$ & 231600016 & 16 & 16 & & -2.742 & 4.569309 & 18 & 2.742 & 7.138618 & 54.84 & 140.90 \\
\hline $23 \mathrm{~s} S \mathrm{SDB}$ & 231700017 & 17 & 17 & 8 & 0 & 4.569309 & 18 & 2.742 & 7.138618 & 27.42 & 70.45 \\
\hline $23 \mathrm{PSSB}$ & 231800018 & 18 & 18 & 8 & $\begin{array}{l}-2.742 \\
\end{array}$ & 4.569309 & 18 & 0 & 7.138618 & 27.42 & 70.45 \\
\hline $24 \mathrm{sDB}$ & 231900019 & 19 & 19 & 8 & -3.5948 & 7.138618 & 18 & 3.59475 & 9.707927 & 71.90 & 184.72 \\
\hline $24 \mathrm{~s} S \mathrm{SDB}$ & $\frac{20150000}{232000020}$ & 20 & $\frac{13}{20}$ & 8 & 0.0540 & |r.1501010 & $\frac{10}{18}$ & $\begin{array}{l}.354975 \\
3.5945\end{array}$ & $\begin{array}{l}.1 .707927 \\
.707927 \\
\end{array}$ & $\frac{1.30}{35.95}$ & $\begin{array}{l}90.12 \\
92.36 \\
\end{array}$ \\
\hline 24 P_SDB & 232100021 & 21 & 21 & $\frac{8}{8}$ & -3.5948 & \begin{tabular}{|c|}
7.138618 \\
\end{tabular} & 18 & & $\begin{array}{l}.707927 \\
9.707927\end{array}$ & 35.95 & 92.36 \\
\hline $25 \mathrm{sDB}$ & 232200022 & 22 & 22 & 8 & -.4 .5098 & 9.707927 & 18 & 4.50975 & 12.70793 & 90.20 & 270.59 \\
\hline 25 SSDB & 232300023 & 23 & 23 & 8 & & 9.707927 & 18 & 4.50975 & 12.70793 & 45.10 & 135.29 \\
\hline $25 \mathrm{PSSDB}$ & 232400024 & 24 & 24 & 8 & -4.5098 & 9.707927 & 18 & 0 & 12.70793 & 45.10 & 135.29 \\
\hline $26 \mathrm{sDB}$ & 232500025 & 25 & 25 & 8 & -5.8873 & 12.70793 & 18 & 5.88725 & 15.70793 & 117.75 & 353.24 \\
\hline $26 \mathrm{ssDB}$ & 232600026 & 26 & 26 & 8 & & 12.70793 & 18 & 5.88725 & 15.70793 & 58.87 & 176.62 \\
\hline $26 \mathrm{PSSB}$ & 232700027 & 27 & 27 & 8 & -5.8873 & 12.70793 & 18 & & 15.70793 & 58.87 & 176.62 \\
\hline $31 \mathrm{sDB}$ & 232800028 & $\frac{28}{28}$ & 28 & 18 & -1.356 & & 30 & 1.356 & & 32.54 & 65.09 \\
\hline 31 S_SDB & 232900029 & 29 & 29 & 18 & 0 & 0 & 30 & 1.356 & 4 & 16.27 & 32.54 \\
\hline $31 \mathrm{P}$ SDB & 233000030 & 30 & 30 & 18 & -1.356 & & 30 & 0 & & 16.27 & 32.54 \\
\hline $32 \mathrm{SDB}$ & 233100031 & 31 & 31 & 18 & -3.4485 & & 30 & 3.4485 & 4.569309 & 82.76 & 212.65 \\
\hline $325 \mathrm{sDB}$ & 233200032 & 32 & 32 & 18 & & & 30 & 3.4485 & 4.569309 & 41.38 & 106.32 \\
\hline 32 P_SDB & 233300033 & 33 & 33 & 18 & -3.4485 & & 30 & 0 & 4.569309 & 41.38 & 106.32 \\
\hline 3_3_sDB & 233400034 & 34 & 34 & 18 & -4.6775 & 4.569309 & 30 & 4.6775 & 7.138618 & 112.26 & 288.43 \\
\hline $33 \mathrm{~s} \mathrm{sDB}$ & 233500035 & 35 & 35 & 18 & & 4.569309 & 30 & 4.6775 & 7.138618 & 56.13 & 144.22 \\
\hline $33 \mathrm{PSDB}$ & 233600036 & 36 & 36 & 18 & -4.6775 & 4.569309 & 30 & & 7.138618 & 56.13 & 144.22 \\
\hline 34 _SDB & 233700037 & 37 & 37 & 18 & -5.5858 & $\begin{array}{l}7.138618 \\
\end{array}$ & 30 & 5.58575 & \begin{tabular}{|l|}
9.707927 \\
\end{tabular} & 134.06 & 344.44 \\
\hline 34 s sDD & 233800038 & 38 & $\frac{38}{38}$ & 18 & 0 & 7.138618 & 30 & 5.58575 & 9.707927 & 67.03 & 172.22 \\
\hline 34 P & 233900039 & 39 & 39 & 18 & -5.5858 & 7.138618 & 30 & & 9.707927 & 67.03 & 172.22 \\
\hline $35 \mathrm{sDB}$ & 234000040 & 40 & 40 & 18 & -6.5265 & 9.707927 & 30 & 6.5265 & 12.70793 & 156.64 & 469.91 \\
\hline $35 \mathrm{~s} s \mathrm{SDB}$ & 234100041 & 41 & 41 & 18 & & 9.707927 & 30 & 6.5265 & 12.70793 & 78.32 & 234.95 \\
\hline $35 \mathrm{P} \mathrm{SDB}$ & 234200042 & 42 & 42 & 18 & -6.5265 & 9.707927 & 30 & & 12.70793 & 78.32 & 234.95 \\
\hline $36 \mathrm{sDB}$ & 234300043 & 43 & 43 & 18 & -.7 .8675 & \begin{tabular}{|l|l|}
12.70793 \\
\end{tabular} & 30 & 7.8675 & \begin{tabular}{|l|l|}
15.70793 \\
\end{tabular} & 188.82 & 566.46 \\
\hline $36 \mathrm{~s} S \mathrm{SDB}$ & 234400044 & 44 & 44 & 18 & & $\begin{array}{l}12.70793 \\
\end{array}$ & 30 & 7.8675 & 15.70793 & 94.41 & 283.23 \\
\hline $36 \mathrm{P}$ SDB & 234500045 & 45 & 45 & 18 & .7 .8675 & 12.70793 & 30 & & \begin{tabular}{|l|l|}
15.70793 \\
\end{tabular} & 94.41 & 283.23 \\
\hline $41 \mathrm{SDB}$ & 234600046 & 46 & 46 & 30 & -2.2565 & & 42 & 2.2565 & & 54.16 & 108.31 \\
\hline 41 S_SDB & 234700047 & 47 & 47 & 30 & & 0 & 42 & 2.2565 & & 27.08 & 54.16 \\
\hline $41 \mathrm{PSDB}$ & 234800048 & 48 & 48 & 30 & -2.2565 & & 42 & 0 & & 27.08 & 54.16 \\
\hline $42 \mathrm{SDB}$ & 234900049 & 49 & 49 & 30 & -5.419 & & 42 & 5.419 & 4.569309 & 130.06 & 334.15 \\
\hline $4{ }_{2} 2 \mathrm{~S}$ SDD & 235000050 & 50 & 50 & 30 & 0 & & 42 & 5.419 & 4.569309 & 65.03 & 167.08 \\
\hline $42 \mathrm{PSCB}$ & 235100051 & 51 & 51 & 30 & -5.419 & & 42 & & 4.569309 & 65.03 & 167.08 \\
\hline 4 _3_SDB & 235200052 & 52 & 52 & 30 & -6.8138 & 4.569309 & 42 & 6.81375 & 7.138618 & 163.53 & 420.16 \\
\hline $433 \mathrm{~s}$ SDB & 235300053 & 53 & 53 & 30 & 0 & 4.569309 & 42 & 6.81375 & 7.138618 & 81.77 & 210.08 \\
\hline 4_3P SDB & 235400054 & 54 & 54 & 30 & -6.8138 & 4.569309 & 42 & 0 & 7.138618 & 81.77 & 210.08 \\
\hline $44 \mathrm{sDB}$ & 235500055 & 55 & 55 & 30 & .7 .668 & 7.138618 & 42 & 7.668 & 9.707927 & 184.03 & 472.84 \\
\hline $4-4 \mathrm{SSDB}$ & $\frac{235000056}{23500056}$ & 56 & 56 & $\frac{30}{30}$ & r. & \begin{tabular}{|l|} 
r. \\
7.138618 \\
\end{tabular} & $\frac{42}{42}$ & $\frac{1.600}{7.668}$ & $\begin{array}{l}.1000721 \\
.707927 \\
\end{array}$ & $\frac{104.03}{92.02}$ & $\frac{472.64}{236.42}$ \\
\hline $44_{4} \mathrm{P} S \mathrm{SDB}$ & 235700057 & 57 & 57 & 30 & .7 .668 & 7.138618 & 42 & & 9.707927 & 92.02 & 236.42 \\
\hline $45 \mathrm{SDB}$ & 235800058 & 58 & 58 & 30 & -8.5055 & 9.707927 & 42 & 8.5055 & \begin{tabular}{|l|}
12.70793 \\
\end{tabular} & 204.13 & 612.40 \\
\hline 3.9 & 4.0 & & $\uplus$ & 4 & & & & & & & \\
\hline
\end{tabular}

Figure 3-9 - SSCS/PA “Input" Sheet (Right Side)

In Step 5 after all SDB's have been generated, the SSCS/PA model assigns each vital compartment in the model to the "Compartments" sheet, Figure 3-10, to SBDs. 


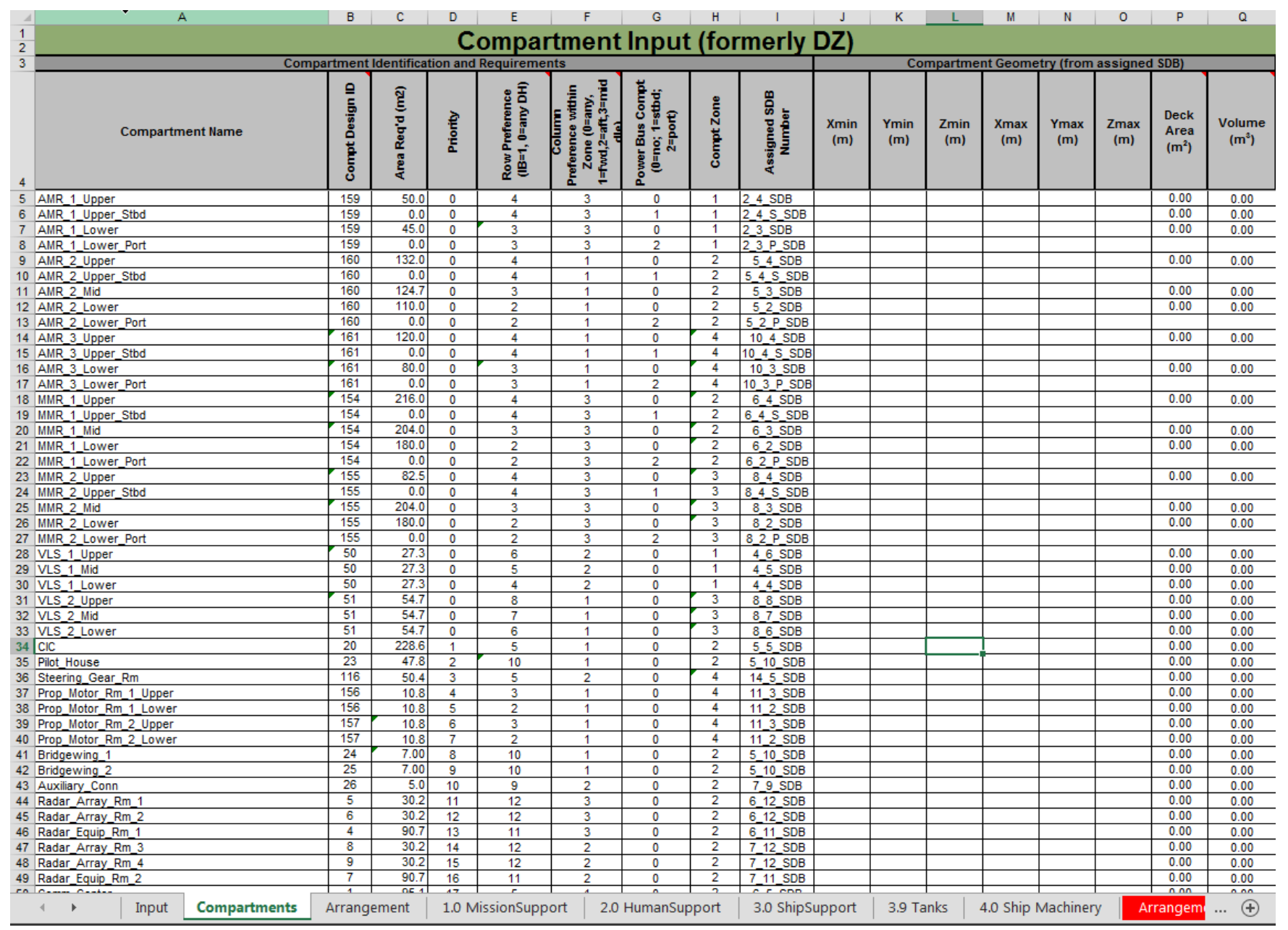

Figure 3-10 - SSCS/PA “Compartments" Sheet

The Compartments Sheet includes the set of compartments, their priorities and their preferred locations in the ship. Compartments are assigned to SDBs, using priorities generated by the user/designer for the C\&RE for the specified set of compartments based on operability needs. Each compartment also has a Deck (or row), Longitudinal subdivision (column), and Zone (group of columns) preference within the ship and a minimum required deck area calculated in Step 3. Each compartment is assigned to a SBD in specific row and column combinations in two dimensions, visualized on the "Arrangements" sheet Figure 3-11. This sheet shows the output of the SSCS/PA Module, the 2D general arrangement used for Vital Component assignment. 


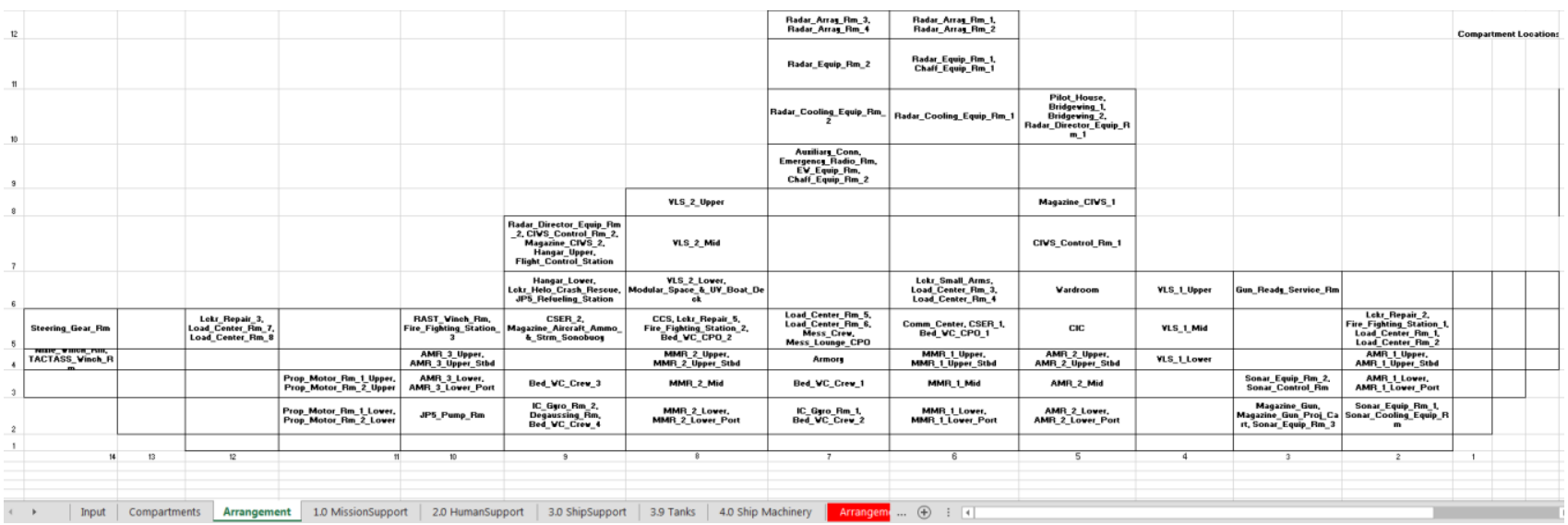

Figure 3-11 - 2-D SSCS/PA Arrangements Sheet

\begin{tabular}{|c|c|c|c|c|c|c|c|c|c|c|c|c|c|}
\hline & & & & & & & 263.178 & 349.248 & & & \multicolumn{3}{|c|}{ Original Area } \\
\hline & & & & & & & 263.178 & 349.248 & & & & & \\
\hline & & & & & & & 263.178 & 349.248 & 253.248 & & & & \\
\hline & & & & & & & 263.178 & 349.248 & 253.248 & & & & \\
\hline & & & & & & 350.888 & 263.178 & 349.248 & 253.248 & & & & \\
\hline & & & & & 350.664 & 350.888 & 263.178 & 349.248 & 253.248 & & & & \\
\hline & & & & & 350.664 & 350.888 & 263.178 & 349.248 & 253.248 & 229.35 & 188.82 & 117.745 & 75.275 \\
\hline 142.9472 & 162.036 & 164.736 & 166.8 & 210.065 & 337.344 & 337.696 & 253.29 & 334.672 & 237.126 & 204.132 & 156.636 & 90.195 & 47.955 \\
\hline 121.5897 & 143.528 & 151.448 & 157.044 & 200.42 & 324 & 325.072 & 243.912 & 320.664 & 222.384 & 184.032 & 134.058 & 71.895 & 39.62 \\
\hline \multirow[t]{12}{*}{107.1781} & 94.4 & 105.708 & 138.672 & 185.21 & 305.096 & 308.168 & 231.534 & 302.672 & 205.434 & 163.53 & 112.26 & 54.84 & \\
\hline & & 68.168 & 100.9387 & 136.735 & 258.224 & 266.128 & 200.34 & 260.136 & 171.588 & 130.056 & 82.764 & 35.62 & \\
\hline & & & & 98.26 & 223.584 & 156.64 & 88.542 & 114.48 & 73.992 & 54.156 & 32.544 & 25.18 & \\
\hline & & & & & & & & & & & & & \\
\hline & & & & & & & & & & & & & \\
\hline & & & & & & & 60.436 & 60.436 & & & \multicolumn{3}{|c|}{ Assigned Area } \\
\hline & & & & & & & 90.654 & 99.204 & & & & & \\
\hline & & & & & & & 24.1744 & 24.1744 & 91.81353 & & & & \\
\hline & & & & & & & 40.122 & 0 & 0 & & & & \\
\hline & & & & & & 54.66667 & 0 & 0 & 6.19 & & & & \\
\hline & & & & & 262.91 & 54.66667 & 0 & 0 & 6.19 & & & & \\
\hline & & & & & 237.9 & 54.66667 & 0 & 12.1 & 59.8 & 27.33333 & 44 & 0 & 0 \\
\hline 50.43109 & 0 & 25.52681 & 0 & 28.11073 & 158.922 & 145.9887 & 166 & 315.906 & 228.59 & 27.33333 & 0 & 31.73754 & 0 \\
\hline 47.3 & 0 & 0 & 0 & 120 & 0 & 82.49931 & 10 & 215.9822 & 132 & 27.33333 & 0 & 50 & 0 \\
\hline \multirow[t]{12}{*}{0} & 0 & 0 & 21.65333 & 80 & 105.1 & 203.9832 & 105.1 & 203.9832 & 124.6667 & 0 & 25.8048 & 45 & \\
\hline & & 0 & 21.65333 & 15 & 126.5837 & 179.9852 & 115.2765 & 179.9852 & 110 & 0 & 146.512 & 17.2032 & \\
\hline & & & & 0 & 0 & 0 & 0 & 0 & 0 & 0 & 0 & 0 & \\
\hline & & & & & & & & & & & & & \\
\hline & & & & & & & & & & & & & \\
\hline & & & & & & & 202.742 & 288.812 & & & \multicolumn{3}{|c|}{ Area Remaining } \\
\hline & & & & & & & 172.524 & 250.044 & & & & & \\
\hline & & & & & & & 239.0036 & 325.0736 & 161.4345 & & & & \\
\hline & & & & & & & 223.056 & 349.248 & 253.248 & & & & \\
\hline & & & & & & 0 & 263.178 & 349.248 & 247.058 & & & & \\
\hline & & & & & 87.754 & 0 & 263.178 & 349.248 & 247.058 & & & & \\
\hline & & & & & 70.354 & 0 & 263.178 & 337.148 & 193.448 & 0 & 144.82 & 117.745 & 75.275 \\
\hline 92.5161 & 162.036 & 139.2092 & 166.8 & 181.9543 & 178.422 & 191.7073 & 87.29 & 18.766 & 8.536 & 0 & 156.636 & 58.45746 & 47.955 \\
\hline 74.2897 & 143.528 & 151.448 & 157.044 & 0 & 324 & 0 & 233.912 & 0 & 0 & 0 & 134.058 & 0 & 39.62 \\
\hline \multirow[t]{3}{*}{107.1781} & 94.4 & 105.708 & 117.0187 & 0 & 199.996 & 0 & 126.434 & 0 & 0 & 163.53 & 86.4552 & 0 & \\
\hline & & 68.168 & 117.0187 & 121.735 & 131.6403 & 0 & 85.0635 & 0 & 0 & 130.056 & 83.308 & 18.4168 & \\
\hline & & & & 98.26 & 223.584 & 156.64 & 88.542 & 114.48 & 73.992 & 54.156 & 32.544 & 25.18 & \\
\hline
\end{tabular}

Figure 3-12 - Example Arrangeable Area 2-D Model 
As each compartment is assigned to a SDB the arrangeable area and volume remaining in the SDB is reduced, as shown in Figure 3-12.

When a preferred SDB does not have enough arrangeable area or volume for a compartment, the compartment is then placed in an alternate subdivision block.

\subsection{VTVM Model}

The VTVM is an Excel spreadsheet that uses Visual Basic (VBA) macros which interact with the data populated into Excel worksheets to calculate an Overall Measure of Vulnerability (OMOV) for a given ship design. The OMOV is then used as a Measure of Performance in the effectiveness calculation within the C\&RE process. In the following sections a "sheet" refers to a worksheet name that exists within the VTVM. These sheets store all the data used for calculations within the VTVM. In the VTVM the following worksheets are used to store VTVM inputs and calculated data:

- Subdivision Blocks

- Compartments

- Systems

- VC's

- Threat Library

- VC Library

- Hit Distribution

- System Availability (Results)

- VC Availability (Results)

- $\quad$ RBD System Import (Working Sheet) 
A "VBA Module" refers to the executable code that performs calculations and sheet modifications in the VTVM. These VBA modules are run in the following order:

1. Import Geometry (from SSCS/PA)

2. Import Systems (from deactivation diagrams)

3. Check System Fidelity

4. Import Power Systems and Integrate with VC's (from deactivation diagrams)

5. Generate Hit Distribution

6. Apply Physical Damage

7. Perform System Vulnerability Analysis

\subsubsection{VTVM Ship Geometry and Preliminary Arrangements (Step 1)}

Following execution of the SSCS/PA Model module, each compartment is assigned to a $\mathrm{SDB}$, the data associated with the primary subdivision and compartment are then re-organized and populated into the VTVM Subdivision and Compartments sheets, Figure 3-13 and Figure 3-14, using the Visual Basic Module "Geometry Import". Primary Subdivision Block inputs are described in Table 3-3, Compartment inputs are described in Table 3-4.

Table 3-3 - VTVM Primary Subdivision Block Inputs

\begin{tabular}{|c|c|}
\hline Primary Subdivision Block Inputs & Definition/Purpose \\
\hline Primary Subdivision Block Names & Prescribed Unique Primary Subdivision Block Name \\
\hline Subdivision ID & Formula that determines a unique ID Number for Each Primary Subdivision Block \\
\hline Primary Subdivision Block Number & Primary Subdivision Block Number for which the compartment is assigned \\
\hline Xmin & Minimum Longitudinal Coordinate Value \\
\hline Xmax & Maximum Longitudinal Coordinate Value \\
\hline$Y \min$ & Maximum Transverse Coordinate Value \\
\hline Ymax & Minimum Vertical Coordinate Value \\
\hline Zmin & Maximum Vertical Coordinate Value \\
\hline Zmax & Deck Area Available in the Subdivision \\
\hline Deck Area & Volume Available in the Subdivision \\
\hline Volume & The longitudinal region in which the subdivision block resides \\
\hline Zone & Mardinate Value \\
\hline
\end{tabular}




\begin{tabular}{|c|c|c|c|c|c|c|c|c|c|}
\hline \multicolumn{10}{|c|}{ Primary Subdivision summary } \\
\hline \multicolumn{4}{|c|}{ Subdivision Description } & \multicolumn{6}{|c|}{ Subdivision Geometry } \\
\hline Primary Subdivision Block Name & $\begin{array}{l}\text { Subdivision } \\
\text { ID }\end{array}$ & Zone & $\begin{array}{c}\text { Primary } \\
\text { Subdivision Block } \\
\text { Number } \\
\end{array}$ & $\begin{array}{l}\text { Xmin } \\
(\mathrm{m})\end{array}$ & $\begin{array}{l}\text { Ymin } \\
(\mathrm{m})\end{array}$ & $\begin{array}{l}\mathrm{Zmin} \\
(\mathrm{m})\end{array}$ & $\begin{array}{l}\mathrm{Xmax} \\
(\mathrm{m})\end{array}$ & $\begin{array}{l}\text { Ymax } \\
(\mathrm{m})\end{array}$ & $\begin{array}{l}\mathrm{Zmax} \\
(\mathrm{m})\end{array}$ \\
\hline 1_5_SDB & 0 & 1 & 1 & -10.000 & -2.000 & 13.000 & 2.000 & 2.000 & 16.000 \\
\hline 1_5_S_SDB & 0 & 2 & 2 & -10.000 & 0.000 & 13.000 & 2.000 & 2.000 & 16.000 \\
\hline 1_5_P_SDB & 0 & 3 & 3 & -10.000 & -2.000 & 13.000 & 2.000 & 0.000 & 16.000 \\
\hline $2{ }^{2}{ }^{2} \mathrm{SDB}$ & 0 & 4 & 4 & 2.000 & -1.000 & 2.000 & 8.000 & 1.000 & 6.000 \\
\hline $2{ }^{2}{ }^{2} \mathrm{~S}-\mathrm{SDB}$ & 0 & 5 & 5 & 2.000 & 0.000 & 2.000 & 8.000 & 1.000 & 6.000 \\
\hline 2_2_P_SDB & 0 & 6 & 6 & 2.000 & -1.000 & 2.000 & 8.000 & 0.000 & 6.000 \\
\hline $2 \_3 \_S D B$ & 0 & 7 & 7 & 2.000 & -2.000 & 6.000 & 8.000 & 2.000 & 9.000 \\
\hline 2_3_S_SDB & 0 & 8 & 8 & 2.000 & 0.000 & 6.000 & 8.000 & 2.000 & 9.000 \\
\hline 2_3_P_SDB & 0 & 9 & 9 & 2.000 & -2.000 & 6.000 & 8.000 & 0.000 & 9.000 \\
\hline 2_4_SDB & 0 & 10 & 10 & 2.000 & -3.000 & 9.000 & 8.000 & 3.000 & 13.000 \\
\hline 2_4_S_SDB & 0 & 11 & 11 & 2.000 & 0.000 & 9.000 & 8.000 & 3.000 & 13.000 \\
\hline 2_4_P_SDB & 0 & 12 & 12 & 2.000 & -3.000 & 9.000 & 8.000 & 0.000 & 13.000 \\
\hline $2 \_5 \_S D B$ & 0 & 13 & 13 & 2.000 & -4.000 & 13.000 & 8.000 & 4.000 & 16.000 \\
\hline 2_5_S_SDB & 0 & 14 & 14 & 2.000 & 0.000 & 13.000 & 8.000 & 4.000 & 16.000 \\
\hline 2_5_P_SDB & 0 & 15 & 15 & 2.000 & -4.000 & 13.000 & 8.000 & 0.000 & 16.000 \\
\hline 3_1_SDB & 0 & 16 & 16 & 8.000 & -1.000 & 0.000 & 16.000 & 1.000 & 2.000 \\
\hline 3_1_S_SDB & 0 & 17 & 17 & 8.000 & 0.000 & 0.000 & 16.000 & 1.000 & 2.000 \\
\hline 3_1_P_SDB & 0 & 18 & 18 & 8.000 & -1.000 & 0.000 & 16.000 & 0.000 & 2.000 \\
\hline 3_2_SDB & 0 & 19 & 19 & 8.000 & -2.000 & 2.000 & 16.000 & 2.000 & 6.000 \\
\hline 3_2 ${ }^{2}{ }^{5}{ }^{2}$ SDB & 0 & 20 & 20 & 8.000 & 0.000 & 2.000 & 16.000 & 2.000 & 6.000 \\
\hline 3_2 ${ }^{2}$ P_SDB & 0 & 21 & 21 & 8.000 & -2.000 & 2.000 & 16.000 & 0.000 & 6.000 \\
\hline 3_3_SDB & 0 & 22 & 22 & 8.000 & -3.000 & 6.000 & 16.000 & 3.000 & 9.000 \\
\hline 3_3_S_SDB & 0 & 23 & 23 & 8.000 & 0.000 & 6.000 & 16.000 & 3.000 & 9.000 \\
\hline 3_3_P_SDB & 0 & 24 & 24 & 8.000 & -3.000 & 6.000 & 16.000 & 0.000 & 9.000 \\
\hline 3_4_SDB & 0 & 25 & 25 & 8.000 & -4.000 & 9.000 & 16.000 & 4.000 & 13.000 \\
\hline
\end{tabular}

Figure 3-13 - VTVM Primary Subdivision Input Sheet

Table 3-4 - VTVM Compartment Input Categories

\begin{tabular}{|c|c|}
\hline Compartment Inputs & Definition/Purpose \\
\hline Compartment Name & Prescribed Unique Compartment Name \\
\hline Compartment ID & $\begin{array}{c}\text { Formula that determines a unique ID Number for Each } \\
\text { Compartment }\end{array}$ \\
\hline Compartment Number & Prescribed Unique Compartment Number \\
\hline Primary Subdivision Block Number & $\begin{array}{c}\text { Primary Subdivision Block Number for which the } \\
\text { compartment is assigned }\end{array}$ \\
\hline Xmin & Minimum Longitudinal Coordinate Value \\
\hline Xmax & Maximum Longitudinal Coordinate Value \\
\hline Ymin & Minimum Transverse Coordinate Value \\
\hline Ymax & Maximum Transverse Coordinate Value \\
\hline Zmin & Minimum Vertical Coordinate Value \\
\hline Zmax & Maximum Vertical Coordinate Value \\
\hline Deck Area & Deck Area Required by the Compartment \\
\hline Volume & Volume Required by the Compartment \\
\hline Zone & The longitudinal region in which the compartment resides \\
\hline
\end{tabular}




\begin{tabular}{|c|c|c|c|c|c|c|c|c|c|c|}
\hline \multicolumn{11}{|l|}{ Compartment Input } \\
\hline \multicolumn{5}{|c|}{ Compartment Identification } & \multicolumn{6}{|c|}{ Compartment Geometry } \\
\hline Compartment Name & Compartment ID & Zone & Compartment Number & $\begin{array}{c}\text { Primary } \\
\text { Subdivision } \\
\text { Block Name }\end{array}$ & $\begin{array}{c}\mathrm{Xmin} \\
(\mathrm{m})\end{array}$ & $\underset{(\mathrm{m})}{\mathrm{Ymin}}$ & $\begin{array}{l}\mathrm{Zmin} \\
(\mathrm{m})\end{array}$ & $\underset{(\mathrm{m})}{\mathrm{Xmax}}$ & $\underset{(\mathrm{m})}{\mathrm{Ymax}}$ & $\underset{(\mathrm{m})}{\mathrm{Zmax}}$ \\
\hline CIC & 0 & 2 & 1 & $6 \_4$ SDB & 0.000 & 0.000 & 0.000 & 0.000 & 0.000 & 0.000 \\
\hline Pilot_House & 0 & 2 & 2 & 6 9_SDB & 0.000 & 0.000 & 0.000 & 0.000 & 0.000 & 0.000 \\
\hline Bridgewing & 0 & 2 & 3 & 6 -9_SDB & 0.000 & 0.000 & 0.000 & 0.000 & 0.000 & 0.000 \\
\hline WC_Bridge & 0 & 2 & 4 & 6 - 9 SDB & 0.000 & 0.000 & 0.000 & 0.000 & 0.000 & 0.000 \\
\hline Chart_Rm & 0 & 2 & 5 & 6 - 9 SDB & 0.000 & 0.000 & 0.000 & 0.000 & 0.000 & 0.000 \\
\hline Steering_Gear_Rm & 0 & 4 & 6 & $14 \_4$ SDB & 0.000 & 0.000 & 0.000 & 0.000 & 0.000 & 0.000 \\
\hline Radar_Array_Rm_1 & 0 & 2 & 7 & $6 \_8$ SDB & 0.000 & 0.000 & 0.000 & 0.000 & 0.000 & 0.000 \\
\hline Radar_Array_Rm_2 & 0 & 2 & 8 & $6{ }^{8}{ }_{-} \mathrm{SDB}$ & 0.000 & 0.000 & 0.000 & 0.000 & 0.000 & 0.000 \\
\hline Radar_Equip_Rm_1 & 0 & 2 & 9 & $6{ }^{8}$ _SDB & 0.000 & 0.000 & 0.000 & 0.000 & 0.000 & 0.000 \\
\hline Radar_Array_Rm_3 & 0 & 3 & 10 & $10 \_9 \_$SDB & 0.000 & 0.000 & 0.000 & 0.000 & 0.000 & 0.000 \\
\hline Radar_Array_Rm_4 & 0 & 3 & 11 & 10_9_SDB & 0.000 & 0.000 & 0.000 & 0.000 & 0.000 & 0.000 \\
\hline Radar_Equip_Rm_2 & 0 & 3 & 12 & 10_9_SDB & 0.000 & 0.000 & 0.000 & 0.000 & 0.000 & 0.000 \\
\hline Comm_Center & 0 & 2 & 13 & $6{ }^{4}-\mathrm{SDB}$ & 0.000 & 0.000 & 0.000 & 0.000 & 0.000 & 0.000 \\
\hline CSER_1 & 0 & 2 & 14 & $6{ }^{4} \_$SDB & 0.000 & 0.000 & 0.000 & 0.000 & 0.000 & 0.000 \\
\hline CSER_2 & 0 & 3 & 15 & $10{ }^{4}-\mathrm{SDB}$ & 0.000 & 0.000 & 0.000 & 0.000 & 0.000 & 0.000 \\
\hline Radar_Cooling_Equip_Rm_1 & 0 & 2 & 16 & $6 \_6 \_\mathrm{SDB}$ & 0.000 & 0.000 & 0.000 & 0.000 & 0.000 & 0.000 \\
\hline Radar_Cooling_Equip_Rm_2 & 0 & 3 & 17 & $9 \_6$ SDB & 0.000 & 0.000 & 0.000 & 0.000 & 0.000 & 0.000 \\
\hline Radar_Director_Equip_Rm_1 & 0 & 2 & 18 & $6 \_9 \_\mathrm{SDB}$ & 0.000 & 0.000 & 0.000 & 0.000 & 0.000 & 0.000 \\
\hline Radar_Director_Equip_Rm_2 & 0 & 3 & 19 & $10{ }_{-}{ }_{3}$ SDB & 0.000 & 0.000 & 0.000 & 0.000 & 0.000 & 0.000 \\
\hline VLS_1_Upper & 0 & 1 & 20 & 5_5_SDB & 0.000 & 0.000 & 0.000 & 0.000 & 0.000 & 0.000 \\
\hline VLS_1_Mid & 0 & 1 & 21 & 5_4_SDB & 0.000 & 0.000 & 0.000 & 0.000 & 0.000 & 0.000 \\
\hline VLS_1_Lower & 0 & 1 & 22 & 5 & 0.000 & 0.000 & 0.000 & 0.000 & 0.000 & 0.000 \\
\hline VLS_2_Upper & 0 & 4 & 23 & $111_{4} \_\mathrm{SDB}$ & 0.000 & 0.000 & 0.000 & 0.000 & 0.000 & 0.000 \\
\hline VLS_2_Mid & 0 & 4 & 24 & $11{ }^{3}{ }^{2} \mathrm{SDB}$ & 0.000 & 0.000 & 0.000 & 0.000 & 0.000 & 0.000 \\
\hline VLS_2_Lower & 0 & 4 & 25 & $11 \_2 \_$SDB & 0.000 & 0.000 & 0.000 & 0.000 & 0.000 & 0.000 \\
\hline Gun_Ready_Service_Rm & 0 & 1 & 26 & $4 \_5 \_S D B$ & 0.000 & 0.000 & 0.000 & 0.000 & 0.000 & 0.000 \\
\hline Magazine_Gun & 0 & 1 & 27 & $4{ }^{2} \_\mathrm{SDB}$ & 0.000 & 0.000 & 0.000 & 0.000 & 0.000 & 0.000 \\
\hline Magazine_Gun_Proj_Cart & 0 & 1 & 28 & $4{ }^{2}-\mathrm{SDB}$ & 0.000 & 0.000 & 0.000 & 0.000 & 0.000 & 0.000 \\
\hline CIWS_Control_Rm_1 & 0 & 1 & 29 & 5_5_SDB & 0.000 & 0.000 & 0.000 & 0.000 & 0.000 & 0.000 \\
\hline CIWS_Control_Rm_2 & 0 & 3 & 30 & 9_7_SDB & 0.000 & 0.000 & 0.000 & 0.000 & 0.000 & 0.000 \\
\hline Magazine_CIWS_1 & 0 & 1 & 31 & 5_5_SDB & 0.000 & 0.000 & 0.000 & 0.000 & 0.000 & 0.000 \\
\hline Magazine_CIWS_2 & 0 & 3 & 32 & 9_8_SDB & 0.000 & 0.000 & 0.000 & 0.000 & 0.000 & 0.000 \\
\hline
\end{tabular}

Figure 3-14 - VTVM Compartment Input Sheet

Once all SDBs and compartments with their $\mathrm{x}, \mathrm{y}, \mathrm{z}$ boundaries have been populated into the VTVM, the VTVM places VCs into their assigned compartments and SDB's which defines the VC location necessary for vulnerability analysis.

\subsubsection{VTVM Ship Systems and Vital Components (Step 2)}

Figure 3-15 shows the ship level RBD, which defines the capability logical structure used in the VTVM. Ship Systems and Vital Components are determined to be present in a VTVM model by their specified DV options and related Reliability Block Diagram RBD. This total ship capability RBD represents each of the Warfighting, Mobility, and Damage Control capabilities necessary for a design to complete its mission. 


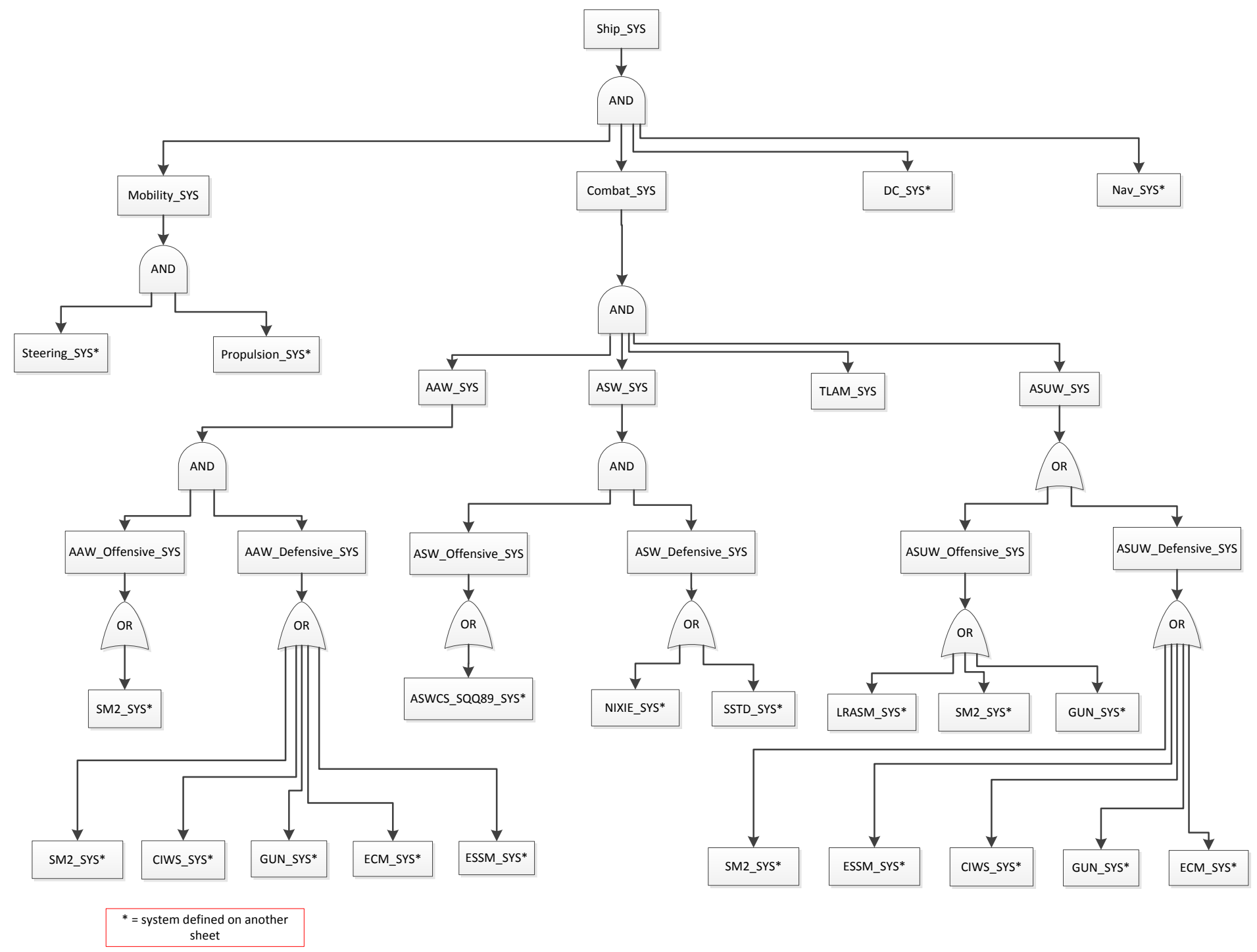

Figure 3-15 - Total Ship Capability RBD

To evaluate the availability of these capabilities, RBD's are generated for each system option within the design space: Propulsion systems, Power Generation and Distribution Systems, Combat Systems and Damage Control Systems, and are used in the VTVM to determine the designs Overall Measure of Vulnerability. It is important to decouple power generation architecture and its arrangement in the ship from other systems and their arrangement, so power systems are handled separately and finally the two are "hooked up", providing electric power to all VCs requiring power. This is described in Section 3.3.4. RBDs are initially generated using 
ITEM Toolkit or Visio software and serve as deactivation diagrams for system logic. ITEM has the advantage of being able to export a text based RBD file that can be imported into the VTVM. In the case study discussed in Chapter 4, system option architectures for: Propulsion, Anti-Air Warfare, Anti-Surface Warfare, Anti-Submarine Warfare, Power Generation and distribution system within the design space are generated following the form outlined in Figure 3-16.

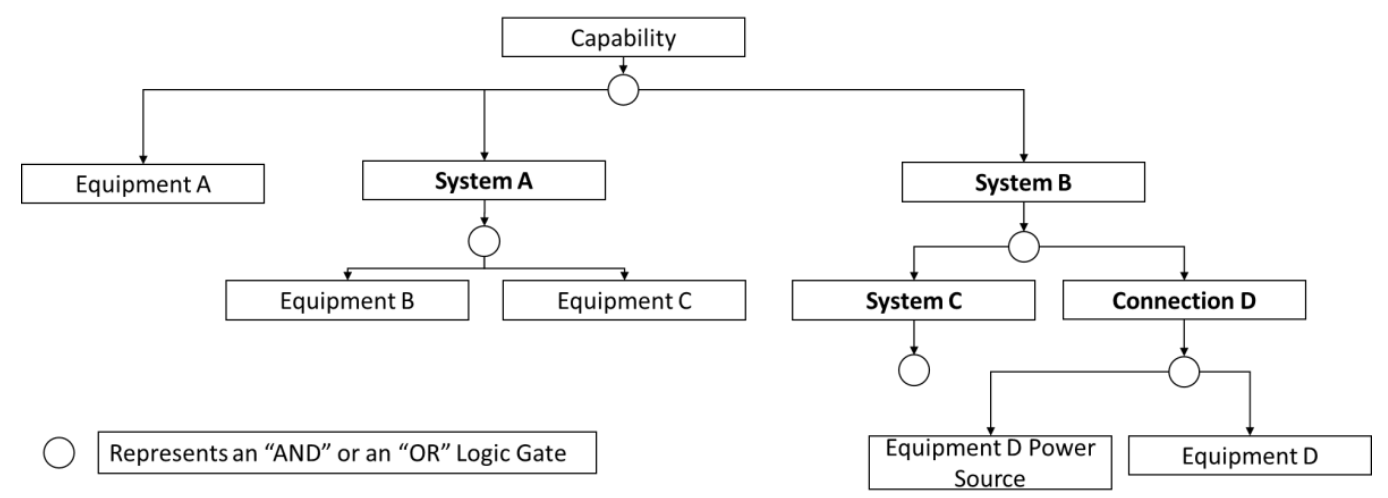

Figure 3-16 - Example RBD Hierarchy

RBD's are generated for each ship capability. Specific rules must be used during the RBD generation. The system hierarchy must start with ship capabilities which use VCs and systems as dependents to represent their capability required functionality as seen in Figure 3-16. A "System" in the VTVM refers to any combination of VCs, Connections, and sub-systems required to accurately describe the systems capability. An example of a system hierarchy is shown in Figure $3-17$.

Secondly, systems in the VTVM can be designed in two ways: 1) A standard system, as noted by the system name having the designation "_SYS" attached to the end of the name; and "connections" as noted by the connection system having the designation "_CONN" attached to the name. Connections (_CONN) are only used within the power distribution system while standard systems are used across all RBDs. A “_SYS” system represents a standard system combining any number of VC's, connections and subsystems as shown in Figure 3-17. 


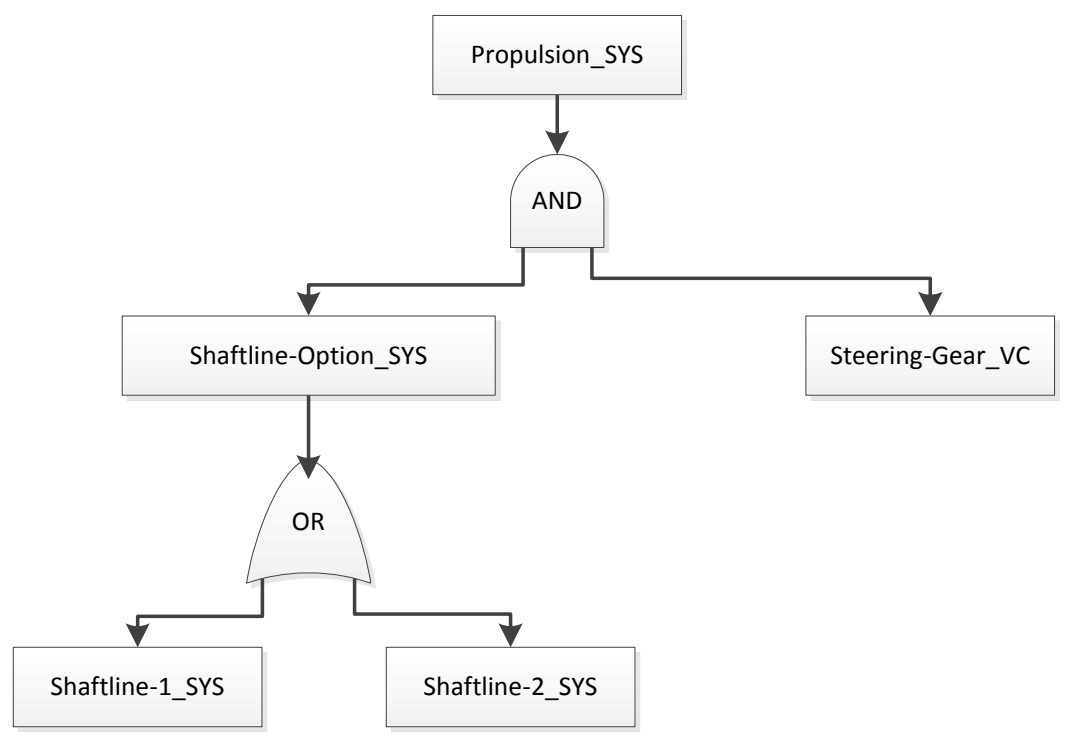

Figure 3-17 - Standard System Hierarchy

A connection system (_CONN), Figure 3-18, is only used within the power distribution system and connects one or more VCs or Systems to available power sources. Systems and connections require logic gates (AND/OR) designations, as described below, to identify dependents in the system.

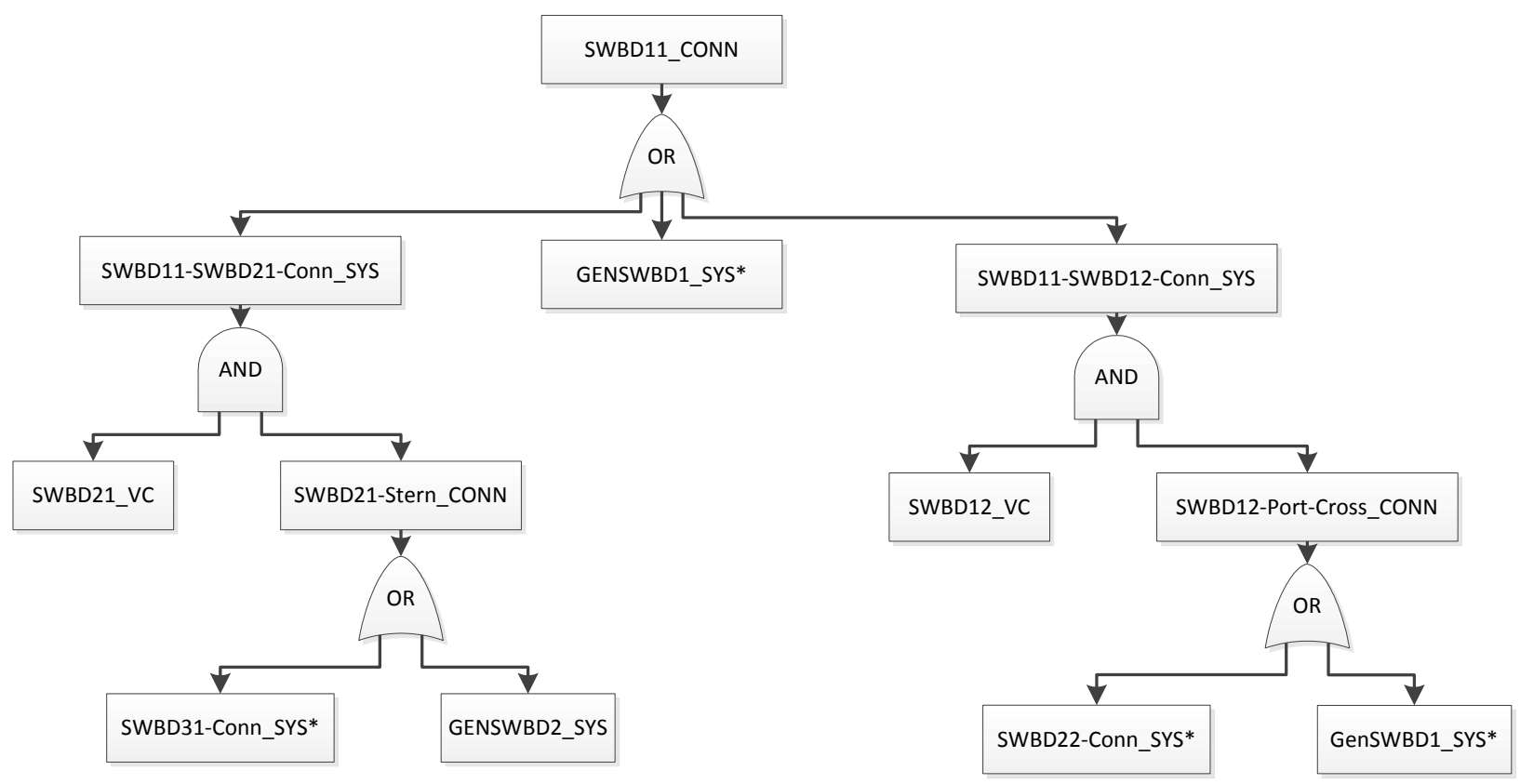

Figure 3-18 - Connection System (_CONN) Hierarchy 
Every entity used in the model, a VC, System, or Connection, must be identified by their endings "_VC", “_SYS”, or “_CONN" respectively. These notations are required by the VTVM to identify which type of data is being processed.

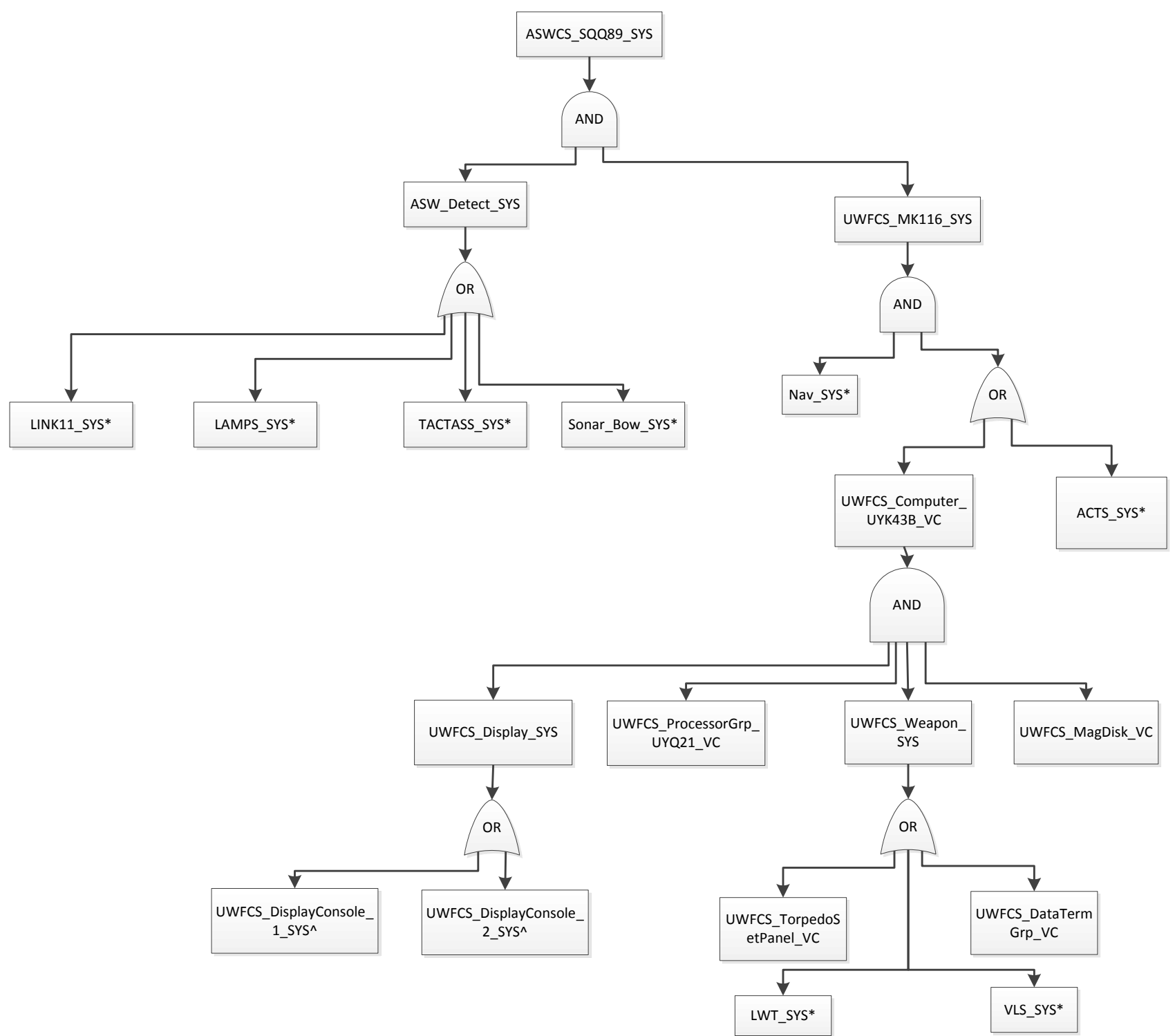

Figure 3-19 - Full Example System Logic Build Methodology Required for the VTVM

Finally, the RBD must ensure that only systems and connections have dependents. This means that to add an additional level of system description, a system or connection block complete with gate logic designation must be used, as seen in Figure 3-19. In Figure 3-19, a full SQQ89 system RBD is shown, visualizing a typical RBD structure. The SQQ89 capability is dependent on both 
the ASW Detection system and Underwater Fire Control System (UWFCS-MK116) through an "AND" gate. Each of these two "_SYS" systems now has multiple system, and VC dependents. Tracking through the UWFCS system down to the next level, the Navigation system and one of either the UWFCS Computer VC or the Aegis Combat Trainer system are required for UWFCS functionality. In all cases as you move down the RBD, “_SYS” and "_VC" elements must alternate with logic elements and vice versa. RBDs in other models and the literature survey do not always adhere to this format, but it is essential in the VTVM because it enables a line by line text coding of the RBDs as used in our "systems" worksheet. Once the RBD is generated and checked a text file is exported into excel format and saved, Figure 3-20.

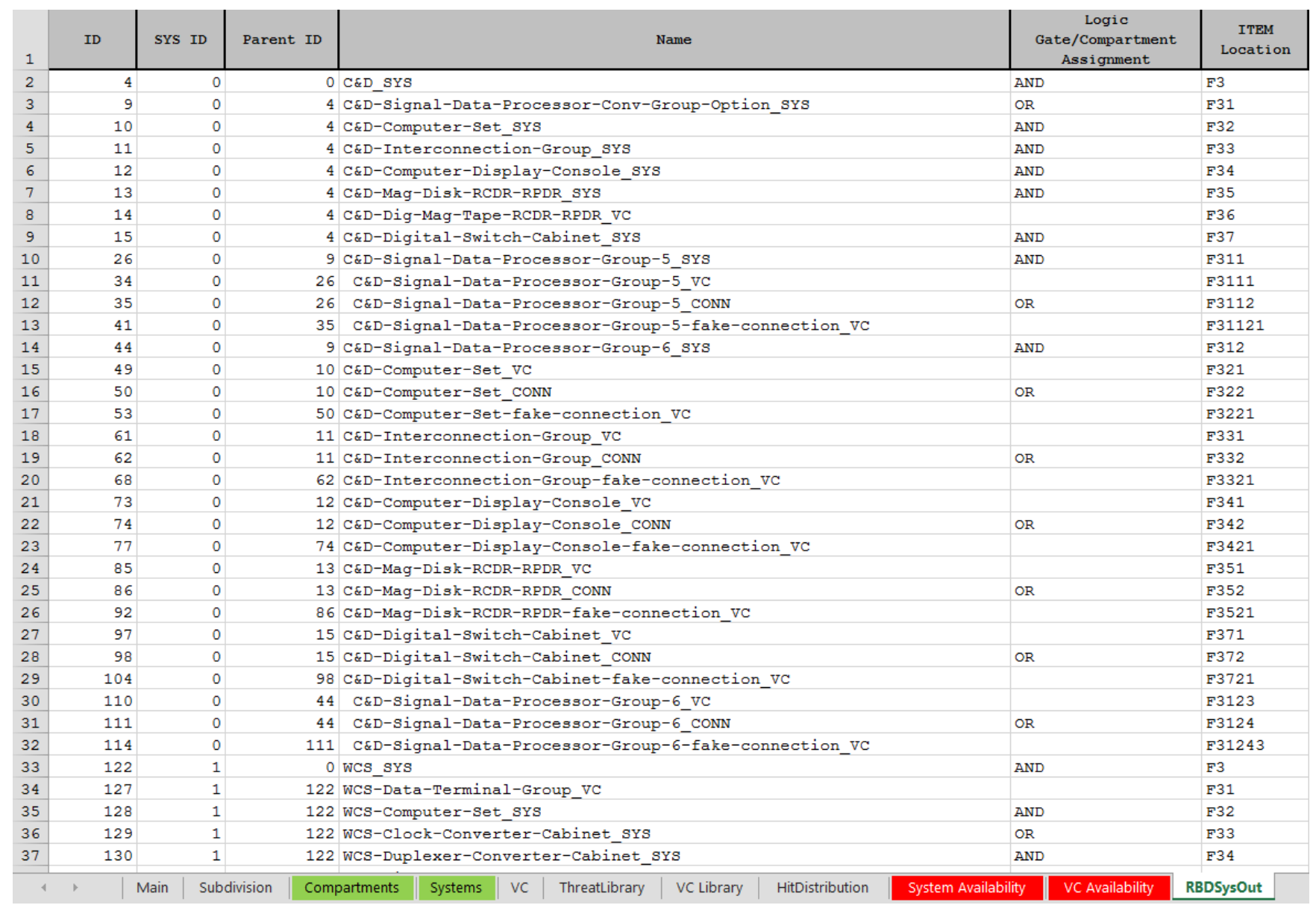

\section{Figure 3-20 - Example RBD Export File}


This data is read by the VTVM and stored on multiple sheets to build a library of VC's, systems, and their connectivity within the VTVM as a multi-line system logic description and VC table. Vital Components are populated into the VTVM on the "VC" sheet, Figure 3-21.

\begin{tabular}{|c|c|c|c|c|}
\hline \multicolumn{5}{|c|}{ VC Identification } \\
\hline vc Name & VCID & Subdivision & Compartment & Vc Number \\
\hline SWBD11_VC & 0 & 2_5_S_SDB & 2_5_S_SDB & 1 \\
\hline SWBD12 VC & 0 & 25 P SDB & 25 P SDB & 2 \\
\hline SWBD21_VC & 0 & 6 5_S_SDB & 6 5_S_SDB & 3 \\
\hline SWBD22_VC & 0 & 6_5_P_SDB & 6_5_P_SDB & 4 \\
\hline SWBD31_VC & 0 & 9_5_S_SDB & 9_5_S_SDB & 5 \\
\hline SWBD32_vC & 0 & 9_5_P_SDB & 9_5_P_SDB & 6 \\
\hline SWBD41_vC & 0 & 12_5_S_SDB & 12 5_S_SDB & 7 \\
\hline SWBD42_VC & 0 & 12_5_P_SDB & 12 5_P_SDB & 8 \\
\hline SWBD11_vC & 0 & 2_5_S_SDB & 2_5_S_SDB & 9 \\
\hline PCM13_VC & 0 & 2_5_S_SDB & Load_Center_Rm_1 & 10 \\
\hline LC11_VC & 0 & 2_5_S_SDB & Load_Center_Rm_1 & 11 \\
\hline GENSWBD2_VC & 0 & 6_6_P_SDB & Load_Center_Rm_4 & 12 \\
\hline GENSWBD3_VC & 0 & 7_5_S_SDB & Load_Center_Rm_5 & 13 \\
\hline LC12_VC & 0 & 2_5_P_SDB & Load_Center_Rm_2 & 14 \\
\hline PCM12_VC & 0 & 2_5_P_SDB & Load_Center_Rm_2 & 15 \\
\hline PCM11_VC & 0 & 2_5_S_SDB & Load_Center_Rm_1 & 16 \\
\hline PMM1_VC & 0 & 7_5_S_SDB & Load_Center_Rm_5 & 17 \\
\hline PCM1_VC & 0 & 7_5_S_SDB & Load_Center_Rm_5 & 18 \\
\hline PMM12_VC & 0 & 12_5_P_SDB & Load_Center_Rm_ 8 & 19 \\
\hline $\mathrm{PCM} 12$ VC & 0 & 12_5_P_SDB & Load_Center_Rm_ 8 & 20 \\
\hline LC14_VC & 0 & 2_5_P_SDB & Load_Center_Rm_2 & 21 \\
\hline PCM14_VC & 0 & 2_5_P_SDB & Load_Center_Rm_2 & 22 \\
\hline PGM1_VC & 0 & $6{ }^{2}-\mathrm{SDB}$ & MMR_1_Lower & 23 \\
\hline PGM2_VC & 0 & 8_2_SDB & MMR_2_Lower & 24 \\
\hline GENSWBD1_VC & 0 & 2_5_S_SDB & Load_Center_Rm_1 & 25 \\
\hline SSG1_VC & 0 & 2_3_SDB & AMR_1_Lower & 26 \\
\hline GENSWBD4_VC & 0 & 12_5_P_SDB & Load_Center_Rm_ 8 & 27 \\
\hline SSG2_VC & 0 & $10 \_3$ SDB & AMR_3_Lower & 28 \\
\hline LC21_VC & 0 & $6 \_6 \_S \_S D B$ & Load_Center_Rm_3 & 29 \\
\hline PCM22_VC & 0 & 6_6_P_SDB & Load_Center_Rm_4 & 30 \\
\hline PCM21_VC & 0 & 6_6_S_SDB & Load_Center_Rm_3 & 31 \\
\hline PCM2 4_VC & 0 & 6_6_P_SDB & Load_Center_Rm_4 & 32 \\
\hline
\end{tabular}

\section{Figure 3-21 - VTVM "VC" Sheet}

All VCs used within all system RBDs generated for use with the VTVM are described in the "VC Library" sheet, Figure 3-22, where they are assigned a compartment, Mass, Footprint (Area) and Lethality. This worksheet functions as a "database" for VCs imported into the VTVM and is used to assign VC's to Compartments, Subdivision Blocks, and Zones. 


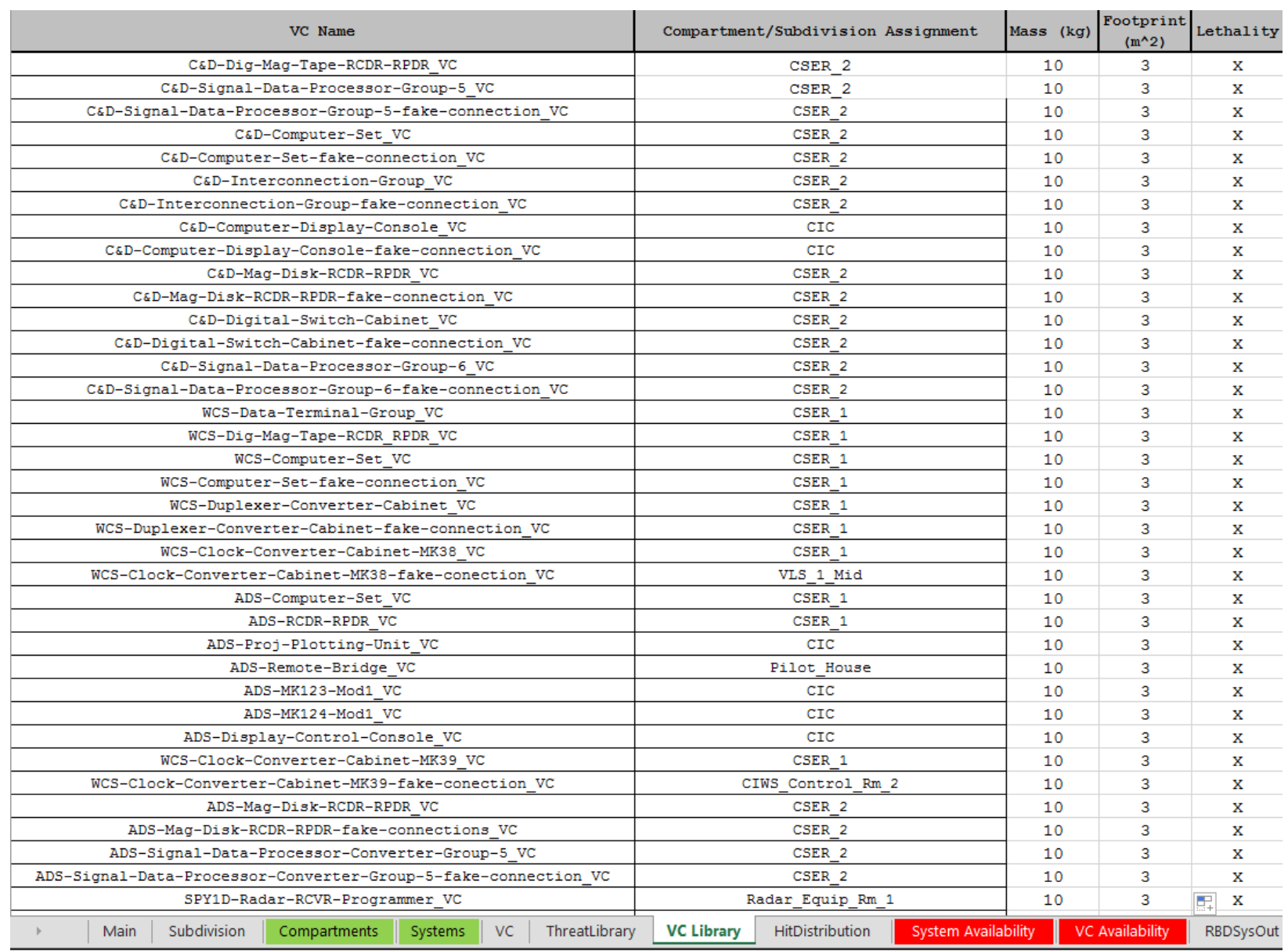

Figure 3-22 - VTVM "VC Library" Worksheet

\begin{tabular}{|c|c|c|c|c|c|c|c|c|}
\hline \multicolumn{9}{|l|}{ Systems } \\
\hline \multicolumn{7}{|c|}{ System Description } & \multirow{2}{*}{$\begin{array}{c}\text { Logic Dependency } \\
\text { Dependency } \\
\# 1\end{array}$} & \multirow[b]{2}{*}{$\begin{array}{c}\text { Dependency } \\
\# 2\end{array}$} \\
\hline System Name & $\begin{array}{l}\text { System } \\
\text { ID }\end{array}$ & $\begin{array}{c}\text { Unique } \\
\text { Identifi } \\
\text { er }\end{array}$ & $\begin{array}{c}\text { Sys } \\
\text { Number }\end{array}$ & $\begin{array}{l}\text { Gate } \\
\text { Type }\end{array}$ & $\begin{array}{c}\# \text { of } \\
\text { SubSystems }\end{array}$ & $\begin{array}{c}\# \text { of } \\
\text { Elements }\end{array}$ & & \\
\hline SWBD11_SYS & $1 \_0$ & 0 & 1 & AND & 1 & 1 & SWBD11_VC & GENSWBD1_SYS \\
\hline GENSWBD1_SYS & $2{ }^{2} 0$ & 0 & 2 & AND & 0 & 2 & GENSWBD1_VC & SSG1_VC \\
\hline SWBD12_SYS & 3_0 & 0 & 3 & AND & 1 & 1 & SWBD12_VC & GENSWBD1_SYS \\
\hline SWBD21_SYS & $4 \_0$ & 0 & 4 & AND & 1 & 1 & SWBD21_VC & SWBD21-Source-Option_SYS \\
\hline SWBD22 SYS & $5 \_0$ & 0 & 5 & AND & 1 & 1 & SWBD22 VC & PBUS SYS \\
\hline SWBD31_SYS & $6 \_0$ & 0 & 6 & AND & 1 & 1 & SWBD31_VC & GENSWBD3_SYS \\
\hline GENSWBD3_SYS & 7_0 & 0 & 7 & AND & 1 & 1 & GENSWBD 3 _VC & GENDSWBD3-Power-Option_SYS \\
\hline SWBD32_SYS & $8 \_0$ & 0 & 8 & AND & 1 & 1 & SWBD32_VC & GENSWBD3_SYS \\
\hline SWBD 41_SYS & $9+0$ & 0 & 9 & AND & 1 & 1 & SWBD41_VC & GENSWBD4_SYS \\
\hline GENSWBD4_SYS & $10 \_0$ & 0 & 10 & AND & 0 & 2 & GENSWBD 4 _VC & SSG2_VC \\
\hline SWBD42 SYS & 110 & 0 & 11 & AND & 1 & 1 & SWBD 42 V $C$ & GENSWBD4 SYS \\
\hline PBUS SYS & $12 \_0$ & 0 & 12 & $\mathrm{OR}$ & 4 & 0 & GENSWBD2 SYS & GENSWBD 3 SYS \\
\hline GENSWBD2 SYS & $13 \_0$ & 0 & 13 & AND & 1 & 1 & GENSWBD2 $\mathrm{VC}$ & GENSWBD2-Power-Option SYS \\
\hline LC11-CONN_SYS & $14 \_0$ & 0 & 14 & $\mathrm{OR}$ & 1 & 1 & SWBD11-Conn_SYS & PCM13_VC \\
\hline SWBD11-Conn_SYS & $15 \_0$ & 0 & 15 & AND & 1 & 1 & SWBD11_VC & SWBD11-Port-Cross_CONN \\
\hline SWBD11_CONN & 16 & 0 & 16 & $\mathrm{OR}$ & 3 & 0 & SWBD11-SWBD21-Conn_SYS & SWBD11-SWBD12-Conn_SYS \\
\hline SWBD11-SWBD21-Conn_SYS & $17 \_0$ & 0 & 17 & AND & 1 & 1 & SWBD21_VC & SWBD21-Stern_CONN \\
\hline SWBD11-SWBD12-Conn_SYS & $18 \_0$ & 0 & 18 & AND & 1 & 1 & SWBD12_VC & SWBD12-Port_Cross_CONN \\
\hline SWBD21-Stern_CONN & $19{ }^{2} 0$ & 0 & 19 & OR & 2 & 0 & GENSWBD2_SYS & SWBD31-Stern-Conn_SYS \\
\hline SWBD31-Stern-Conn_SYS & $20 \_0$ & 0 & 20 & AND & 1 & 1 & SWBD31_VC & SWBD31-Stern_CONN \\
\hline SWBD31-Stern_CONN & $21 \_0$ & 0 & 21 & OR & 2 & 0 & PBUS SYS & SWBD41-Stern-Conn_SYS \\
\hline SWBD41-Stern-Conn_SYS & $22 \_0$ & 0 & 22 & AND & 1 & 1 & SWBD41_VC & SWBD41-Port-Cross-END_CONN \\
\hline SWBD41-Port-Cross-END_CONN & $23 \_0$ & 0 & 23 & OR & 2 & 0 & GENSWBD4_SYS & SWBD41-Port-Option_CONN \\
\hline LC11_SYS & $24 \_1$ & 1 & 24 & OR & 2 & 0 & LC11-LOCAL_SYS & LC11-CONN_SYS \\
\hline LC11-LOCAL_SYS & $25 \_0$ & 0 & 25 & AND & 1 & 2 & PCM13_VC & SWBD11_SYS \\
\hline
\end{tabular}


Table 3-5 - VTVM Systems Input Data Categories

\begin{tabular}{|c|c|}
\hline System Inputs & Definition/Purpose \\
\hline System Name & Prescribed Unique Primary Subdivision Block Name \\
\hline System ID & $\begin{array}{l}\text { Formula that determines a unique ID Number for Each } \\
\text { Primary Subdivision Block }\end{array}$ \\
\hline System Number & $\begin{array}{l}\text { Primary Subdivision Block Number for which the } \\
\text { compartment is assigned }\end{array}$ \\
\hline Gate Type & $\begin{array}{l}\text { Logic Identifier that determines the type of assigned } \\
\text { Dependencies (Designated by "AND" or "OR") }\end{array}$ \\
\hline \# of Required Subsystems & $\begin{array}{l}\text { Value used during analysis phase that represents the } \\
\text { number of Systems that exist within a system }\end{array}$ \\
\hline \# of Required Elements & $\begin{array}{c}\text { Value used during analysis phase that represents the } \\
\text { number of VCs that exist within a system }\end{array}$ \\
\hline Dependency \# XX & Any System or VC required by a System \\
\hline Unique Identifier & $\begin{array}{l}\text { Any Value or String necessary to further classify the } \\
\text { compartment }\end{array}$ \\
\hline
\end{tabular}

Figure 3-23 is the VTVM "Systems" Worksheet. Each system has 8 columns of data, shown in Table 3-5. Of the 8 columns, the three most important to the RBD are the system gate logic, and the subsystem and elemental system dependencies that are used to determine system availability. Gate logic is defined using "AND” or "OR” logic gates. An "AND” gate represents a system for which all dependencies of those listed are required to be available for system availability. An "OR" gate represents a system for which only 1 dependency of those listed is required to be available for system availability.

The system and VC data in the RBD's is imported into the VTVM using the Systems Import VBA Module. This module reads in a set of Item generated export files based on the systems selected in the design. During import, the VBA module first looks for systems, iterating though each top level system, with their own unique System ID number, designated by the RBD software. Within ITEM and Visio each new sheet represents other separate elements referring to a particular parent ID belonging to the same ship system and is assigned a specific System ID number. Each top level system is assigned a Parent ID Number and its own unique ID. Once the Systems Import VBA Module has isolated a specific system, it iterates through any VC or system 
with the same current System ID, and matches Systems and VC's with their Parent ID to link systems and their dependents. When a system and all of its dependents are located within the text export file, the information is then populated onto the "Systems" sheet, Figure 3-23, within the VTVM. Each individual system is built from the top down, any sub-system used across multiple systems is logically connected within the VTVM, and therefore there is no need to re-build systems.

\subsubsection{System Fidelity Check (Step 3)}

Following the import of all systems and VC's, a System Fidelity Check VBA Module is run to ensure there is no circular logic present in the model. This check iterates through each system to check that no system is a dependent on itself, and the each systems root element is a VC. This process ensures that there are no infinite loops present in the models system logic.

\subsubsection{Power Distribution System (Step 4)}

Zonal distribution system architectures use multiple elements within each ship zone as sources to distribute power to VCs in that zone. These source VCs, in our model, are load centers, each of which are assigned to a load center room. Each load center receives power through its connection to an available power source such as a ship service generator (SSG) or Power Generation Module (PGM) in its own zone and through its zonal bus switchboards that receive power from other zones.

Figure 3-24 shows an example one-line diagram for an IPS power distribution system used to build power RBDs. This is a zonal ring bus system where the only connectivity between zones is through port and starboard medium voltage busses. Power is distributed into zones through Port and Starboard zonal bus switchboards and power conversion modules. This example shows each 
of the power end users, Load Centers, power sources, SSGs and PGMs, Bus switchboards, and some other equipment necessary for power generation and distribution.

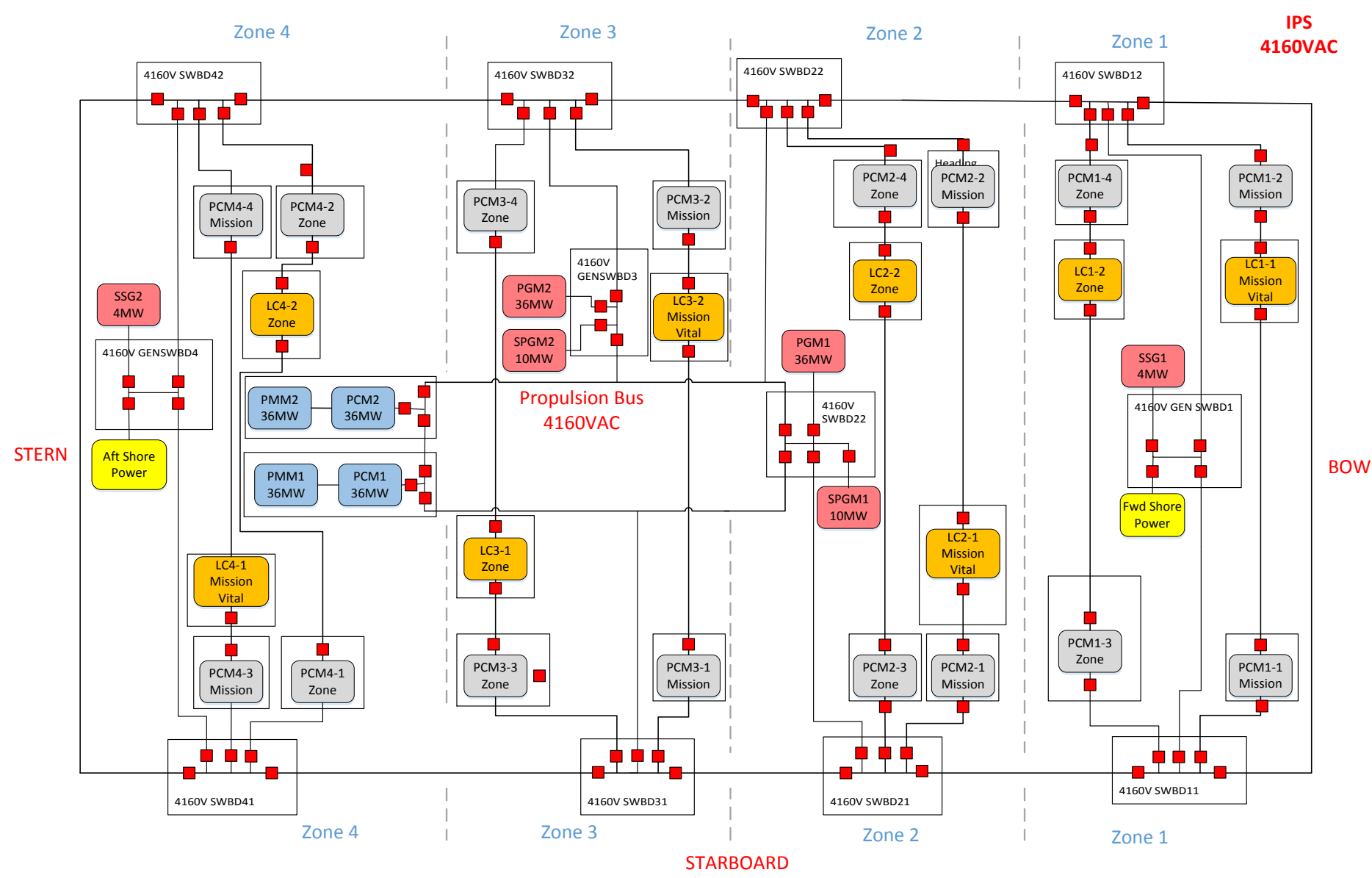

Figure 3-24 - IPS Dual Ring Bus Distribution System adapted from "Electric Architecture Leap Ahead Swampworks Project" by Bradshaw and Robinson, 2013. Used under fair use, 2015.

Because the number of zones in a ship design is variable and the locations of VCs requiring power are not known before their preliminary arrangement, each VC cannot be assigned a load center power source until after all VCs and the load center rooms have been located within the ship. Non-electric ship systems are decoupled initially from power generation and distribution systems and arranged first, but most all VCs require power. So, after all VCs are located, the power distribution and generation subsystems must be integrated with the non-electric systems. This is done with a separate application module within the VTVM, called the Power Import VBA module, 
which connects the load centers in a zone to all of the non-power VC's for all other systems in that zone. This requires additional RBD architecture that cannot be completed until after VC arrangements.

Load Center RBDs connected to SSGs or PGMs in the same zone and to their zonal bus switchboards which are in turn connected through the ring bus shown in Figure 3-24 to power in other zones are developed for each load center, as seen in Figure 3-25, using ITEM software and imported into the VTVM.

Figure 3-25 and Figure 3-26 show the RBDs for Load Center 1-1 (LC11) and bus switchboard 1-1 (SWBD11). This load center receives power through power conversion modules 1-1 (PCM11) or 1-2 (PCM12). PCM11 receives power through SWBD11 and PCM12 through SWBD 12. Each bus switchboard has an RBD similar to Figure 3-26 that that receives power from its own zone and from either direction in the bus.

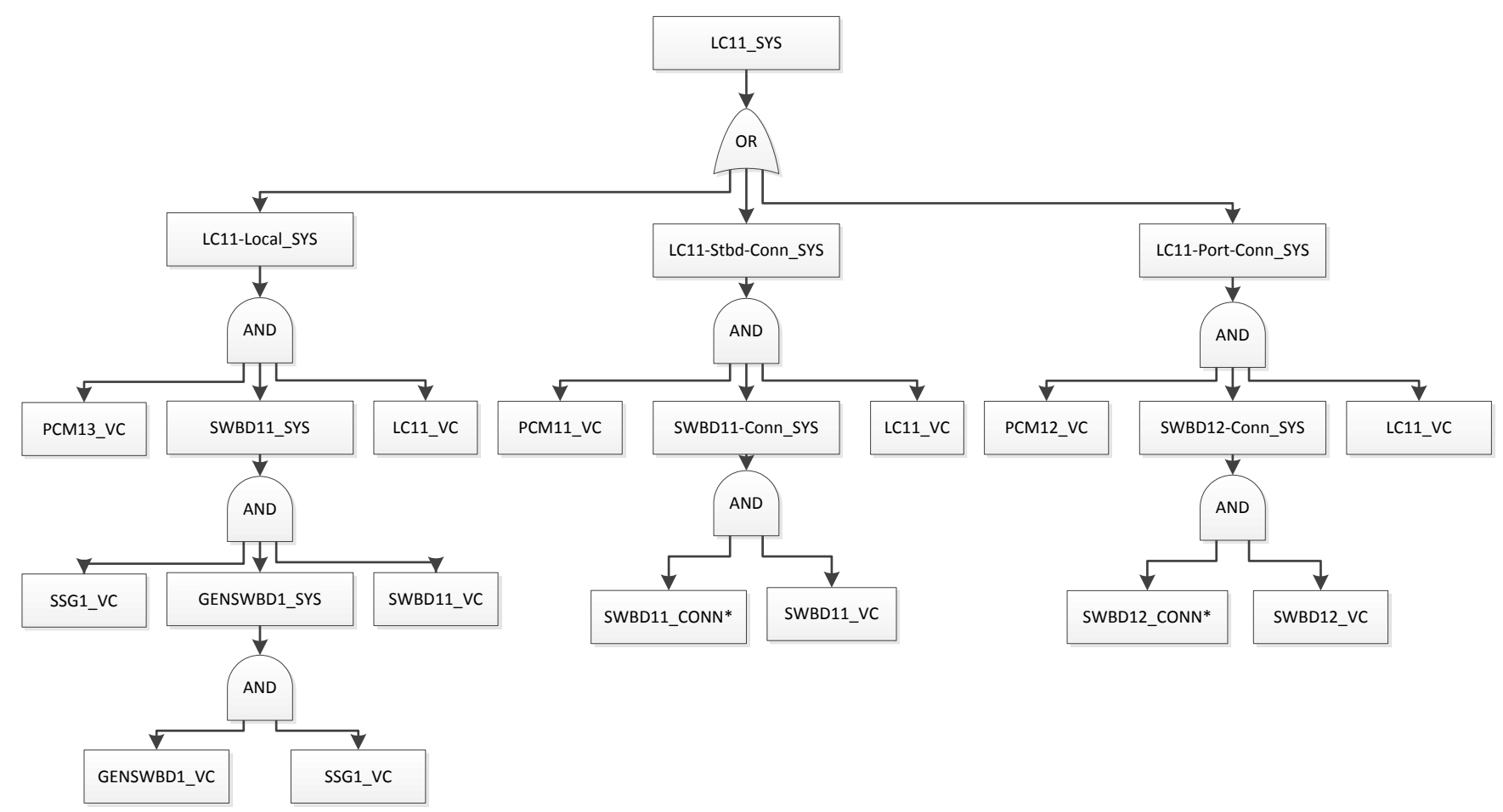

Figure 3-25 - Example Load Center Power Distribution System RBD 


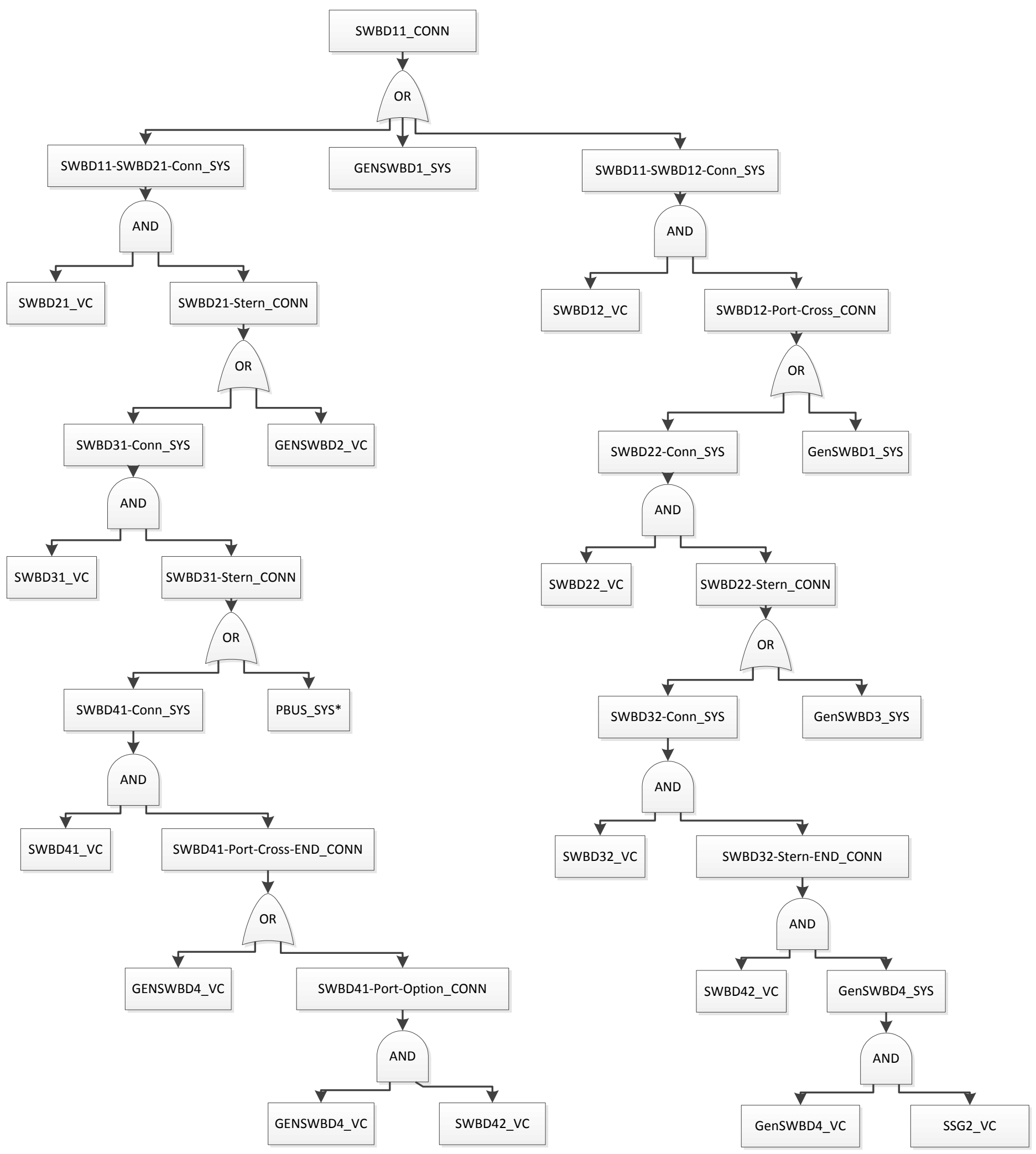

Figure 3-26 - Example Connection Power Distribution System RBD 
Once load center rooms and load centers are located within the ship, all non-electric VC's are assigned 1 or 2 power load centers in their respective zones to connect to the power generation and distribution system. This is done in the VTVM Power Import VBA Module using one of two methods depending on whether or not the $\mathrm{VC}$ is a dependent of a system whose logic gate is an "AND" or an "OR" gate.

For each of these methods the Power Import VBA Module first adds zonal power option systems to the "Systems" sheet within the VTVM, Figure 3-27, based on the specified type option (PSYS) and the number of zones in the ship. These systems use "OR" gates between available Load Centers within a single zone.

The generation and distribution options for this study are an Integrated Power System, Hybrid Dual Ring Bus, and Zonal Electric distribution system. All three systems are modified zonal distribution systems and are separated into 4 zones.

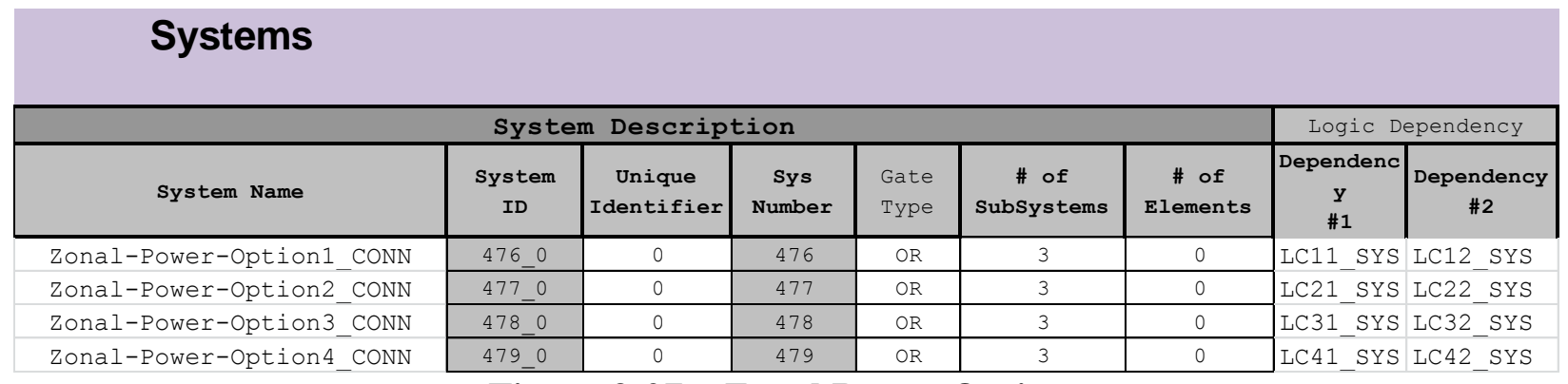

Figure 3-27 - Zonal Power Options

The Power Application logic within the VTVM steps through each system, on the “systems" sheet, to locate VC's requiring power. Once a VC is identified, same zone alternative Load Center sources are determined by the gate logic for the system in which the VC is specified. Once the VTVM locates a VC requiring power, if that VC is required by a system through an "AND" gate, a dependency is added to the system description requiring a power source from the zone in which the VC resides, as shown in Figure 3-28. 


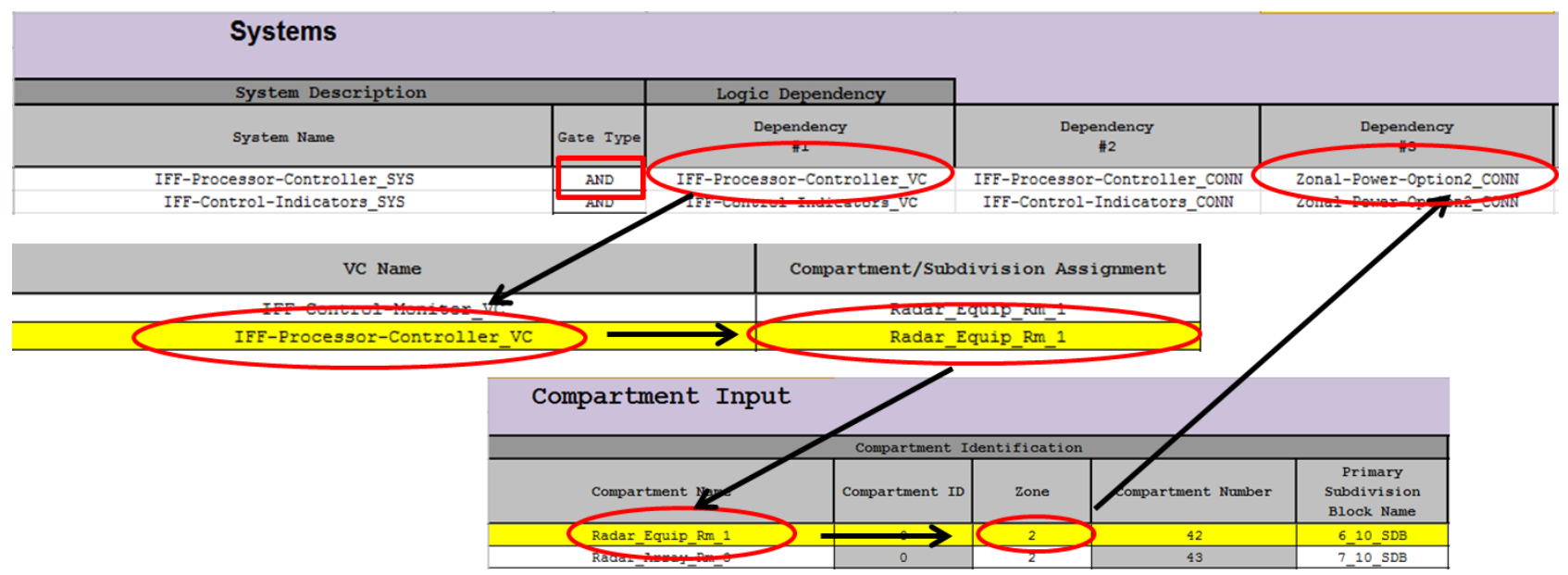

Figure 3-28 - Power Distribution System Application (AND Gate)

Figure 3-28 shows an example where the "IFF-Processor-Controller_VC" is a dependency of the "IFF-Processor-Controller_SYS" through an "AND" gate. The VTVM locates this VC on the "VC Library" sheet with the compartment to which the VC is assigned. The VTVM reads the Zone in which the compartment is assigned from the "Compartments" sheet. The Zonal Power options for that zone are assigned as dependencies to the "IFF-Processor-Controller_SYS".

If the $\mathrm{VC}$ is required by a system through an "OR" gate, the $\mathrm{VC}$ is removed as dependent from the system and replaced by a new system using the VC name, removing the "NC" designation, and replacing it with "andPower_SYS". This newly generated system is then added to the "systems" sheet within the VTVM. This system is assigned two dependents using an "AND" gate, the original VC, and a power source option from Figure 3-27, for the zone in which the VC resides, as shown in Figure 3-29.

Figure 3-29 shows an example where the "GPS-Control-Indicator-1_VC" is required by the "GPS-Control-Indicator_SYS" though an "OR" gate. The VTVM then adds a new system in the "systems" sheet called "GPS-Control-Indicator-1 andPower_SYS" and assigns the "GPS-ControlIndicator-1_VC" as the first dependency. Next the VTVM locates the "GPS-Control-Indicator1_VC" VC on the "VC Library" sheet, Figure 3-22, with the compartment in which the VC is 
assigned. The VTVM then locates that compartment on the "Compartments" sheet, and reads the Zone in which the compartment is assigned. The Zonal Power option, as shown in Figure 3-27, for that zone is now assigned as a dependency to the "GPS-Control-Indicator-1-Power_SYS".

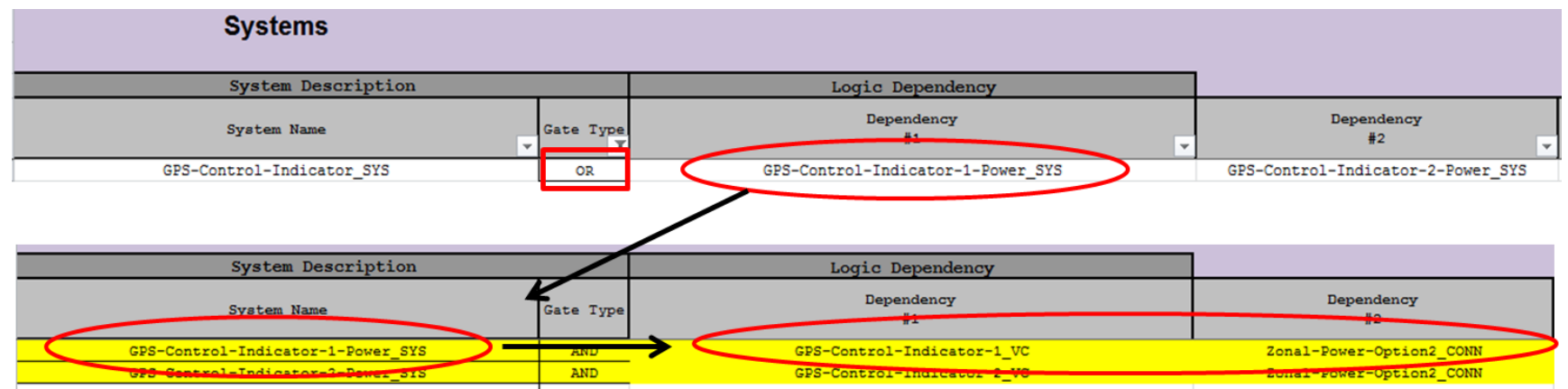

Figure 3-29 - Power Distribution System Application (OR Gate)

\subsubsection{Threat Module (Step 5 and Step 6)}

Vulnerability is determined through the application of multiple hit damage results as discussed in Section 2.2.3 for the selected threats used to evaluate the design from the "Threat Library" sheet, Figure 3-30. The Threats to be used in the VTVM are selected during the C\&RE or PA\&V processes, based on the Opsits and DRM of the ship, and used for all designs in the design space to provide "apples to apples" comparisons of system vulnerability across ship designs.

In Figure 3-30, each threat is assigned a Threat ID number, column 1, and a threat type, column 3. Threats are classified as AIREX or UNDEX trajectories which alter the hit distribution by determining whether the threat detonates above or below the ship's waterline.

Each threat also has a mean and standard deviation for longitudinal location (X) and height (Z) location that determine the hit distribution density. The threat's penetration into the ship (Y) is determined by its mass (column 17), initial velocity (column 18), drag coefficient (column 19), and fuse delay mean and standard deviation (columns 20 and 21). The threats detonation impact radius is determined by its equivalent TNT mass (column 11) which is measured in kilograms. 
VCs are determined to be killed based on the damage method selected, and once all VCs have been determined to be functional or non-functional, the Systems Analysis Module is run to determine system availability.

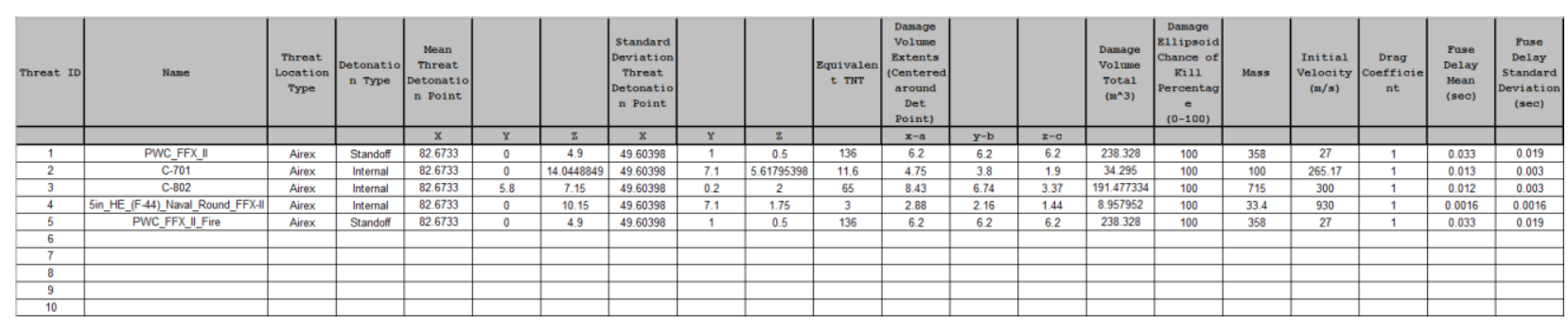

Figure 3-30 - VTVM "Threat Library" Sheet

\subsubsection{System Analysis Module (Step 7)}

The Systems Analysis Module within the VTVM assesses the impact of total ship VC functionality after each hit for each threat using the ship RBD architecture determined in Sections 3.3 and 3.4. This module tracks through the ship system RBD Figure 3-15, and records the functionality of each VC within a system for each hit point. Each VC's functionality, for each hit, can then be summed across all hits in order to determine each VCs overall probability of kill given hit.

The module records the results in the VC Availability Matrix on the "VC Availability" sheet, Figure 3-31, and uses them to calculate the availability of each system in the ship RBD. The module then sets the availability of each system composed entirely of VC's to " 1 " meaning available, or "0" meaning unavailable on the "Systems Availability" sheet, Figure 3-32, based on the number of available VC's under the systems logic gate. If the system has an "OR" logic gate, only one dependent $\mathrm{VC}$ is required to be available for system availability. If the system has an “AND" logic gate all dependent VC's are required for system availability. 


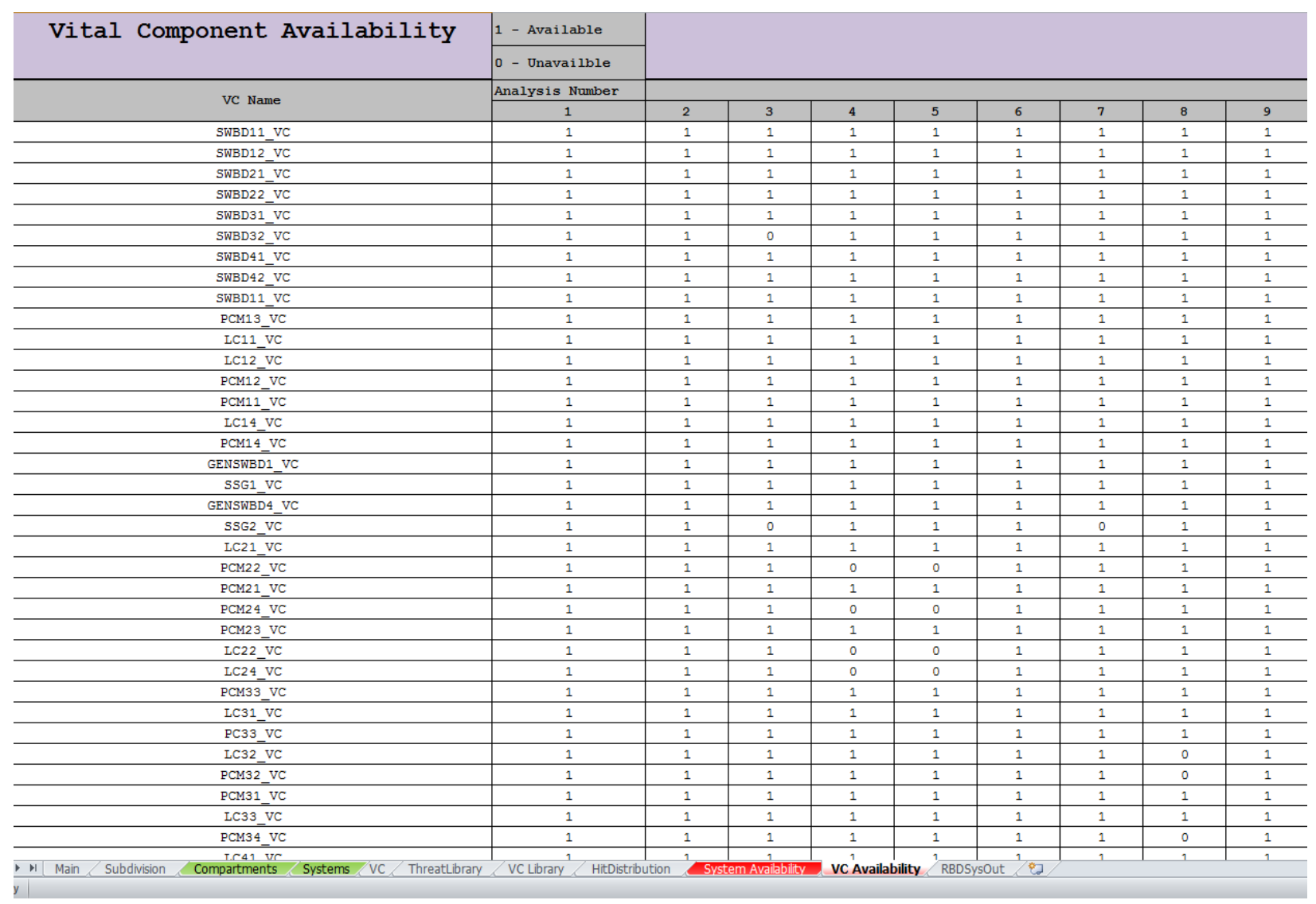

\section{Figure 3-31 - VTVM "VC Availability" sheet}

Next the "Systems" sheet is updated considering any system that requires any combination of VC's and Systems or Systems alone. The runs until every system has been assigned an availability of " 1 " or " 0 ". This tabulation of availabilities is done within arrays in the VBA. The process results in a score or " 1 " or " 0 " assigned to each system within the model for each analysis, an analysis being the entire set of systems and VC's as impacted by a single detonation at a single location. A probability of kill given hit is calculated over all threat hit locations by summing each system availability over all hits for a single threat, and dividing by the number of hits, as shown in Equation (3-8).

$$
\frac{\sum_{1}^{n} \text { System_Score }_{n}}{n}=\text { System Availability Probability }
$$




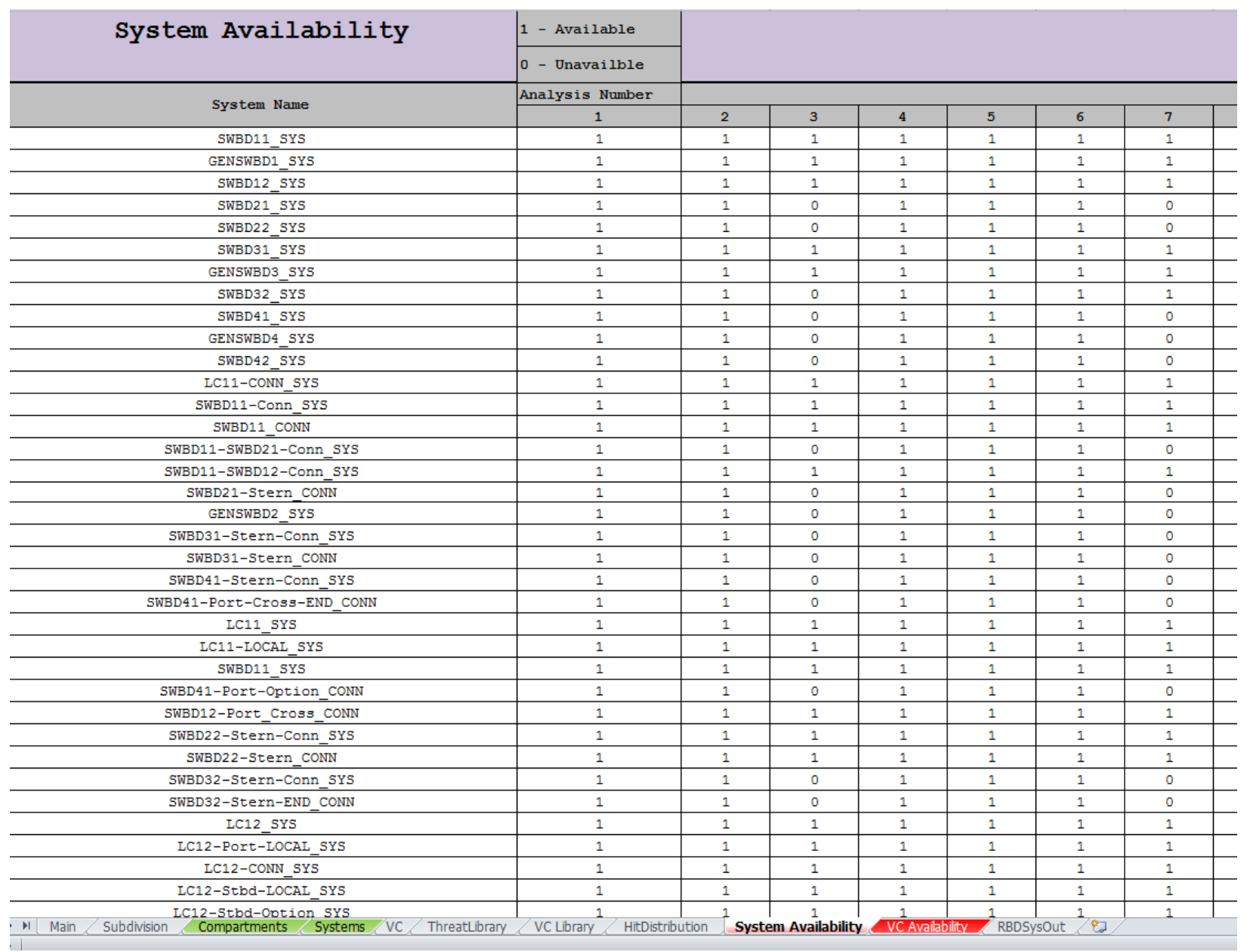

Figure 3-32 - VTVM "System Availability" sheet

System_Score is an individual hit system availability and $\mathrm{n}$ is the total number of hits. Once every System Availability probability is calculated, the VTVM then combines systems to assign the total ship a single overall measure of vulnerability (OMOV) value, as discussed in the following sections.

\subsection{Methodology for Measuring Vulnerability}

Performance measurement is defined as "the process of collecting, analyzing and/or reporting information regarding the performance of an individual, group, organization, system or component” (Munir \& Blount, 2014). Collecting performance data typically involves engineering analysis or testing and engineering metrics which for vulnerability performance we have called 
vulnerability measures of performance (VMOPs). These VMOPs are the statistical availability of ship systems in response to specific threats. These statistical availabilities are calculated using RBDs. Above the system availability level, resulting capabilities are considered. This is an analysis of performance in terms of its effect on mission capabilities. This thesis considered three approaches to this effectiveness analysis: 1) application of system availabilities after hit (VMOPs) or probabilities of kill given hit $\left(\mathrm{P}_{\mathrm{k} / \mathrm{h}}\right)$ in actual war-gaming operational effectiveness models (OEMs); 2) the use of vulnerability performance requirements and requirement levels at the system level to evaluate capability; or 3) rolling up performance from the systems level up to the warfighting area (AAW, ASW, ASUW) level using RBDs, and then combining availabilities for warfighting area capabilities using expert opinion and the analytical hierarchy process (AHP) to calculate one overall OMOV for the ship.

OEMs considering vulnerability are the most correct and rigorous approach to assessing mission effectiveness. This approach is being developed at Virginia Tech and was discussed briefly in Section 2.3. For this thesis, we used Approach 3.

In Approach 2, vulnerability performance requirements are needed to determine metrics that assess vulnerability performance directly without explicitly calculating their effectiveness. Vulnerability Performance Levels can be used to define these requirements and their impact on capability in place of an actual effectiveness assessment. For example, we could propose three survivability levels of performance: Survivability Performance Level 1 (SP1) which requires a ship to be able to stay afloat and stable following a damage event; Survivability Performance Level 2 (SP2) which requires Survivability Performance Level 1 and also requires a ship to have sufficient power, propulsion, and ship systems to maneuver; and Survivability Performance Level 3 (SP3) which requires Survivability Performance Level 2 and also requires various offensive and 
defensive weapons capabilities. These criteria with system logic can be used to evaluate the vulnerability of both ship systems and hull. Fire propagation and flooding through time are not considered explicitly for these measures of performance.

The failure to achieve SP1 could be defined as a threat event that causes damage along or below the waterline which exceeds a specified watertight zone flooding limit. The SP1 score would be the probability of this flooding event not occurring. The SP2 score could be determined using Equation (3-9):

$$
S P 2=S P 1 * \sum_{1}^{N p r o p} \frac{\text { Shaftline1 Availability }}{\text { Nprop }}+\frac{\text { Shaftline2 Availability }}{\text { Nprop }}
$$

The shaft line availabilities are the probabilities of availability as determined through the implementation and evaluation of the propulsion systems logic (RBD) following a threat event

SP3 requires that the threat must not cause damage which degrades the ships ability to detect, defend against, and engage enemy Surface Vessels, Submarines, Aircraft, missiles and torpedoes each at short, medium, and long ranges as defined by the Required Operational Capabilities (ROC's) of the design. Each combat system warfighting area has two types of components: offensive components, and defensive components. Offensive components are classified as any weapon system whose intended design is to attack the enemy, or "Archer". Defensive components are classified as any weapon system whose intended design is to prevent a hit from another vessels weapon, or "Arrow". The VMOP for each warfighting area is determined by combining the scores from its offensive and defensive weapons availabilities using pairwise comparison and weights derived using the Analytical Hierarchy Process (AHP). These VMOPs can then be combined into an SP3 score using the same AHP method. The final overall measure of vulnerability (OMOV) equals SP2 times SP3. 
In this study we used Approach 3 in which a Pairwise Comparison, shown in APPENDIX $\mathrm{B}$, was performed to determine the relative importance of each system warfighting area shown in Figure 3-33 and to calculate the Overall Measure of Vulnerability (OMOV). This includes the relative importance of defensive and offensive capabilities discussed above. In addition to mobility and combat systems, we considered damage control system availability and steering system availability.

As shown in Figure 3-33, the availability of mobility was compared to combat systems and damage control, and the AAW, ASW, and ASUW combat systems were compared to each other to determine their relative level of importance to the ship mission. Additionally, the offensive and defensive capabilities for each of AAW, ASW, and ASUW combat systems, were compared to determine their relative importance to the ship mission.

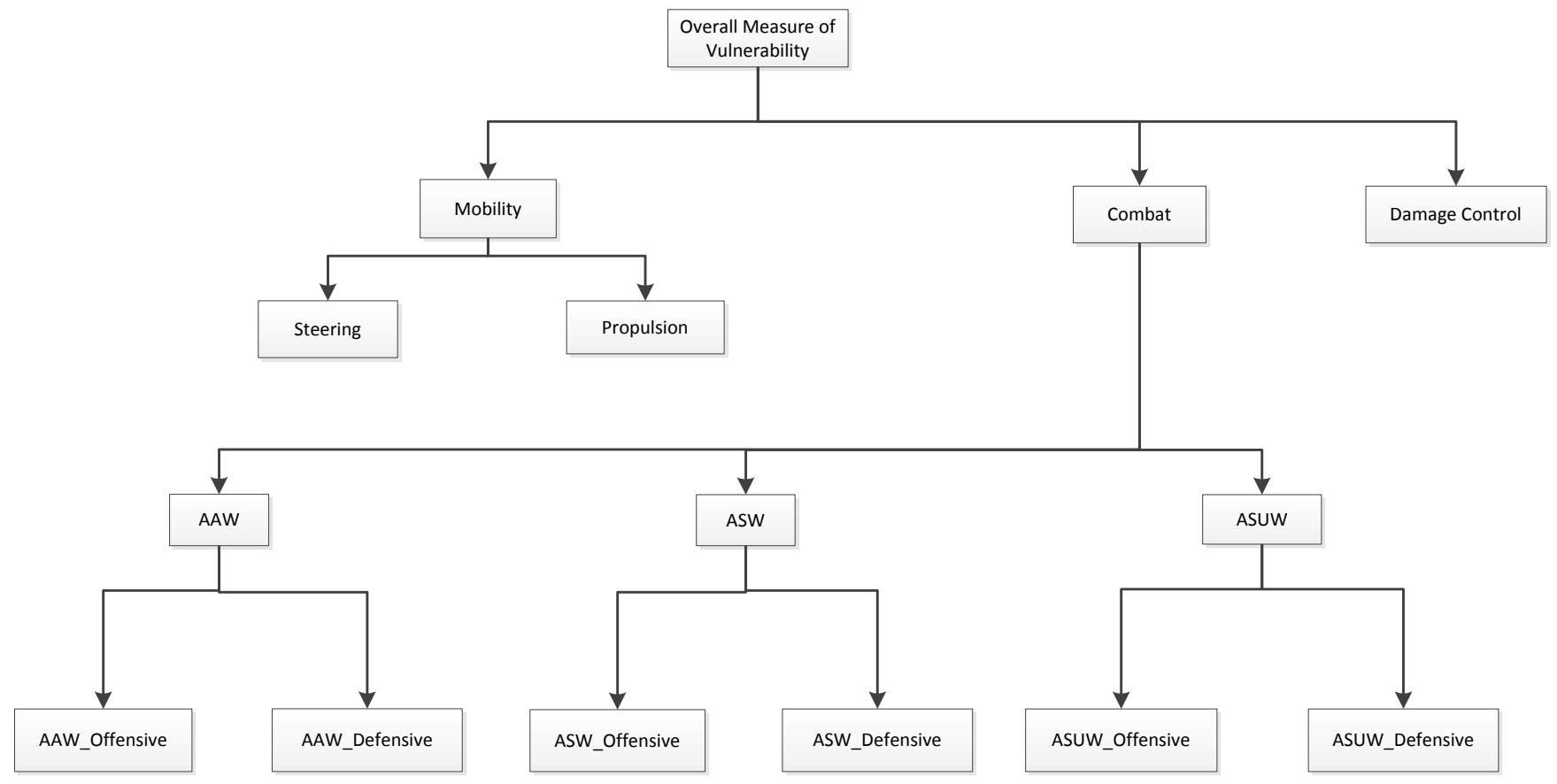

Figure 3-33 - Overall Measure of Vulnerability Hierarchy 
The result of this analysis is a series of weights used for a weighted summation to determine the Overall Measure of Vulnerability. These weights are stored adjacent to their capability in the "Main" sheet within the VTVM.

Following the systems analysis which determines each system's availability probability, these probabilities are combined into system availabilities and ship warfighting availability, and an Overall Measure of Vulnerability is calculated using Equation (3-10):

$$
\text { OMOV }=\left(w_{1} * \text { Combat }+w_{2} * \text { Mobility }+ \text { DamageControl } * w_{3}\right)
$$

where the sum of the weighting factors (w1, w2, w3) are equal to 1 , as determined using the pairwise comparison. 


\section{CHAPTER 4 - DDGX CASE STUDY}

Concept and Requirements Exploration (C\&RE) was performed for a notional DDGX as a preliminary proof of concept in using an Overall Measure of Vulnerability. Mission requirements were specified in an Initial Capabilities Document (ICD) and the C\&RE included the entire process from ICD to MOGO as shown in Figure 1-2. This case study considered three propulsion and power options. Combat systems were the same for all designs. A unique preliminary arrangement for each system option was generated as described in Section 3.2.

\subsection{Ship Propulsion System Options}

Eight propulsion options, shown in Table 4-1, were considered in a previous DDG Study, but only three were used here. For this case study, PSYS options 5, 6, and 7 were selected to begin to assess the influence of considering vulnerability on design selection and to test the VTVM. The design variable "PSYS" selects both the power and propulsion system. The three selected systems are discussed in Sections 4.1.1 through 4.1.3.

\section{Table 4-1 - Propulsion and Power System Options \\ 1=MD COGAG,1 shaft, $2 \times$ GTMPE, $3 \times$ SSG \\ 2=MD CODAG,1 shaft, 1xGTMPE, 1 XDMPE, 3xSSG \\ $3=M D$ CODAG, 1 shaft, $1 \times$ GTMPE, $2 \times D M P E, 3 \times S S G$

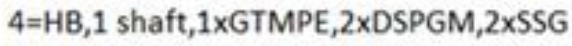 \\ 5=MD CODAG, 2 shafts, $2 \times$ GTMPE, $2 \times D M P E, 3 \times S S G$ \\ 6=HB, 2 shafts, $2 \times$ GTMPE, $2 \times D S P G M, 2 \times S S G$ \\ 7=IPS,2 shafts,2xGTPGM,2xDSPGM,2xSSG \\ 8=MD COGAG,2 shafts,4xGTMPE, 3×SSG,2 MMR,3 AMR}

In Table 4-1 MD indicates mechanical drive, IPS indicates integrated power system, HB indicates mechanical and IPS hybrid, GTMPE indicates gas turbine main propulsion engine, SSG indicates ship service generator, DMPE indicates diesel main propulsion engine and DSPGM indicates diesel secondary power generation module. 


\subsubsection{Combined Diesel and Gas Turbine (CODAG), Option 5}

The CODAG propulsion system Option 5 is a two-shaft mechanical drive system. It uses diesel engines for cruise and adds gas turbines for sustained speed. CODAG as implemented in this study is illustrated in the RBD, Figure 4-1. This RBD shows the CODAG propulsion system architecture which requires one of two shaft lines to be functional. Each shaftline requires functional propulsor system, shaft and bearings system, reduction gear system, MPE group system, propulsion control system, sea water cooling system, and fuel oil service system.

\subsubsection{Integrated Power System (IPS), Option 7}

The Integrated Power System Option 7 uses gas turbine and diesel power generation modules (PGMs and SPGMs) to generate $4160 \mathrm{VAC}$ power that is converted for ship service power and for propulsion (McCoy, 2009). Variable speed Propulsion Motor Modules (PMMs) drive fix pitch propellers, eliminating the need for gearbox and CRP propeller systems. The RBD architecture for the IPS system is shown in Figure 4-2. This RBD requires 1 of 2 shafts to be functional. Each shaftline requires a shaft and bearings system, PMM system, propulsion control system, and a fixed-pitch propeller. Removing the mechanical connection between the propulsors and engines creates several advantages over other propulsion systems including the increased freedom to place the generators in locations atypical from mechanical drive ship designs. IPS is also able to reduce acoustic signatures by decoupling the noisy engines from the water. The architecture of an IPS also allows further flexibility for future weaponry like rail guns which will require large amounts of power for short bursts or pulses. IPS is a good option for a ship whose mission requires high speed, low signatures, and increased flexibility for future ship weapons and sensors. Electrical power for the propulsion motors is provided from a $4160 \mathrm{VAC}$ electric propulsion bus as shown in Figure 4-5 and discussed in Section 4.2.2. 


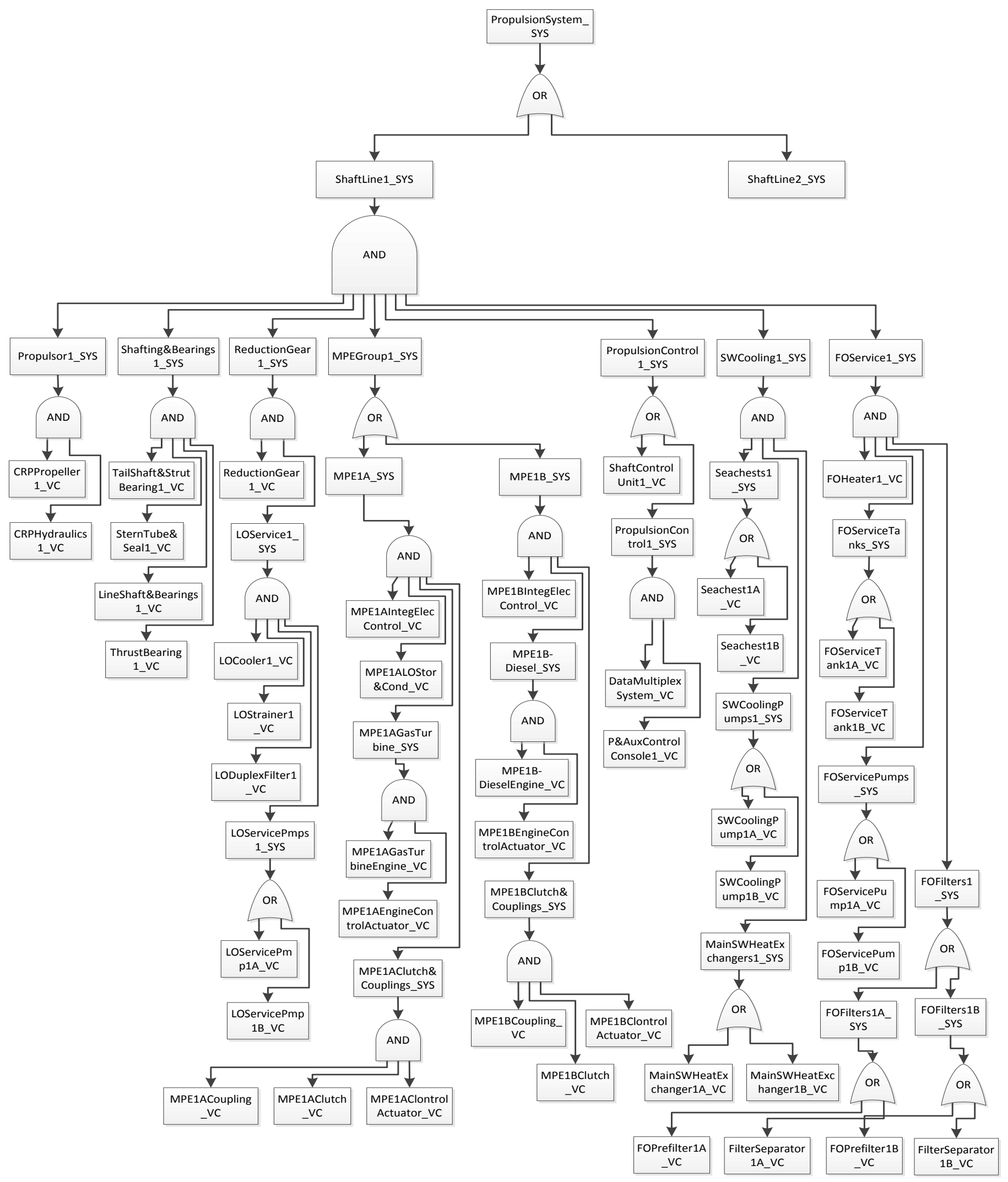

Figure 4-1 - CODAG System Architecture 


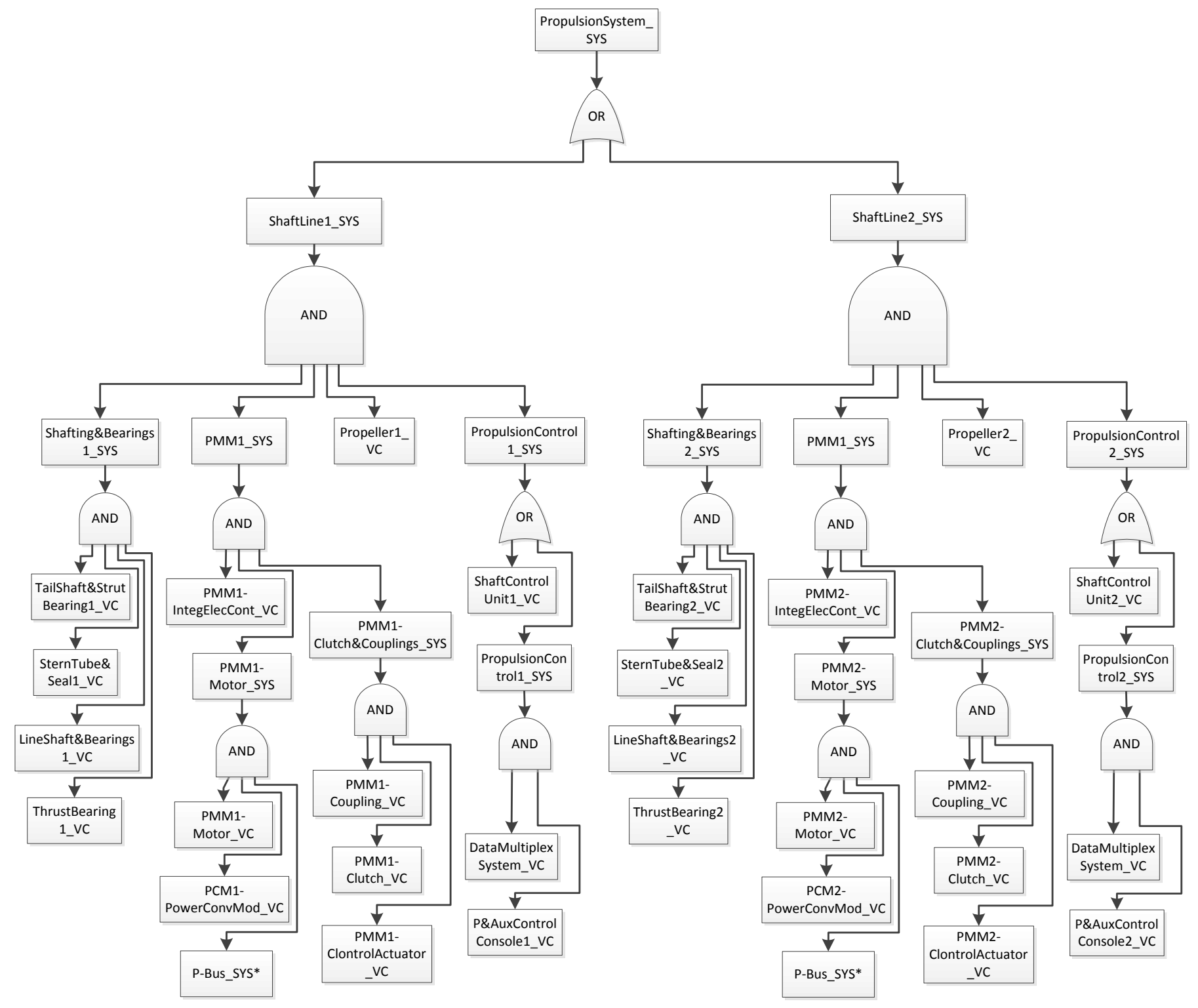

Figure 4-2 - IPS System Architecture

\subsubsection{Hybrid Electric Drive (HED), Option 6}

Hybrid Electric Drive Option 6 combines mechanical and electric drive with gas turbines for mechanical drive propulsion and electric power for ship service and secondary electric propulsion using propulsion motors connected through the reduction gears in parallel with the gas turbines as illustrated in the RBD in Figure 4-3 (Steele, 2011). This RBD shows the HED system architecture which requires 1 of 2 shaftlines to be functional. Each shaftline requires functional propulsor 
system, shaft and bearing system, reduction gear system, MP group system, propulsion control system, sea water cooling system, and fuel oil service system. Electric power for the propulsion motors is provided from a secondary electric propulsion bus shown in Figure 4-6 and discussed in Section 4.2.3.

\subsection{Ship Power Generation and Distribution System}

Power generation and distribution systems discussed in Sections 4.2.1 through 4.2.3 are integrated with the propulsion systems discussed in the previous sections. Each has unique and survivable architectures consistent with the propulsion systems and ship service power they provide.

\subsubsection{Zonal Electric Distribution System (ZEDS)}

Figure 4-4 shows the zonal electric distribution system (ZEDS) without propulsion bus which supports only ship service power requirements. This concept divides the ship into four primary zones, each with two primary vital load centers and one generator switchboard attached to a ship service generator. The VTVM treats the vital load centers as the primary means of providing power to VC's within a zone. Each vital load center receives power from two (port and starboard) redundant power conversion modules and bus switchboards. Bus switchboards can receive power from their own zone or from the bus in either direction. For example, Switchboard 11 can receive power from the generator switchboard in zone 1 , or through a connection to switchboards 21 or 12 in the port and starboard busses. The busses in this system are 480 VAC. 


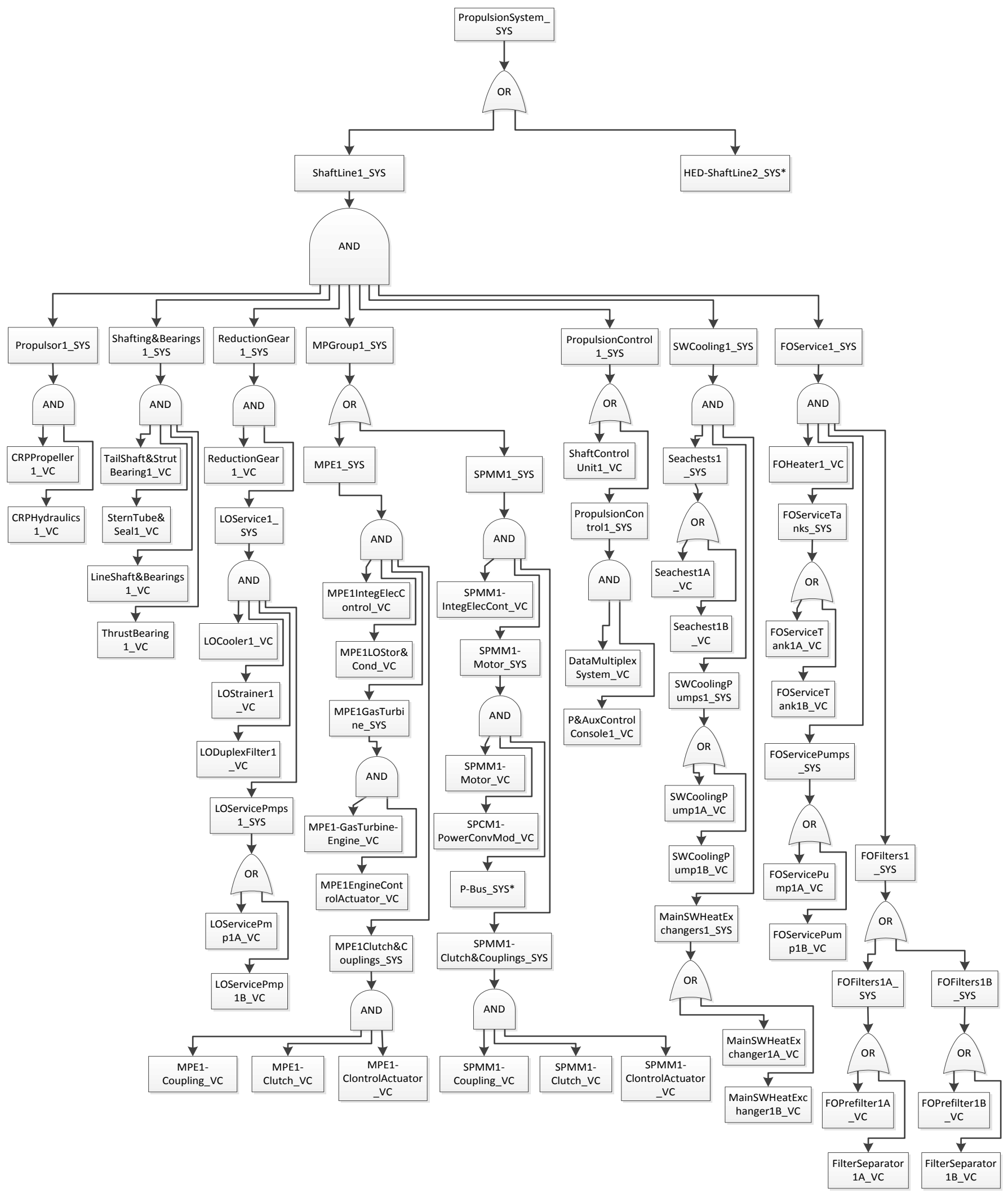

Figure 4-3 - Example Hybrid Electric Drive System Architecture 


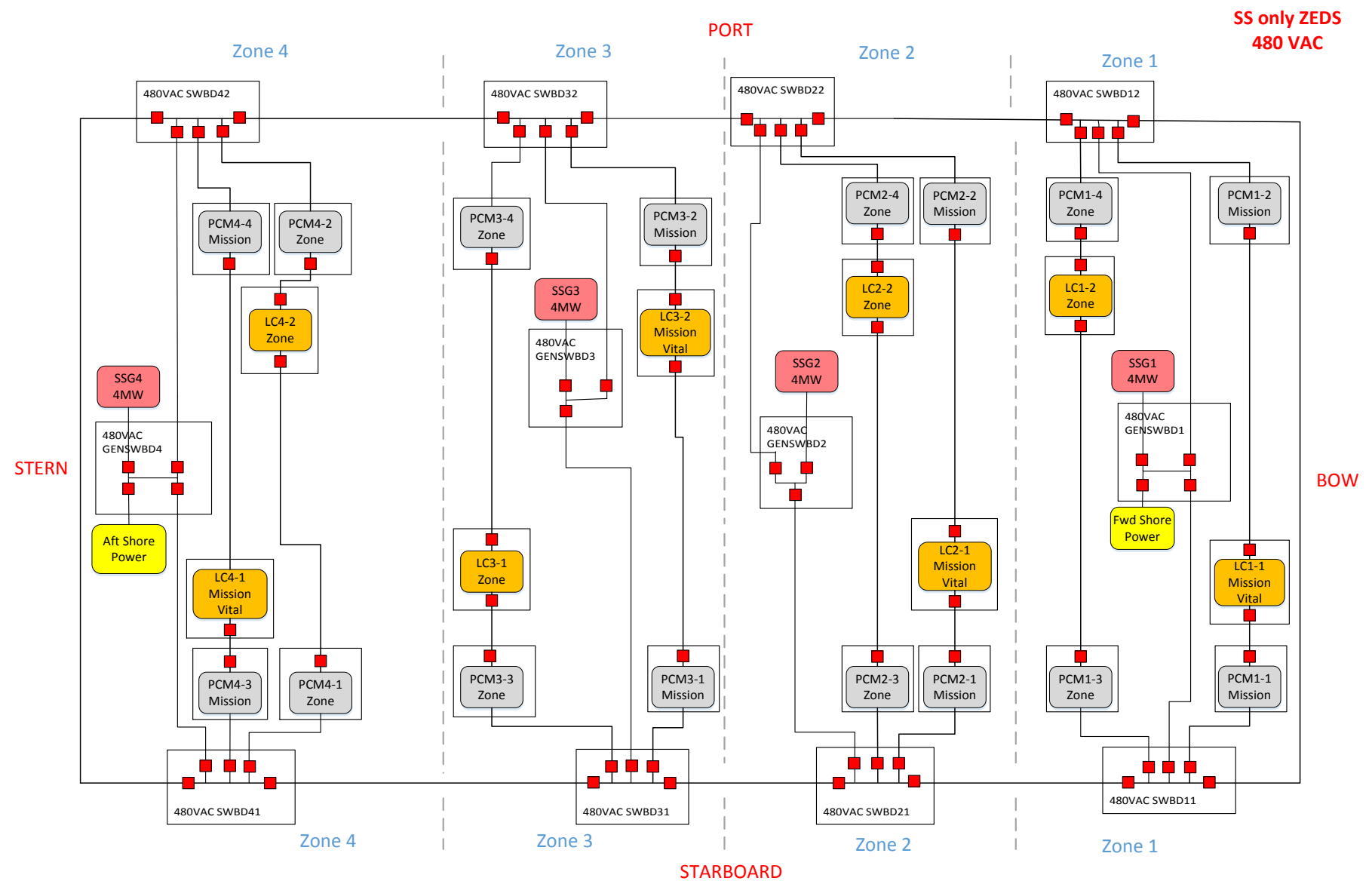

Figure 4-4 - Zonal Electric Distribution adapted from "Electric Architecture Leap Ahead

Swampworks Project” by Bradshaw and Robinson, 2013. Used under fair use, 2015.

\subsubsection{IPS Dual Ring Bus}

The Integrated Power System Dual Ring Bus also serves four zones, each with two vital load centers and one generator switchboard. Important differences between the IPS and ZED systems are that the generator switchboards in zones 2 and 3 are connected to Power Generation Modules (PGMs), Secondary Power Generation Modules (SPGMs), and the propulsion bus instead of ship service generators. The ring and propulsion busses both operate at 4160VAC. Power to the load centers is provided through redundant bus connections or local power options and power conversion modules as discussed in Section 4.1.2. All vital load centers have at least two sources of power. 


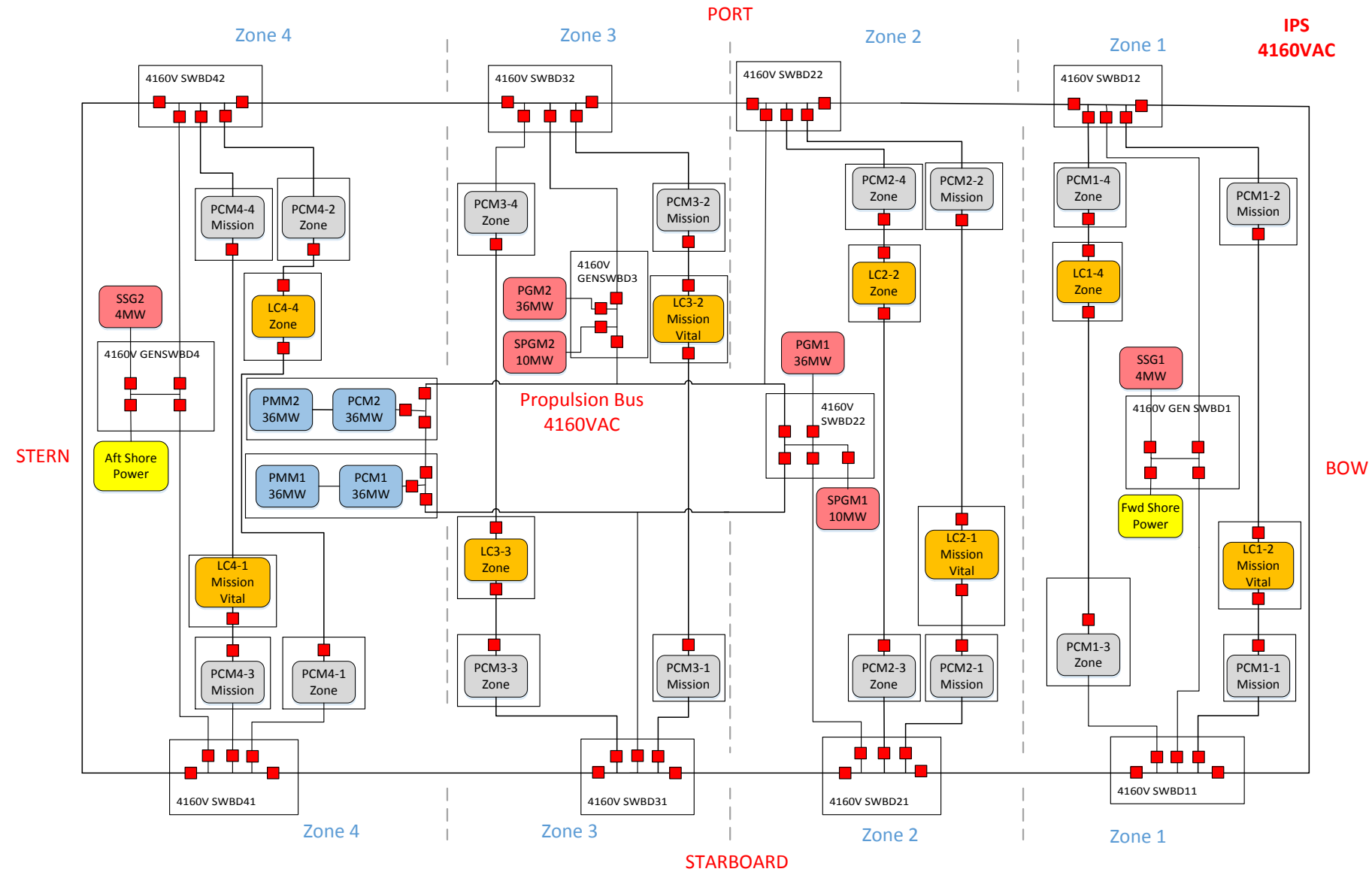

Figure 4-5 - IPS Dual Ring Bus Distribution System adapted from "Electric Architecture Leap Ahead Swampworks Project" by Bradshaw and Robinson, 2013. Used under fair use, 2015.

\subsubsection{HED Dual Ring Bus}

The Hybrid Electric Drive (HED) Dual Ring Bus also provides power to the ship in four zones, each with two vital load centers and one ship service generator or SPGM with redundant connections to both port and starboard busses. HED is a hybrid combination of IPS and ZEDS. It has diesel SPGMs on a propulsion bus providing power to propulsion motors connected to the reduction gears, not directly to the propulsion shafts. Power to the load centers is provided through 
redundant bus connections or local power options as discussed in Section 4.1.3. The ring and propulsion busses both operate at 4160VAC.

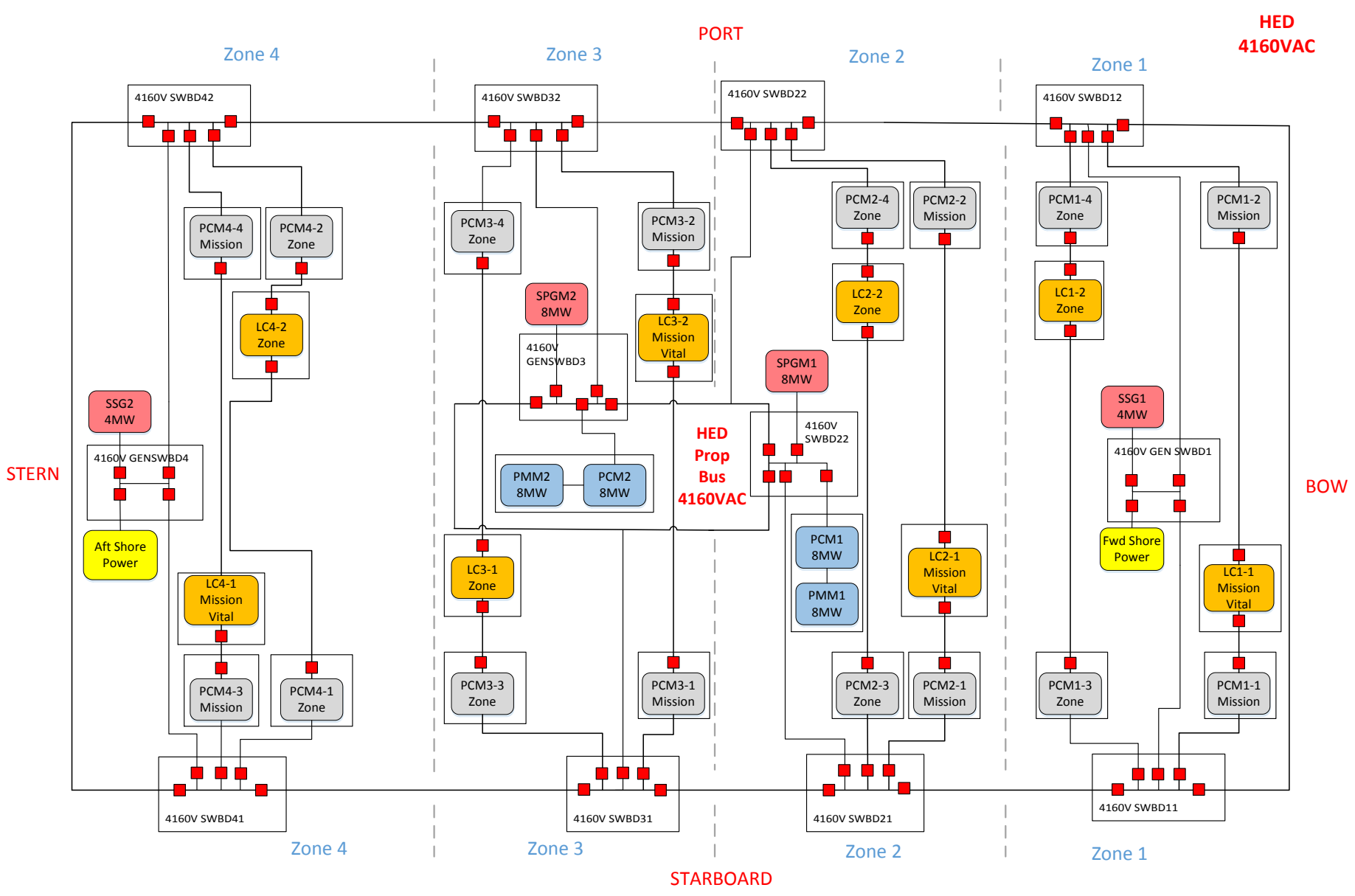

Figure 4-6 - Hybrid Dual Ring Bus Distribution System adapted from "Electric Architecture Leap Ahead Swampworks Project" by Bradshaw and Robinson, 2013. Used under fair use, 2015.

\subsection{Ship Combat Systems}

Sections 4.3.1 through 4.3.3 discuss the systems selected for the case study combat system options. A combat system provides a combination of offensive and defense capabilities. Each warfighting DV in the original DDG Study had three options. Option 1 is the Goal, meaning the most capable suite designed to complete the ship mission. Option 3 is the Threshold, meaning the 
minimum system capabilities necessary to complete the ship mission. Option 2 is offers a suite with capabilities in between Options 1 and 3. This thesis considers only Option 1 in each warfighting area.

\subsubsection{Anti-Air Warfare (AAW)}

The Anti-Air Warfare options provide primarily a defensive capability with detect, control, and engage components. The detection systems detect and track air threats. The control systems target, fire and control the ship's AAW weapons, and the weapon itself intercepts the threat. A typical weapons suite includes a radar, fire control system, Interrogator Friend of Foe (IFF) capability, and short, medium and long-range weapons. The weapon suite options defined in the C\&RE for DDGX are listed in Table 4-2. For this case study only AAW Option 1 is used, the RBD of which is shown in Figure 4-7.

Table 4-2 - AAW System Options

\begin{tabular}{|c|c|c|}
\hline Design Variables & Values & Description \\
\hline \multirow{3}{*}{ AAW/SEW/GMLS/STK } & Option 1 & $\begin{array}{l}\text { SPY-1D radar, AEGIS Combat System, MK99 GMFCS, MK } 37 \\
\text { Tomahawk Weapon System (TWS) , AN/SPQ-9B radar, } 2 \text { x SPG 62, } 64 \\
\text { Cell VLS MK 41, } 2 \text { x CIWS, SLQ-32[V]3, } 6 \text { x MK } 137 \text { LCHRs (combined } \\
\text { MK } 53 \text { SRBOC \& NULKA LCHR), } 6 \text { x Mk137 LCHR loads, NULKA } \\
\text { Magazine, SRBOC Magazine, IRST, IFF,VLS Missile Loadout (SM2, } \\
\text { ASROC, Tomahawk, ESSM, LRASM) }\end{array}$ \\
\hline & Option 2 & $\begin{array}{l}\text { SPY-1F Radar, AEGIS Combat System, MK99 GMFCS, MK } 37 \\
\text { Tomahawk Weapon System (TWS), } 1 \text { x SPG 62, AN/SPQ-9B radar, } 32 \\
\text { Cell MK 41, } 16 \text { Cell MK 48, } 2 \text { x CIWS, SLQ-32[V]3, } 4 \text { x MK } 137 \text { LCHRS } \\
\text { Loads (4 NULKA, } 12 \text { SRBOC), NULKA magazine (12 NULKA), SRBOC } \\
\text { Magazine, IRST, IFF,VLS Missile Loadout (SM2, ASROC, Tomahawk, } \\
\text { ESSM, LRASM) }\end{array}$ \\
\hline & Option 3 & $\begin{array}{l}\text { EADS TRS 3D, COBATSS-21, } 16 \text { Cell MK } 48 \text { VLS, MK } 37 \text { Tomahawk } \\
\text { Weapon System (TWS), AN/SWG-1 Harpoon WCS, } 2 \text { x MK } 141 \\
\text { Harpoon Launcher, } 1 \text { x MK } 143 \text { ASROC Launcher, } 2 \text { x MK } 112 \\
\text { Tomahawk Launcher, } 1 \text { x CIWS, WBR } 2000 \text { ESM, } 2 \text { XSKWS DECOY } \\
\text { LAUNCHER, IRST, IFF,VLS Missile Loadout (ESSM) }\end{array}$ \\
\hline
\end{tabular}




\subsubsection{Anti-Submarine Warfare (ASW)}

The Anti-Submarine Warfare options provide both offensive and defensive capability. The detection systems detect and track submerged threats, while the control systems select targets, control the ship's weapons, and fire the weapons and/or countermeasures to distract or intercept the target. In AAW, incoming missiles and aircraft are the primary targets, but in ASW torpedoes are more difficult to detect and intercept so enemy submarines are the primary targets. A typical weapons suite includes sonar, torpedo tubes, torpedo fire control system, underwater countermeasures, and LAMPS helos with sonobuoys and lightweight (LW) torpedoes. The ASW weapon suite options defined in the C\&RE for DDGX are shown in Table 4-3. For this case study only ASW Option 1 is used, the RBD for which is shown in Figure 4-8 and Figure 4-9. 


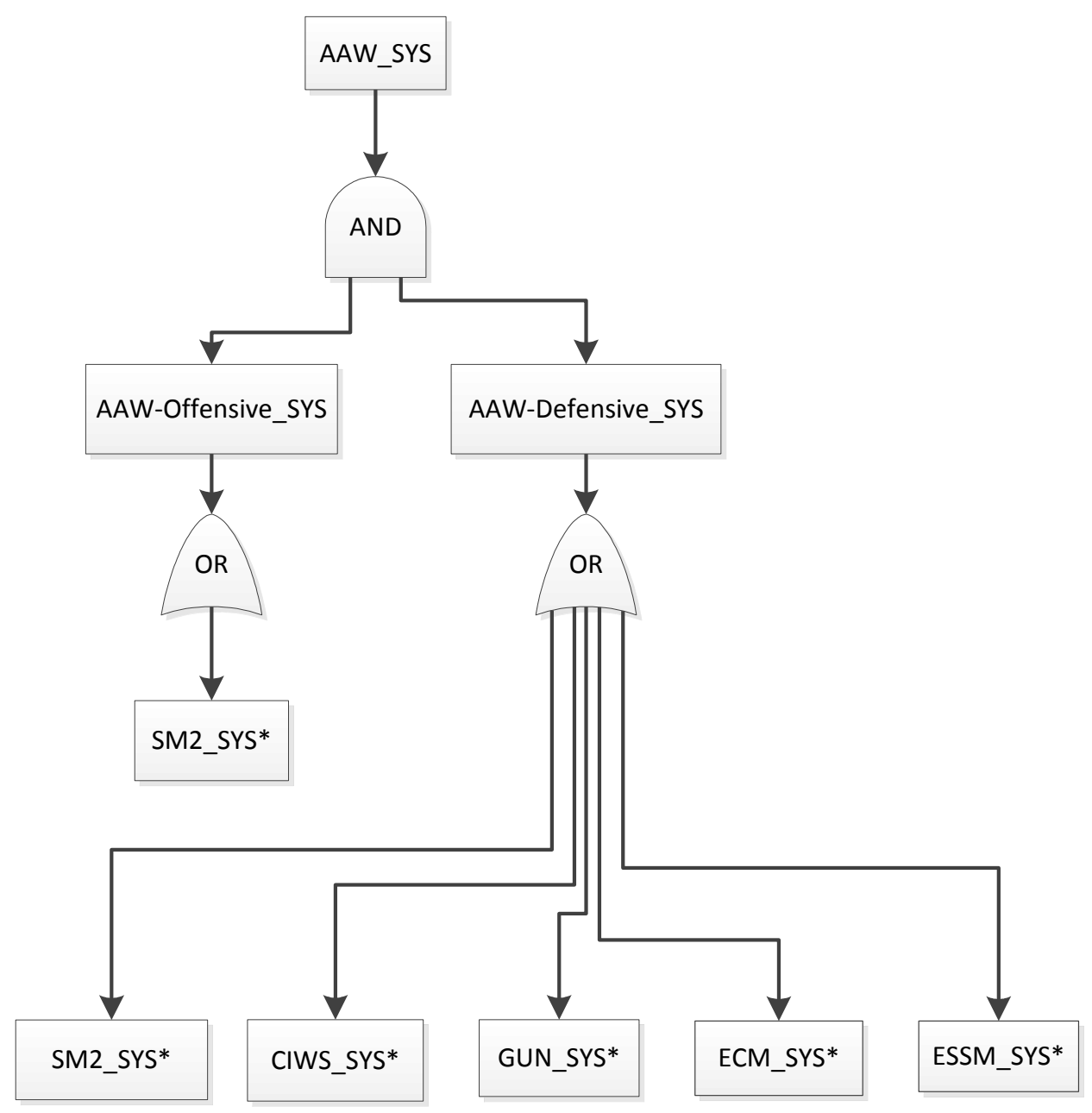

Figure 4-7 - AAW RBD System Architecture

\subsubsection{Anti-Surface Warfare (ASUW)}

The Anti-Surface Warfare capability includes both offensive and defensive capability. The detection systems detect and track surface and aerial threats, while the control systems target and aim the ships weapons, and the weapon itself fires countermeasures or projectiles to distract or intercept the target. 
Table 4-3 - ASW System Options

\begin{tabular}{|c|c|}
\hline \multirow{9}{*}{ ASW system altemative } & $\begin{array}{l}\text { Option 1(DDX 1): SQS-53C,SQR-19 TACTAS, Nixie, } \\
\text { 2xMK } 32 \text { Triple Tubes, MK } 309 \text { Torpedo FCS,SQQ } \\
\text { 89 FCS, MK } 116 \text { UWFCS }\end{array}$ \\
\hline & $\begin{array}{l}\text { Option 2(DDG-51/DDX3\&4): SQS-53C,SQR-19 } \\
\text { TACTAS, Nixie, 2xMK } 32 \text { Triple Tubes, SQQ } 89 \\
\text { FCS, MK } 116 \text { UWFCS }\end{array}$ \\
\hline & $\begin{array}{l}\text { Option 3(DDX-2): SQS-53C,Nixie,2xMK } 32 \text { Triple } \\
\text { Tubes, SQQ } 89 \text { FCS, MK } 116 \text { UWFCS }\end{array}$ \\
\hline & $\begin{array}{l}\text { Option 4(DD-963/993): SQS-53B,SQR-19 TACATS, } \\
\text { Nixie, 2xMK } 32 \text { Triple Tubes, SQQ } 89 \text { FCS, MK } 116 \\
\text { UWFCS }\end{array}$ \\
\hline & $\begin{array}{l}\text { Option 5(DDGX-1E): SQS-56,SQR-19 TACTAS, Nixie, } \\
\text { 2xMK } 32 \text { Triple Tubes, MK } 309 \text { Torpedo FCS, SQQ } \\
\text { 89 FCS }\end{array}$ \\
\hline & $\begin{array}{l}\text { Option 6(CG-47): SQS-53B,SQR-19 TACATS, Nixie, } \\
\text { 2xMK } 32 \text { Triple Tubes, MK } 116 \text { UWFCS }\end{array}$ \\
\hline & $\begin{array}{l}\text { Option 7(FFG-7): SQS-56,SQR-19 TACATS, Nixie, } \\
\text { 2xMK } 32 \text { Triple Tubes, SQQ } 89 \text { FCS }\end{array}$ \\
\hline & $\begin{array}{l}\text { Option } 8 \text { (DDX-7): SQS-56, Nixie, 2xMK } 32 \text { Triple } \\
\text { Tubes, MK } 309 \text { Torpedo FCS, SQQ } 89 \text { FCS }\end{array}$ \\
\hline & Option 9(DDX 5\&6): Nixie \\
\hline
\end{tabular}

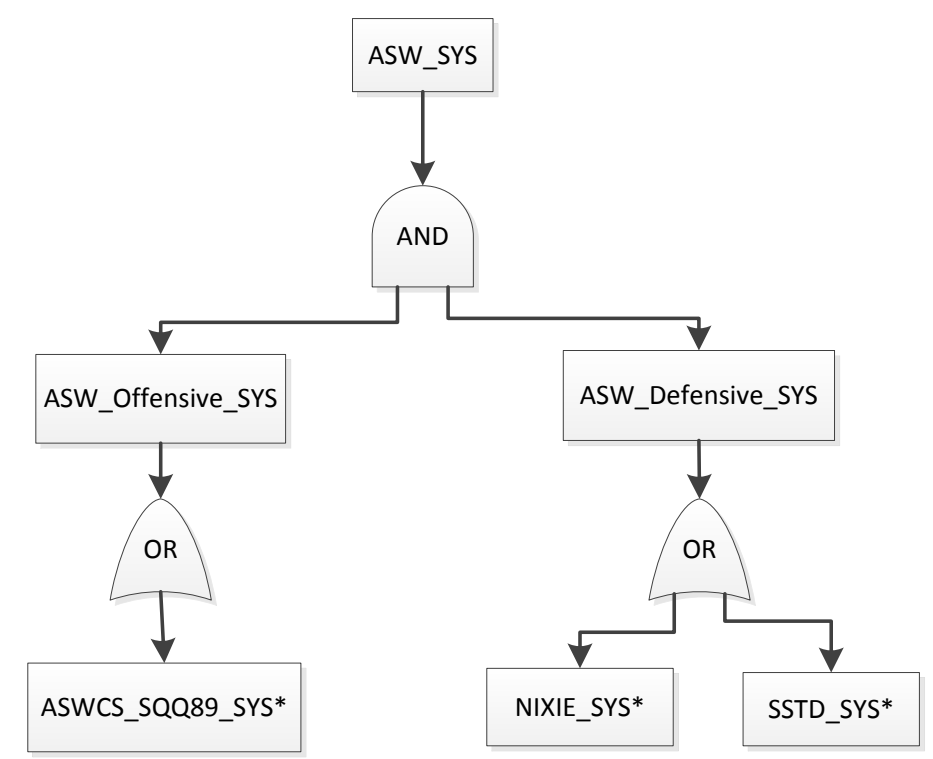

Figure 4-8 - ASW RBD System Architecture

A typical ASUW weapons suite includes Surface Search Radar, Gun or Missile Control system, ASM, projectile and small arms. For this case study only ASUW Option 1 is considered, the RBD for which is shown in Figure 4-10. 


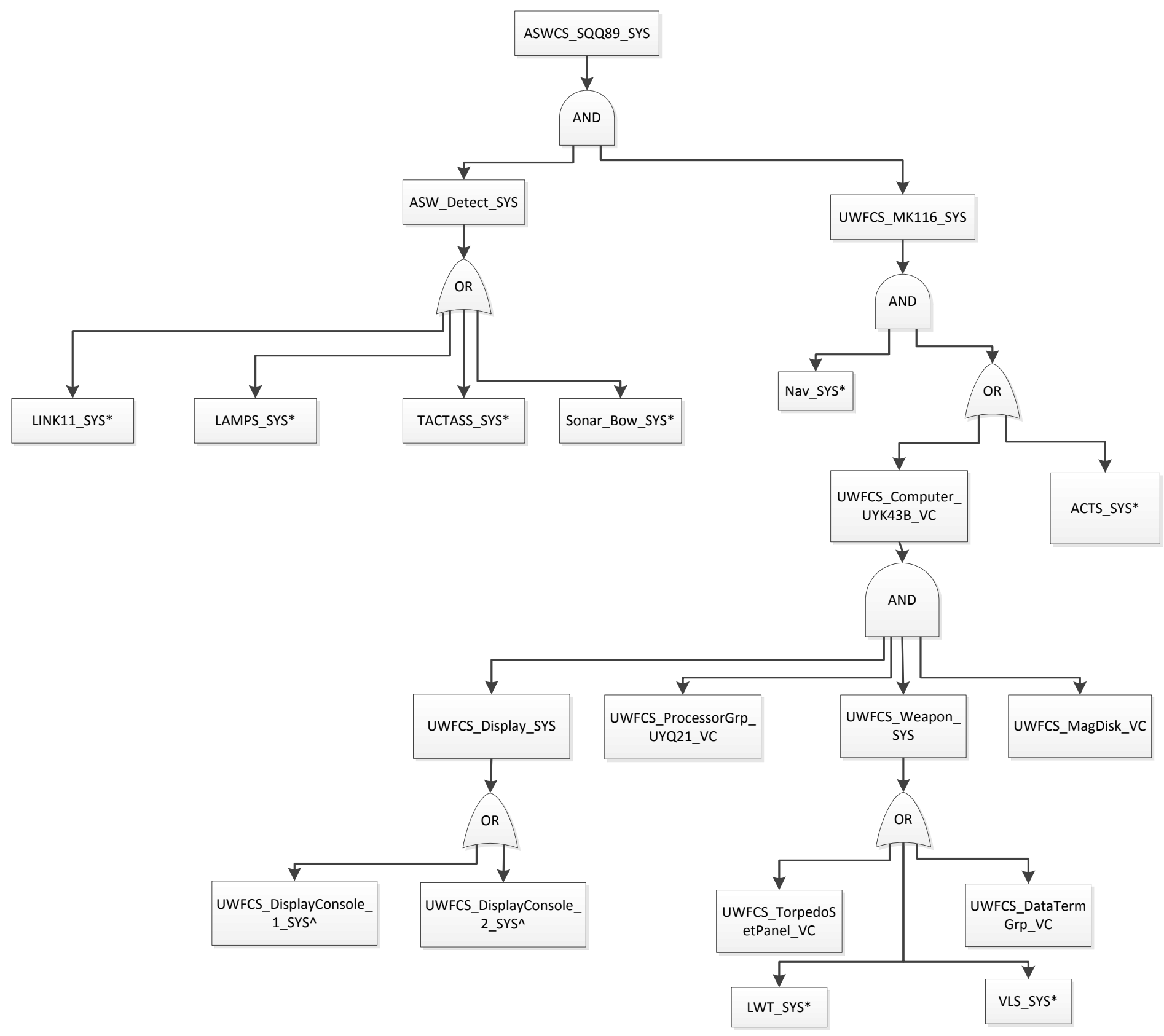

Figure 4-9 - ASWCS SQQ89 System RBD

Table 4-4 - ASUW System Options

\begin{tabular}{|l|l|}
\hline \multirow{5}{*}{ ASUW system altematives } & $\begin{array}{l}\text { Option 1(DDG-51): SPS-67,SPS-64,MK 160/34 GFCS, } \\
\text { Harpoon WCS SWG-1, Small Arms }\end{array}$ \\
\cline { 2 - 3 } & $\begin{array}{l}\text { Option 2(CG-47/DD-963/993): SPS-55,SPQ-9,MK 86 } \\
\text { GFCS, Harpoon WCS SWG-1, Small Arms }\end{array}$ \\
\cline { 2 - 2 } & $\begin{array}{l}\text { Option 3(DDX 6\&7): SPS-55,SPS-64, Harpoon WCS } \\
\text { SWG-1, Small Arms }\end{array}$ \\
\cline { 2 - 2 } & $\begin{array}{l}\text { Option 4(DDX 1-5/FF G-7/DDGX-A):SPS-55, Harpoon } \\
\text { WCS SWG-1, Small Arms }\end{array}$ \\
\hline
\end{tabular}




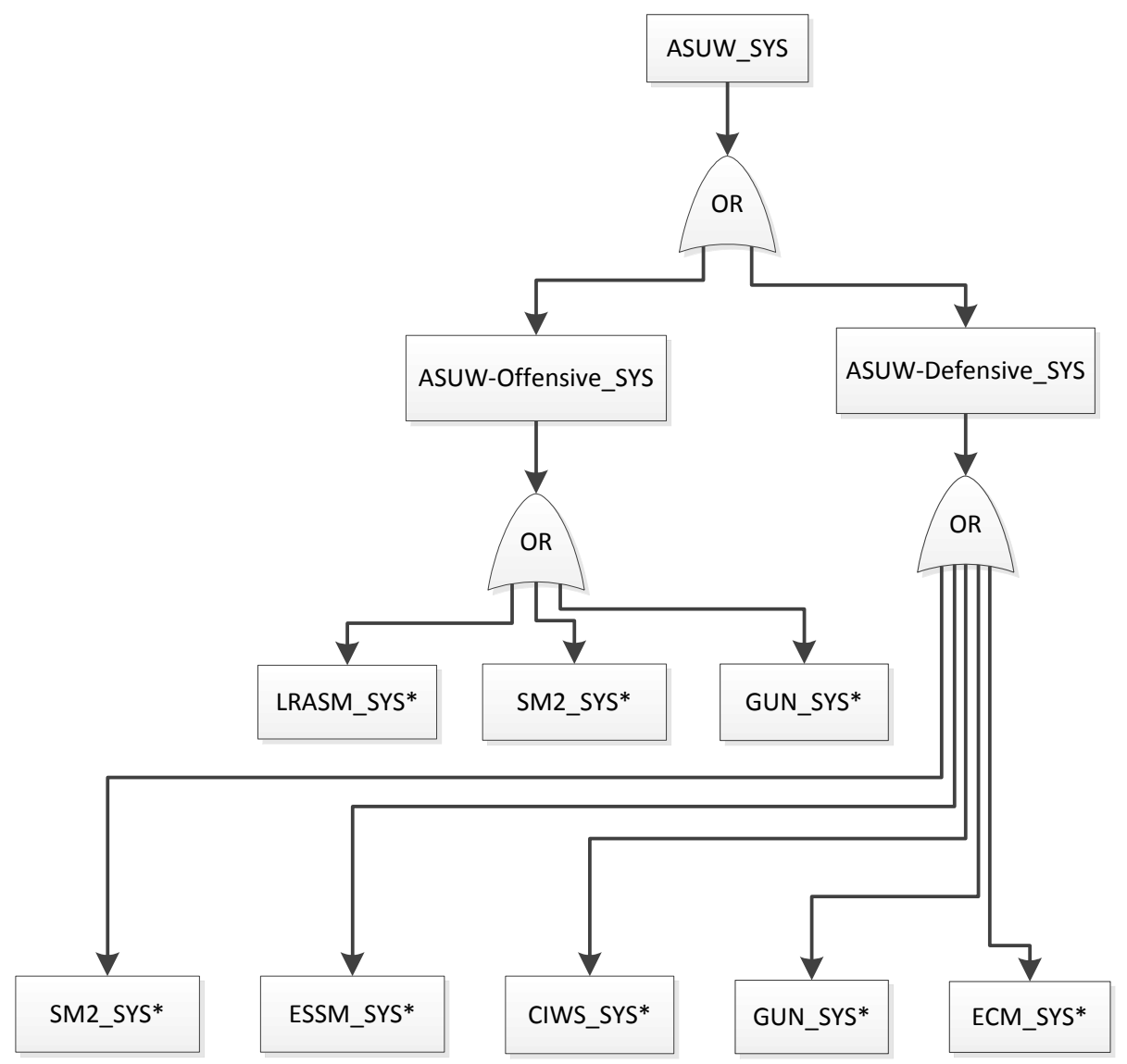

Figure 4-10 - ASUW RBD System Architecture

AAW, ASW, and ASUW capability system VCs are provided power from the selected power generation and distribution system as described in Section 3.3.4.

\subsection{DDGX PA\&V Process and Overall Measure of Vulnerability}

Preliminary baseline designs were created by the PA\&M model representing the specified combinations of system options. In this study only the propulsion system options (PSYS) were varied. Designs using propulsion system Options 5, 6, and 7 (CODAG, HED, and IPS) from Table 4-1 were explored keeping all other system options constant. Estimated baseline ship parameters and preliminary design arrangements were developed for each of these designs. Design names are generated during this process by combining the system option values in the following order: AAW, ASUW, ASW, Power, and Propulsion. For example, a design name 11155 represents a design using goal combat system options (options 111) and specified power and propulsion system 
options (options 55, 66, or 77). This is an important convention because in a full design exploration hundreds of designs will be generated for the full matrix of system options and their characteristics will be saved under these names. Each of the three designs was evaluated to determine its OMOV as discussed in Chapter 3. After analysis in the PA\&V model, the designs were synthesized in the SSM to assess their feasibility and validate the method. Characteristics for these three baseline designs are listed in Table 4-5. Multi-objective genetic optimizations were also performed to assess the impact of considering vulnerability on the design non-dominated frontier. These results are presented in Section 4.5.

Combat system option selection has a major effect on lightship weight and displacement and since combat systems were the same for the three baseline designs, their preliminary length overall (LOA) values are similar. Each of the design options has a synthesized waterline length ranging from 152.56 to 153.60 meters and draft ranging from 6.46 to 6.50 meters. Each has sufficient arrangeable area and similar preliminary arrangements as shown in Figure 4-11 and Figure 4-12. The preliminary arrangements have 2 Main Machinery Rooms (MMRs), 3 Auxiliary Machinery Rooms (AMRs), 3 repair lockers, and 8 load center rooms, two in each zone. Design 11177 has propulsion motor rooms for its propulsion motors. Designs 11155 and 11166 do not require propulsion motor rooms.

The vulnerability of each DDGX design was analyzed with a hit distribution calculated as discussed in 2.2.3 for 200 C-701 Anti-Ship Missile (ASM) hits whose parameters are shown in Figure 3-30. A C-701 is a versatile Chinese-made ASM that is also capable as an air to surface missile and uses a combination of Infra-red and radar to track its targets. The missile is seaskimming with a cruise height of 15-20m (FAS, C-701). 
Table 4-5 - Case Study System Baseline Design Characteristics

\begin{tabular}{|c|c|c|c|c|}
\hline \multirow{2}{*}{\begin{tabular}{|l} 
SSM Module \\
\end{tabular}} & \multirow{2}{*}{\begin{tabular}{|l|} 
Parameter \\
\end{tabular}} & \multicolumn{3}{|c|}{ Design Options } \\
\hline & & 11155 & 11166 & 11177 \\
\hline \multirow{16}{*}{ Hull } & Mass & 10067.7 & 9977.31 & 10179.4 \\
\hline & LOA & 161.13 & 160.64 & 161.731 \\
\hline & LWL & 153.029 & 152.564 & 153.6 \\
\hline & BWL & 19.2332 & 19.1749 & 19.3048 \\
\hline & Draft & 6.48121 & 6.46148 & 6.50542 \\
\hline & D10 & 15.3073 & 15.2608 & 15.3645 \\
\hline & $\mathrm{CP}$ & 0.65985 & 0.65983 & 0.65988 \\
\hline & $C x$ & 0.78033 & 0.78043 & 0.78022 \\
\hline & Vdmax & 18813.8 & 18756.3 & 18884.1 \\
\hline & $\mathrm{Cb}$ & 0.51489 & 0.51493 & 0.51484 \\
\hline & GMtoB & 0.07959 & 0.07948 & 0.07972 \\
\hline & $\mathrm{Cw}$ & 0.79865 & 0.79867 & 0.79862 \\
\hline & LCB & 87.405 & 87.1393 & 87.7309 \\
\hline & VCB & 3.9639 & 3.95183 & 3.97871 \\
\hline & KG & 8.44741 & 8.42354 & 8.4767 \\
\hline & BMt & 6.01079 & 5.99254 & 6.03319 \\
\hline \multirow{2}{*}{ Space } & Nprop & 2 & 2 & 2 \\
\hline & NMMR & 2 & 2 & 2 \\
\hline \multirow{4}{*}{ Electric } & BKWmcr & 81183.4 & 80120.5 & 81164.7 \\
\hline & KWmfIm & 7016.61 & 6945.54 & 7035.3 \\
\hline & KW24avg & 3205.72 & 3172.84 & 3213.9 \\
\hline & Vaux & 2301.63 & 2278.32 & 2307.77 \\
\hline HullR\&P & Vs & 28.2617 & 28.5579 & 28.1705 \\
\hline \multirow{9}{*}{ Weight } & W1 & 3856.65 & 3813.34 & 3912.16 \\
\hline & W2 & 986.761 & 930.762 & 1145.12 \\
\hline & W3 & 324.921 & 295.169 & 296.228 \\
\hline & W4 & 616.79 & 615.816 & 617.985 \\
\hline & W5 & 830.081 & 823.565 & 837.305 \\
\hline & W6 & 587.696 & 584.372 & 591.778 \\
\hline & W7 & 290.224 & 290.224 & 290.224 \\
\hline & Wls & 8242.43 & 8088.57 & 8459.89 \\
\hline & KG & 6.88053 & 6.81889 & 6.95796 \\
\hline \multirow{2}{*}{ Tankage } & $E$ & 5647.63 & 6160.86 & 4940.74 \\
\hline & $\mathrm{Ee}$ & 0.61361 & 0.76025 & 0.41164 \\
\hline \multirow{10}{*}{ Feasability } & Atr & 7466.31 & 7433.51 & 7475.96 \\
\hline & Ata & 8855.17 & 8407.33 & 8968.41 \\
\hline & Cgmb & 0.16088 & 0.163 & 0.1582 \\
\hline & Eta & 0.18602 & 0.131 & 0.19963 \\
\hline & Evs & 0.00935 & 0.01992 & 0.00609 \\
\hline & Cfola & 1240.32 & 1258.4 & 1314.77 \\
\hline & CTOC & 2803.95 & 2815.27 & 2924.2 \\
\hline & OMOR & 0.05556 & 0.05556 & 0.285 \\
\hline & OMOE & 0.75126 & 0.83126 & 0.83907 \\
\hline & OMOV & 0.828 & 0.848 & 0.846 \\
\hline
\end{tabular}




\begin{tabular}{|c|c|c|c|c|c|c|c|c|}
\hline & & Radar_Array_Rm_3, Radar_Array_Rm_4 & $\begin{array}{l}\text { Radar_Array_Rm_1, } \\
\text { Radar_Array__Rm_2 }\end{array}$ & & & & & \\
\hline & & Radar_Equip_Rm_2 & Radar_Equip_Rm_1, Chaff_Equip_Rm_1 & & & & & \\
\hline & & Radar_Cooling_Equip_Rm_2 & Radar_Cooling_Equip_Rm_1 & $\begin{array}{l}\text { Pilot_House, Bridgewing_1, } \\
\text { Bridgewing_2, } \\
\text { Radar_Director_Equip_Rm_1 }\end{array}$ & & & & \\
\hline & & $\begin{array}{l}\text { Auxiliary_Conn, Emergency_Radio_Rm, } \\
\text { EW_Equip_Rm, Chaff_Equip_Rm_2 }\end{array}$ & & & & & & \\
\hline & VIs_2_Upper & & & Magazine_CIWs_1 & & & & \\
\hline $\begin{array}{l}\text { Radar_Director_Equip_Rm_2, } \\
\text { CWw_Control_Rm_2, Magazine_IWS_2, } \\
\text { Hangr_Upper, Flight_Control_Station }\end{array}$ & VLs_2_Mid & & & CIWS_Control_Rm_1 & & & & \\
\hline $\begin{array}{c}\text { Hangar_Lower, Lckr_Helo_Crash_Rescue, } \\
\text { JPS_Refueling_Station }\end{array}$ & $\begin{array}{l}\text { VLS_2_Lower, } \\
\text { Modular_Space_\&_UV_Boat_Deck }\end{array}$ & & $\begin{array}{c}\text { Lckr_Small_Arms, Load_Center_Rm_3, } \\
\text { Load_Center_Rm_4 }\end{array}$ & Wardroom & VLS_1_Upper & Gun_Ready_Service_Rm & & \\
\hline $\begin{array}{c}\text { CSER_2, } \\
\text { Magazine_Aircraft_Ammo_\&_Strm_Sono } \\
\text { buoy }\end{array}$ & $\begin{array}{l}\text { CCS, Lckr_Repair_5, } \\
\text { Fire_fighting_Station_2, Bed_WC_CPO_2 }\end{array}$ & $\begin{array}{l}\text { Load_Center_Rm_5, } \\
\text { Load_Center_Rm_6, Mess_Crew, } \\
\text { Mess_Lounge_CPO }\end{array}$ & $\begin{array}{l}\text { Comm_Center, CSER_1, } \\
\text { Bed_WC_CPO_1 }\end{array}$ & CIC & VLs_1_Mid & & $\begin{array}{l}\text { Lckr_Repair_2, } \\
\text { Fire_fighting_tation_1, } \\
\text { Load_Center_Rm_1, } \\
\text { Load_Center_Rm_2 }\end{array}$ & \\
\hline & MMR_2_Upper & Armory & MMR_1_Upper, MMR_1_Upper_Stbd & AMR_2_Upper, AMR_2_Upper_Stbd & VIS_1_Lower & & AMR_1_Upper, AMR_1_Upper_Stbd & \\
\hline Bed_Wc_crew_3 & MMR_2_Mid & Bed_Wc_crew_1 & MMR_1_Mid & AMR_2_Mid & & $\begin{array}{l}\text { Sonar_Equip_Rm_2, } \\
\text { Sonar_Control__Rm }\end{array}$ & AMR_1_Lower, AMR_1_Lower_Port & \\
\hline $\begin{array}{c}\text { IC_Gyro_Rm_2, Degaussing_Rm, } \\
\text { Bed_WC_Crew_4 }\end{array}$ & MMR_2_Lower & IC_Gyro_Rm_1, Bed_WC_Crew_2 & MMR_1_Lower, MMR_1_lower_Port & AMR_2_Lower, AMR_2_Lower_Port & & $\begin{array}{l}\text { Magazine_Gun, } \\
\text { Magazine_Gun_Proj_Cart, } \\
\text { Sonar_Equip_Rm_3 }\end{array}$ & $\begin{array}{l}\text { Sonar_Equip_Rm_1, } \\
\text { Sonar_Cooling_Equip_Rm }\end{array}$ & \\
\hline Tank & Tank & Tank & Tank & Tank & Tank & Tank & Tank & \\
\hline & 8 & & & 5 & 4 & 3 & 2 & 1 \\
\hline
\end{tabular}

Figure 4-11 - Case Study Preliminary Arrangement Example (Bow, Zones 1, 2, 3)

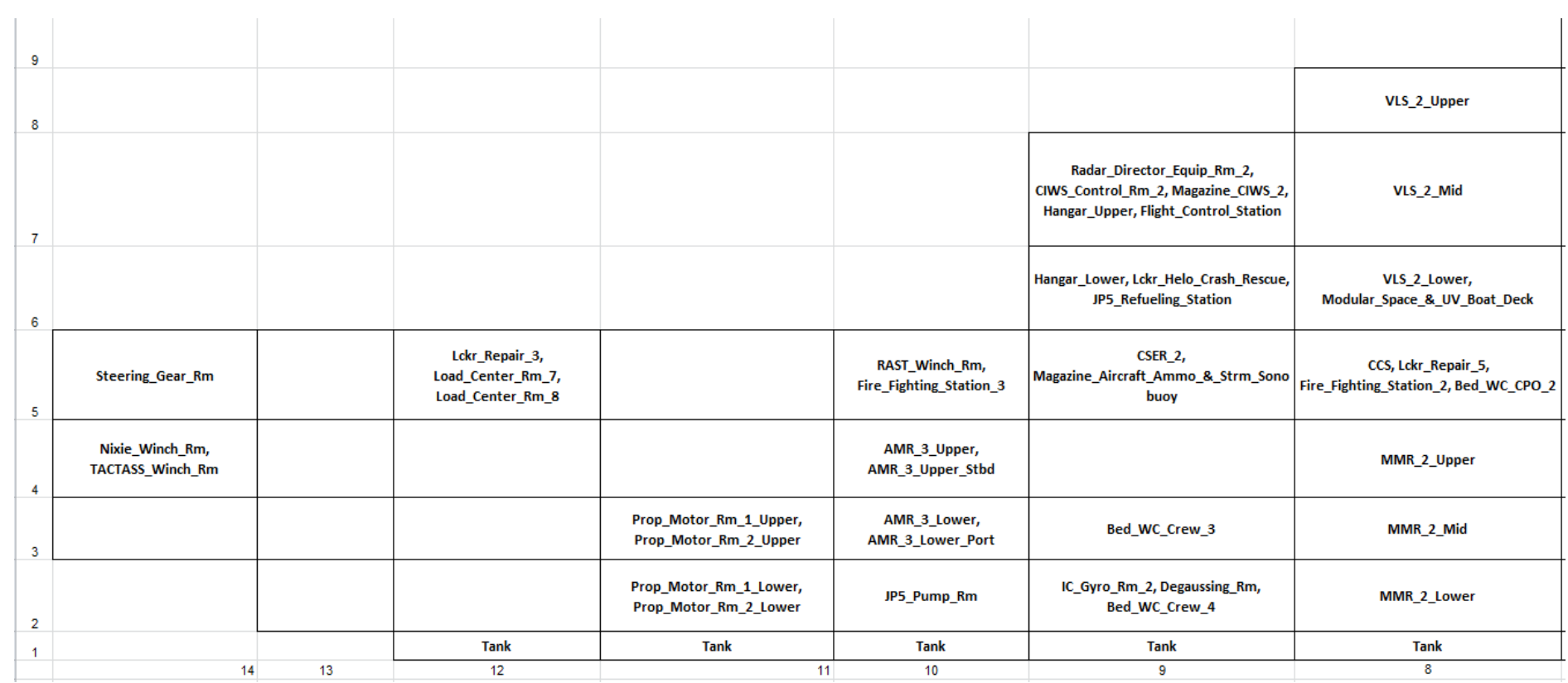

Figure 4-12 - Case Study Preliminary Arrangement Example (Stern, Zones 3, 4) 
An example of these hit distributions is shown in Figure 4-13. Once the distribution is generated, the damage application method is executed. The probability of ellipsoid intersection for each SDB is visualized using the color code shown in Table 4-6. An example result is shown in Figure 4-14.

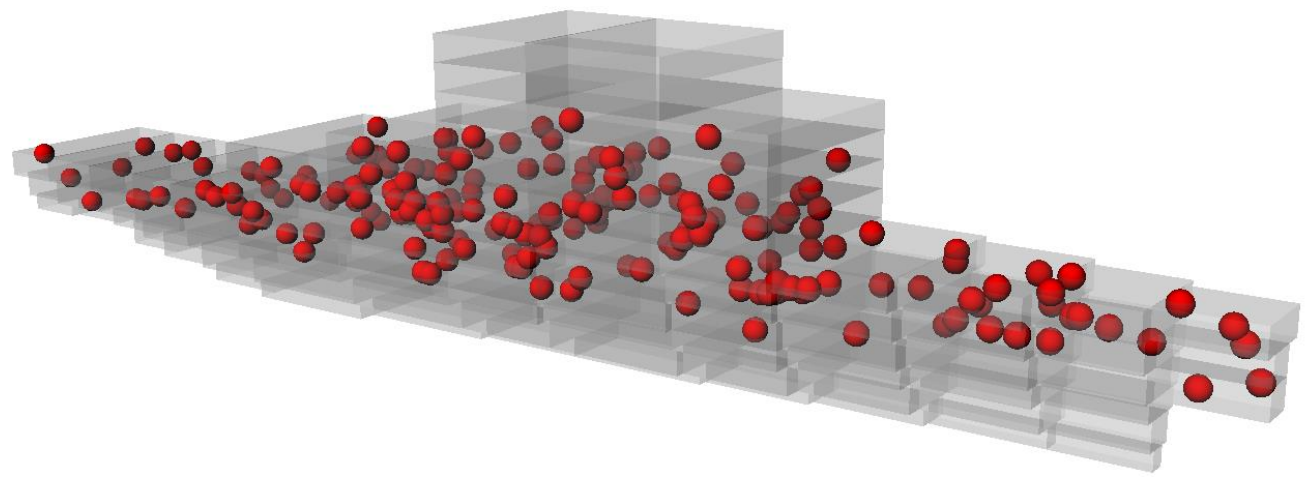

Figure 4-13 - Example C-701 Hit Distribution

Table 4-6 - Subdivision Block Probability of Ellipsoid Intersection

\begin{tabular}{|c|c|}
\hline $\begin{array}{c}\text { SDB Probability of } \\
\text { Intersection }\end{array}$ & Color \\
\hline 0 & \\
\hline $.01-.05$ & \\
\hline $.06-.10$ & \\
\hline $.11-.20$ & \\
\hline $.21-.30$ & \\
\hline $.31-.99$ & \\
\hline 1 & \\
\hline
\end{tabular}

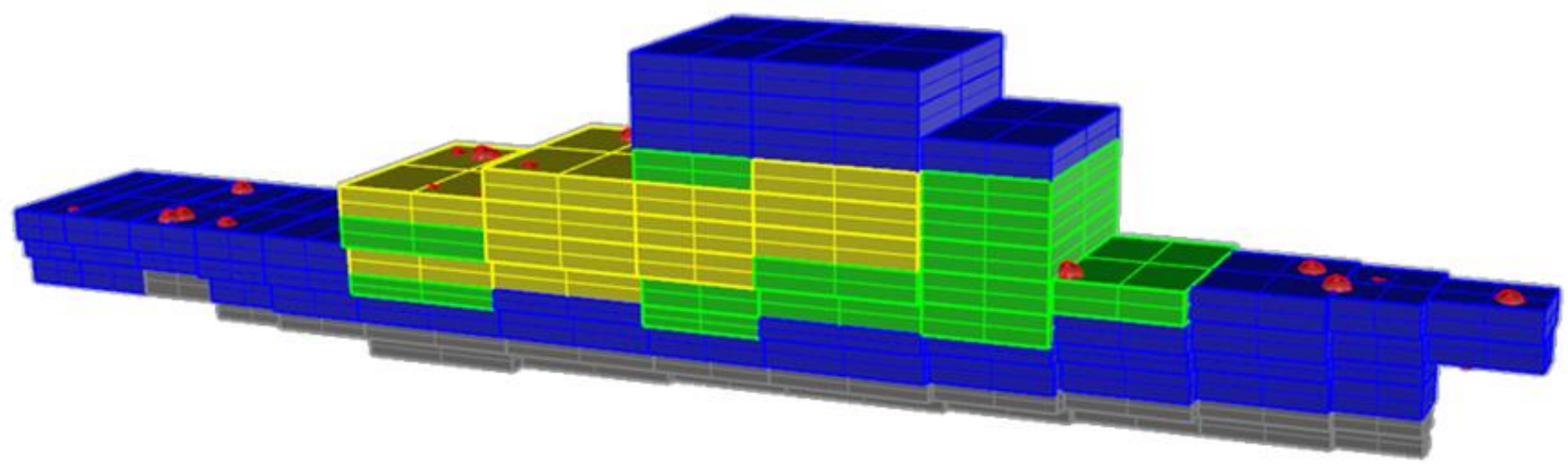

Figure 4-14 - Subdivision Block Probability of Ellipsoid Intersection 
Table 4-7 lists the vulnerability results for the three designs considered in this case study. As expected, the Hybrid and IPS systems outperformed the CODAG design for mobility as these systems have more redundancy. There is also an effect on combat systems because the power distribution system affects the availability of power to support combat system vital components (VCs). The largest effects are seen in AAW and ASW Offensive and Defensive capabilities due to the improved availability of power to ship zones 2 and 3.

Table 4-7 - Vulnerability Analysis Results

\begin{tabular}{|c|c|c|c|}
\cline { 2 - 4 } \multicolumn{1}{c|}{} & \multicolumn{3}{|c|}{ Results } \\
\hline Design Name & $\mathbf{1 1 1 5 5}$ & $\mathbf{1 1 1 6 6}$ & $\mathbf{1 1 1 7 7}$ \\
\hline Mobility & 0.845 & 0.875 & 0.880 \\
\hline Damage Control & 0.900 & 0.900 & 0.900 \\
\hline AAW System & 0.825 & 0.835 & 0.832 \\
\hline ASW System & 0.903 & 0.938 & 0.915 \\
\hline ASUW System & 0.967 & 0.967 & 0.967 \\
\hline Strike System & 0.500 & 0.530 & 0.510 \\
\hline Offensive AAW System & 0.505 & 0.535 & 0.515 \\
\hline Defensive AAW System & 0.985 & 0.985 & 0.990 \\
\hline Offensive ASW System & 0.945 & 0.980 & 0.955 \\
\hline Defensive ASW System & 0.840 & 0.875 & 0.855 \\
\hline Offensive ASUW System & 0.930 & 0.930 & 0.920 \\
\hline Defensive ASUW System & 0.985 & 0.985 & 0.990 \\
\hline OMOV & 0.828 & 0.848 & 0.846 \\
\hline
\end{tabular}

Prior to ship synthesis, it was not known whether or not the designs in the case study were feasible with sufficient area, power, stability, endurance speed, and range to meet the design's requirements. Each of the three designs, Table 4-5, had sufficient area and volume as determined by the SSM Space Available module for their designs. Each design also had sufficient power to satisfy their required maximum functional load with margins (KWmflm). The GM/B ratio for each design was within the required range of $0.08-0.15$. The sustained speed for all designs exceeded the threshold speed of 28kts and their endurance range exceeded the minimum range of $4000 \mathrm{~nm}$ 
required for the DDGX design. Each preliminary baseline design is feasible based on the SSM $\underline{\text { results. }}$

The HED and IPS design options have substantially greater effectiveness than the CODAG system. The HED system has an OMOE of 0.831 and the IPS has an OMOE of 0.839 as compared to the CODAG system's OMOE of 0.751 . This difference is in part due to the fact that the OMOE was calculated with vulnerability scores included as VMOPs within the OMOE equation. Each of the OMOV values shown in Table 4-7 were linked from the PA\&V to the SSM within the OMOE calculation through their inclusion as an MOP with a weight of 0.062 as shown in Table 4-8. The OMOE is calculated using Equation 4-1.

Table 4-8 - OMOE MOP Weights

\begin{tabular}{|c|c|}
\hline MOP & Weighting \\
\hline AAW \&CCC & 0.156 \\
\hline ASW/MCM & 0.084 \\
\hline ASUW/NSFS & 0.083 \\
\hline C4ISR & 0.087 \\
\hline Sustainted Speed & 0.056 \\
\hline Endurance Range & 0.053 \\
\hline Seakeeping & 0.061 \\
\hline Provisions Duration & 0.050 \\
\hline Vulnerability & 0.062 \\
\hline NBC & 0.054 \\
\hline RCS & 0.080 \\
\hline Acoustic Signature & 0.065 \\
\hline Magnetic Signature & 0.051 \\
\hline IR Ssignature & 0.058 \\
\hline
\end{tabular}

$$
O M O E=\sum_{1}^{n} M V O P_{n} * V O P_{n}
$$

Referring to Table 4-5, the design using an integrated power system (design 11177) requires the largest ship and has the highest cost. IPS technology also has the highest risk, but results in the greatest overall effectiveness due to its higher OMOV, reduced acoustic signature and greatest margin for future technology requiring power. 


\subsection{Comparison of MOGO with and without OMOV}

After assessing the PA\&V model and considering results that included vulnerability analysis, a comparison was made comparing non-dominated results that consider vulnerability to those that do not. Two multi-objective genetic optimizations (MOGOs) were run with design variables as listed in Table 4-9 and 4-10, adapted from Table 2-1 and Table 2-2. Each MOGO was set to minimize risk and cost and maximize effectiveness. The first MOGO included vulnerability in its OMOE, and the second did not.

Table 4-9 - MOGO Design Variables and Bounds

\begin{tabular}{|c|c|c|}
\hline Variable & Lower Bound & Upper Bound \\
\hline LOA & 130.0 & 165.0 \\
\hline MAINT & 1.0 & 3.0 \\
\hline LtoB & 7.1 & 7.7 \\
\hline BtoT & 3.3 & 3.6 \\
\hline LongPrismaticControl & 0.3 & 0.4 \\
\hline StemRake & 35.0 & 45.0 \\
\hline SectionTightness & 0.4 & 1.0 \\
\hline DeadriseMid & 0.2 & 0.3 \\
\hline FullnessFwd & 0.3 & 0.6 \\
\hline Vdmin & 3000.0 & 6000.0 \\
\hline
\end{tabular}

Table 4-10 - MOGO System Design Options

\begin{tabular}{|l|r|r|}
\hline Variable & Lower Bound & Upper Bound \\
\hline CDHMAT & 1 & 3 \\
\hline PSYS & 5 & 7 \\
\hline GTMPE & 1 & 2 \\
\hline DMPE & 1 & 4 \\
\hline SSGENG & 1 & 3 \\
\hline Ts & 35 & 60 \\
\hline CCC & 1 & 2 \\
\hline AIR & 1 & 2 \\
\hline Ncps & 0 & 2 \\
\hline Ndegaus & 0 & 1 \\
\hline
\end{tabular}

The non-dominated designs from these MOGOs are represented in Figure 4-15 to Figure 4-23. Figure 4-15 shows the PSYS histogram with and without considering OMOV indicating a small shift in preference from both CODAG and IPS to HED which has a higher OMOV. 

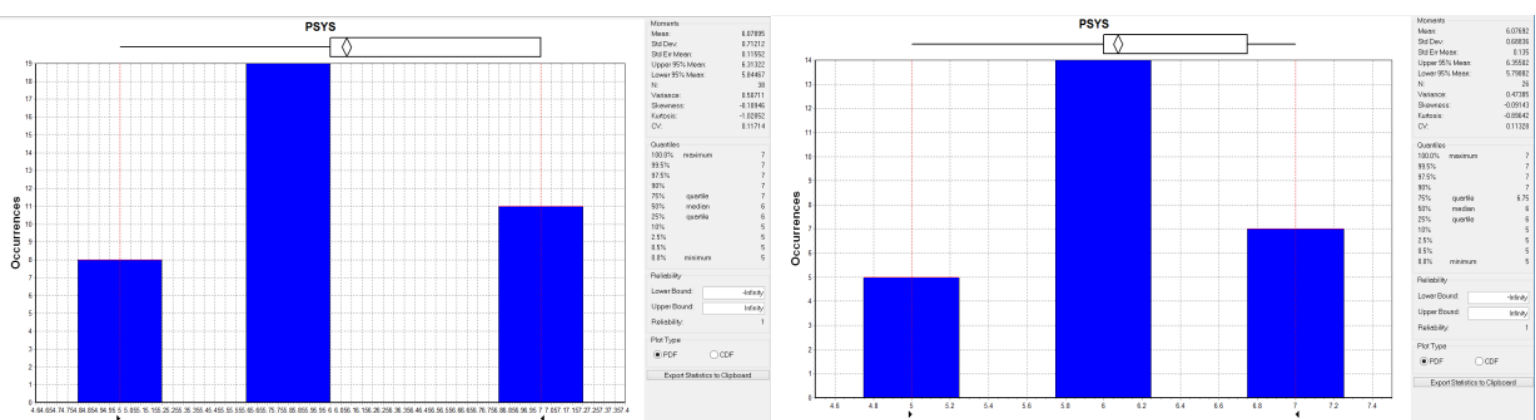

Figure 4-15 - Case Study MOGO PSYS Results Histogram (w/o OMOV; with OMOV)
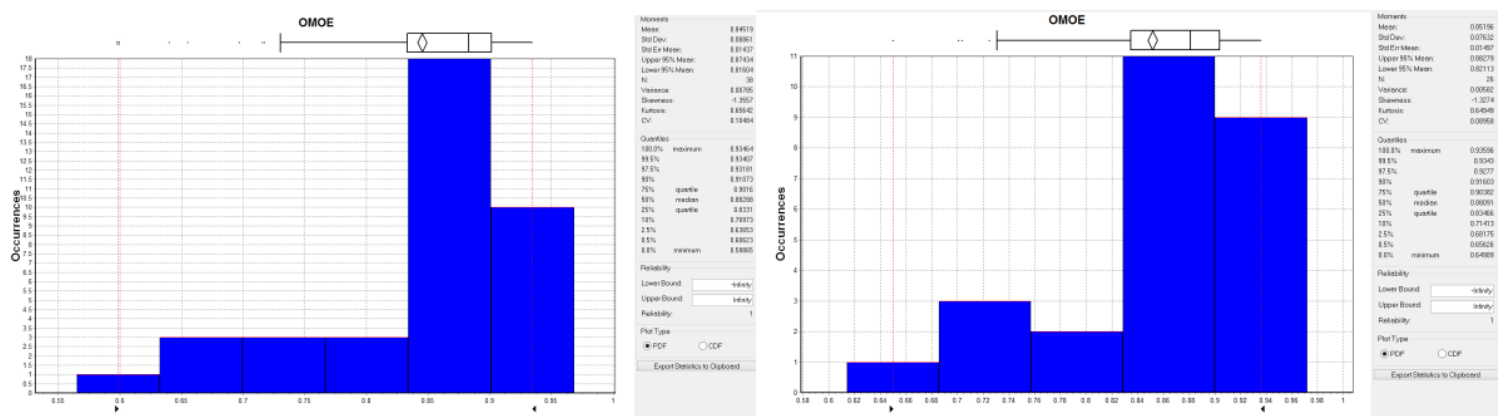

Figure 4-16 - Case Study MOGO OMOE Results Histogram (w/o OMOV; with OMOV)
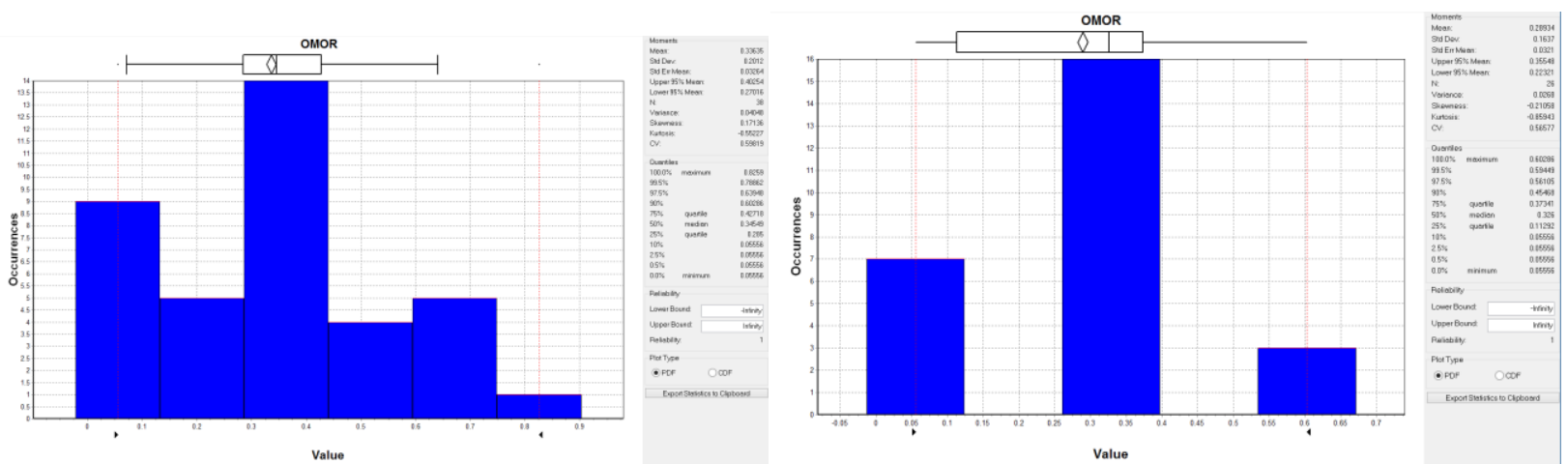

Figure 4-17 - Case Study MOGO OMOR Results Histogram (w/o OMOV; with OMOV)
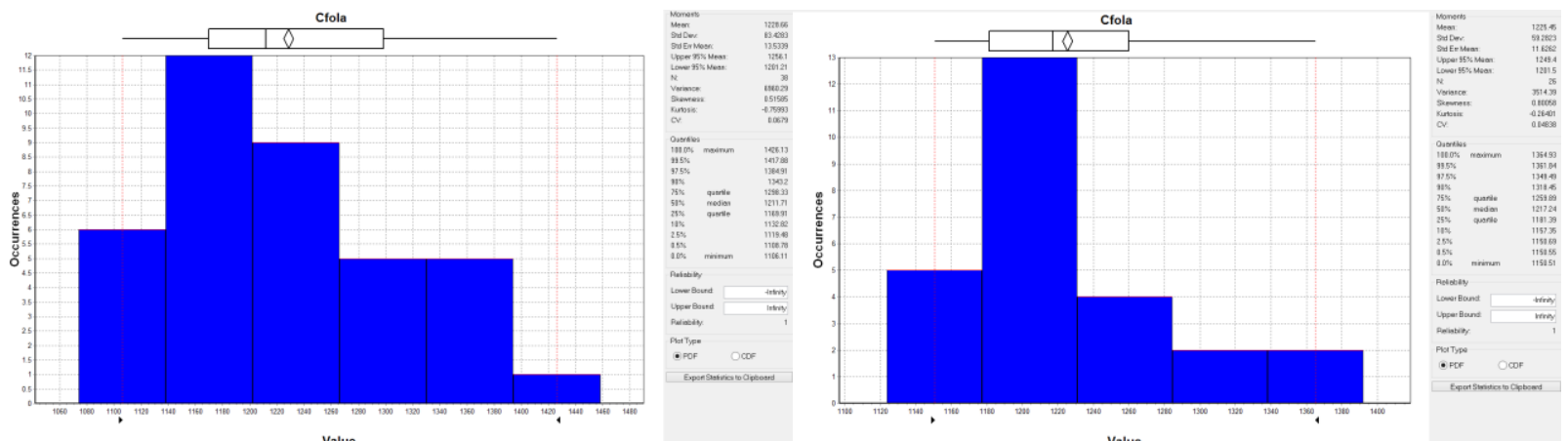

Figure 4-18 - Case Study MOGO Cfola Results Histogram (w/o OMOV; with OMOV) 

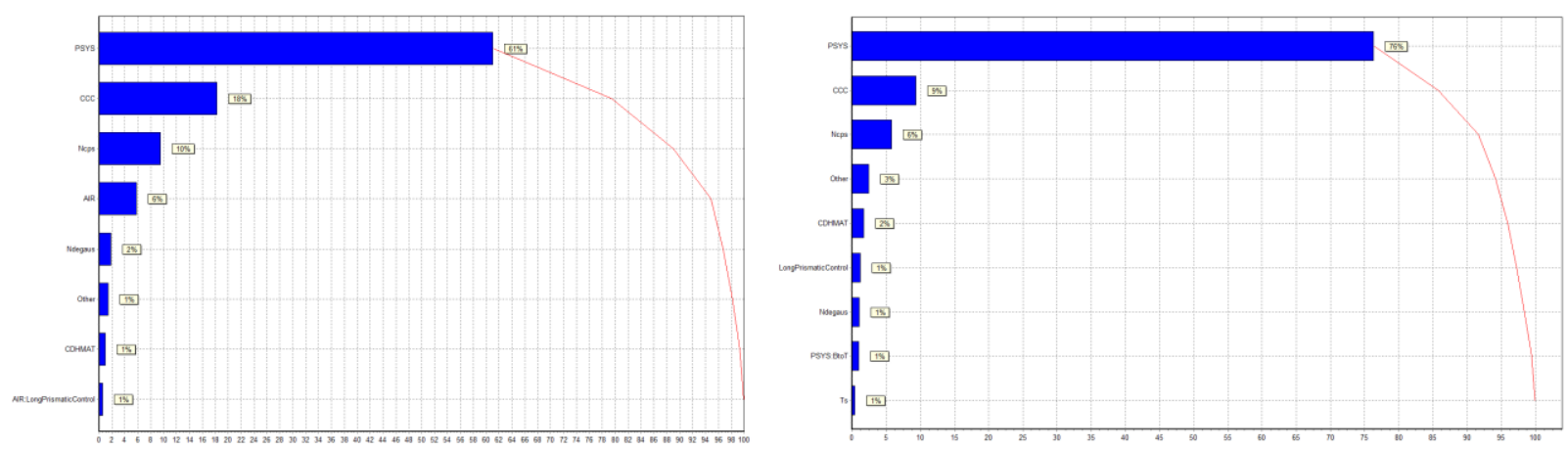

Figure 4-19 - Influence of Design Variables on OMOE (w/o OMOV; with OMOV)

Table 4-11 - PSYS Selection Probability in ND Set

\begin{tabular}{|c|c|c|}
\hline & \multicolumn{2}{|c|}{ Probability of System Selection } \\
\hline PSYS & Without OMOV & With OMOV \\
\hline 5 (Mechanical Drive) & 0.211 & 0.192 \\
\hline 6 (Hybrid) & 0.5 & 0.538 \\
\hline 7 (IPS) & 0.289 & 0.269 \\
\hline
\end{tabular}

Table 4-12 - Characteristic Mean Values for ND Set

\begin{tabular}{|l|r|r|}
\hline & \multicolumn{2}{|c|}{ Mean Value } \\
\hline \multicolumn{1}{|c|}{ Characteristic } & No OMOV & w/OMOV \\
\hline PSYS & 6.079 & 6.077 \\
\hline OMOV & 0.845 & 0.847 \\
\hline OMOE & 0.845 & 0.852 \\
\hline OMOR & 0.336 & 0.289 \\
\hline Cfola & $\$ 1229 \mathrm{M}$ & $\$ 1225 \mathrm{M}$ \\
\hline PSYS Influence & $61 \%$ & $76 \%$ \\
\hline
\end{tabular}

Figure 4-16 shows the OMOE histogram with and without considering OMOV indicating a significant increase in OMOE when vulnerability is included in the design process. Figure 4-17 shows the OMOR histogram with and without considering OMOV indicating a significant decrease in OMOR with the shift from IPS to HED which has lower risk. Figure 4-18 shows the follow ship acquisition cost histogram with and without considering OMOV indicating a decrease in follow-ship acquisition cost (Cfola) with the shift from IPS to HED when considering OMOV. Figure 4-19 shows the influence of the design variables on OMOE with and without considering OMOV indicating a significant increase in the influence of PSYS when considering OMOV. The 
preference shift from CODAG and IPS to HED when considering vulnerability is also shown clearly in Table 4-11. These results show the significant impact of including an OMOV even when the impact of only one design variable (PSYS) is considered.

Figure 4-20 and Figure 4-21 show the non-dominated frontiers without and with considering vulnerability, plotting effectiveness versus cost and risk. The main differences in the non-dominated frontiers considering and not considering vulnerability is the increase in effectiveness of the lower vulnerability designs (higher OMOV) when vulnerability is considered. The frontier including vulnerability, Figure 4-21, is more linear than that of the frontier excluding vulnerability as many of the higher effectiveness designs use the less vulnerable HED PSYS option whose vulnerability is increased when OMOV is included.

Figure 4-22 shows the non-dominated frontier considering vulnerability with effectiveness (OMOE) as a function of cost and OMOV (instead of OMOR). Moving from the lower left (lower OMOE) to the upper right (higher OMOE) we find first the CODAG designs, then HED, and finally the IPS designs shown in Figure 4-23. The lower OMOV of the HED designs has raised their OMOE to be competitive with the IPS design even at the high end cost and risk.

A possible explanation for the higher OMOV calculated for the HED designs is that the HED propulsion shafts are not explicitly modeled as VCs in the HED RBDs. The IPS designs have propulsion motors in their RBDs and these VCs are located in Propulsion Motor Rooms aft of MMR2. This effectively makes their power trains more vulnerable than in HED. This will be corrected in the next analyses. 


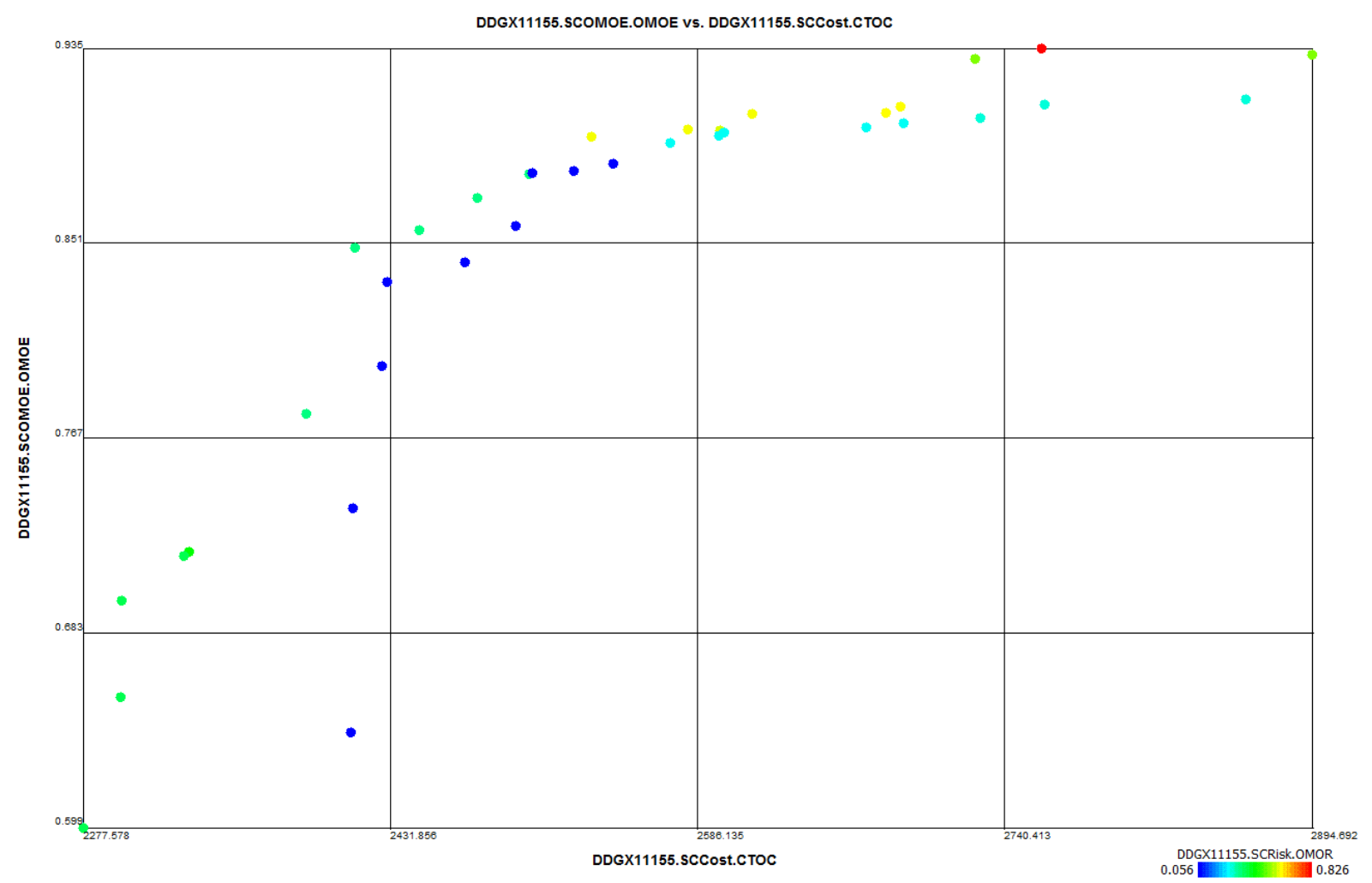

Figure 4-20 - DDGX Non-Dominated Frontier (without Vulnerability)

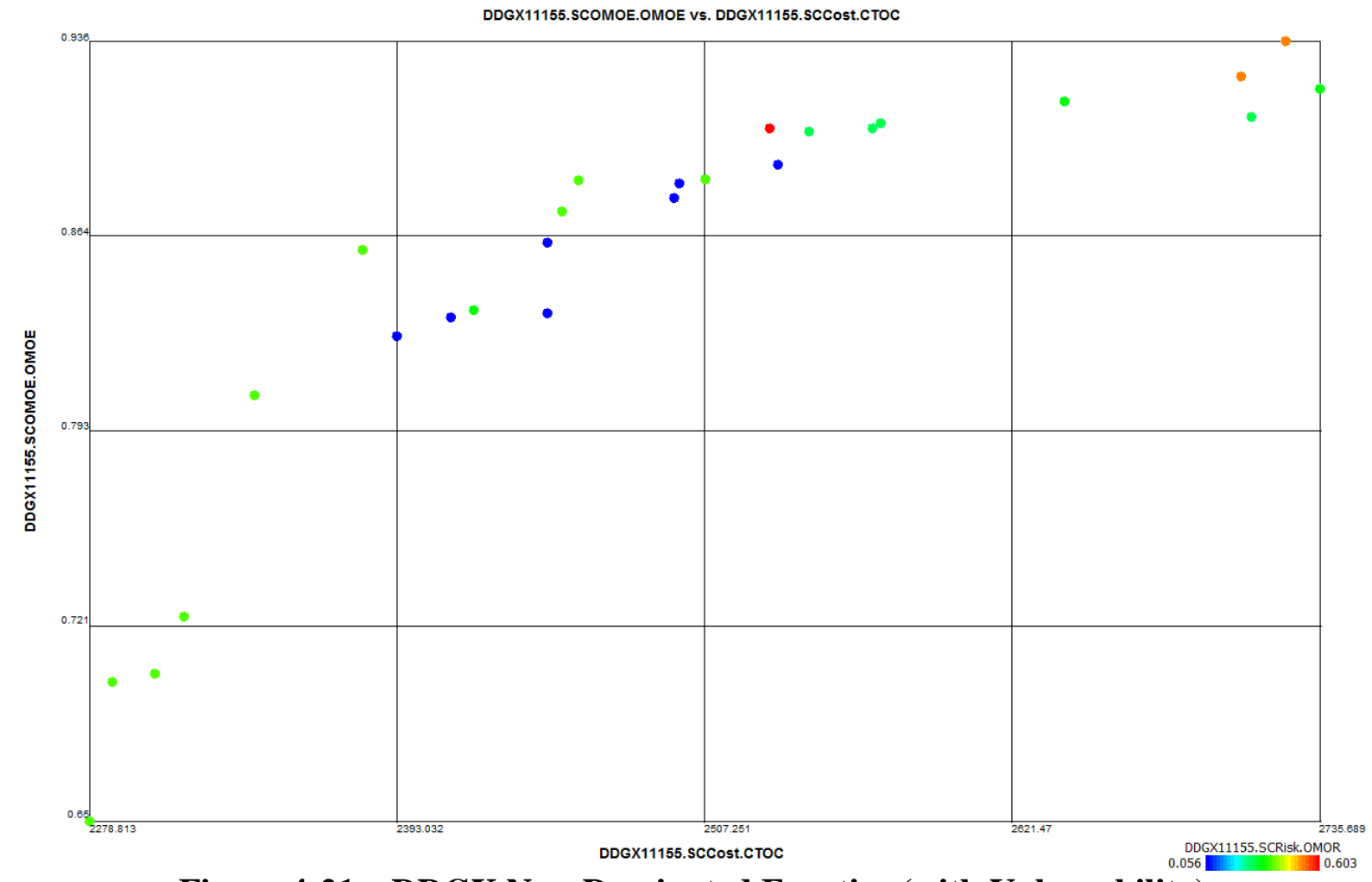

Figure 4-21 - DDGX Non-Dominated Frontier (with Vulnerability) 


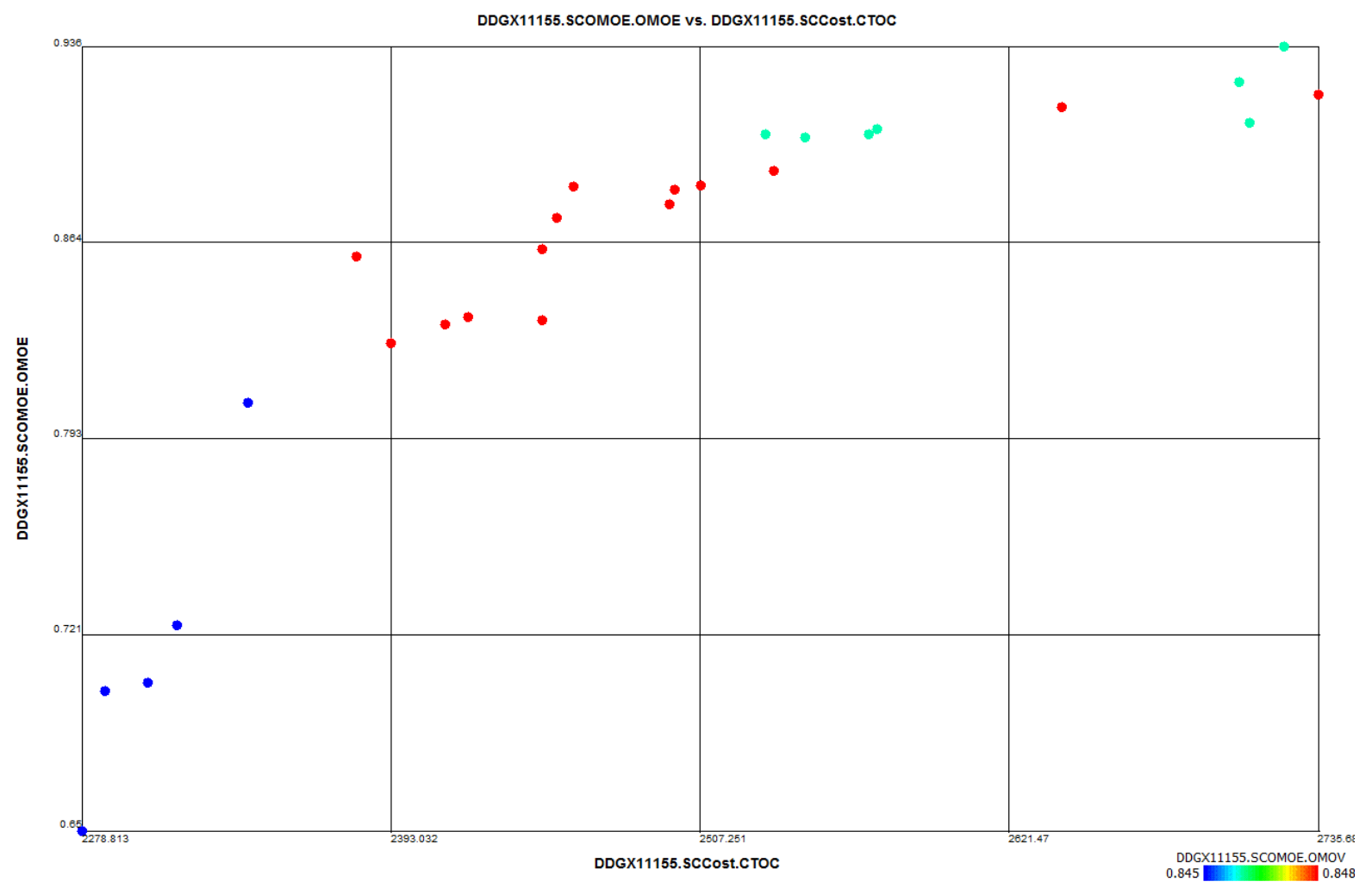

Figure 4-22 - DDGX Effectiveness vs Cost and OMOV (with Vulnerability)

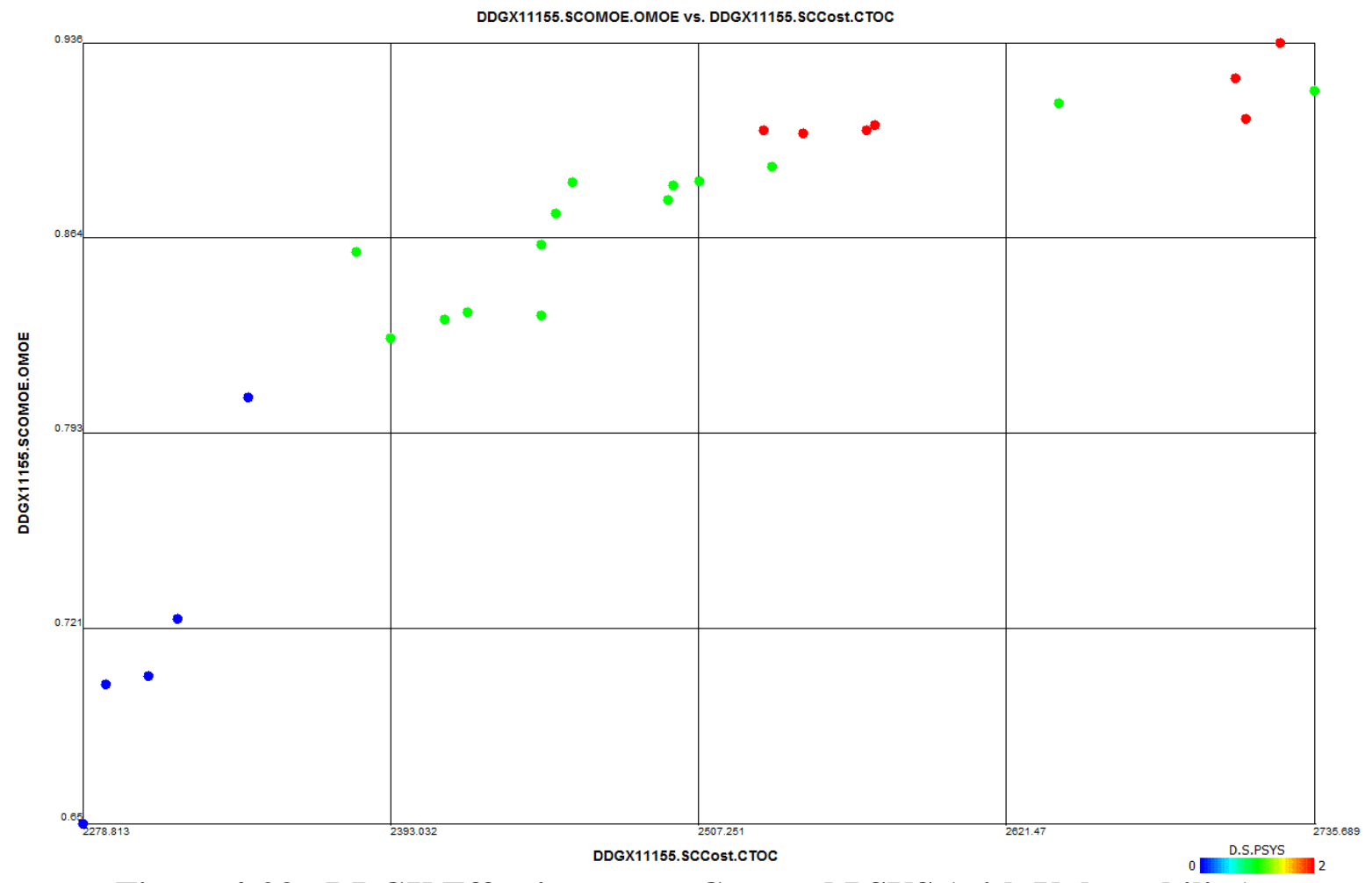

Figure 4-23 - DDGX Effectiveness vs Cost and PSYS (with Vulnerability) 


\section{CHAPTER 5 - CONCLUSIONS AND FUTURE WORK}

This thesis presents a methodology and analysis tool to explore ship system vulnerability using a simplified preliminary arrangement and vulnerability modeling approach. Using a new Preliminary Arrangement and Vulnerability (PA\&V) model, an Overall Measure of Vulnerability (OMOV) is calculated for a series of baseline ship designs and applied to the larger concept exploration design space. A number of simplifying approaches were demonstrated including: 1) The use of AABB subdivision blocks (SDBs) vice curvilinear geometry to analyze threat damage; 2) Assignment of vital components (VCs) to compartments and compartments to SDBs rather than using $\mathrm{x}, \mathrm{y}, \mathrm{z}$ coordinates for VCs; 3) The use of a damage ellipsoid approach with SDBs and assigned VCs to determine availability of the VCs after hit; 4) The use of a simple compartment assignment algorithm and model; and 5) The use of a smaller series of system option baseline designs ( 250) to specify OMOV performance in a larger ship concept exploration process (C\&RE) and design space that typically will consider 1000s of designs. The over-riding question about these simplifications is their ability to provide and support sufficiently accurate and detailed analysis for concept exploration decisions.

\subsection{Conclusions}

As a result of this research, we have tentatively concluded that:

1. The preliminary baseline designs, sized and created for assessing the vulnerability of various combinations of systems in the design space, are generally feasible designs. This assessment is based on post-PA\&V synthesis (SSM) results.

2. The vulnerability performance of the baseline designs can be assumed for designs with the same installed systems over the entire full design space. This remains mostly an 
assumption. This has only been demonstrated with limited data and requires a more complete DOE and analysis to substantiate.

3. Results show the significant impact of including an OMOV when the impact of only one design variable (PSYS) is considered.

4. This method is sufficiently efficient and fast for use in concept exploration and is consistent with our current model geometry and fidelity.

The feasibility of our baseline designs will continue to be verified as we continue to use this model with larger design spaces and particularly with combat system design variables. While it will take hundreds or thousands of combinations of systems and ship designs to prove that the inclusion of vulnerability during concept design can improve design decisions, the results from this limited sample size study indicate that it does. Our plan is to immediately extend this study to include combat system DVs. We will also perform a full DOE varying all DVs in the design space to verify the insensitivity of vulnerability results to hullform DVs other than LOA/displacement and the validity of our systems-based baseline design approach.

\subsection{Limitations}

Limitations and assumptions remaining to be proven include:

1. We have not yet demonstrated that the SDB and compartment/VC assignment approach with damage ellipsoids produces vulnerability results that are sufficiently accurate or at least relatively accurate for assessing concept design and making decisions in concept exploration.

2. We have not yet fully demonstrated that including vulnerability results in the OMOE using expert opinion provides a sufficient effectiveness assessment. 
3. Currently topside VCs such as guns and sensors are located in the SDB immediately below their topside locations. This may not give correct results.

4. The current preliminary arrangements algorithm places compartments in their first choice SDB based on operability only. There is no direct consideration of vulnerability.

5. Only AIREX has been considered thus far in our analysis. UNDEX is not considered.

6. Connectivity between vital components (data, piping and cable) is not considered explicitly.

The absence of a true physics-based damage model within this method, despite all of the speed benefits of the damage ellipsoid method, decreases the result fidelity and does not consider equipment resistance to shock and fragmentation. The physics based pressure damage method will help to increase the accuracy of the Overall Measure of Vulnerability, but this is also not a fully physics-based approach.

\subsection{Future Work}

Future work to be performed with this method includes the following:

1. Repeat the process described in this thesis using a full set of DV's with RBDs to evaluate a broader and full concept design space with particular attention to the impact of combat systems.

2. Add topside analysis blocks and include topside VCs such as guns.

3. Add propulsion shaft segments as VCs with appropriate port and starboard SDB locations.

4. Develop and apply the pressure-based ellipsoid method to the same problem as our simplified ellipsoid method and compare results. 
5. Begin with a full physics-based MOTISS analysis with connectivity between vital components and systematically strip away details. Assess the change in results and ultimately evaluate the sufficiency of our ellipsoid methods compared to the higher fidelity physics-based approach for concept exploration.

6. Add a method to optimize preliminary arrangements based on vulnerability and use this arrangement to calculate the OMOV for a given system combination.

7. Use MANA-based OEMs in place of an expert opinion-based OMOE to apply vulnerability results to the warfighting problem and determine effectiveness directly. OEMs will also allow proper consideration of susceptibility, signatures and the relative value of offensive versus defensive capabilities.

8. Complete the development of a simplified UNDEX model analogous to and having similar fidelity with our AIREX approach. Consider damage stability following a hit, blast, structural integrity and shock. 


\section{REFERENCES}

[1] Baker, W.E. Explosions in Air. Wilfred Baker Engineering, San Antonio, 1973.

[2] Bradshaw, K and Robinson, $M$ "Electric Architecture Leap Ahead Swampworks Project "NSWC 2013

[3] Brown, A.J., Barentine, J., "The Impact of Producibility on Cost and Performance in Naval Combatant Design", paper presented to SNAME NE Section, November, 1996

[4] Brown, A.J., Thomas, M., "Reengineering the Naval Ship Concept Design Process", From Research to Reality in Ship Systems Engineering Symposium, ASNE, 1998.

[5] Brown, A.J., Salcedo, J., "Multiple Objective Genetic Optimization In Naval Ship Design", Naval Engineers Journal, Vol. 115, No. 4, pp. 49-61, 2003.

[6] Brown, A.J. (2004), "AOE 5315 Naval Ship Vulnerability and Underwater Explosion Introduction to Survivability OnLine Lecture 1", Virginia Tech Department of Aerospace and Ocean Engineering, January 2004.

[7] Brown, A.J., "Multi-Objective Optimization in Naval Ship Concept Design", Marine Systems and Technology (MAST) 2010 Conference, Rome, Italy, 9-11 November, 2010.

[8] Brown, A.J, Sajdak, J, "Still Re-Engineering the Naval Ship Concept Design Process", Naval Engineers Journal, Vol 127, No 1, March 2015

[9] Chung, Jung-Hoon Close-in UNDEC Shock Simulation ROKNS Cheonan Recent Related R\&D Activities

[10] Cole, R.H. Underwater Explosions. Princeton U.P., Princeton, 1948.

[11] D. Winyall, J. Edwards and A. Brown, "3D Hullform Modeling to Support Naval Ship Design Synthesis and Multi-Objective Optimization," International Ship Design Conference (ISDC), Glasgow, Scotland, (2012).

[12] Doerry, CAPT Norbert, "Zonal Ship Design", presented at the ASNE Reconfiguration and Survivability Symposium, February 16-17, 2005, Atlantic Beach FL.

[13] Doerry, CAPT Norbert, USN, "In-Zone Power Distribution for the Next Generation Integrated Power System," Presented at ASNE Advanced Naval Propulsion Symposium 2008, Arlington, VA, Dec 15-16, 2008

[14] FAS Military Network C-701. N.p., n.d. Web

[15] FBI "The USS Cole Bombing." FBI, 21 May 2010. Web. 
[16] Gillespie, Justin W, “A network Science Approach to Understanding and Generating Ship Arrangements in Early-Stage Design” PHD Dissertation UMichigan 2012

[17] Gillespie, J.W., Daniels, A.S., Singer, D.J., “Approaching Ship Arrangements from a Nonspatial Point of View Using Network Theory", Proceedings of the 11th International Marine Design Conference. 2012. Glasgow, Scotland.

[18] Hicks, PH2 U.S. Navy photo DVID \#DN-ST-88-10218

[19] International Journal of Socialist Renewal "South Korea: The Story of ROKS Cheonan -Repression, Lies and Half Truths | Links International Journal of Socialist Renewal | Links. N.p., n.d. Web

[20] Kehoe, J.W., Graham, C., Brower, K.S., Meier, H.A., "COMPARATIVE NAVAL ARCHITECTURE ANALYSIS OF NATO AND SOVIET FRIGATES, PART I, Naval Engineers Journal, p. 87, October 1980.

[21] Kennell, C., "On the Nature of the Transport Factor Component TFship" Marine Technology, Volume 38, Number 2, pp. 106-111(6), 1 April 2001.

[22] Kerns, Corey M., "Naval Ship Design and Synthesis Model Architecture Using a ModelBased Systems Engineering Approach”, Master's Thesis, Virginia Tech, May 2011 a.

[23] McCoy, Timothy J, Amy Jr. John V. "The State-of-the-Art of Integrated Electric Power and Propulsion Systems and Technologies on Ships"

[24] MOTISS User and Theory Manual, Version 3.0, Alion Science and Technology, Alexandria, VA, 2011.

[25] Navsource Online "Frigate Photo Archive." Frigate Photo Index FFG-31 USS STARK. N.p., n.d. Web

[26] NSWC Carderock Code 223 Ship Systems Itegration Design, "The Navy Ship Design Process" 2012

[27] Sarioz, K. and Sarioz, E., "Practical Seakeeping Performance Measures for High Speed Displacement Vessels", Naval Engineers Journal, No. 4, 2006.

[28] Steele, Jeanette (15 November 2011). "Navy's First Hybrid-Drive Warship Goes To Sea". San Diego Union-Tribune.

[29] Sajdak, J.A.W. and Raisig, G., MOTISS Beta Version 3.0, User \& Theory Manual, Alion Science \& Technology Corporation, 09 January 2011.

[30] Sajdak, J.A.W. Ph.D., Avigdor Shechter, Ph.D., and Moshe Shechter "QUANTIFICATION OF NAVAL COMBATANT'S SUSCEPTIBILITY AS A MEANS OF ENHANCING SURVIVABILITY” Alion Science and Technology 2014 
[31] Sajdak, J.A.W. Ph.D.,, M. Shechter, A. Shechter, R. Miller, and Z. Karni, Early Considerations of Survivability in the Design of Naval Combatants: The Question of Stealth or Armor - Part 1 (Assumptions, Methods, and Approach), ASNE Day, Crystal City, VA, USA, July 2014

[32] Tibbitts, B. and Keane, R.G. (1995), "Making Design Everybody's Job", Naval Engineers Journal

[33] United States. Department of the Navy. Office of the Chief of Naval Operations. OPNAVIST 9070.1A: Survivability Policy and Standards for Surface Ships and Craft of the U.S. Navy. Washington DC, 2012

[34] Upadhaya, B., Munir, R., \& Blount, Y. (2014). Association between Performance Measurement Systems and Organisational Effectiveness. International Journal of Operations \& Production Management, 34(7), 2-2.

[35] Zubaly, Robert B., Applied Naval Architecture 1996

[36] Lauren, M., \& Stephen, R. (2002). Map-aware non-uniform automata (MANA)-A New Zealand approach to scenario modeling. Journal of Battlefield Technology, 5, 27-31.

[37] McIntosh, G. C. (2009). MANA-V (Map Aware Non-uniform Automata-Vector) supplementary manual. Defense Technology Agency.

[38] McIntosh, G. C., Galligan, D. P., Anderson, M. A., \& Lauren, M. K. (2007). MANA version 4.0 user manual (Technical Note 2007/3 NR 1465.). Defense Technology Agency. 


\section{APPENDIX A: ITEM Export Instructions}

Following completion of the RBD design and population of system architecture via RBD generation in ITEM Toolkit the following steps must be followed in order to generate an export (.xls) file compatible with the VTVM Import structure.

Step 1 of 4: Select the Project File for the RBD System in the left hand hierarchy panel, as seen in Figure A - 1

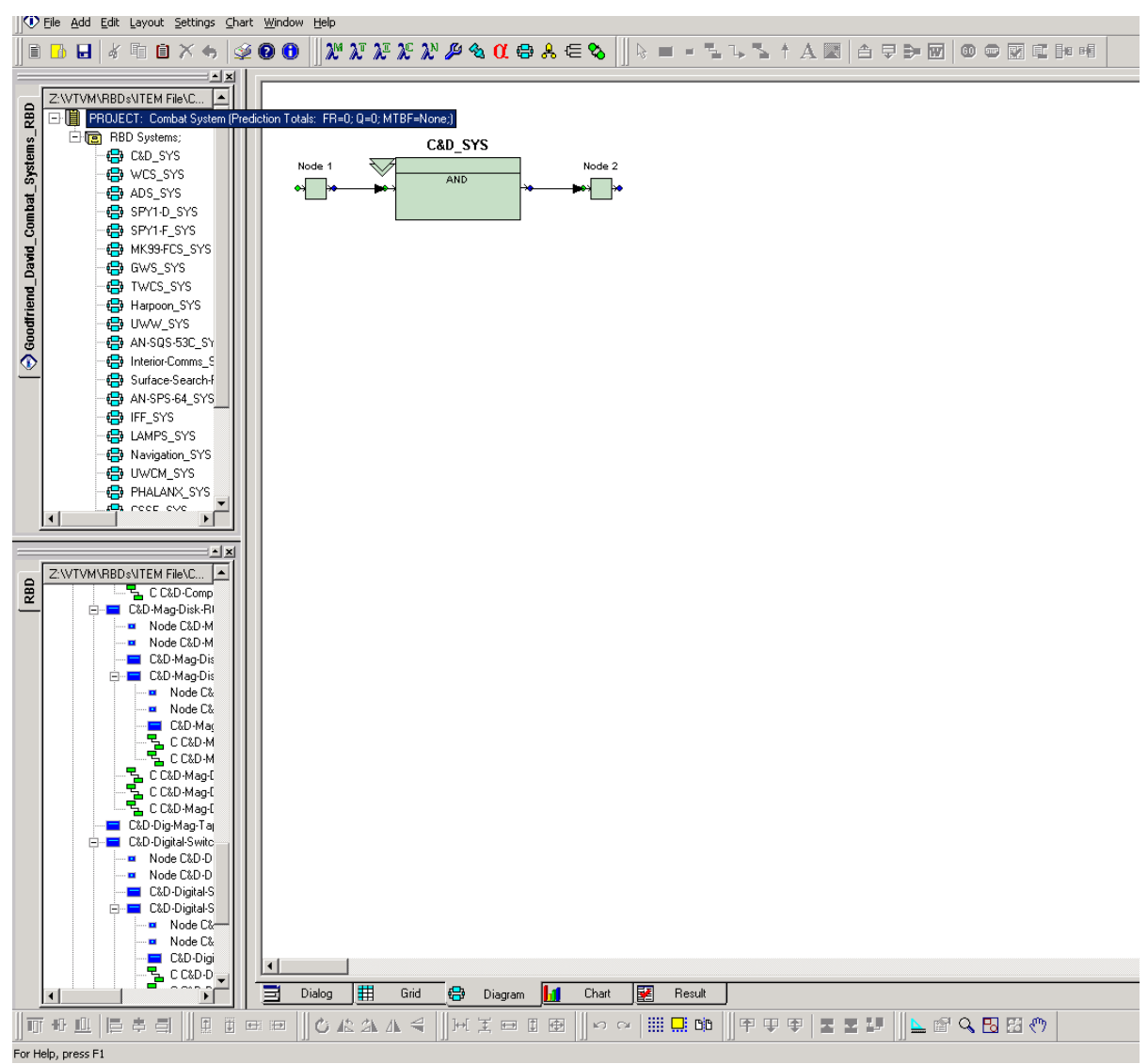

Figure A - 1 - ITEM Export Step 1

Go to File and select Export. When selecting export, if a reliability analysis was not performed within ITEM, an error will pop for each individual RBD System. This error, as seen in Figure A - 2, will exclaim “RBD Results are out of Date". The user can ignore this statement. Select “OK". 


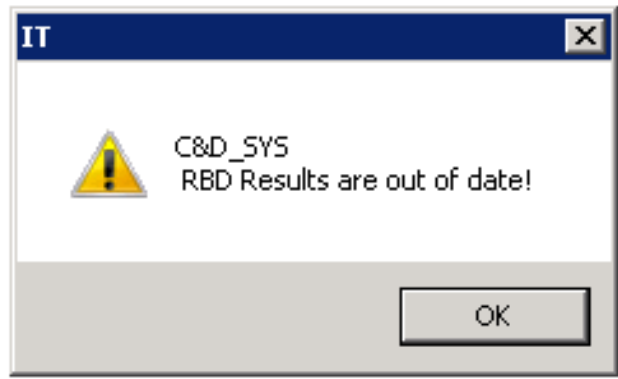

\section{Figure A - 2 - ITEM Export accepted Error}

Step 2 of 4: The Export wizard shall now be visible. Select "RBD Blocks" and click the double right arrow. This action should move the name "RBD Blocks" from the Input Tables Column to the Output Tables Column, as seen in Figure A - 3. Repeat this process for "RBD System". This places the system structure and file locations in the export file. Now click "Next".

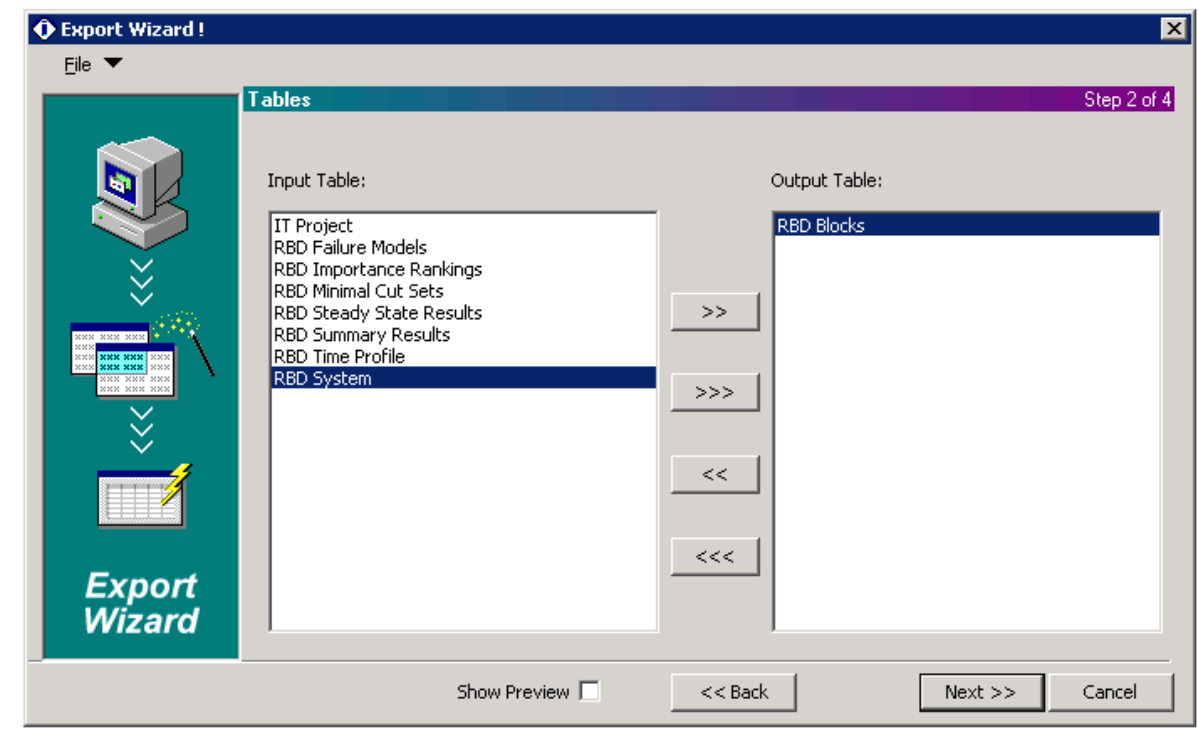

Figure A - 3 - ITEM Export Step 2

Step 3 of 4: The Export window in Figure A - 4 should now be visible. Inside the "Select Table" column select "RBD blocks". This action will populate the "Input Fields" table with multiple system characteristics. Now select the right facing double arrow. This will move the "Input Fields" data to the "Output Fields" column. Repeat process for "RBD System". Now click Next. 


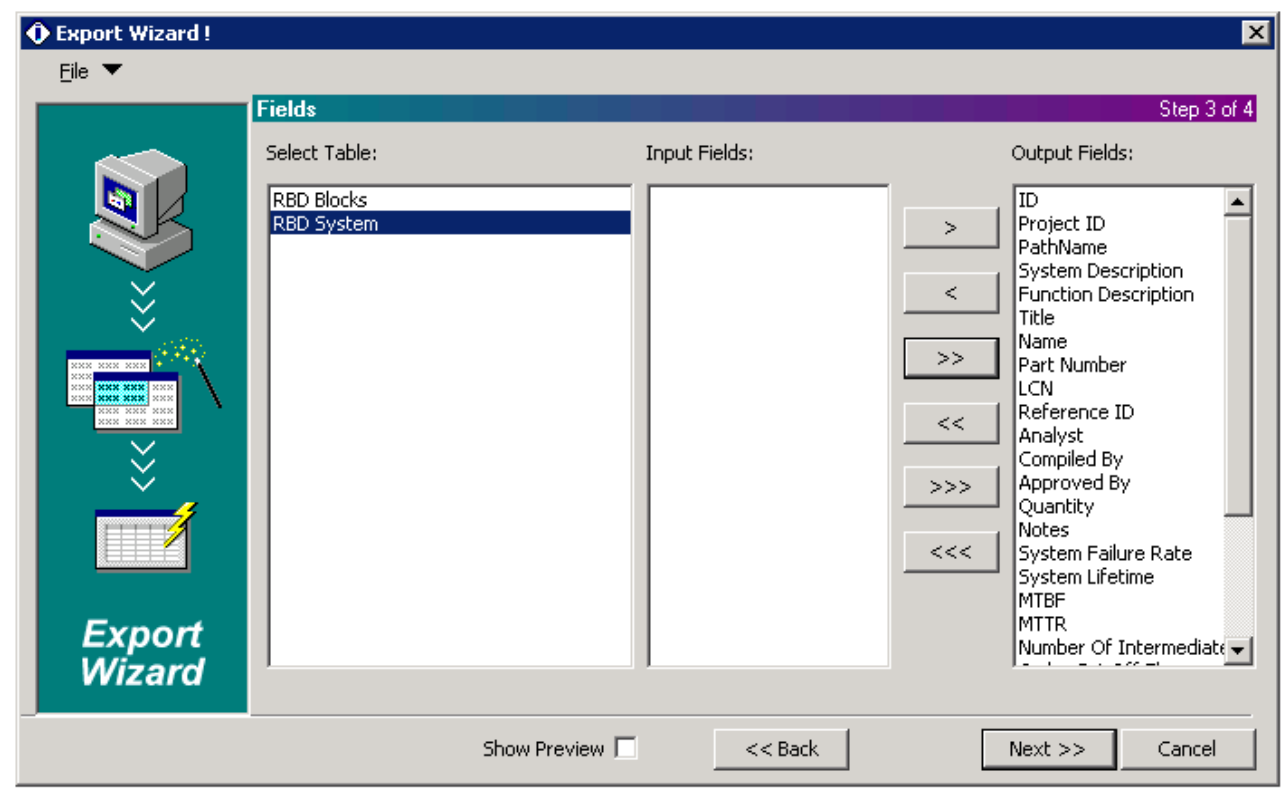

Figure A - 4 - ITEM Export Step 3

Step 4 of 4: The window in Figure A - 5 should now be visible. Under the "Format" drop down, select Microsoft Excel. Select Finish.

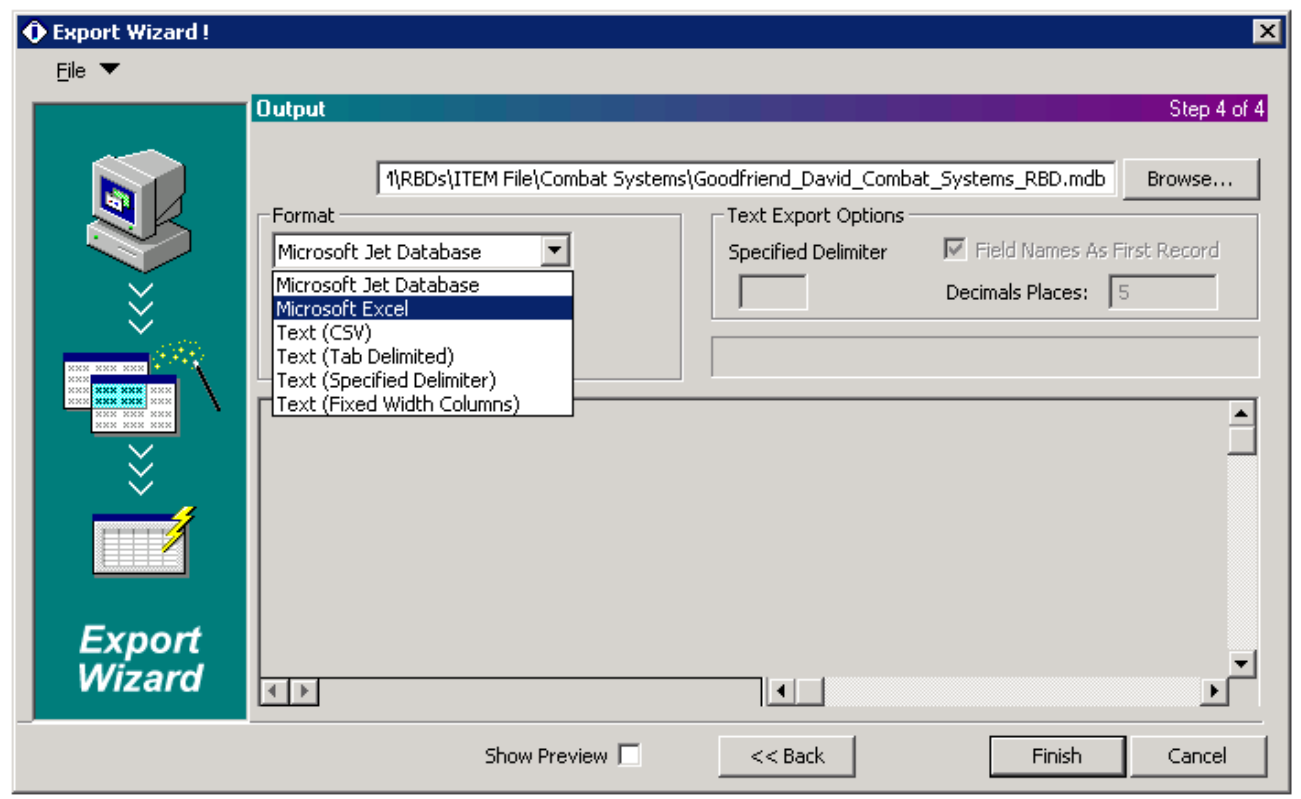

Figure A - 5 - ITEM Export Step 4

Upon export completion a .xls file will be placed in the same folder for which the ITEM RBD file was located. 


\section{APPENDIX B: Pairwise Comparison Calculation}

Ship Performance Option Values (Combat, Mobility, Damage Control)

$$
\begin{aligned}
& A:=\left(\begin{array}{ccc}
1 & \frac{9}{7} & 9 \\
\frac{7}{9} & 1 & 7 \\
\frac{1}{9} & \frac{1}{7} & 1
\end{array}\right) \\
& \mathrm{n}:=3 \quad \mathrm{i}:=1,2 \ldots \mathrm{n} \\
& \mathrm{X} 001:=\text { eigenvecs }(\mathrm{A}) \quad \mathrm{X} 001=\left(\begin{array}{ccc}
-0.931 & 0.786 & -0.609 \\
0.362 & 0.612 & -0.773 \\
0.052 & 0.087 & 0.178
\end{array}\right) \\
& \mathrm{x} 001_{1}:=\mathrm{X} 001_{\mathrm{i}, 2}
\end{aligned}
$$

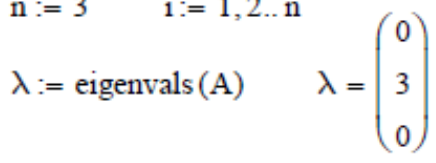

$$
\begin{aligned}
& \lambda_{\max }:=\lambda_{2} \\
& \text { inconsist }:=\frac{\lambda_{\max }-\mathrm{n}}{\mathrm{n}} \\
& \text { inconsist }=0 \\
& \mathrm{x} 001 \\
& \sum_{i=1}^{n} x 001_{1} \\
& \mathrm{w}_{001}=\left(\begin{array}{l}
0.529 \\
0.412 \\
0.059
\end{array}\right)
\end{aligned}
$$


1. AAW VOP (Offensive, Deffensive)

$$
\begin{aligned}
& A:=\left(\begin{array}{ll}
1 & \frac{1}{2} \\
2 & 1
\end{array}\right) \\
& \mathrm{n}:=2 \quad \mathrm{i}:=1 \ldots 2 \\
& \lambda:=\text { eigenvals }(\mathrm{A}) \quad \lambda=\left(\begin{array}{l}
2 \\
0
\end{array}\right) \\
& \lambda_{\max }:=\lambda_{1} \\
& \mathrm{X} 003:=\text { eigenvecs }(\mathrm{A}) \quad \mathrm{X} 003=\left(\begin{array}{cc}
0.447 & -0.447 \\
0.894 & 0.894
\end{array}\right) \\
& \mathrm{x}_{003_{\mathrm{i}}}:=\mathrm{X}^{003_{\mathrm{i}, 1}} \\
& \mathrm{w}_{003_{\mathrm{i}}}:=\frac{{ }_{\mathrm{i} 003_{\mathrm{i}}}^{\mathrm{n}}}{\sum_{\mathrm{i}=1}^{\mathrm{x} 003_{\mathrm{i}}}}
\end{aligned}
$$

2. ASuW VOP (Offensive, Deffensive)

$$
\begin{aligned}
& \mathrm{A}:=\left(\begin{array}{ll}
1 & \frac{1}{2} \\
2 & 1
\end{array}\right) \\
& \mathrm{n}:=2 \quad \mathrm{i}:=1 \ldots 2 \\
& \lambda:=\text { eigenvals }(A) \quad \lambda=\left(\begin{array}{l}
2 \\
0
\end{array}\right) \\
& \lambda_{\max :}=\lambda_{1} \\
& \mathrm{X} 004:=\text { eigenvecs(A) } \\
& \mathrm{X} 004=\left(\begin{array}{cc}
0.447 & -0.447 \\
0.894 & 0.894
\end{array}\right) \\
& \text { inconsist }:=\frac{\lambda_{\max }-}{\mathrm{n}} \\
& \mathrm{x} 004_{\mathrm{i}}:=\mathrm{X} 004_{\mathrm{i}, 1} \\
& \mathrm{w}_{004_{i}}:=\frac{{ }^{\mathrm{x} 004_{\mathrm{i}}}}{\sum_{\mathrm{i}=1}^{\mathrm{n}} \mathrm{x} 004_{\mathrm{i}}} \\
& \text { inconsist }=0 \\
& \mathrm{w}_{004}=\left(\begin{array}{l}
0.333 \\
0.667
\end{array}\right)
\end{aligned}
$$

\section{ASW VOP (Offensive, Deffensive)}

$$
\begin{aligned}
& A:=\left(\begin{array}{cc}
1 & \frac{3}{2} \\
\frac{2}{3} & 1
\end{array}\right) \\
& \mathrm{n}:=2 \quad \mathrm{i}:=1 \ldots 2 \\
& \lambda=\text { eigenvals }(\mathrm{A}) \quad \lambda=\left(\begin{array}{l}
2 \\
0
\end{array}\right) \\
& \lambda_{\max }=\lambda_{1} \\
& \mathrm{X} 005:=\text { eigenvecs }(\mathrm{A}) \quad \mathrm{X} 005=\left(\begin{array}{cc}
0.832 & -0.832 \\
0.555 & 0.555
\end{array}\right) \\
& \text { inconsist }:=\frac{\lambda_{\max }}{\mathrm{n}}
\end{aligned}
$$




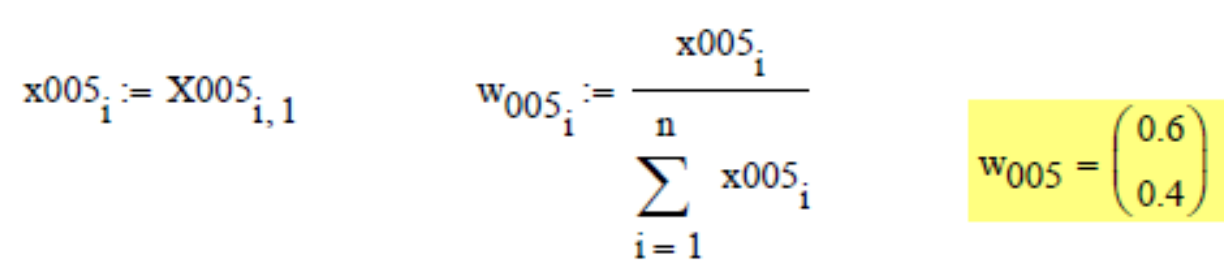$$
\text { inconsist }=0
$$ 